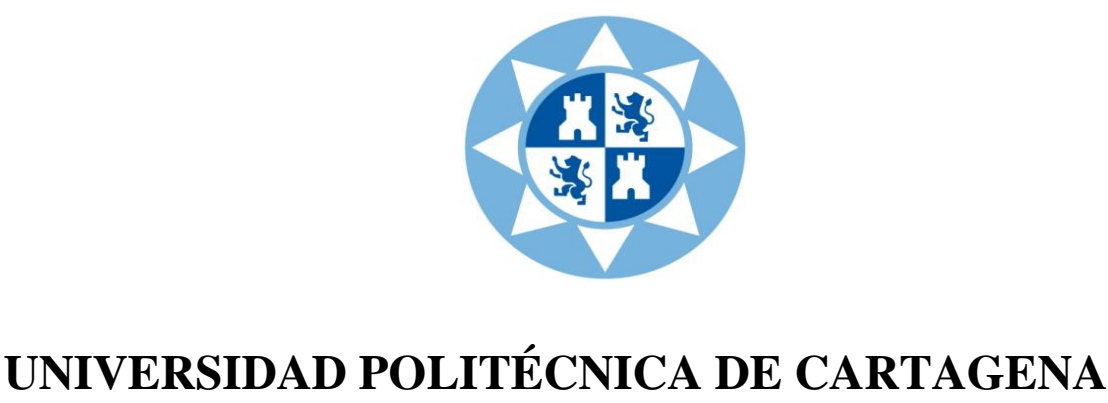

\title{
Innovative development and processing of vegetable-based formulations: purees, juices, sauces and hummus
}

Tâmmila Venzke Klug 2018

Director: Dr. Francisco Artés Hernández Co-Director: Dr. Francisco Artés Calero 


\section{ACKNOWLEDGEMENTS}

It is with immense gratitude that I acknowledge the patience and knowledge of Prof. Dr. Francisco Artés Hernández, Thesis advisor. His guidance helped me in the time during the research and writing process of this Thesis. In addition, I would like to express my fully gratitude to Prof. Dr. Francisco Artés Calero, Thesis co-advisor, for his advice and guidance during all my time in Cartagena. Besides my advisors, I would like to thank Dra. Perla Goméz and Dra. Encarna Aguayo, for their insightful comments and encouragement.

I am also grateful to the Conselho Nacional de Desenvolvimento Científico e Tecnológico $(\mathrm{CNPq})$ of Brazil for financial support and to the Eurolegume Project for financial support of the experiments through the Seventh Research Framework Programme of the European Union - FP7 Research Project no. 613781.

I cannot find words to express my gratitude to Dra. Ascensión Martínez Sánchez, without her knowledge, assistance and friendship, this study would not have been successful. I would like to express also my gratitude to Dr. Ginés Benito Martínez Hernández, for the knowledge and assistance and to Dr. Mariano Otón Alcaráz for his advices, friendship and assistance, always with a smile on his face.

Besides, I wish to express sincere recognition to the Postharvest and Refrigeration Group, Department of Food Engineering at Universidad Politécnica de Cartagena, for their extended long-term support, as well as the members of my $\mathrm{PhD}$ committee. The group has been a source of friendships as well as good advice and collaboration. I am especially grateful to all the people of the group: Noelia Castillejo, Maria José Sanchéz, Dr. Gerardo González, Dr. Alberto Garre and José Ginés Abril. Furthermore, I truly appreciate the friendships and assistance of Elena Collado, who I consider it was an honor to work with. Special thanks goes to exchange interns from Mexico and Brazil, and the students Mar Carrión, Christian Guaita, Paula Rubí and Simona Hasa for the hard work put in this study.

A special thanks to my family. Words cannot express how grateful I am to my mother, father and brothers. Their unconditional support and love for me was what sustained me thus far. I would also like to thank all of my friends who supported and incouraged me to strive towards my goal. 


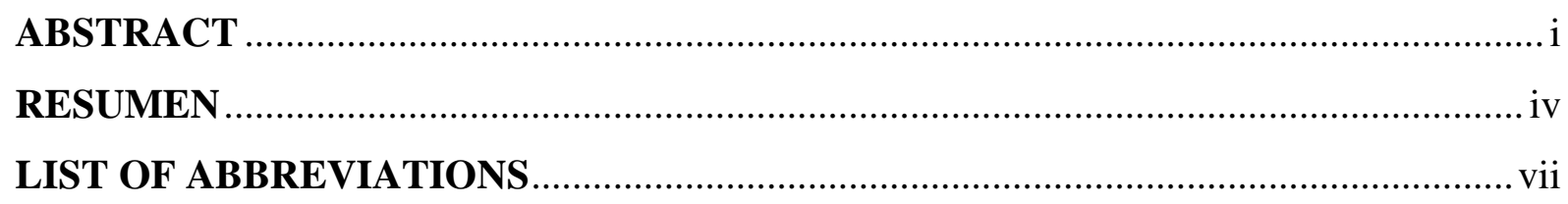

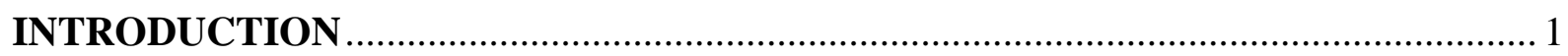

1. BOTANICAL AND AGRONOMICAL CHARACTERISTICS OF HORTICULTURAL PRODUCTS STUDIED ............................................................ 2

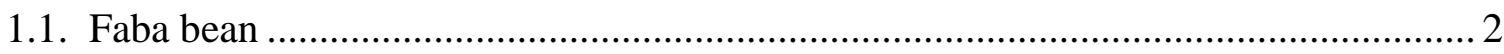

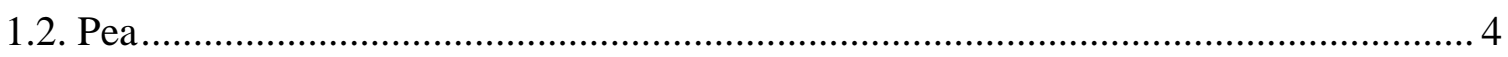

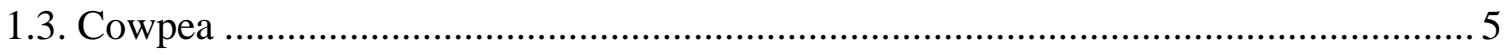

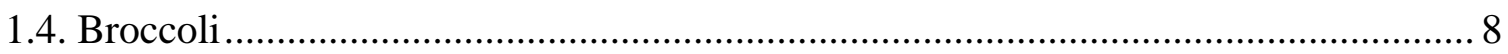

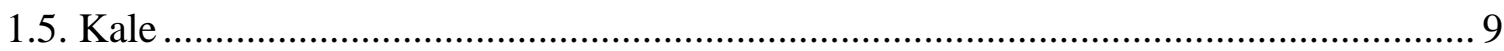

2. NUTRITIONAL AND BIOACTIVE COMPOUNDS OF LEGUMES, BROCCOLI

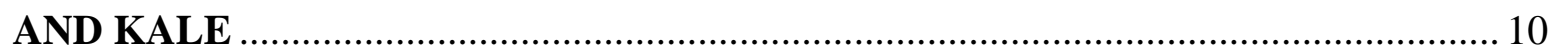

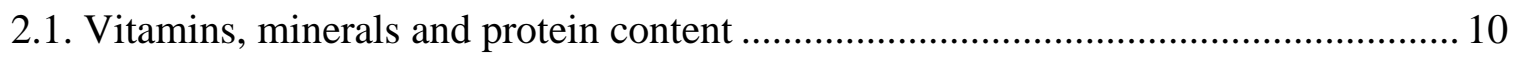

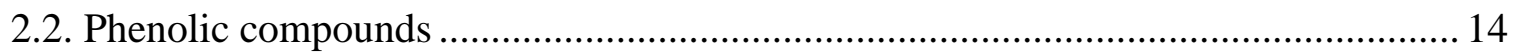

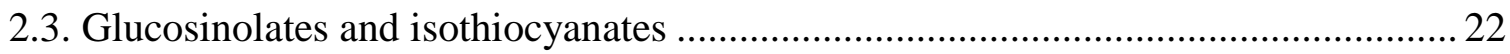

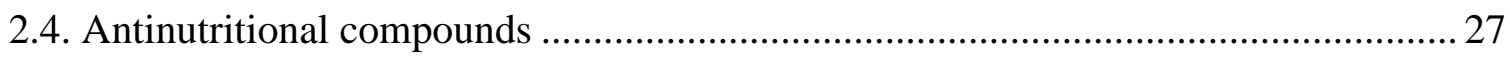

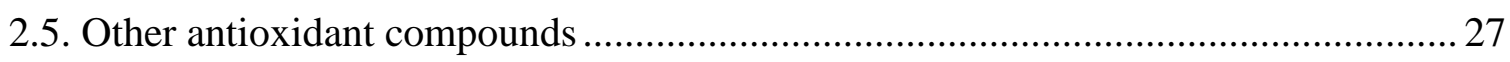

3. 'FIFTH RANGE' PROCESSING OF FRUIT AND VEGETABLES ..................... 30

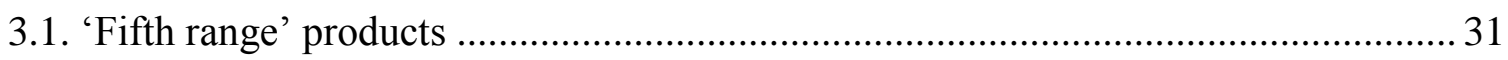

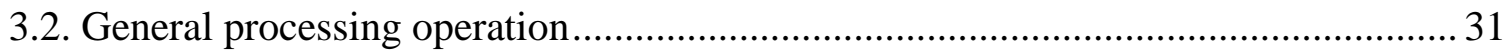

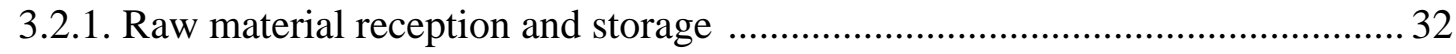

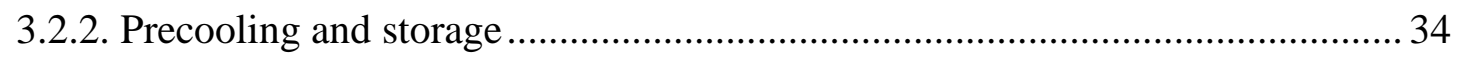

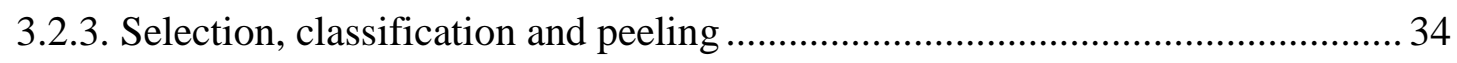

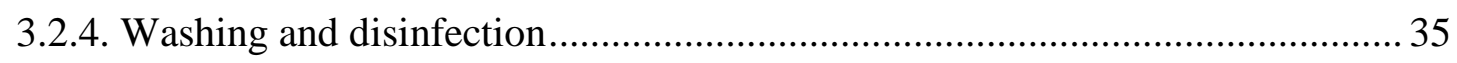

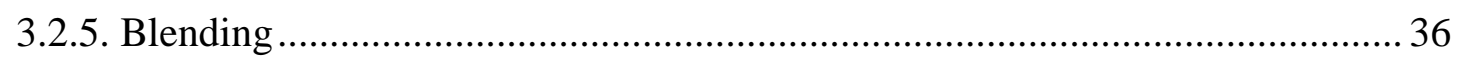

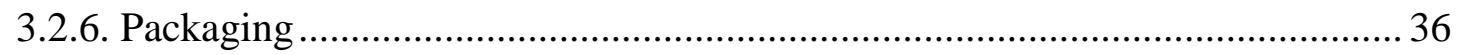


3.2.7. Cooking (thermal and non-thermal treatments) ............................................ 37



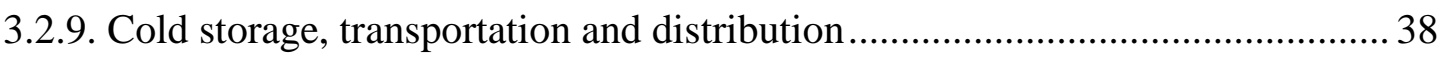

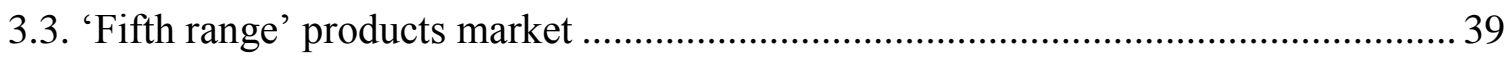

3.4. Safety aspects of the 'fifth range' vegetables ........................................................... 41

\section{CONVENTIONAL AND ECO-INNOVATIVE QUALITY PRESERVATION}

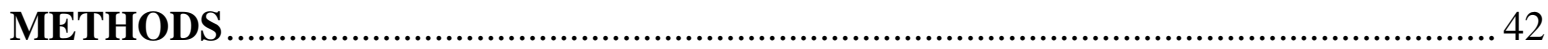

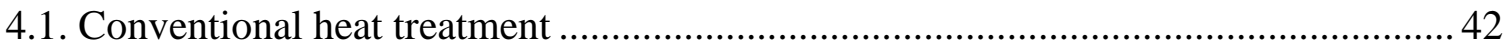

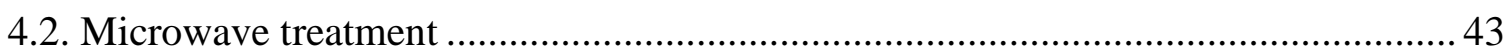

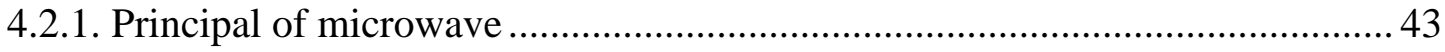

4.2.2. Advantages of microwave technology …........................................................ 46

4.2.3. Limitations and solutions of microwave technology ...................................... 47

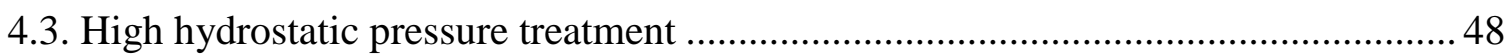

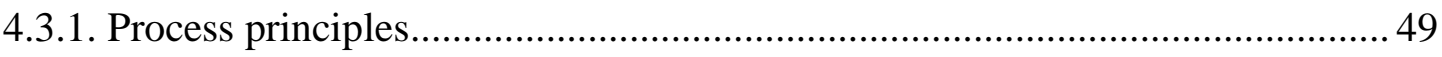

4.3.2. Applications in foods: biochemical changes.................................................. 51

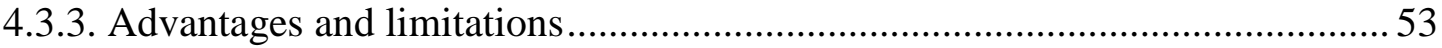

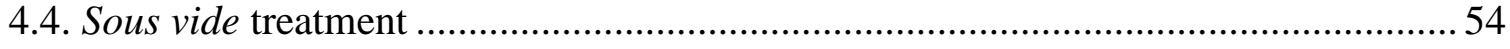

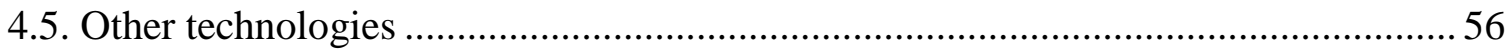

\section{ALTERNATIVE TECHNIQUES FOR INNOVATIVE MINIMAL PROCESSING

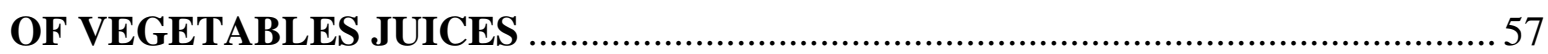

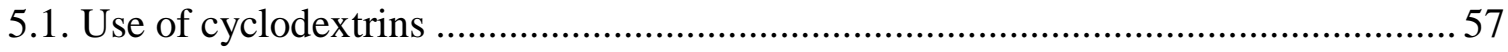

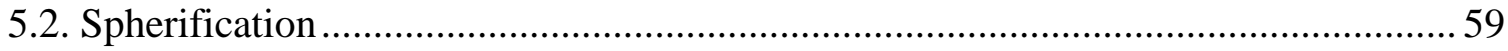

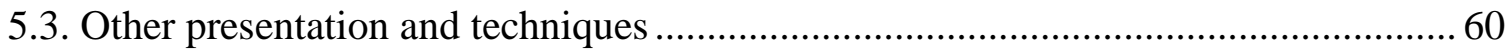

OBJECTIVES

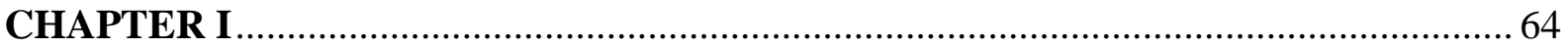

Improving quality of an innovative pea puree by high hydrostatic pressure 
CHAPTER II

Microwave and high hydrostatic pressure processing improved quality of a fresh pea seeds puree during shelf life

CHAPTER III. 109

Cowpea puree: different eco-innovative technologies as alternative in the minimal processing

CHAPTER IV 128

Innovative quality improvement by continuous microwave processing of a faba beans pesto sauce

CHAPTER V

Effect of microwave and high pressure processing on quality of an innovative broccoli hummus

CHAPTER VI

Effect of $\alpha-, \beta$ - and maltosyl $-\beta$-cyclodextrins use on the glucoraphanin/sulforaphane system of broccoli juice.

CHAPTER VII

Effect of stevia supplementation of kale juice spheres on their quality changes during refrigerated shelf life 


\section{ABSTRACT}

The current dietary habits due to lifestyle changes have defined a consumer profile that demands daily, natural, healthy, safe, tasty and convenient foods. However, such current lifestyle usually does not allow the time needed for such meals preparation. Thus, their consumption could be promoted through the development of new elaborates, processed under non-aggressive minimal treatments to preserve, as much as possible, the original quality and assuring safety. Fruit and vegetables are the primary source of mineral, vitamins, secondary plant metabolites and other compounds that support human health and nutrition. The quality of processed product not only depends on that of the raw material, but also on the processing and storage conditions that affect enzymatic reactions and sensorial, nutritional and functional characteristics. Therefore, the food industry needs to produce and guarantee healthy, innovative, ready-to-eat, high quality and safe products with sustainable minimal processing technologies, being able to prolong the shelf life and satisfy the consumer's demand. Consequently, the general objective of this Thesis was to develop innovative vegetable-based formulations such as purees, juices, sauces and hummus prepared as 'fifth range' products with high quality and bioactive compounds content, and prolonged refrigerated shelf life by using emerging sustainable minimal processing techniques.

Legumes are a key component of the Mediterranean diet but its consumption has decreased during last years due to the current lifestyle. Therefore, new convenient legume-based products developed under sustainable technologies seems to be an interesting market. In this work, the ideal composition of purees and sauces based on legumes, as well as the evolution of the microbial and sensory quality were determined. A pea-based puree was developed with a boiling treatment (10 $\mathrm{min}$ ) followed by high hydrostatic pressure (HHP) technology at 550 $\mathrm{kPa}(0,5$ or $10 \mathrm{~min})$ and the rheological properties, associated with enzymatic activity and particle size, as well as on the microbial and sensory quality throughout 36 days at $5{ }^{\circ} \mathrm{C}$, has been studied. After all processing treatments the particle size of pea puree decreased, but it increased during subsequent storage in HHP-treated samples. The HHP treatment $(550 \mathrm{kPa}, 5$ min) showed the highest mean particle size, mean surface diameter and viscosity regarding the remaining treatments. 
Furthermore, the effect of different treatments like microwave (MW) at $9 \mathrm{~kW}$ for $40 \mathrm{~s}, \mathrm{HHP}$ (550 $\mathrm{MPa}, 10 \mathrm{~min}$ ) and high pressure assisted thermal processing (HPTP) at $550 \mathrm{MPa}$ for 10 min to reach $60{ }^{\circ} \mathrm{C}$, on bioactive compounds and sensory quality in a pea puree stored throughout 24 days at $5{ }^{\circ} \mathrm{C}$ were studied. HHP-treated samples showed the best colour and highest vitamin $\mathrm{C}$ retention after storage. Particularly, MW-treated samples showed higher apparent viscosity. Furthermore, HHP and HPTP treatments showed the highest total phenolics compounds content (TPC). Finally, after 24 days at $5{ }^{\circ} \mathrm{C}, \mathrm{MW}$ and HHP treatments showed the highest sensorial quality.

In addition, the effects of differents mild heating treatments MW (8 kW; $40 \mathrm{~s}$ ), HHP (550 $\mathrm{MPa}, 10 \mathrm{~min}$ ) and sous vide $\left(3 \mathrm{~min}, 80^{\circ} \mathrm{C}\right.$ ) on bioactive compounds and sensory quality in a cowpea puree stored throughout 21 days at $5{ }^{\circ} \mathrm{C}$ were studied. Physicochemical properties, especially colour, were greatly influenced by treatments, in where HHP was able to preserve greenness, and improve the consistency, texture and taste.

Subsequently, the effect of an alternative semi-continuous MW pasteurization $(11 \mathrm{~kW} ; 30 \mathrm{~s})$ regarding a conventional pasteurization $\left(85^{\circ} \mathrm{C} ; 5 \mathrm{~min}\right)$ throughout 20 days at $5{ }^{\circ} \mathrm{C}$ in an innovative pesto sauce, made of fresh faba bean seeds was studied. MW treatment improved the sensorial quality of pesto sauce and decreased condensed tannins. Additionally, MWtreated samples showed the best texture, consistency and colour, keeping its chlorophylls and carotenoids content. Accordlingly, MW pasteurization did not negatively affect the TPC and antioxidant capacity (TAC) throughout storage.

Broccoli is a vegetable with excellent nutritional and bioactive properties that may be used as a first-rate ingredient to obtain an innovative high quality hummus variant. Accordlingly, two innovative broccoli (53\% either Parthenon conventional or hybrid Bimi) hummus were formulated and treated with a semi-continuous MW treatment $(9 \mathrm{~kW} ; 40 \mathrm{~s})$ or with HHP (550 $\mathrm{MPa} ; 10 \mathrm{~min} ; 23{ }^{\circ} \mathrm{C}$ ). The microbial, physicochemical, and sensory quality, besides the bioactive compounds content changes throughout 28 days at $5{ }^{\circ} \mathrm{C}$ were studied. MW Parthenon hummus showed better sensory scores at the end of storage while HHP was better for Bimi. Higher (110\%) glucoraphanin was found in HPP Parthenon hummus although MW better preserved sulforaphane. Furthermore, both treatments kept high phenolics levels during storage being better kept by HHP, with also a higher TAC. 
Cyclodextrins (CDs) are macromolecules with wide industrial applications, with particular benefits in the food industry like protection of nutritional/health-promoting compounds, stabilization of flavours, elimination of undesired tastes and browning reactions, among others. Accordlingly, the effects of $\alpha-(10,30$ and $40 \mathrm{mM}), \beta-(3,6$ and $10 \mathrm{mM})$ and maltosyl- $\beta-\operatorname{CDs}(30,60$ and $90 \mathrm{mM})$ on the stability of the health-promoting glucoraphanin/sulforaphane system (with high health benefits) of a broccoli juice during $24 \mathrm{~h}$ at $22{ }^{\circ} \mathrm{C}$ were studied. Maltosyl- $\beta-\mathrm{CD}(90 \mathrm{mM})$ highly retained glucoraphanin content after $24 \mathrm{~h}$ at $22{ }^{\circ} \mathrm{C}$ showing better results than $\beta-\mathrm{CD}(10 \mathrm{mM})$. Furthermore, sulforaphane was efficiently encapsulated with $\beta-\mathrm{CD}$ at just $3 \mathrm{mM}$ being the formed sulforaphane stable during $3 \mathrm{~h}$ at $22{ }^{\circ} \mathrm{C}$. On the other side, $40 \mathrm{mM} \alpha-\mathrm{CD}$ also highly retained glucoraphanin content in broccoli juice, while glucoraphanin levels in juice without CDs decreased by $71 \%$ after $24 \mathrm{~h}$.

Kale is another vegetable with excellent nutritional and bioactive properties, although its consumption as a beverage is highly limited by its bitter flavour. On such scenario, the effects of different stevia extracts (S10, S25 and S50), used as a sweetener to mask bitter flavour, on the quality of kale juice spheres during storage up to 7 days at $5{ }^{\circ} \mathrm{C}$ were studied. Spheres were produced with a double spherification technique that allowed obtaining hydrogel spheres with high mechanical resistance. The addition of stevia extracts did not affect the physicochemical quality of spheres. Particularly, kale juice spheres containing S50 showed the lowest colour changes after 7 days of storage. All spheres showed good microbial quality during storage with loads below $7 \log \mathrm{CFU} \mathrm{g}{ }^{-1}$, regardless of stevia concentration, throughout chilling storage. Sulforaphane content of kale spheres was not affected by stevia addition during storage of spheres up to 7 days at $5^{\circ} \mathrm{C}$. 


\section{RESUMEN}

Los hábitos alimenticios actuales debidos a los cambios en el estilo de vida han definido un perfil de consumidor que demanda diariamente alimentos naturales, saludables, seguros, sabrosos y prácticos. Sin embargo, el estilo de vida actual por lo general no facilita el tiempo necesario para la preparación de tales comidas. Por lo tanto, su consumo debe ser promovido a través del desarrollo de productos convenientes procesados bajo tratamientos mínimos no agresivos para preservar la calidad original tanto como sea posible. Las frutas y hortalizas son la fuente principal en la dieta humana de minerales, vitaminas, metabolitos secundarios y otros compuestos que favorecen la salud y nutrición. La calidad del producto procesado no sólo depende de la calidad de la materia prima vegetal, sino también de las condiciones de procesado y almacenamiento que afectan a las reacciones enzimáticas y a las características sensoriales, nutricionales y funcionales. Por ello, la industria alimentaria necesita satisfacer la demanda actual ofreciendo productos sanos, innovadores, listos para el consumo, de alta calidad y seguros, con tecnologías de procesado mínimo y sostenible, que garanticen la seguridad y una vida útil adecuadas. Por lo tanto, el objetivo general de esta Tesis fue desarrollar formulaciones innovadoras a base de hortalizas, tales como purés, jugos, salsas y hummus, preparados como productos de "quinta gama" con elevado contenido de compuestos bioactivos de alta calidad y una vida útil refrigerada prolongada mediante técnicas emergentes de procesamiento mínimo sostenible.

Las legumbres son un componente clave de la dieta mediterránea, pero su consumo ha disminuido durante los últimos años debido al estilo de vida. Por ello, los nuevos y convenientes productos a base de leguminosas desarrollados con tecnologías sostenibles parecen tener un mercado interesante. En esta Tesis se ha determinado la composición ideal de purés y salsas a base de legumbres, así como la evolución de la calidad microbiológica y sensorial. Se ha estudiado el desarrollo de un puré a base de guisantes con un tratamiento térmico (10 min) seguido de altas presiones hidrostáticas (HHP) a $550 \mathrm{kPa}(0,5$ ó $10 \mathrm{~min})$ y se han determinado las propiedades reológicas asociadas a la actividad enzimática y al tamaño de las partículas, así como la calidad microbiana y sensorial durante 36 días a $5{ }^{\circ} \mathrm{C}$. El tamaño de las partículas del puré de guisantes disminuyó con todos los procesados, pero aumentó durante el almacenamiento en las muestras tratadas con HHP. El tratamiento de HHP (550 
$\mathrm{kPa}, 5 \mathrm{~min}$ ) mostró el mayor tamaño medio de partícula, diámetro medio de superficie y viscosidad respecto a los restantes tratamientos.

Además, se estudiaron los efectos de diferentes tratamientos en horno de microondas (MW) semicontínuo (9 $\mathrm{kW} ; 40 \mathrm{~s})$, HHP (550 MPa, $10 \mathrm{~min}$ ) y el procesamiento térmico asistido por altas presiones (HPTP) a $550 \mathrm{MPa}$ durante $10 \mathrm{~min}$, para alcanzar $60^{\circ} \mathrm{C}$, sobre los compuestos bioactivos y la calidad sensorial en un puré de guisantes almacenado durante 24 días a $5{ }^{\circ} \mathrm{C}$. Las muestras tratadas con HHP mostraron la mayor retención de color y vitamina C durante el almacenamiento, mientras las tratadas con MW mostraron una mayor viscosidad aparente. Además, los tratamientos de HHP y HPTP indujeron el mayor contenido total de fenoles. Finalmente, las muestras tratadas con MW y HHP mostraron la más alta calidad sensorial después de 24 días a $5{ }^{\circ} \mathrm{C}$.

Igualmente, se estudiaron los efectos de diferentes tratamientos térmicos suaves MW (8 kW; $40 \mathrm{~s})$, HHP (550 MPa, $10 \mathrm{~min})$ y sous vide $\left(3 \mathrm{~min}, 80^{\circ} \mathrm{C}\right)$ sobre los compuestos bioactivos y la calidad sensorial en un puré de caupí almacenado durante 21 días a $5{ }^{\circ} \mathrm{C}$. Las propiedades fisicoquímicas, especialmente el color, se vieron muy influenciadas por los tratamientos, en los que el tratamiento HHP fue capaz de preservar el color verde y mejorar la consistencia, la textura y el sabor.

Posteriormente, en una innovadora salsa pesto hecha de semillas de haba fresca, se estudió el efecto de una pasteurización alternativa con un tratamiento semicontinuo por MW $(11 \mathrm{~kW} ; 30$ s) respecto a una pasteurización convencional $\left(85^{\circ} \mathrm{C} ; 5 \mathrm{~min}\right)$ durante 20 días a $5{ }^{\circ} \mathrm{C}$. El tratamiento con MW mejoró la calidad sensorial de la salsa pesto y disminuyó los taninos condensados. Además, las muestras tratadas con MW mostraron la mejor textura, consistencia y color, preservando su contenido de clorofilas y carotenoides. Además, la pasteurización con MW no afectó negativamente los compuestos fenólicos totales (TPC) y la capacidad antioxidante (TAC) durante el almacenamiento.

El brócoli es una hortaliza con excelentes propiedades nutricionales y bioactivas que puede ser un ingrediente idóneo para obtener una innovadora variante de hummus con alta calidad nutricional/bioactiva. De acuerdo con esto, se formularon dos innovadores hummus con brócoli (53\% de hummus de la variedad convencional Partenón o del híbrido Bimi) y se trataron por MW en horno semicontinuo $(9 \mathrm{~kW} ; 40 \mathrm{~s})$ o con $\mathrm{HHP}\left(550 \mathrm{MPa} ; 10 \mathrm{~min} ; 23^{\circ} \mathrm{C}\right)$. 
Se estudió la calidad microbiológica, fisicoquímica y sensorial y los compuestos bioactivos durante 28 días a $5{ }^{\circ} \mathrm{C}$. El hummus de Partenón tratado con MW mostró mejores resultados sensoriales después de 28 días, mientras que el tratamiento HHP fue mejor para el hummus de Bimi. Se observó una concentración de glucorafanina más alta $(110 \%)$ en el hummus de Partenón tratado con HHP, aunque el tratado con MW conservó mejor el contenido de sulforafano. Además, ambos tratamientos mantuvieron altos niveles de fenoles durante el almacenamiento, siendo mejor preservados por HHP, con niveles de TAC también más altos.

Las ciclodextrinas (CDs) son macromoléculas con amplias aplicaciones industriales y beneficios particulares en la industria alimentaria tales como la protección de compuestos nutricionales y promotores de la salud, la estabilización de sabores, la eliminación de sabores no deseados y las reacciones de pardeamiento, entre otros. Se estudiaron los efectos de $\alpha$ - (10, 30 y $40 \mathrm{mM}), \beta-(3,6$ y $10 \mathrm{mM})$ y maltosyl- $\beta$-CDs $(30,60$ y $90 \mathrm{mM})$ sobre la estabilidad del sistema glucorafanina/sulforafano (muy saludable) de un zumo de brócoli durante 24 horas a $22{ }^{\circ} \mathrm{C}$. La maltosyl- $\beta$-CD $(90 \mathrm{mM})$ retuvo bien el contenido de glucorafanina después de $24 \mathrm{~h}$ a $22{ }^{\circ} \mathrm{C}$, con mejores resultados que la $\beta$-CD $(10 \mathrm{mM})$. Además, el sulforafano se encapsuló eficazmente con $\beta-\mathrm{CD}(3 \mathrm{mM})$, siendo estable el sulforafano formado durante $3 \mathrm{~h}$ a $22{ }^{\circ} \mathrm{C}$. Por otro lado, $40 \mathrm{mM} \alpha-\mathrm{CD}$ también retuvo bien el contenido de glucoraphanina en el zumo de brócoli, y los niveles de glucorafanina en el zumo sin CDs disminuyeron un $71 \%$ después de 24 horas.

Otra hortaliza con excelentes propiedades nutricionales y bioactivas es el kale, aunque su consumo como bebida está muy limitado por su sabor amargo. En este caso, se estudiaron los efectos de diferentes extractos de stevia (S10, S25 y S50), utilizados como edulcorantes para enmascarar el sabor amargo, sobre la calidad de esferas de zumo de kale durante 7 días a $5^{\circ} \mathrm{C}$. Las esferas se produjeron con una técnica de doble esferificación que permitió obtener esferas de hidrogel de alta resistencia mecánica. La adición de extractos de stevia no afectó la calidad físico-química de las esferas de kale. En particular, las que contenían S50 mostraron los menores cambios de color después de 7 días de almacenamiento. Todas las esferas mostraron buena calidad microbiológica durante el almacenamiento con cargas siempre por debajo de 7 $\log \mathrm{CFU} \mathrm{g}{ }^{-1}$, independientemente de la concentración de stevia. Además, el contenido en sulforafano de las esferas de kale no se vio afectado por la adición de stevia durante el almacenamiento. 


\section{LIST OF ABBREVIATIONS}

$\Delta \mathrm{E}:$ total colour differences

$\mu:$ micro

AA: ascorbic acid

ABTS: 2,2'-azino-bis (3-thylbenzothiazoline-6-sulphonic acid)

AITC: allyl isothiocyanate

ANOVA: analysis of variance

AOAC: Association of Official Agricultural Chemists

BITC: benzylisothiocyanate

CDs: cyclodextrins

CFU: colony forming units

CGT-ase: cyclodextrin glucosyl transferase enzyme

CIE Lab: Lab colour space, International Commission on Illumination

$\mathrm{CP}$ : conventional pasteurization

CTRL: control

cvs: cultivars

DHA: dehydroascorbic acid

DPPH: 2,2-Diphenyl-1-picrylhydrazyl free radical

FAO: Food and Agriculture Organization of the United Nations

FDA: Food and Drug Administration of the United States of America

FRAP: ferric reducing antioxidant power

fw: fresh weight

GAE: gallic acid equivalents

GLS: Glucosinolates

GPx: glutathion peroxidase

GRAS: generally regarded as safe

GST: glutathione-S-transferase

${ }^{\mathrm{o}} \mathrm{h}$ : Hue angle

HPLC: high-performance (pressure) liquid chromatography

HHP: high hydrostatic pressure 
HPP: high pressure processing

HPTP: high pressure assisted thermal processing

ITC: isothiocyanates

M: mol

MAP: modified atmosphere packaging

MS: mass spectrometry

MW: microwave

$\mathrm{N}$ : normal

NADPH: nicotinamida adenina dinucleótido fosfato

PAL: phenylalanine ammonia-lyase

PE: polyethylene

PEF: pulse electric field

PEITC: phenethylisothiocyanate

PG: polygalacturonase

PME: pectin methyl esterase

POD: peroxidase

PP: polypropylene

PPO: polyphenol oxidase

PS: polystyrene

PVPP: polyvinyl polypyrrolidone

r: Correlation factor

rpm: revolutions per minute

RD: Real Decreto (Spain)

ROS: reactive oxygen species

SAR: specific absorption rate

SD: standard deviation

SFN: sulforaphane

SOD: superoxide dismutase

SSC: soluble solids content

TA: titratable acidity

TAC: total antioxidant capacity

TEAC: trolox equivalent antioxidant capacity 
TPC: total phenolic content

TPTZ: 2,4,6-tripyridyl-s-triazine

UHPLC: ultra high-performance (pressure) liquid chromatography

UK: United Kingdom

WHO: World Health Organization 


\section{BOTANICAL AND AGRONOMICAL CHARACTERISTICS OF HORTICULTURAL PRODUCTS STUDIED}

\subsection{Faba beans}

Faba beans (Vicia faba) belongs to the genus Vicia, tribe Fabeae (syn. Vicieae), family Fabaceae (syn. Legumiosae, Papilionaceae), order Fabales (Vega, 2012). Vicia faba also gaves its name to other crops, especially to Phaseolus and Vigna species (for example, in Spanish: fabes, habichuelas, etc.).

Probably domesticated in the $6^{\text {th }}$ millennium B.C. in the Near East, $V$. faba spread quickly (Cubero, 1974) i) to central Europe and the Eurasiatic plains through Anatolia, the Danube Valley and the Caucasus; ii) to North Africa and the Iberian Peninsula through the Mediterranean coast and islands; iii) from Egypt and Arabia to Ethiopia, iv) from Mesopotamia to India, and v) from the Near East to China, probably during the first millenium A.D. In the $16^{\text {th }}$ century, the crop was introduced to America by European colonizers and since 1980, the crop has been widely grown in Australia.

Faba bean prefers clay-lime, chalky, well-drained and textured soils, with neutral $\mathrm{pH}$, although it adapts to a wide $\mathrm{pH}$ range (6 to 9 ) as well as to sandy-loam soils, especially in humid regions. Exchanges of germplasm between latitudes shows that many faba bean cvs require long days to flower and mature (photoperiod sensitive) while others appear to be daylength-neutral (Patrick and Stoddard, 2010).

Vicia faba is an annual diploid crop with a strong taproot. The plant is more or less erect and branches, if present, usually arise from the crown. Stems are square in cross-section, hollow and glabrous. The compound leaves have no tendrils, and the number (4-8) and shape (oval to lanceolate) of leaflets depend on the variety or landrace, their margins being straight or slightly undulated. Stipules usually show a dark spot with an extrafloral nectary (Vega, 2012). The seeds are 1-3 cm diameter and are oblong to ovoid in shape (Figure 1). The colour of the seeds going from brown to red or green. Plants are typical of warn zones for autumn and winter crops and in cold ones they must be sown in spring. Its flowers are papilionate, with a single ovary, usually with 3-5 ovules (in some accessions up to 12) and 10 stamens, of which 1 is free and filaments of the other 9 are united in a sheath around the ovary. Nectaries 
are present at the bottom of the corolla tube. Racemes are short, the number of flowers varying from 1-2 to 10-12, usually 4-6 (Figure 2), and even exceptionally more in some minor cultivars (Vega, 2012).

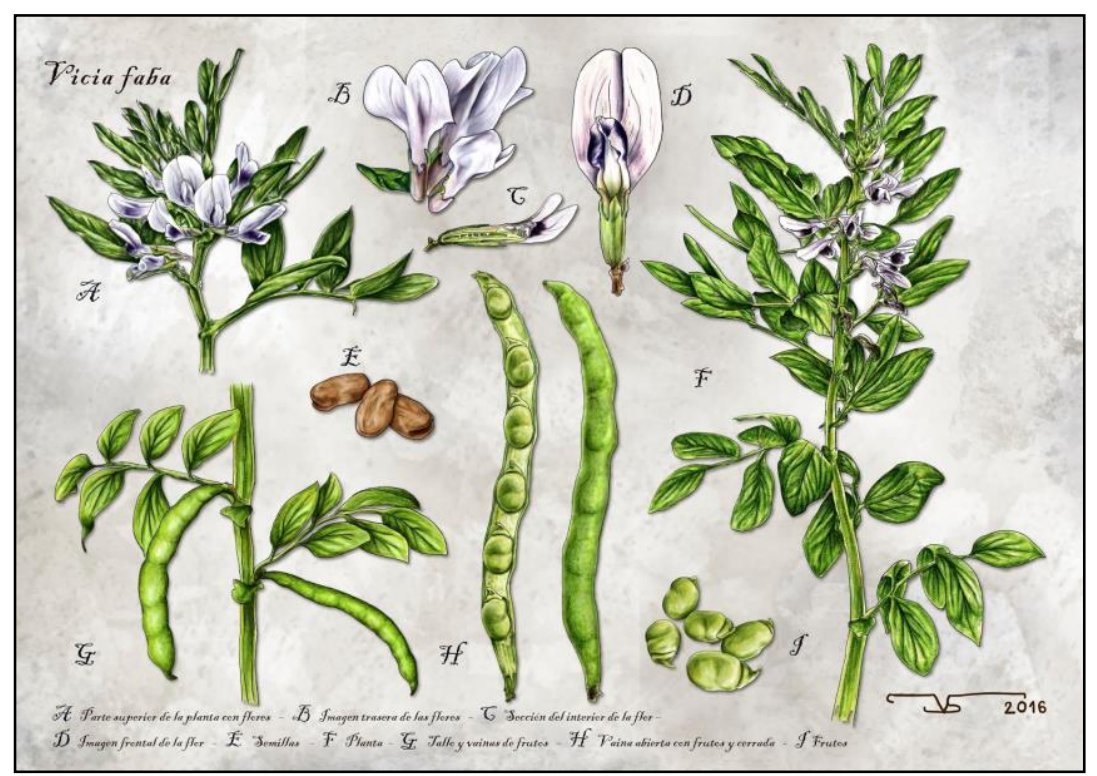

Figure 1. Plant of Vicia faba. A: upper part of the plant with flowers, B: back of the flower, C: Inner section of the flower, D: Front part of the flower, E: seeds, F: Plant, G: stem and pots, H: pods, I: fruits (www.blog.illustraciencia.info)

The pod is a typical legume. The number of pods depends on several genetic and environmental factors. Usually 1-4 pods are produced per node, erect or decumbent; a better fruit/flower ratio is one of the main breeding objectives (Vega, 2012). Pod length can vary from $2-3 \mathrm{~cm}$ to $30-40 \mathrm{~cm}$, or even $50 \mathrm{~cm}$ in some horticultural accessions (Figure 2). 

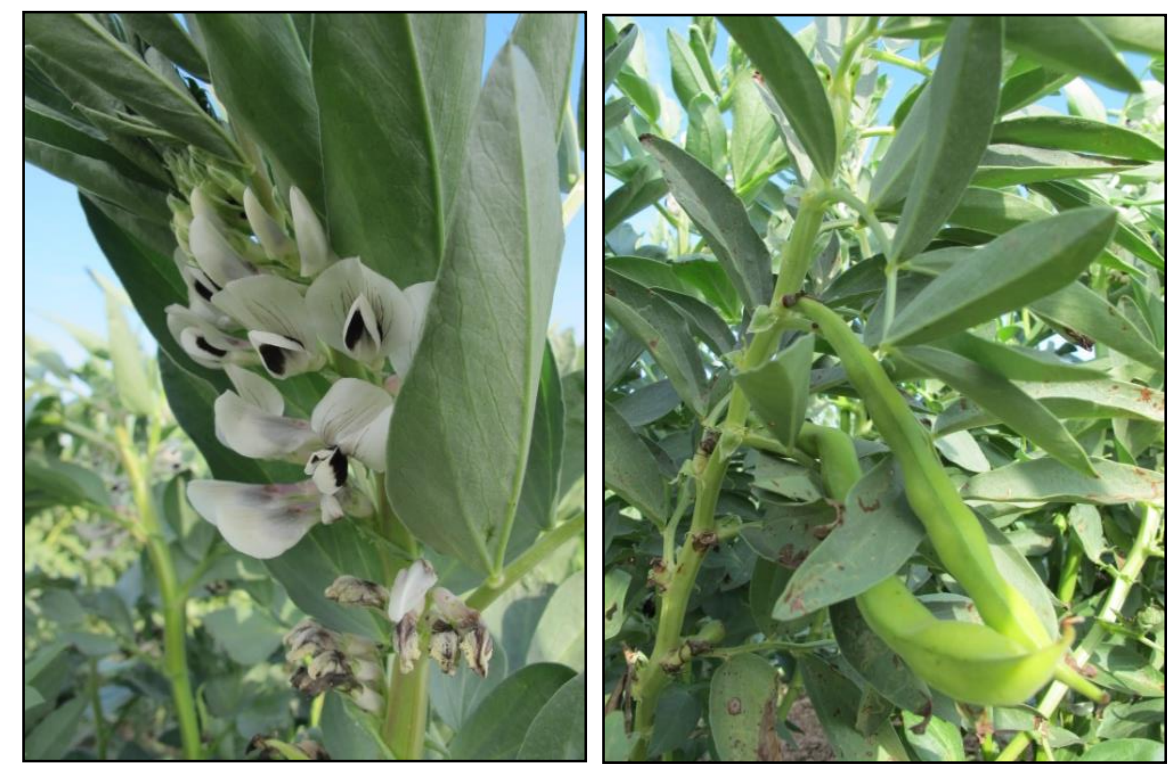

Figure 2. Flowers (left) and pods (right) of Vicia faba

\subsection{Peas}

Peas (Pisum sativum), a very polymorphic specie, appear in the Mediterranean or in the Middle East. Archaeological evidences indicate that it was well under cultivation in the Near Eastern and Greek Neolithic settlements as early as 6,000 B.C. The introduction of peas into primitive agriculture must have taken place rapidly as, alongside cereals, they had become widely used by Greek and Roman times (Savage and Deo, 1989).

Pea cultivation is favoured in dry land areas where the weather is cool and moisture is abundant during early growth, but where the rainfall is minimal during the later stages of development.

Pisum sativum is a climbing annual plant, with pods oblong-obovate, whitish or yellowish when ripe, and with 6-10 globular seeds in each pod (Figure 3), harvested at immature physiological stage, when the pods were almost round and with the seeds $70 \%$ of full size. Their quality indices include that peas should be uniformly bright green, fully turgid, clean and free for damage. 


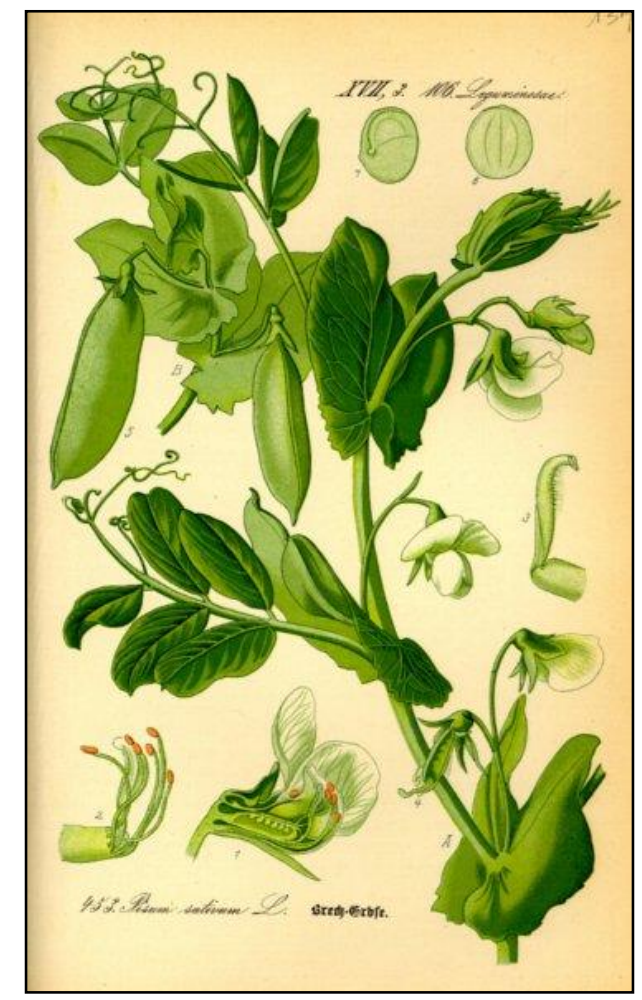

Figure 3. Plant of Pisum sativum (http.www.biolib.de)

\subsection{Cowpea}

Cowpea (Vigna unguiculata) was first domesticated in West Africa 5,000-6,000 years ago and was introduced into Europe around 300 B.C. Although some reports suggest that cowpea has been cultivated in Europe at least since the $18^{\text {th }}$ century B.C. and possibly from prehistoric times onward, others suggest that it was only introduced in Europe around 300 B.C., where it still remains as a minor crop in the southern part. From Europe, more specifically from Portugal and Spain, this legume was distributed in the $17^{\text {th }}$ century to the New World (Badiane et al., 2014).

Cowpea is a diploid species belongs to the division Magnoliophyta, class Magnoliopsida, order Fabales, family Leguminosae, tribe Phaseoleae, genus Vigna. The domesticated forms are subdivided into four cultivar-groups essentially based on seed and pod characters. These cultivar-groups are unguiculata grown as pulse (Figure 4), biflora (catjang) used mainly as forage, sesquipedalis (asparagus bean) grown as a vegetable, and textilis cultivated for the fibres of its long floral peduncles. Cowpea is the Vigna unguiculata most 
popular worldwide name, although local names such as black-eyed beans, black-eyed peas, pink-eyes or southern peas (all used in the USA), 'frijol caupí' (Spanish speaking countries in America), 'lobia' (India), 'caupi' (Brazil), 'caupí' and 'carilla' (Spain), 'niébé' (French speaking countries of Africa), and 'feijão-frade' (Portugal, Brazil) are used (Carvalho et al., 2017).

This crop is well adapted to a wide range of soil types from sands to heavy, including low fertility soils. Plants grow in an extensive range of temperatures, with $28{ }^{\circ} \mathrm{C}$ as the optimal one. Early flowering cowpea can produce a crop of dry grain in only 60 days, whereas longer season cowpeas may require more than 150 days to produce mature pods, depending on photoperiod (Ehlers and Hall, 1996).

Flowers emerge in alternate pairs on racemes at the distal ends of long peduncles, with usually two flowers per inflorescence. Flowers have a short life cycle, opening in the early day and closing at approximately midday, after which they usually wilt and collapse (Figure 5). Corollas can be purple, mauve-pink, yellow or white. Each peduncle commonly develops two or three pods and pods differ in size, shape, colour and texture. Seeds differ in size and colour, ranging from white, cream, green, buff, red, brown or black and can be kidney, ovoid, crowder, globose or rhomboid and are characteristic by the presence of an eye, as a result of the different pigmentations encircling the hilum (Carvalho et al., 2017). Cowpea can be harvested at three different stages of maturity: green snaps, green-mature, and dry. Depending on temperature and fresh-market demand, peas are ready for harvest 16 to 17 days after bloom (60 to 90 days after planting). Cowpea characteristics vary widely and that grain size is the most important single factor-influencing price. 


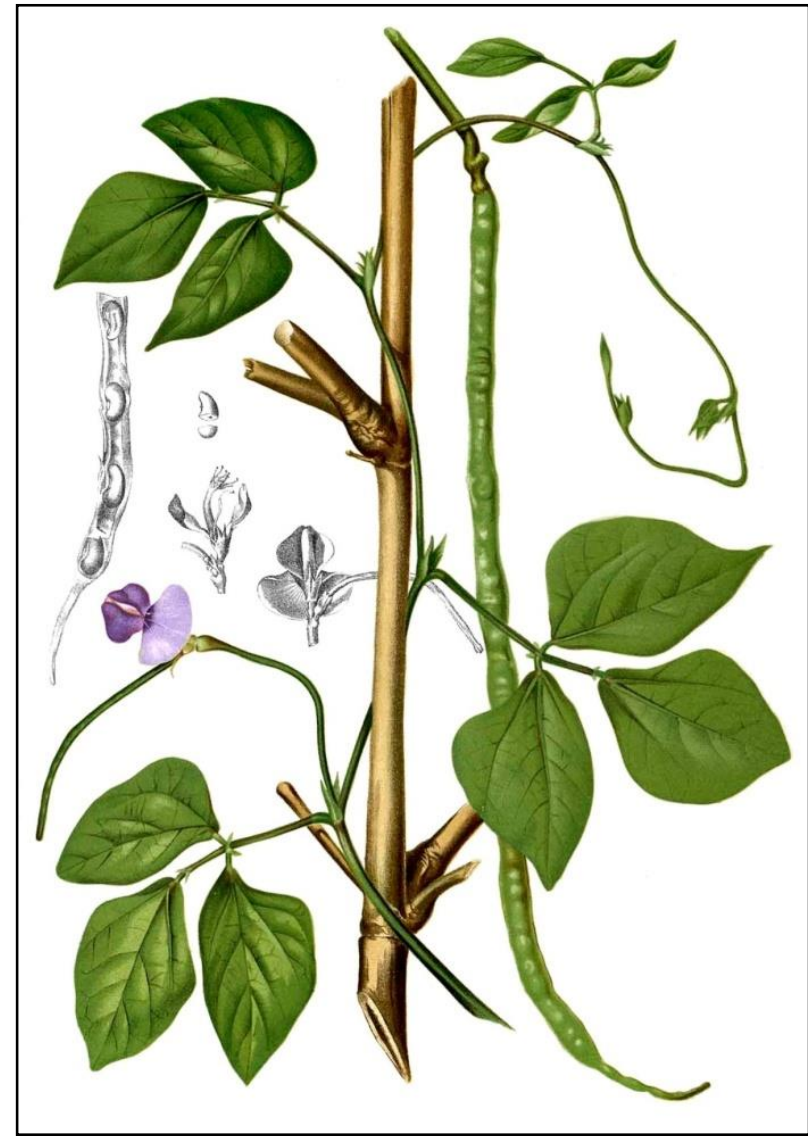

Figure 4. Plant of Vigna unguiculata (http.bibdigital.rjb.csic.esspaindex.php)
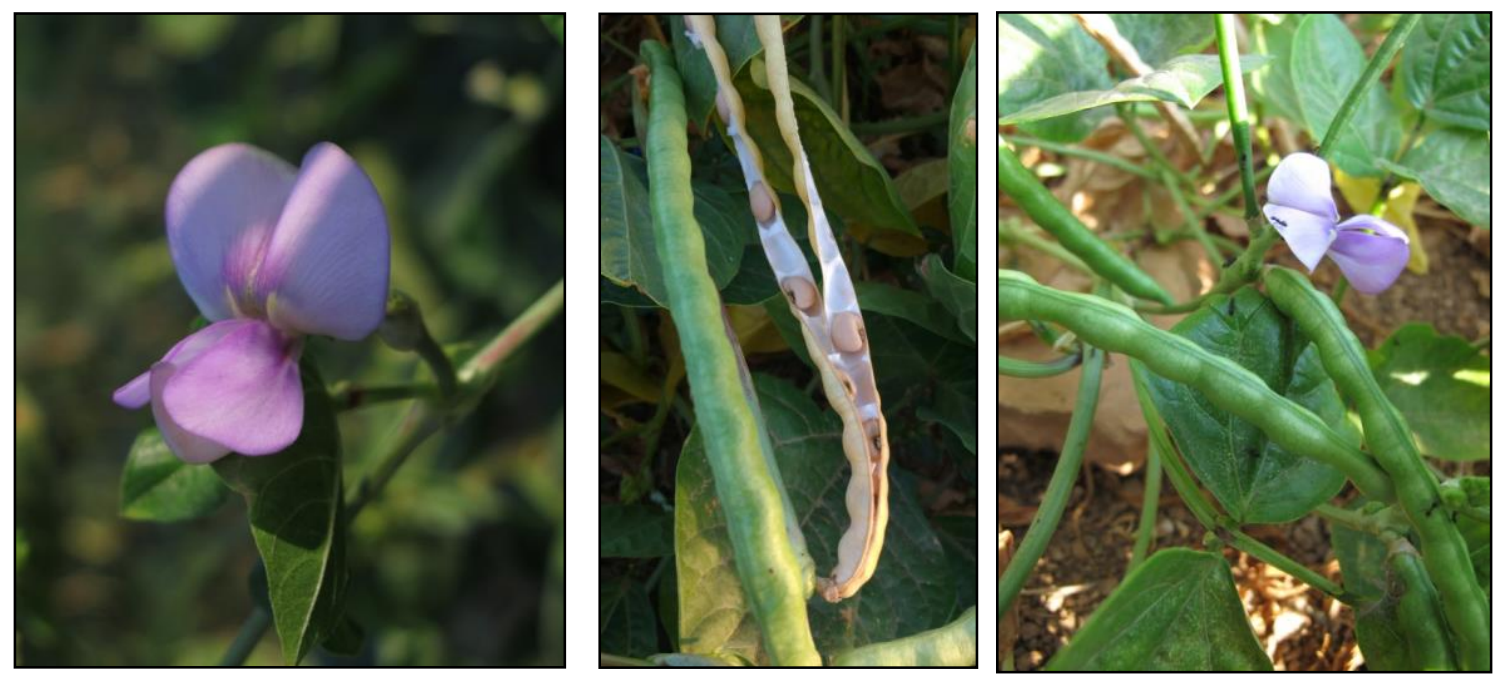

Figure 5. Flowers (left), fresh pods (center) and dry pods (right) of Vigna unguiculata 


\subsection{Broccoli}

Broccoli (Brassica oleracea, Italica group) is a vegetable of the Brassicaceae family. The word broccoli comes from the Italian plural of broccolo, diminutive of brocco (shoot), based on the Latin word brocchus (projecting). In this Family are also included other vegetables such as arugula, cauliflower, collards, bokchoy (Chinese cabbage), kailan (Chinese broccoli), kale, mustard greens, radish, turnips, watercress, rutabaga and Brussels sprouts.

By 8,000 years ago, plants of the mustard family, to which broccoli phylogenetically belongs, were cultivated for food by the civilizations of Persia and China. The phylogenetic parent of broccoli was a wild cabbage taken to Persia after the Aryan invasion of Europe, from where they diffused it throughout the Mediterranean region. The first accurate knowledge about the genus Brassica begins with the Hellenic culture, 25 centuries ago. Lately, during the Roman Empire, this broccoli ancestor reached the Italian peninsula, where it was cultivated for human consumption from the first century A.C. The actual broccoli varieties have been developed from selections of desirable types that have mainly occurred in Italy within the past 2,000 years. During the past 300 years, due to the horticultural selection, some types of Brassica became highly improved, culminating in the cauliflowers and the heading broccoli. In the mid $20^{\text {th }}$ century, the broccoli production spread from Italy to the rest of Europe and, lately, to the rest of the world (Buck, 1956).

Broccoli is a cool-season crop that grows preferably with extended cool weather in spring and fall (or during winter months in mild areas). The optimum daily temperatures for broccoli growth are ranged between 18 and $23{ }^{\circ} \mathrm{C}$. The adult plant can reach $60-90 \mathrm{~cm}$ of height and $60 \mathrm{~cm}$ of diameter. The edible part of the plant corresponds to the inflorescence, which has a characteristic green-blue colour (Figure 6) and a special slight bitter taste. The broccoli head weight, for most commercial varieties, ranges between $550 \mathrm{~g}$ in cv. Bohr and $766 \mathrm{~g}$ in cv. Parthenon (Rogers, 2009).

Bimi ${ }^{\circledR}$ (Sakata Vegetables Europe) is a natural hybrid between broccoli and kailan. This hybrid was firstly developed by the Sakata Seed Company of Yokohama (Japan). This vegetable is characterized by a floret at the end of each stem (Figure 6). The kailan-hybrid broccoli has a flavour softer and more delicate than the conventional broccoli, so it can be eaten either raw or cooked. 

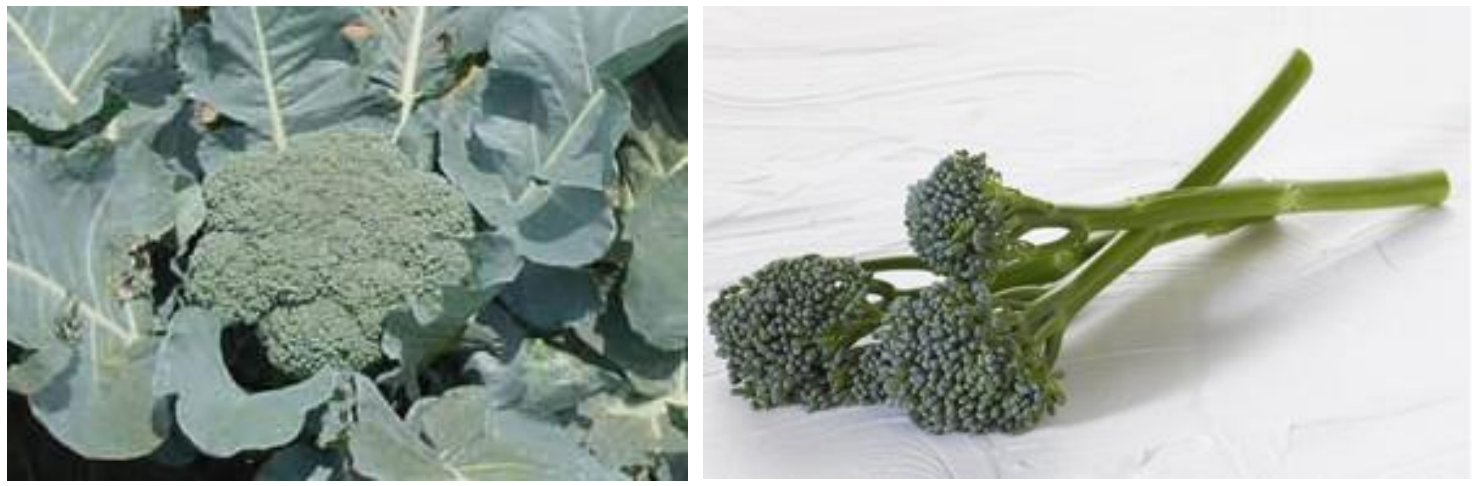

Figure 6. Conventional Broccoli (cv. Parthenon) (left) and Bimi ${ }^{\circledR}$ : A kailan-hybrid broccoli (right) (http://www.bellaverde.co.uk/).

\subsection{Kale}

Kale (Brassica oleracea) is a valuable fresh vegetable during wintertime given its tolerance against frost. It is mostly assumed to have originated from wild cabbage occurring on cliffs and rocky coasts along the Atlantic, but this is still under dispute. The term kale is rather widely used for different morphological types of large leafed B. oleracea varying in leaf morphology and sometimes described as different varieties (Hahn et al., 2016). Kale belongs to the division Magnoliophyta, Class Magnoliopsida, Order Brassicales, Family Brassicaceae, genus Brassica.

Kales are biannual crops. Leaf consumption period starts 3 months after the transplant and finishes at the pre-flowering stage, which occurs almost 1 year after transplanting. It is a very rustic crop that is adapted to different environmental conditions and does not need high inputs in order to develop (Vilar et al., 2008). 


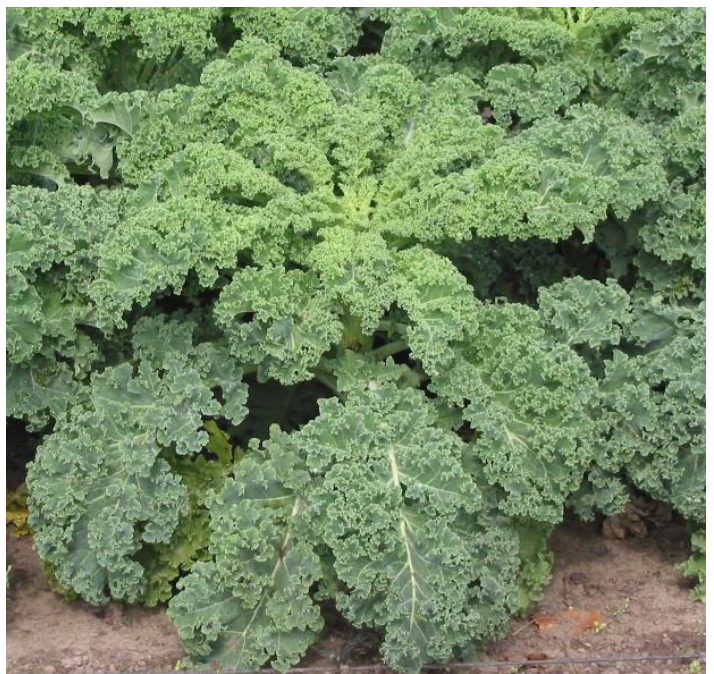

Figure 7. Kale (Brassica oleracea var. sabellica).

\section{NUTRITIONAL AND BIOACTIVE COMPOUNDS OF LEGUMES, BROCCOLI AND KALE}

Bioactive compounds present in fruit and vegetables are metabolites and chemical compounds of secondary plant metabolism, which are found in small amounts in plants as opposed to other macronutrients. They contribute significantly to regulating the mechanisms of protection against stress and have biological properties of interest for the prevention of some diseases in humans who consume them (Hooper and Cassidy, 2006).

Many vegetables are a important source of bioactive compounds (phenolics, glucosinolates, vitamins, carotenes, antioxidants, etc.) which have a beneficial effects in blood lipid, glucose levels, insulin resistance, in inflammatory and oxidative processes, and also in prevention of various types of cancers as well as heart diseases (Boye et al., 2010; Wang et al., 2011; Alshikh et al., 2015).

\subsection{Vitamins, minerals and protein content}

Legumes and their seeds contain many vitamins such as B group, mainly folic acid, K, and C, among others. Brassica act as a good source of natural antioxidants due to the high levels of vitamins B6, C, K, among others, as well as dietary essential minerals $(\mathrm{Ca}, \mathrm{Mg}, \mathrm{Na}$, $\mathrm{K}, \mathrm{Fe}, \mathrm{Zn}$, etc.). An overview of vitamins and minerals concentrations in some legumes, broccoli and kale is provided in Table 1, based mainly on the USDA-ARS database (2018). 
Vitamins, present in minute amounts in natural foodstuffs are a group of complex organic compounds, essential for normal metabolism. In relation to vitamin $\mathrm{C}$ (vit $\mathrm{C}$, ascorbic acid), this can exist in two forms: reduced the exact ascorbic acid (AA) which in physiological $\mathrm{pH}$ occurs in its anion form or an ascorbate-and oxidized one-dehydroascorbic acid (DHA), which is a product of two-electron oxidation of AA. Vit C is a cofactor for at least eight enzymatic reactions involved in key bodily processes including protecting white blood cells, the biosynthesis of collagen, carnitine, tyrosine and peptides hormones, preventing harmful genetic mutations. Also it plays the essential role in neurotransmission and neuronal maturation and functions (Eldridge et al., 1989). Moreover, in association with vit $\mathrm{E}$, it can prevent oxLDL-induced overexpression of vascular endothelial growth factor (VEGF), responsible for atherosclerotic plaque formation (Rodríguez et al., 2005). According to the later recommendations, vit $\mathrm{C}$ consumption should be $75 \mathrm{mg}$ per day (women) and 90 mg per day (men) (Waly et al., 2015). Broccoli and kale $c v s$ may be considered as excellent vit $\mathrm{C}$ content. Koh et al. (2009) reported $573.5-1,313.5 \mathrm{mg} \mathrm{kg} \mathrm{g}^{-1}$ of vit $\mathrm{C}$ in several commercial broccoli $c v s$. Additionally, kale $c v s$ shown levels between $238-573 \mathrm{mg} \mathrm{kg}^{-1} \mathrm{fw}$ (Becerra-Moreno et al., 2014). According to the USDA nutrient database, the vit $\mathrm{C}$ content can be as high as $400 \mathrm{mg} \mathrm{kg}^{-1} \mathrm{fw}$ in green peas (Table 1).

Folates belong to B9 group vitamins and folic acid refers to synthetic oxidized forms. Folates are involved in important one-carbon metabolism by serving as the acceptor and donors of one-carbon units in a variety of reactions. Insufficient dietary folate has been suggested as a possible risk factor for cardiovascular disease, colon cancer and neural tube defects, as well birth defects during pregnancy (Hefni and Witthöft, 2014). Legumes are also source of folic acid mainly faba beans seeds. Hefni et al. (2015) evaluated faba beans $c v s$ consumed in Egypt and observed that the mean folate content in the green faba beans ranged from 110 to $130 \mu \mathrm{g} 100 \mathrm{~g}^{-1}$ fw or 535 to $620 \mu \mathrm{g} 100 \mathrm{~g}^{-1}$ dry matter.

Minerals play different roles in the body among which, participation in the construction of the body and regulation of its function especially in bone construction, transport of $\mathrm{O}_{2}$, production of melatonin, heart function, development of the central nervous system, regulation of blood sugar, cofactor for the enzyme activity, regulation of chemical reactions, protection of cells from oxidative damage and regulation of immune system function, etc. (Khayat et al., 2017). Kale cvs have high contents in vitamins and minerals, 


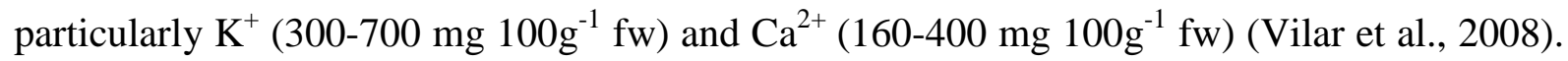
Based on $100 \mathrm{~g}$ of fresh kale leaf consumption per day, it can contribute to $10-15 \%$ of the recommended daily allowance (RDA) for $\mathrm{K}(4,700 \mathrm{mg} /$ day $)$ and $\mathrm{Ca}(1,000 \mathrm{mg} /$ day $)$, respectively. Legumes represent also a valuable source of minerals, particularly $\mathrm{Fe}, \mathrm{Mg}, \mathrm{P}, \mathrm{K}$, $\mathrm{Zn}$ and $\mathrm{Cu}$ (Table 1).

In relation to protein content, legumes containing almost twice the amount of proteins compared to cereals. The protein content amounts is $5.4 \%$ f.w. in green pea seeds and $7.9 \%$ in immature seeds of faba beans (Table 1). The nutritional value of legumes as protein sources depends also on the amino acid composition. Proteins predominating are globulins and albumins, while prolamins and glutemins are the minor proteins (Tiwari and Singh, 2012). Legume protein are generally high in lysine, leucine, isoleucine, aspartic acid, glutamic acid and arginine, but lack methionine, cysteine and tryptophan (Iqbal et al., 2006). 
Table 1. Water and energy content and nutrient concentrations of legumes, broccoli and kale. The dates originate from the USDA-ARS (2018).

\begin{tabular}{|c|c|c|c|c|c|}
\hline \multirow{2}{*}{ Constituents } & \multicolumn{5}{|c|}{ Content $\left(\right.$ per $\left.100 \mathrm{~g}^{-1} \mathrm{fw}\right)$} \\
\hline & $\begin{array}{c}\text { FABA BEAN } \\
\text { IMMATURE SEEDS }\end{array}$ & $\begin{array}{c}\text { PEA GREEN } \\
\text { SEEDS }\end{array}$ & $\begin{array}{c}\text { COWPEA } \\
\text { SEEDS }\end{array}$ & BROCCOLI & KALE \\
\hline$\overline{\text { Energy (kcal) }}$ & 88 & 81 & 116 & 34 & 49 \\
\hline Water (g) & 73 & 79 & - & 89 & 84 \\
\hline Proteins (g) & 7.9 & 5.4 & 7.7 & 2.8 & 4.3 \\
\hline Carbohydrates (g) & 17.6 & 14.5 & 20.7 & 6.6 & 8.7 \\
\hline Fiber $(\mathrm{g})$ & 7.5 & 5.7 & 6.5 & 3.0 & 3.6 \\
\hline Fats $(\mathrm{g})$ & 0.7 & 0.4 & 0.5 & 0.4 & 0.9 \\
\hline \multicolumn{6}{|l|}{ Vitamins } \\
\hline Vitamin B1 (mg) & 0.13 & 0.27 & 0.202 & 0.071 & 0.110 \\
\hline Vitamin B2 (mg) & 0.29 & 0.13 & 0.055 & 0.117 & 0.130 \\
\hline Vitamin B3 (mg) & 2.25 & 2.09 & 0.495 & 0.639 & 1.0 \\
\hline Vitamin B6 (mg) & 0.10 & 0.17 & 0.1 & 0.175 & 0.271 \\
\hline Folic acid (Vit. B9) $(\mu \mathrm{g})$ & 148 & 65 & - & 63 & 141 \\
\hline Vitamin C (mg) & 3.7 & 40 & 2.5 & 100 & 120 \\
\hline Vitamin E (mg) & 1.16 & 0.13 & 0.28 & 0.621 & 1.5 \\
\hline Vitamin $\mathrm{K}(\mu \mathrm{g})$ & 40.9 & 25 & 1.7 & 154 & 704.8 \\
\hline \multicolumn{6}{|l|}{ Total Minerals (mg) } \\
\hline $\mathrm{Ca}$ & 37 & 25.4 & 24 & 47 & 150 \\
\hline $\mathrm{Fe}$ & 1.6 & 1.9 & 2.51 & 0.7 & 1.47 \\
\hline $\mathrm{Mg}$ & 33 & 32.2 & 53 & 21 & 47 \\
\hline $\mathrm{Zn}$ & 0.9 & 0.7 & 1.29 & 0.41 & 0.56 \\
\hline $\mathrm{Na}$ & 18 & 2 & 4 & 33 & 38 \\
\hline K & 332 & 247 & 278 & 316 & 491 \\
\hline $\mathrm{P}$ & 129 & 113 & 156 & 66 & 92 \\
\hline
\end{tabular}


In a survey of Spanish landrace accessions, protein content in cowpea varied between 14.8 to $23.6 \%$ in dry weight, depending on the genotype (Martos-Fuentes et al., 2015). Globulins constitute with 55-58\%, the major seed proteins in cowpea, followed by albumins, basic glutelins, acid glutelins and prolamins (Gupta et al., 2010). Cowpea seeds protein shows

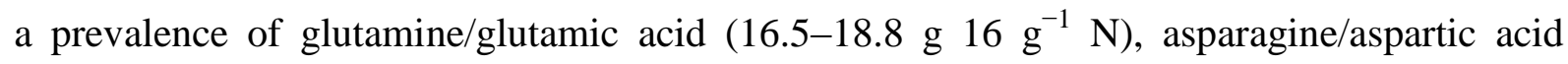

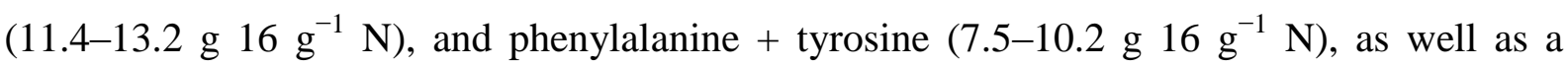
secondary prevalence of arginine, leucine, lysine, valine and proline (Carvalho et al., 2012).

\subsection{Phenolic compounds}

Phenolic compounds constitute one of the most numerous group of plant secondary metabolites, with more than 8,000 phenolic structures known. Chemically, these compounds have at least one aromatic ring in which at least one hydrogen is substituted by a hydroxyl group (Strack, 1997). These compounds are produced for protection against UV light, insects, viruses and bacteria, and are secondary metabolities from plants and fungi. Furthermore, It is believed that phenolic compounds were fundamental for plants to gain their terrestrial environment, such as lignin which stimulates the development of the vascular system, giving stiffness to the vessels. There are even certain plant species that develop phenolic compounds with allelopathic action, to inhibit the growth of other plant competitors, such as caffeic and ferulic acids (Gross, 1985). Phenolics range from simple, low molecular weight, single aromatic-ringed compounds to large and complex tannins and derived polyphenols. They can be subdivided into 6 general groups: flavonoids, phenolic acids, phenolic alcohols, stilbenes, lignans and tannins (Cömert and Gökmen, 2017).

Flavonoids, the largest group of phenolic compounds, consist of 15 carbon atoms, structured in $\mathrm{a}_{6}-\mathrm{C}_{3}-\mathrm{C}_{6}$ carbon skeleton with 2 aromatic ring (A and $\mathrm{B}$ ), joined by a 3-carbon bridge in the form of a heterocyclic ring (called ring $\mathrm{C}$ ) (Figure 8). The side group variations on rings $\mathrm{B}$ and $\mathrm{C}$ result in the diversity of the flavonoid classes such as flavones, flavonols (3hydroxyflavone), flavanols, isoflavones and anthocyanidins (Liu-Smith and Meyskens, 2016). The structure of phenolic acids is a benzene ring linked to a carboxylic group (benzoic acid) or to a propenoic acid (cinnamic acid), so they are subdivided into two main groups: hydroxycinnamic acids and hydroxybenzoic acids. The extensive diversity of compounds is related to the number and position of hydroxyl groups on the aromatic ring, with the same 
basic skeleton (Figure 8). Examples of hydroxybenzoic acids that are well-known are: gallic, vanillic, p-hydroxybenzoic, and syringic acids, whereas sinapic, caffeic, ferulic and pcoumaric acids are the most commonly known hydroxycinnamic acids (Bhanja et al., 2016).

Phenolic alcohols are 2-phenylethanol, 3,4-dihydroxyphenyl ethanol (hydroxytyrosol), p-hydroxyphenyl ethanol (tyrosol), and 3,4-dihydroxyphenyl ethanol-glucoside. Hydroxytyrosol and tyrosol, as the most common phenolic alcohols, present in olives, olive oil and olive mill wastewater (Oroian and Escriche, 2015).

Stilbenes (two aromatic rings with an ethane bridge) are derived from the phenylpropanoid pathway and are found in three forms: oligomeric form (dimers, trimers, or polymers of resveratrol), monomeric (resveratrol, oxyresveratrol) and other stilbenes (including $\varepsilon$-viniferin and pallidol) (Chong et al., 2009). The major class of phytoestrogens are the lignans that possessing a 1,4- diarylbutane structure (Cassidy et al., 2000). Tannins are high-molecular-weight phenolic compounds, wich contain many phenolic hydroxyl groups in their structures, causing the chemical heterogeneity among the tannins. Condensed tannins, hydrolyzable tannins, and the phlorotannins are the three main classes of tannins. They are considered highly effective antioxidants (Przywitowski et al., 2016; Cömert and Gokmen, 2017). 


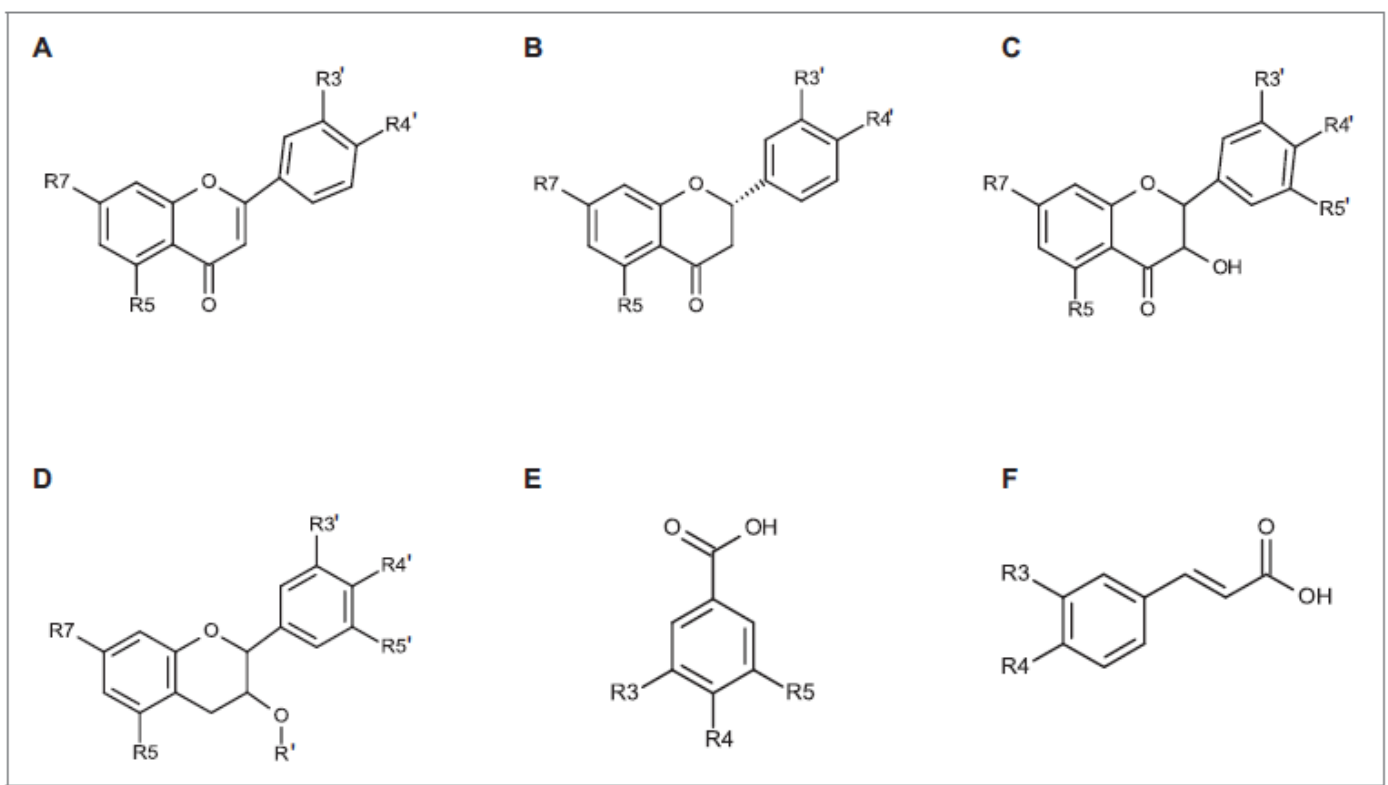

Figure 8-Chemical structures of some phenolic compounds: (A) flavones (luteolin: R3 $\mathrm{R} 4{ }_{-}, \mathrm{R} 7, \mathrm{R} 5=\mathrm{OH}$; apigenin: R4_, R5, R7 = OH, R3 = H), (B) flavanone (hesperetin: $\mathrm{R} 3 \_, \mathrm{R} 5, \mathrm{R} 7=\mathrm{OH}, \mathrm{R} 4{ }_{-}=\mathrm{OCH} 3$; naringenin: $\left.\mathrm{R} 4{ }_{-}, \mathrm{R} 5, \mathrm{R} 7=\mathrm{OH}, \mathrm{R} 3{ }_{-}=\mathrm{H}\right),(\mathrm{C})$ flavonols (quercetin: R3_, R4_, R5_, R7 = OH; myricetin: R3_, R4_, R5_, R5, R7 = OH), (D) flavanols (catechin: R4_, R5_, R5, R7 = OH, R3 = H, R_ = H; epigallocatechin: R3_, R4_, R5_, R_, R5, R7 = OH), (E) hydroxybenzoic acid (gallic acid: R3, R4, R5 = OH; $p$ hydroxybenzoic acid: R3, R5 = H, R4 = OH; vanillic acid: $\mathrm{R} 3=\mathrm{H}, \mathrm{R} 4=\mathrm{OH}, \mathrm{R} 5=$ $\mathrm{OCH} 3$ ), and (F) hydroxycinnamic acid (caffeic acid: R3, R4 = OH; ferulic acid: R3 = OCH3; R4 = OH; p-coumaric acid: R3 = H; R4 = OH) (Cömert and Gökmen, 2017).

Phenolic acids can be synthesized from the shikimate pathway from 1-phenylalanine or 1-tyrosine according to Rice-Evans et al. (1996) (Figure 9). Phenylalanine and tyrosine are very important amino acids in this pathway since these amino acids are the common precursors for the majority of the natural phenolic products (Heleno et al., 2015). 


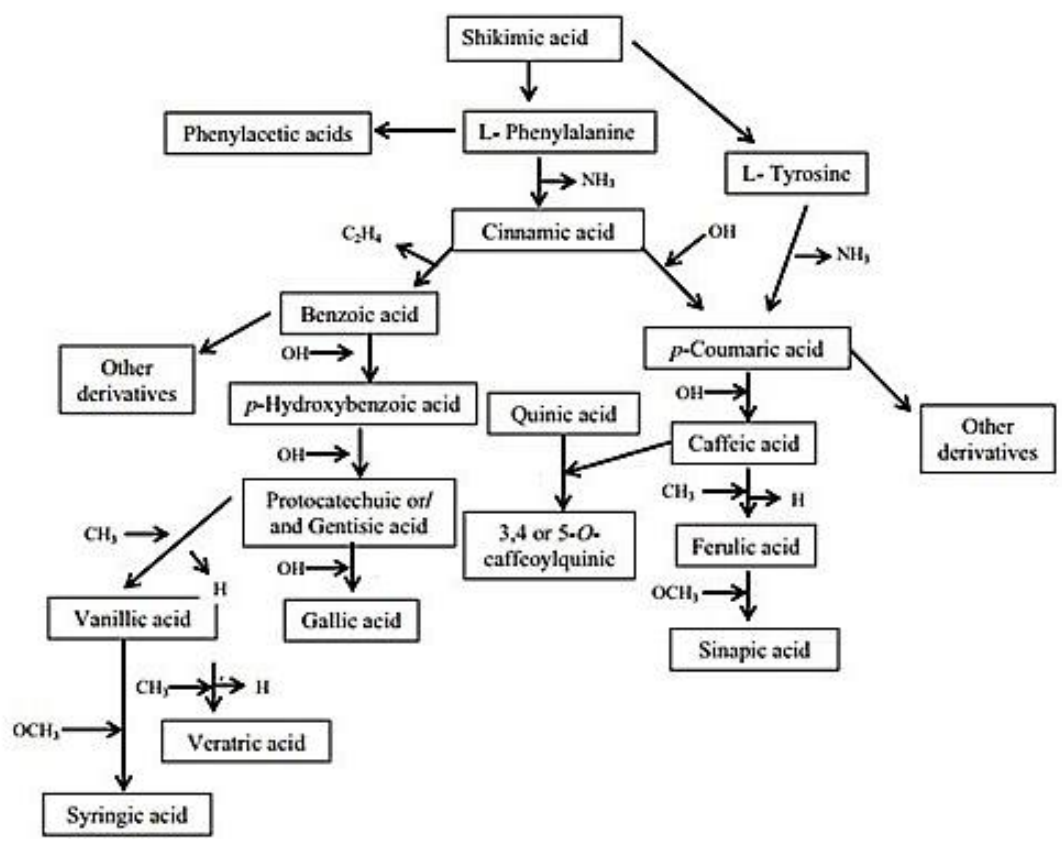

Figure 9: General representation of the phenolic acids biosynthesis derived from the shikimic acid pathway. Adapted from Heleno et al. (2015).

Absorption pathways of polyphenols in the gastrointestinal tract in showed in Figure 10, where microorganisms, enzymes and even glucose transporters are involved (AcostaEstrada et al., 2014). The metabolism of free phenolic compounds ingested with food start in the lumen of the small intestine followed by postabsorption modifications in the liver or other organs. For absorption of flavonoids bound to sugar molecules, some enzymes ( $\beta$ glucosidade) in the small intestine break down the sugar molecules that get attached to the flavonoids and allow for a release of the flavonoid skeleton. The level absorption of polyphenols is influenced by many factors, like as solubility, food matrix, processing, (Cifuentes-Gómez et al., 2015), chemical attachments on the polyphenol (Guo and Bruno, 2015), among others.

Phenolic compounds plenty of biologically significant functions such as protection against oxidative stresses and degenerative diseases, because they have what is considered the ideal chemical structure for free radical-scavenging activity, such as transition metal-chelating potential and reactivity as a hydrogen/electron-donating agent (Rice-Evans et al., 1997). 


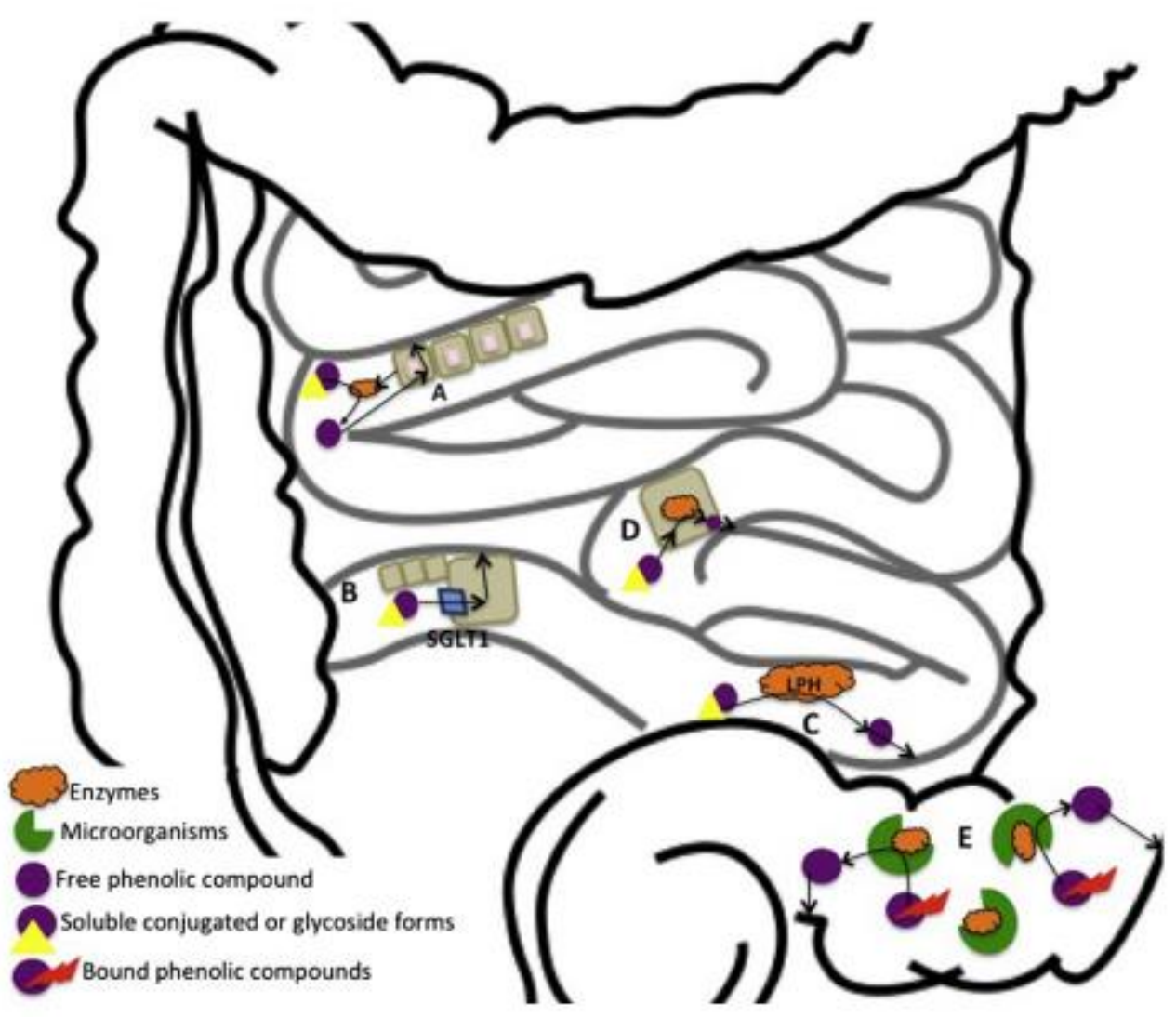

Figure 10. Absorption pathways of bound phenolic compounds in the gastrointestinal tract. (A) Hydrolysis of bound soluble conjugated forms by mucosa cells cinnamoyl esterases. (B) Soluble conjugated forms transport into enterocytes by the sodium dependent glucose transporter SGLT1. (C) Lactase phloridzine hydrolase (LPH) ( $\beta$-glycosidase) of the brush border hydrolysis soluble conjugated phenolic compounds. (D) Epithelial cells cytosolic bglucosidase hydrolyzes glycosides, and aglycones are formed after absorption. (E) Esterase and xylanase activities of colon microorganism (e.g. Clostridium spp., Eubacterium spp., and Bifidobacterium adolescentis) (Acosta-Estrada et al., 2014).

These compounds might offer indirect protection by the activation of endogenous defense systems and with the modulation of cellular signaling processes (Singh et al., 2017a). Gallic acid showed anticancer properties in prostate carcinoma (Kaur et al., 2009), a potential activity as an anti-HSV-2 (Herpes simplex virus) agent (Kratz et al., 2008). Vanillic acid and syringic acid showed hepatoprotective activities, suggesting that the administration of 
syringic acid and vanillic acid could suppress hepatic fibrosis in chronic liver injury (Itoh et al., 2010). The p-coumaric acid also revealed antitumor activities against breast (MCF7), NCI-H460 and HCT15 carcinoma cell lines (Heleno et al., 2014). Caffeic and ferulic acids showed higher antioxidant activities measured by ABTS [2,2'-azino-bis (3thylbenzothiazoline-6-sulphonic acid)] and ferric reducing antioxidant power (FRAP) (Piazzon et al., 2012) and antimicrobial potential against pathogenic bacteria and fungi (Alves et al., 2013).

In summary, the phenolic compounds have many health benefits, some of which are acting as antioxidant, anticarcinogenic, anti-ulcer, anti-allergenic, anti-artherogenic, anti inflammatory, anti-thrombotic, immunemodulating, anti-microbial cardioprotective, vasodilatory and analgesic agents (Balasundram et al., 2006). Furthermore phenolic compounds can affect the sensory properties of foods where tannins largely contribute to the astringency of foods (Klug et al., 2018; Troszyńska et al., 2006).

The concentration of some phenolic compounds in immature seeds of peas and cowpea are showed in Table 2. Phenolic acids and their derivates flavanols, flavan-3-ols, anthocyanins, condensed tannins are the main polyphenol compounds present in legumes. Cowpea phenolic acid profile appears to be dominated by derivatives of protocatechuic, ferulic, and p-coumaric acids (Cai et al., 2003), although composition is variable depending on the phenotype. Flavonoids, phenolic acids and procyanidins are the dominant phenolic compound present in peas and faba beans.

The main phenolic compounds found in broccoli are flavonoids (mainly flavonols but also anthocyanins) and the hydroxycinnamic acids (Table 3). Furthermore, Redovniković et al. (2012) studied the phenolic content of 13 broccoli cvs, reporting data ranges of 15.5-26.9, 4.2-7.9 and 0.4-3.2 $\mathrm{mg} \mathrm{g}^{-1} \mathrm{dw}$ for total phenolic, and sinapic and caffeic acid derivates, respectively. Additionally, Ayaz et al. (2008) identified protocatechuic (131 ng g-1 fw), phydroxybenzoic (624 $\mathrm{ng} \mathrm{g}^{-1} \mathrm{fw}$ ), vanillic (115 $\left.\mathrm{ng} \mathrm{g}^{-1} \mathrm{fw}\right)$, p-coumaric (2308 $\left.\mathrm{ng} \mathrm{g}^{-1} \mathrm{fw}\right)$, caffeic $\left(4,887 \mathrm{ng} \mathrm{g}^{-1} \mathrm{fw}\right)$ and ferulic acids $\left(4,269 \mathrm{ng} \mathrm{g}^{-1} \mathrm{fw}\right)$ as the most abundant in kale leaves.

Table 2. Concentration of some phenolic compounds in seeds of peas and cowpea seeds 


\begin{tabular}{|c|c|c|}
\hline COMPOUNDS & $\begin{array}{c}\text { PEAS } \\
(\mu \mathrm{g} / \mathrm{g} \mathbf{d w})\end{array}$ & $\begin{array}{l}\text { COWPEA } \\
(\mu \mathrm{g} / \mathrm{g} \mathrm{dw})\end{array}$ \\
\hline Catechin & $0.0-25.0$ & $17-297$ \\
\hline Epicatechin & $46.3-67.1$ & $0.0-11.3$ \\
\hline Gallic acid & $21.0-93.1$ & 0.2 \\
\hline Vanillic acid & $0.0-3.2$ & 2.5 \\
\hline Protocatechuic acid & $2.7-19.8$ & trace-3.6 \\
\hline Caffeic acid & $5.0-9.9$ & trace- 1.0 \\
\hline Coumaric acid & 2.4-6.1 & $0.9-3.6$ \\
\hline \multicolumn{3}{|l|}{ Sinapic acid } \\
\hline Ferulic acid & $0.0-1.9$ & trace- 6.2 \\
\hline Quercetin & & trace- 10.0 \\
\hline Quercetin 3-O-glucoside & & $0.9-15.3$ \\
\hline Quercetin 3-O-galactoside & $0.0-0.9$ & 3.6 \\
\hline Apigenin-6-O-glucoside & trace-24.6 & \\
\hline \multicolumn{3}{|l|}{ Luteolin-8-C-glucoside } \\
\hline Apigenin-8-C-glucoside & $0.8-1.3$ & \\
\hline Myricetin 3-O-glucoside & & 9.64 \\
\hline Delphinidin3-O-glucoside & & $230-1450$ \\
\hline Malvidin3-O-glucoside & & $110-390$ \\
\hline Cyanidin3-O-glucoside & & $210-1030$ \\
\hline
\end{tabular}

References: Cowpea: (Cui et al., 2003; Cai et al., 2012; Dueñas, 2005; Ojwang et al., 2013). Pea: (Fratianni et al., 2014; Dueñas et al., 2004). 
Table 3. Variation of phenolic compounds found in broccoli and kale cultivars

\begin{tabular}{|c|c|c|}
\hline Phenolic Compound & Broccoli & Kale \\
\hline Quercetin (Q) derivatives & $\mathrm{x}$ & $\mathrm{x}$ \\
\hline Q-3-O-sophorotrioside-7-O-sophoroside & $\mathrm{x}$ & $\mathrm{x}$ \\
\hline Q-3-O-sophorotrioside-7-glucoside & $\mathrm{x}$ & $\mathrm{x}$ \\
\hline Q-3-O-sophoroside-7-O-glucoside & $\mathrm{x}$ & $\mathrm{x}$ \\
\hline Q-3,7-di-O-glucoside & $\mathrm{x}$ & $\mathrm{x}$ \\
\hline Q-3-O-sophoroside & $\mathrm{x}$ & $\mathrm{x}$ \\
\hline Q-3-O-glucoside & $\mathrm{x}$ & \\
\hline Q-3-O-(caffeoyl)-sophorotrioside-7-O-glucoside & $\mathrm{x}$ & \\
\hline Q- 3-O-(sinapoyl)-sophorotrioside-7-O-glucoside & $\mathrm{x}$ & \\
\hline Q-3-O-(feruloyl)-sophorotrioside-7-O-glucoside & $\mathrm{X}$ & \\
\hline Q-3-O-(p-coumaroyl)-sophorotrioside-7-Oglucoside & $\mathrm{X}$ & \\
\hline Q-3-O-(caffeoyl)-sophoroside-7-O-glucoside & $\mathrm{x}$ & $\mathrm{X}$ \\
\hline Q-3-O-(methoxycaffeoyl)-sophoroside-7-Oglucoside & & $\mathrm{x}$ \\
\hline Q-3-O-(sinapoyl)-sophoroside-7-O-glucoside & & $\mathrm{x}$ \\
\hline \multicolumn{3}{|l|}{ Kaempferol $(\mathrm{K})$ derivatives } \\
\hline K-3-O-sophorotrioside-7-O-sophoroside & $\mathrm{x}$ & $\mathrm{x}$ \\
\hline K-3-O-sohorotrioside-7-O-glucoside & $\mathrm{x}$ & \\
\hline K-3-O-sophoroside-7-O-diglucoside & $\mathrm{x}$ & \\
\hline K-3,7-di-O-glucoside & $\mathrm{x}$ & $\mathrm{x}$ \\
\hline K-3-O-sophoroside & $\mathrm{x}$ & $\mathrm{x}$ \\
\hline K-O-(sinapoyl)-sophorotrioside-7-O-sophoroside & $\mathrm{x}$ & \\
\hline \multicolumn{3}{|l|}{ Hydroxycinnamic acids } \\
\hline Sinapylglucoside & & $\mathrm{x}$ \\
\hline Ferulic acid & & $\mathrm{x}$ \\
\hline 4-feruloyl quinic acid & & $\mathrm{x}$ \\
\hline Sinapic acid & & $\mathrm{x}$ \\
\hline 1,2-disinapoylgentiobiose & $\mathrm{x}$ & $\mathrm{x}$ \\
\hline
\end{tabular}

References: Broccoli: (Vallejo et al., 2004; Llorach et al., 2003; Cartea et al., 2011). Kale: (Olsen et al., 2009; Velasco et al., 2011). 


\subsection{Glucosinolates and isothiocyanates}

Glucosinolates (GLS) are alkyl aldoxime-O-sulfate esters with a $\beta$-Dthioglucopyranosyl at the aldoximecarbon in Z-configuration to the ester group, formed by the plants from any of the eight amino acids: alanine, valine, leucine, isoleucine, phenylalanine, methionine, tyrosine, and tryptophan (Hayes et al., 2008). Four types of GLS can be found: aromatic (derived from valine, leucine, isoleucine and phenylalanine), aliphatic (derived from methionine), alkenyl (the last two derived from methionine), and indoles GLS (derived from tryptophan) (Wallsgrove and Bennett, 1995). GLS are the water-soluble organic compounds that contain S and N (Figure 11), and that have a vacuolar location (Deng et al., 2015). The major sources of GLS and isothiocyanates (ITC) are broccoli, Brussels sprouts, cabbage, cauliflower, horseradish, turnip, kale, as well as mustard species (Verkerk et al., 2009).

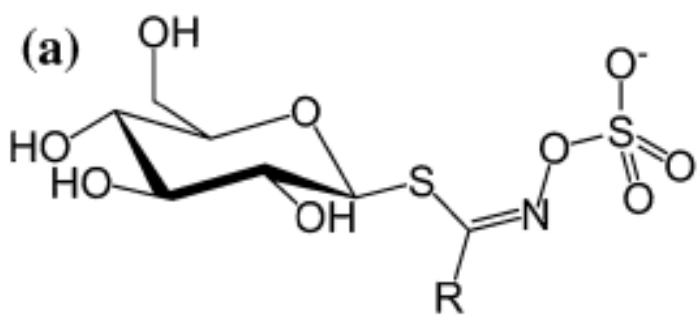

(b)

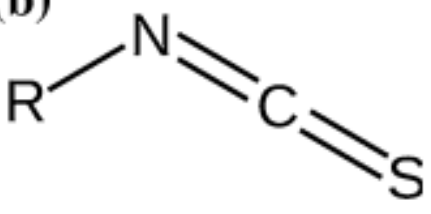

Figure 11. Chemical structure of glucosinolates (a) and isothiocyanates (b). $R$ is the side group that is responsible for the variation in the biological activities (Deng et al., 2015)

The biosynthesis of GLS is performed through three independent stages: (a) chain elongation of selected precursor amino acids (only Met and Phe), (b) formation of the core GLS structure, and (c) secondary modifications of the amino acid side chain (Figure 12) (Sønderby et al., 2010). 


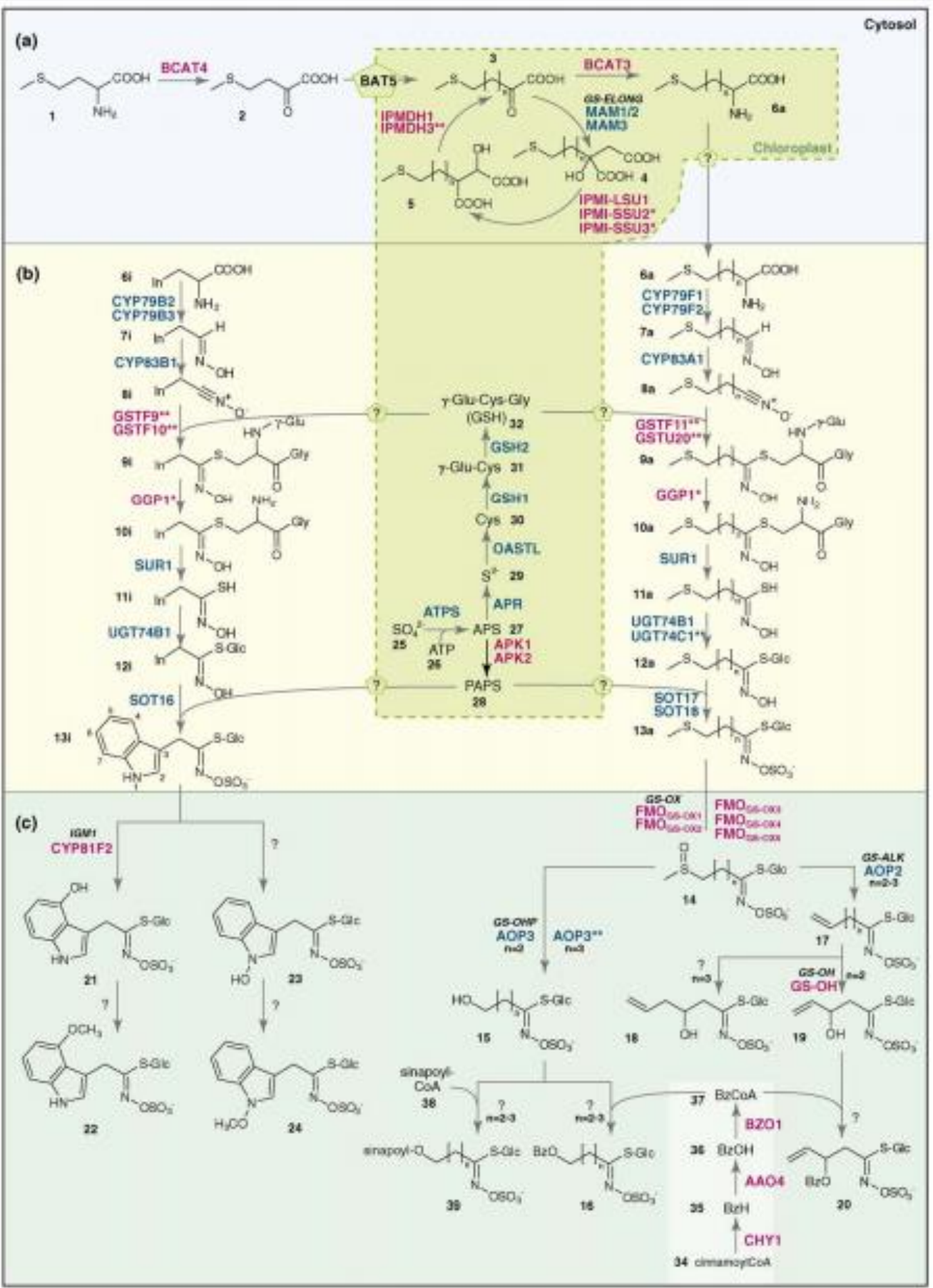

Figure 12. Aliphatic and indolic glucosinolate biosynthetic pathways in the Brassica Arabidopsis thaliana (Sønderby et al., 2010): (a) Chain elongation machinery; (b) Biosynthesis of core glucosinolate structure; (c) Secondary modifications. Abbreviations: APR, APS reductase; APS, adenosine-50 phosphosulfate; Bz, benzoyl; BzH, benzaldehyde; $\mathrm{BzOH}$, benzoic acid; BzCoA, benzoyl-coenzyme A; In, 30-indolyl; OAS-TL, Oacetylserine(thiol)lyase; PAP, adenosine-30,50-bisphosphate; and PAPS, 30phosphoadenosine-50-phosphosulfate 
Myrosinase (thioglucoside glucohydrolase; EC 3.2.3.1), is the enzyme that catalyses the hydrolysis (breakdown) of GLS, and is stored in separate cell compartments from the GLS. Disruption of cell membranes, due to cell damage (processing or chewing) leads thus to contact between GLS and the myrosinase isoenzymes, then, this enzyme catalyzes the GLS conversion to ITC by several reactions (Figure 13) (Deng et al., 2015). Other products of the GLS hydrolysis can be thiocyanates, epithionitriles, oxazolidine-2-thiones and nitriles, both without bioactive properties, depending upon the side chain structures, reaction conditions (pH, Fe ions presence, water dilution, etc.) and protein factors (e.g. ESP) (Hanschen et al., 2017).

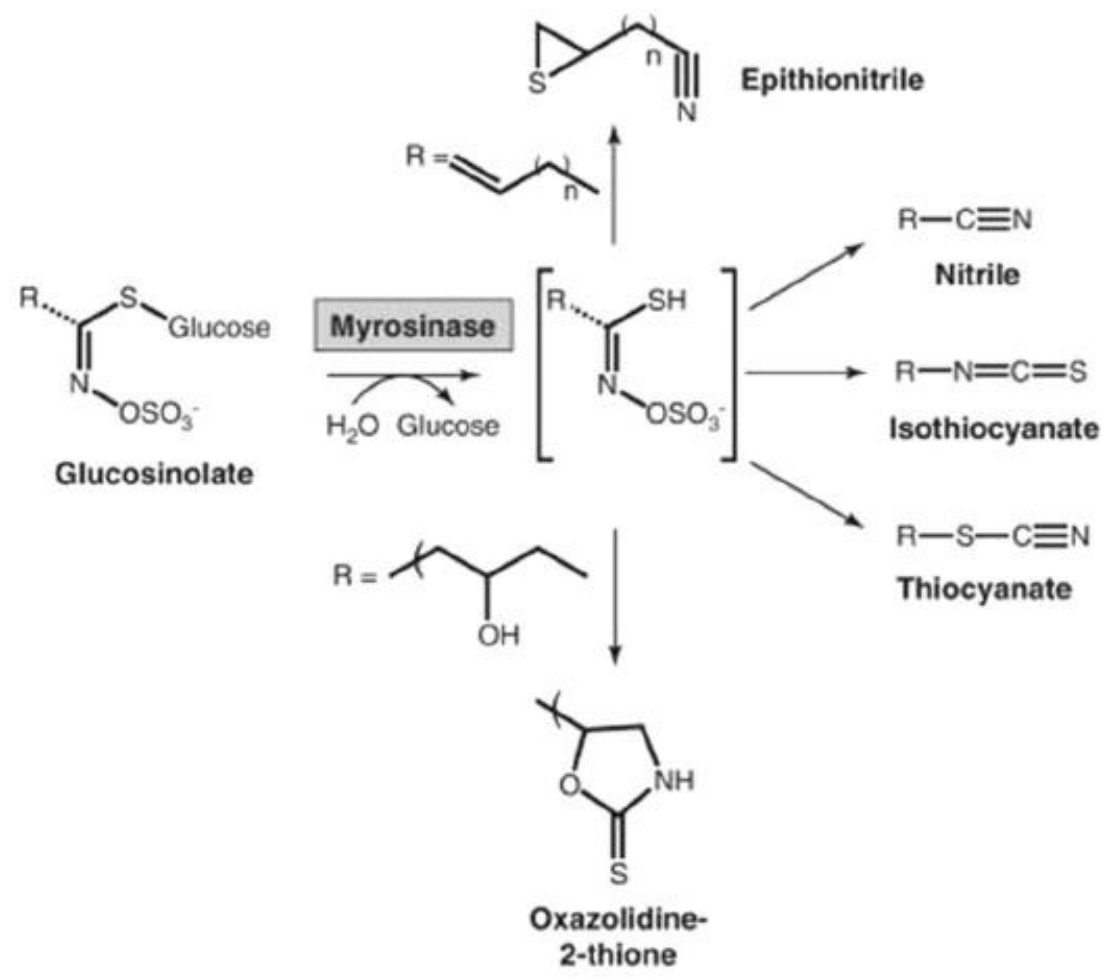

Figure 13. Myrosinase reaction products. Adapted from Deng et al., 2015.

GLS profiles and content may vary among Brassica species. This content is highly influenced by genetics, but their concentrations can also be significantly altered by the environment on which the crop is grown (Jeffery et al., 2003). GLSs in general and ITCs in particular act as effective preventions against a multitude of pathogens because these compounds have insecticidal, antifungal and antimicrobial properties (Van Ommen Kloeke et 
al., 2012). The main GLS found in broccoli and kale are glucoraphanin, glucobrassicin and proigoitrin (Table 4).

The intake of ITCs has been correlated with reduced cancer risk of colorectal cancer, prostate cancer and lung cancer (Gründemann and Huber, 2018). Some of the widely studied ITCs that have potent anticancer effects are allyl isothiocyanate (AITC), benzylisothiocyanate (BITC), phenethylisothiocyanate (PEITC), and sulforaphane (SFN) (Gupta et al., 2014).

Chemopreventive effects of ITCs are exerted by inhibition of the bioactivation of carcinogens by phase I drug metabolizing enzymes (Figure 14) (Yoshigae et al., 2013) and induce induces phase II detoxifying enzymes quinone reductase and glutathione-S-transferase (GST) in the animal tissues (Figure 14) (Munday and Munday, 2004). Phase II enzymes, such as GST, NADPH quinine oxidoreductase, and UDP-glucuronosyltransferases play an important role in detoxifying carcinogens as well as xenobiotics. ITCs are known to induce phase II enzymes that further explain the cancer chemopreventive activity of ITCs (Talalay et al., 1995; Brooks et al., 2001). ITCs thus modulate phase I and II enzymes to reduce the bioactivation of carcinogens as well as enhanced detoxification. This dual mechanism leads to reduced binding of carcinogens with the DNA and hence less mutagenic or carcinogenic effects (Gupta et al., 2014). Furthermore, SFN derived from broccoli sprouts has been linked to prevention of cardiovascular disease in rats (Wu et al., 2004) and against vascular complications in diabetes (Yamagishi and Matsui, 2016). 


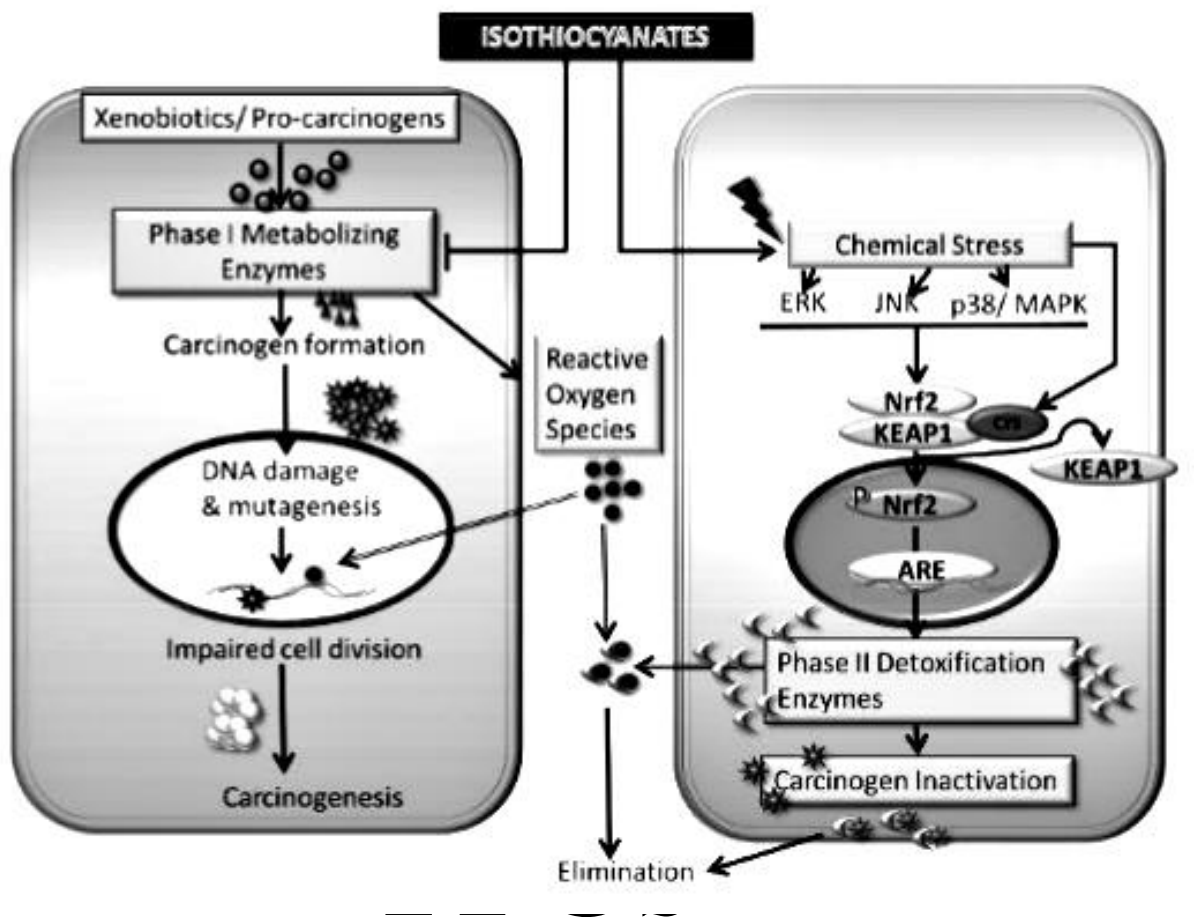

Figure 14. Chemopreventive effects of ITCs (Gupta et al., 2014).

Table 4. Main glucosinolates of broccoli and Kale cvs (Deng et al., 2015)

\begin{tabular}{lllcc|}
\hline Trivial name & Systematic name & Class & \multicolumn{2}{c|}{ Content $\boldsymbol{\mu m o l ~} \mathbf{~ 1 0 0 ~}^{\mathbf{- 1}}$ fresh wt } \\
\cline { 4 - 5 } & & & Broccoli & Kale \\
\hline Glucoraphanin & 4-Methylsulphinylbutyl & Aliphatic & $29.8-88.3$ & $0-28.9$ \\
Glucobrassicin & 3-Indolylmethyl & Indolyl & $42.4-71.7$ & $44.2-102.3$ \\
Proigoitrin & (2R) 2-Hydroxy-3-butenyl & Alkenyl & $0.0-3.7$ & $0.0-158.1$ \\
Gluconapin & 3-Butenyl & Alkenyl & $0.0-0.2$ & $0.0-4.1$ \\
Glucoerucin & 4-methylthiobutyl & Aliphatic & $1.1-3.7$ & $0.0-0.9$ \\
Sinigrin & 2-Propenyl & Aliphatic & $0.0-1.6$ & $0.0-28.7$ \\
Gluconasturtiin & 2-Penylethil & Aromatic & $0.0-1.9$ & $0.0-17.5$ \\
\hline
\end{tabular}




\subsection{Antinutritional compounds}

Antinutrients or non-nutritional factors are defined as compounds which when consumed can interfere with the intake, digestion, absorption and utilization of beneficial and essential organic nutrients and inorganic minerals contained in nutrients. They can act by either binding to the nutrients to prevent their absorption (sequestration), react with nutrients to form undigestible compounds (chelation) or inhibit enzymatic proteins in the digestive process of the body (Duc et al., 1999; Goyoaga et al., 2011; Przywitowski et al., 2016). Saponins, phytic acid, tannins and oligosaccharides (verbascose, stachyose and raffinose) are examples of non-nutritional in legumes seeds.

Nevertheless, there are evidences that many non-nutritional may be beneficial in the prevention of diseases like cancer and coronary diseases, when consumed on a regular basis (Muzquiz et al., 2012). Physiological effects and benefices of some non-nutritional factors of faba beans seeds are showed in Table 5 .

\subsection{Other antioxidant compounds}

The $\mathrm{O}_{2}$ is inevitable for aerobic life, yet during the normal metabolic process above $5 \%$ of inhaled $\mathrm{O}_{2}$ is transformed to reactive oxygen species (ROS), such as superoxide anion $\left(\mathrm{O}_{2}{ }^{-}\right), \mathrm{H}_{2} \mathrm{O}_{2}$, and hydroxyl radical $\left({ }^{\circ} \mathrm{OH}\right)$, as a natural byproduct of $\mathrm{O}_{2}$ metabolism. Furthermore external factor such as environmental pollution, tobacco smoking, irradiation, and exposure to xenobiotics byproducts are others sources of free radicals. These highly reactive molecules react with the other molecules like DNA, proteins, carbohydrates, and lipids by means of their unpaired electrons and generate oxidative stress that causes damage to all cell structures (Devasagayam et al., 2004).

Oxidative stress, is a result of an imbalance between free radical production and antioxidant defenses, which is associated with damage to a wide range of molecular species including lipids, proteins, and nucleic acids (McCord, 2000). The initiation, promotion, and progression of cancer have been linked to the imbalance between ROS and the antioxidant defense system. Oxidative stress also have been associated in the development of autoimmune disorders, arthritis, aging, cardiovascular and neurodegenerative diseases (Pham-Huy et al., 2008). Antioxidant is a molecule stable enough to donate an electron to a rampaging free 
radical and neutralize it, thus reducing its capacity to damage. The antioxidant property of a compound can be determined by its five main characteristics: (i) hydrogen or electron donating potentials that is reduction potential, (ii) fate of the resultant antioxidant derived radical compound, (iii) unpaired electron stabilization and delocalization capacity, (iv) reactivity with other antioxidant compounds, and $(\mathrm{v})$ the transition metal chelating potential (Rice-Evans et al., 1997).

Table 5. Main non-nutritional factors of faba beans and their effect on humans.

\begin{tabular}{|c|c|c|c|c|}
\hline & TANNINS & RAFFINOSE & PHYTIC ACID & SAPONINS \\
\hline $\begin{array}{c}\text { PHYSIOLOGYCAL } \\
\text { EFFECTS }\end{array}$ & $\begin{array}{l}\text {-Decreases } \\
\text { availability of } \\
\text { minerals, } \\
\text { proteins and } \\
\text { starch }\end{array}$ & $\begin{array}{l}\text { - Gas formation } \\
\text { in the colon }\end{array}$ & $\begin{array}{l}\text { Decreases } \\
\text { availability of } \\
\text { minerals (form } \\
\text { insoluble complexes } \\
\text { with essential } \\
\text { minerals }\left(\mathrm{Cu}^{2+}\right. \\
\mathrm{Zn}^{2+}, \mathrm{Fe}^{3+} \text { and } \\
\left.\mathrm{Ca}^{2+}\right) \text {, proteins and } \\
\text { starch }\end{array}$ & $\begin{array}{l}\text { - Decreases nutrient } \\
\text { absorption } \\
\text { - Depression of growth } \\
\text { - Affect smooth muscle } \\
\text { activity } \\
\text { - Can impart a bitter and } \\
\text { astringent taste }\end{array}$ \\
\hline BENEFITS & $\begin{array}{l}\text { - Antioxidant } \\
\text { activity } \\
\text { - Decreased } \\
\text { blood glucose } \\
\text { concentration } \\
\text { - Antimicrobial } \\
\text { effect }\end{array}$ & $\begin{array}{l}\text { - Prebiotic effect } \\
\text {-Increased } \\
\text { solubility of } \\
\text { minerals }\end{array}$ & $\begin{array}{l}\text { - Toxic metal } \\
\text { bonding } \\
\text {-Delayed glycemic } \\
\text { response }\end{array}$ & $\begin{array}{l}\text { - Antimicrobial effect } \\
\text { - Decreases cholesterol } \\
\text { concentration } \\
\text {-Immunostimulatory, and } \\
\text { anticarinogenic effects }\end{array}$ \\
\hline $\begin{array}{l}\text { CONCENTRATION } \\
\text { (faba beans) }\end{array}$ & $0.7-7.8 \mathrm{~g} / \mathrm{kg}(1)$ & $4.0-5.0 \mathrm{mg} / \mathrm{g}(2)$ & $3.8-13.45 \mathrm{mg} / \mathrm{g}(3)$ & $\begin{array}{c}\text { Soyasapogenol B }(0.02 \\
\mathrm{mg} / \mathrm{g}) \\
\text { Soyasaponin I } \\
(0.04 \mathrm{mg} / \mathrm{g})(4)\end{array}$ \\
\hline
\end{tabular}

1: Przywitowski et al. (2016); 2: Goyoaga et al. (2011); 3: Duc et al. (1999); 4: Ha et al. (2014). 
Fortunately, the human body has certain defense systems against free radicals such as the enzymes superoxide dismutase (SOD), glutathion peroxidase (GPx), etc (Ho et al., 1998) or antioxidants produced during normal metabolism (glutathione, ubiquinol, uric acid) (Shi et al., 1999), maintaining a balance between the formation and elimination of these free radicals. Nevertheless, this defense system has to be maintained by exogenous antioxidants that are naturally present in foods, beverages or dietary supplements. Dietary antioxidants are compounds that delay or inhibit the oxidation process in foods or in the human body and prevent diseases related to oxidative stress (Cömert and Gökmen, 2017). According to their origin, antioxidants can be classified into two major groups; enzymatic and non-enzymatic. Some of these antioxidants are endogenously produced, including enzymes, low-molecularweight molecules, and enzyme cofactors. Many non-enzymatic antioxidants are obtained from dietary sources (Figure 15) (Bunaciu et al., 2012). Dietary antioxidants can be classified into various classes, of which polyphenols is the largest class. The other classes include vitamins, carotenoids, organosulfur compounds, and minerals (Figure 15).

Especially, a diet rich in vegetables and fruits as good sources of natural antioxidants, which can lower blood pressure, reduce risk of heart disease and stroke, prevent some types of cancer, in addition to a number of other health benefits (Muzquiz et al., 2012; Kocot et al., 2017). The total antioxidant capacity (TAC) of a sample is determined by the synergistic interactions between different antioxidant compounds and for the specific reaction mechanism of each of them. The TAC of any food is influenced by physiological factors (such as maturity, variety, senescence) (Prior et al., 1998) and technological factors such as storage or processing conditions (Castillejo et al., 2017; Arjmandi et al., 2017a). 


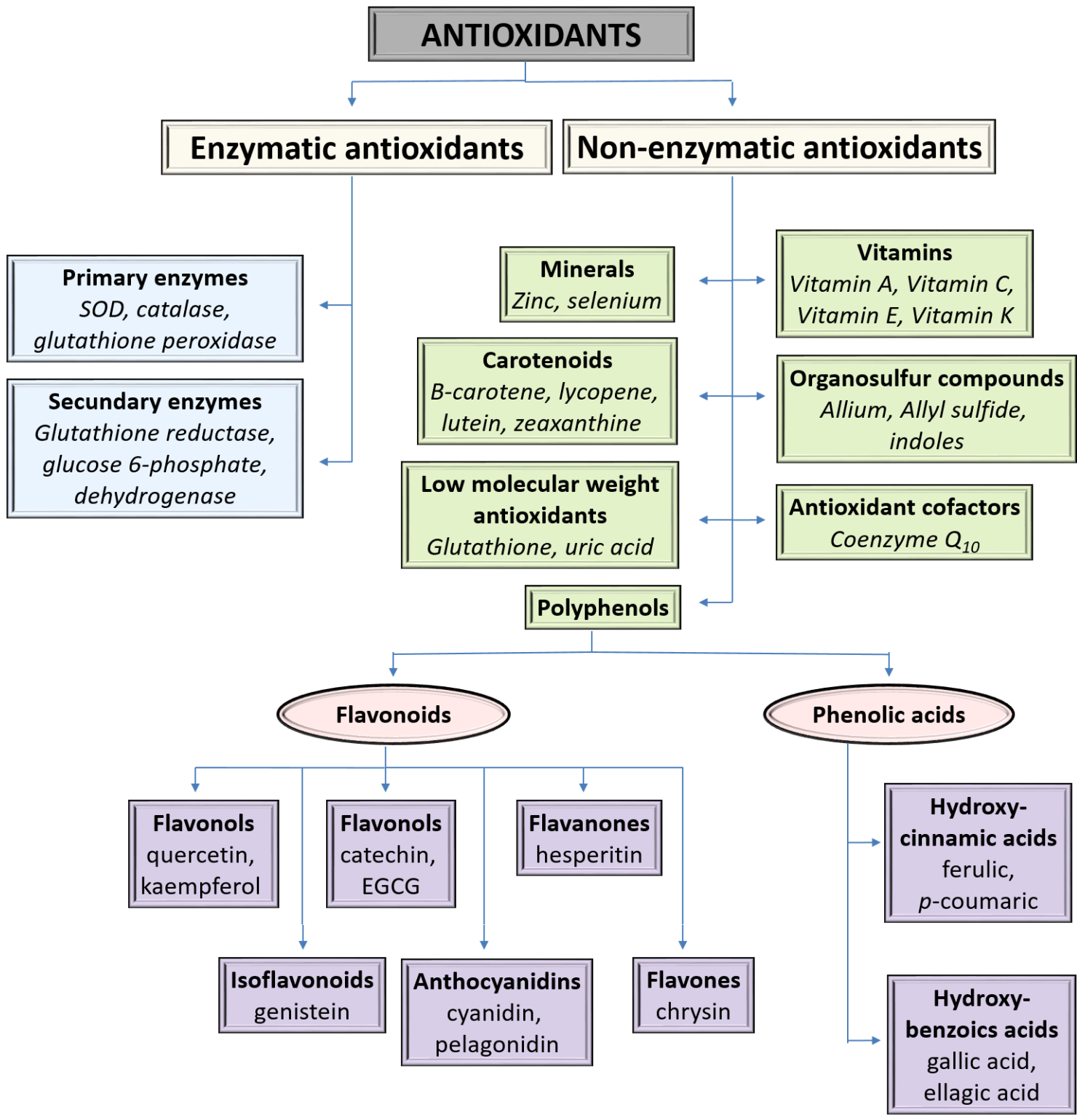

Figure 15. Antioxidant compounds classification (Bunaciu et al., 2012).

\section{3. 'FIFTH RANGE' PROCESSING OF FRUIT AND VEGETABLES}

There is an actual trend towards increasing the consumption of healthy foods since consumers are concerned about the diet influence on health and well-being. Furthermore, changes in consumers' lives have gradually transformed supermarket shelves over the past few years, with a strong preference of healthy products that are easy to eat, drink, prepare and 
or cook. Therefore, the food industry needs to produce convenient healthy innovative readyto-eat high quality and safe products to satisfy the consumers demand, so, the 'fifth range' industry is a good market opportunity, mainly in the fruit and vegetables sector.

\section{1. 'Fifth range' products}

The most common thermal treatment for food preservation is sterilization. Nevertheless, this treatment is very aggressive with the nutritional and sensory properties of food, mainly in fruit and vegetables. So it is necessary to develop new processing technologies that manage to keep levels of functional compounds originally present in the plant product. Consequently, the application of mild heat treatments with a subsequent chilled storage firstly defined the 'fifth range' industry of fruit and vegetables. In fact vegetable foods of the 'fifth range' are those that have been subjected to different culinary processes and packed followed by a heat treatment with strict control of time and temperature between 50$85^{\circ} \mathrm{C}$ and then chilling stored without the use of additives. These foods only require minimal preparation or just a preheating for consumption in a microwave or conventional oven. Such treatments achieve a product with an adequate microbiological quality to prolong its shelf life up to 1-3 months at chilling temperature, depending on the intensity of processing treatments (De Ancos et al., 2016).

'Fifth range' horticultural products are in accordance with the characteristics demanded by consumers, because they are ready-to-eat products of high sensory and nutritional quality, similar to domestically prepared meals but with a longer shelf life guarantying the microbiological safety. The main 'fifth range' products are cooked vegetables (cooked, roasted, grilled, etc.), soups, purees, sauces and vegetable mixes among other preparations (Artés and Artés-Hernández, 2012; De Ancos et al., 2016).

\subsection{General processing operation}

The current processing technology for 'fifth range' products is centered on the 'cook and chill' term, which is a concept where food is prepared and heat treated, packaging (prior or after cooking), fast cooling (blast chilling) and chilling storage until consumption. The quick decrease in temperature inhibits the growth of spoilage and pathogenic microorganisms 
in their vegetative and spores forms (Díaz-Molins, 2009). The 'fifth range' vegetables can be described by the following characteristics:

- Heat-treated products, ready-to-eat and marketed under refrigeration.

- Preheated prior to consumption, usually in MW or conventional oven.

- Usually packaged in plastic materials.

- It is required to maintain the cold chain until consumption (processing, packaging, storage and distribution).

The different steps of the 'cook and chill' technology to juices, hummus and sauces products are summarized in Figure 16.

\subsubsection{Raw material reception and storage}

Generally, vegetables quality at harvest may be influenced by the following preharvest factors (Ntatsi et al., 2018):

- Genetic factors: specie, varieties, etc.

- Climate conditions: temperature, light, relative humidity, pluviometry, etc.

- Agricultural practices: fertilization, pesticides, irrigation type, etc.

- Soil conditions: soil type, $\mathrm{pH}$, humidity, microbiota, mineral composition, etc.

When referred to legumes, pods must be harvested at the appropriate ripening stage (Figure 17), as if they are harvested too early, the economic yield will be lower than can be expected. On the contrary, if harvesting is delayed, the pods will harden and the product will be much less valuable, since both the nutritional value and the texture of green seeds are influenced by the developmental stage. Faba bean pods are usually harvested at the "milk stage" (a more advanced stage of growth), when pods have reached full size but they are still green and the seeds are immature, attaining a dry matter of 20-35\%. Faba bean pods of high quality should be shiny green and the seeds should be tender, creamy and uniformly developed (Lisiewska et al., 1999; Nunes, 2008). 


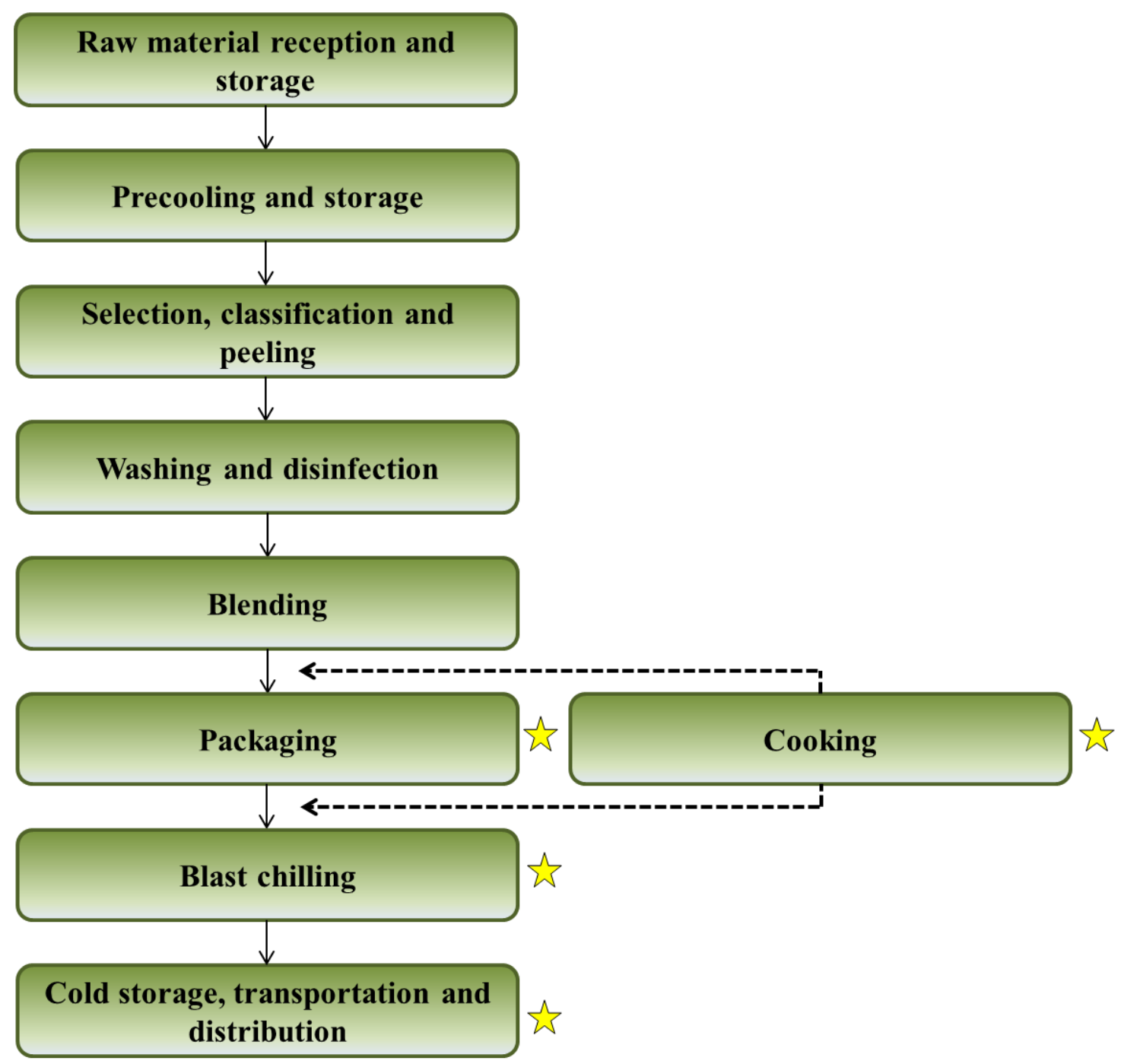

Figure 16. Flow chart of the 'cook and chill' technology in the 'fifth range' industry (vegetable puree). 政 Critical factors affecting the commercial life of the 'fifth range' products (Martínez-Hernández et al., 2016).

The consumer perception about green pea quality is generally determined by the texture quality. Therefore, in pea crops aiming to produce green seeds for fresh market, freezing, or canning, the harvet time is commonly determined using a tenderometer that provides the pea softness to reach an optimal quality produce. Peas seeds for canning could be slightly firmer, so is recommended a tenderometer reading about 120 and peas for fresh market and freezing should be harvested when the tenderometer reading is about 100 (Salunkhe et al., 1993). 

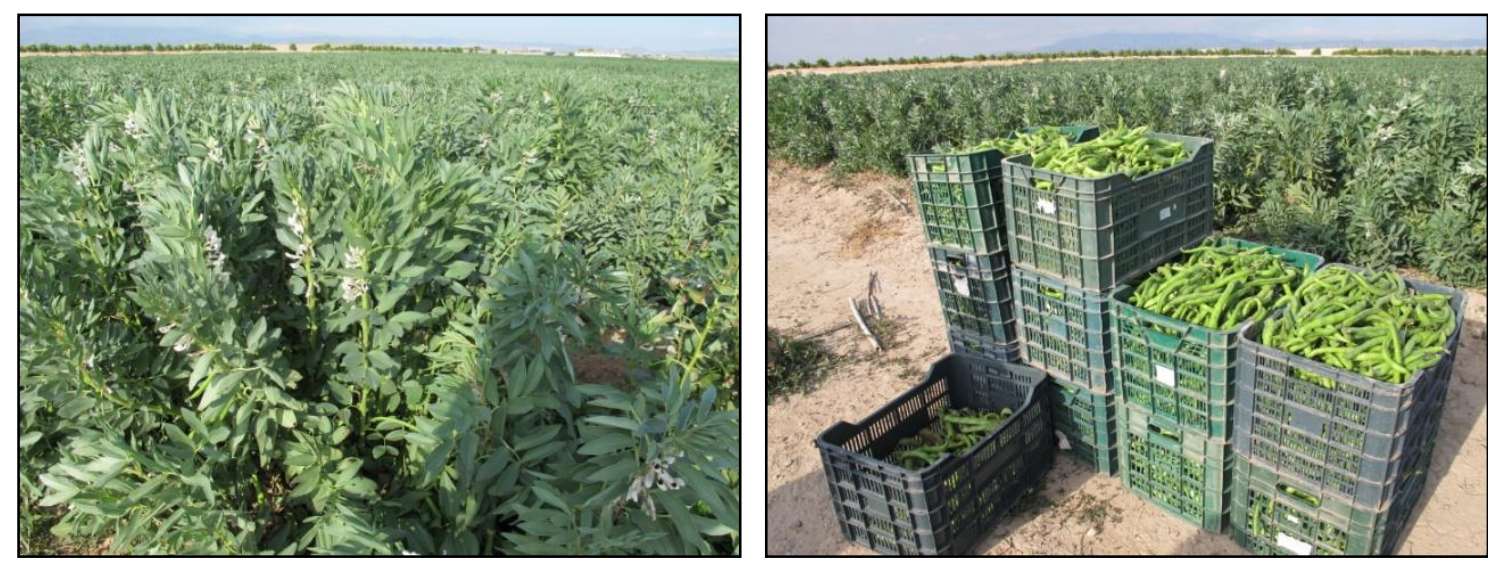

Figure 17. Growing field of faba beans (left) and collected faba beans pods (right)

\subsubsection{Precooling and storage}

The objective of the precooling is to quickly remove the heat that the plant material brings from the field after harvesting. This is one of the most important steps to extend the shelf life of these high-metabolic-rate vegetables, slows down the stress generated during the processing stages and maintains better product quality. To regulate the supply to the processing line, the pre-cooling of the raw material $\left(0-4{ }^{\circ} \mathrm{C} ; 90-95 \% \mathrm{RH}\right)$ is recommended, and can be for a few hours or a day before processing (Artés and Artés-Hernández, 2003).

\subsubsection{Selection, classification and peeling}

After reception at the processing plant, the raw material is carefully inspected regarding quality standards, which will decide the acceptance of the product. The weight of the classified raw material is necessary in order to control the processing steps, formulation of the product and quality control. Vegetables must be of a similar size, uniformly developed, and not have pathological or physiological disorders. The peeling of pods increases the respiration rates, ethylene emission and tissue damage of the product and therefore accelerates the senescence of the tissue and reduces resistance to microbial contamination. In order to minimize these undesirable effects of peeling, it is higly recommended (Artés and ArtésHernández, 2003) that the pods will be peeled in a cold room $\left(5 \pm 1^{\circ} \mathrm{C}\right)$ and the obtained seeds immediately immersed in cold water at $4 \pm 1{ }^{\circ} \mathrm{C}$ (Figure 18). The cutting equipment should be cleaned, disinfected and sharpened at regular intervals every working day. 

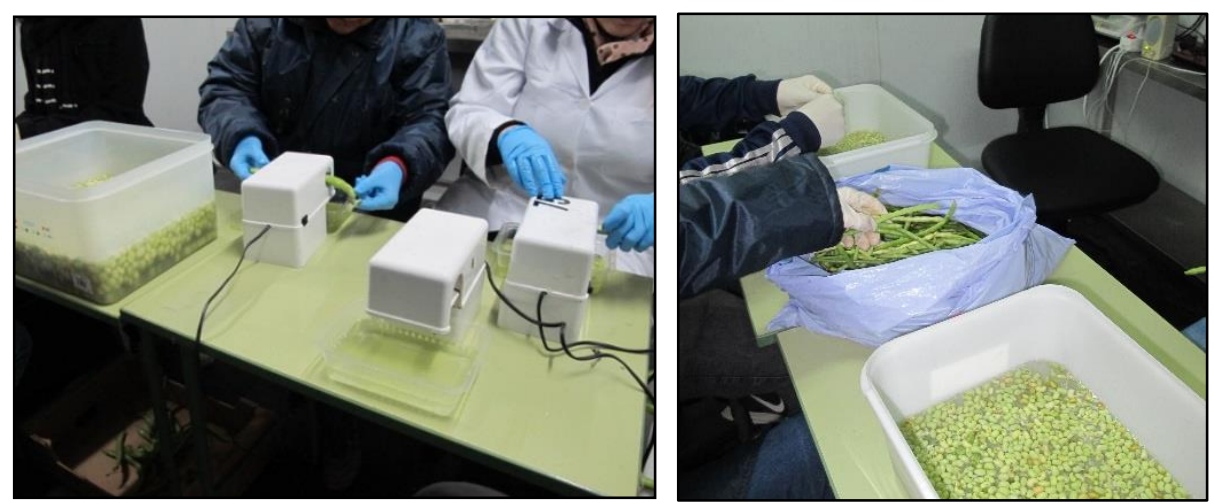

Figure 18. Peeling of faba beans (left) and cowpea (right) in a cold room.

\subsubsection{Washing and disinfection}

The washing and disinfection of vegetables is commonly made with cold chlorinated $(\mathrm{NaClO})$ water $\left(1-2{ }^{\circ} \mathrm{C} ; 100-150 \mathrm{mg} \mathrm{L}^{-1}\right.$ free chlorine), which is acidified $(\mathrm{pH}$ 6.5-7.5) with citric acid to increase the bacteriostatic effect of $\mathrm{NaClO}$. Usually, the contact time is around 2 min (Figure 19). This disinfectant is inexpensive, easy to use, and reasonably effective. However, concerns regarding the possibility of formation of hazardous disinfection byproducts, such as trihalomethanes, led to the development of studies in the search for alternatives to that (Ölmez and Kretzschmar, 2009). Accordingly, alternative sanitizing treatments have been studied such as UV-C radiation, chemical substances generally recognized as safe (GRAS) (acetic acid, citric acid, etc.), electrolyzed water, etc (Artés et al., 2009).
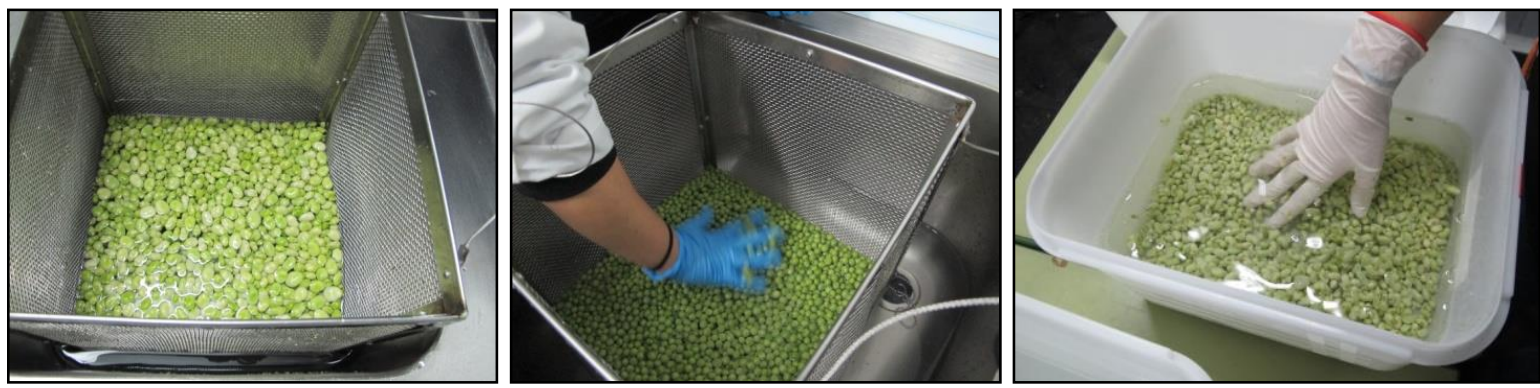

Figure 19. Faba beans (left), peas (centre) and cowpea (right) sanitation with $\mathrm{NaClO}$ 


\subsubsection{Blending}

For minimal food and beverage processing, mixing and blending systems, including fluid agitators, batch and continuous mixers to blenders, etc., can be used. In Figure 20, the Robot Cook ${ }^{\circledR}$ used for the current experiments is presented.
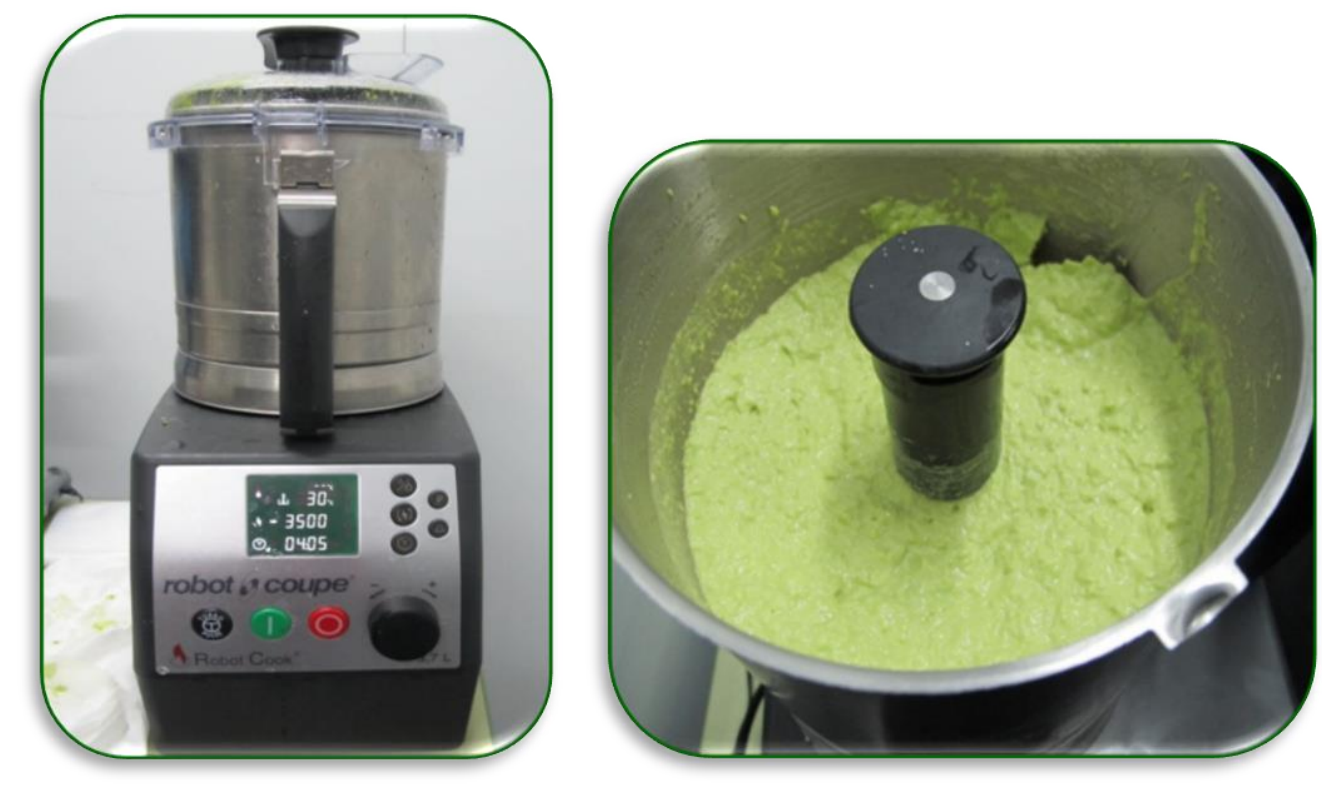

Figure 20. Robot Cook ${ }^{\circledR}$ (Robot Coupe, Vincennes Cedex, France) (left) and blended faba bean pesto sauce (right)

\subsubsection{Packaging}

The packaging step is crucial to prevent the microbiological and chemical deterioration during the processing and storage of 'fifth range' products. In the 'fifth range' industry the following main types of packaging technologies are used (Rodgers, 2007):

1. Vacuum: the air from the container is almost completely evacuated.

2. Controlled atmosphere: a single gas or mixture of gases is injected in the container after the removal of the air and is subjected to a constant control during the storage period. The most used gases are $\mathrm{CO}_{2}$ and $\mathrm{N}_{2}$. 
3. Modified atmosphere: similar to the latter but it is reached by the use of polymeric films and no control during the storage period is practiced.

In the vacuum packaging, the product is placed in an air-tight pack, the air is sucked out and the package sealed (Figure 21). By removing air from around the product, the $\mathrm{O}_{2}$ levels within packaging are reduced, impeding the ability of aerobic microorganisms to grow and spoil the product. The lack of $\mathrm{O}_{2}$ also reduces the amount of spoilage due to oxidation (Díaz-Molins, 2009).

An example of production method based on in-pack cooking and pasteurization in one continuous process is showed in Figure 21, where: 1. Place the product: the ingredients are put in the tray, either by machine or by hand; 2. Film and valve application: The film and valve are applied in an automated process; 3 . Cooking: The now sealed package is cooked and pasteurized in a MW tunnel. During pasteurization the valve opens to let out steam, and with it almost all $\mathrm{O}_{2}$. The valve closes and a vacuum is created; 4. Cooling: The pasteurized and vacuumed meal moves on into a cooling unit, and now the fresh-made meals are ready for the store shelves.
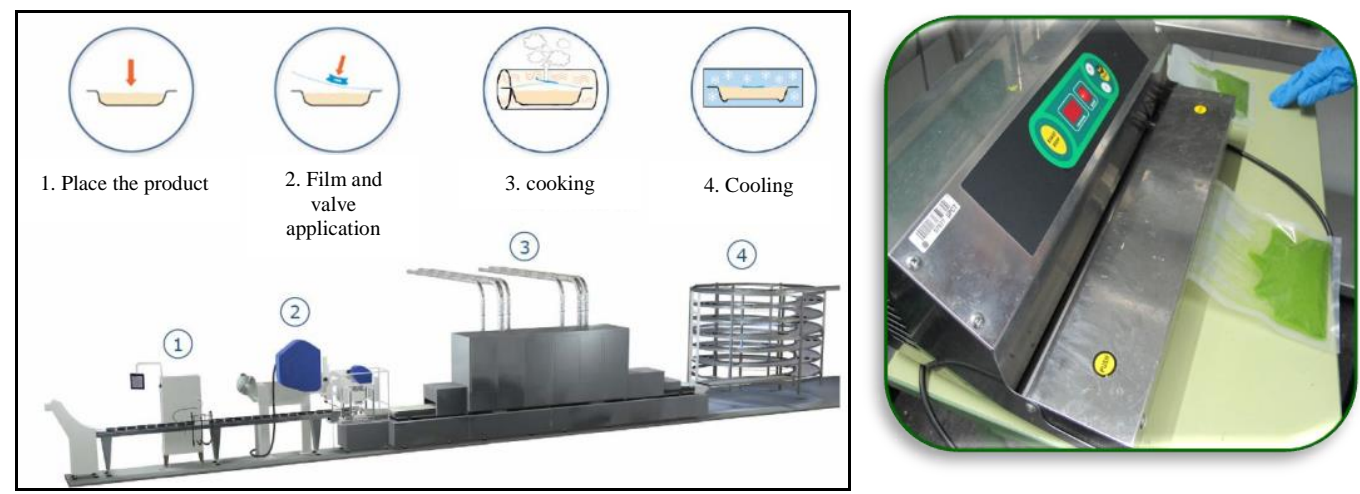

Figure 21. MicVac ${ }^{\circledR}$ system (MicVac Company) (left) and vacuum packaging of a puree (right)

\subsubsection{Cooking (thermal and non-thermal treatments)}

Preservation treatments (thermal or non-thermal) may be conducted prior to packaging or after packaging. Packaging of the product followed by treatment is preferred in order to avoid cross contamination during packaging, which may be made under strict aseptic 
conditions. Conventional treatments such as pasteurization or sterilization are employed in food processing with the aim to preserve and extends the shelf life of the products, and ensures consumer safety. These treatments are associated with the application of hightemperature for an extended period of time, thus guaranteeing an appropriate destruction of the microorganisms. However, product quality can be deteriorated resulting in losses of heatsensitive nutrients and undesirable sensorial changes. For that reason, nowadays, several emerging technologies, including MW, radio frequency heating, pulse electric fields treatment, HHP, ultrasonic applications and oscillating magnetic fields, are being investigated to improve and replace conventional heating processing (Escajeda et al., 2018). Among these techniques, in this Ph.D. Thesis, MW, HHP and sous vide have been studied.

\subsubsection{Blast chilling}

The RH and temperature conditions reached after the cooking step might favor a quick microbial growth in the 'fifth range' processed products, so it is recomended that the maximum time to start the blast chilling must be less than $30 \mathrm{~min}$. Air, water and plates blast chillers, and cold rooms are the most used devices to decrease the temperature of the cooked product (Zhang and Sun, 2006).

\subsubsection{Cold storage, transportation and distribution}

Chilling is crucial during storage and shelf life of the 'fifth range' products. The main hazard associated during cold storage is the possible germination and growth of spores that have survived to the thermal treatment. The storage temperatures of these products should be in the range of $1-4{ }^{\circ} \mathrm{C}$, being very important an accuracy of the cold room of $\pm 0.5{ }^{\circ} \mathrm{C}$ (DíazMollins, 2009). Such cold room should be close to the blast chiller to avoid excessive temperature fluctuations. In this way, the refrigerated transport and distribution will retard the microbial growth and a long shelf life of 6-42 days can be achieved, depending of the commodity and cooking method used (Martínez-Hernández et al., 2016). 


\section{3 'Fifth range' products market}

The market of 'fifth range' products has highly increased in the recent years. Europe dominated the global ready meals market, accounting for one-third of the total market share around the world in 2016. UK leads the top-five list of countries with the highest turnover of 'fifth range' products. In Spain, the consumption of these products is increasing each year. The delayed development of 'fifth range' products in Spain, compared to France and UK, has been due to the sociodemographic differences with the latter countries. Therefore, this food sector opens an interesting market opportunity (Mintel, 2010).

According to the Spanish Ministry of Agriculture, sales in 2016 of ready meals for households exceeded 591 million $\mathrm{kg}$, an increase of $3.5 \%$ over the last previous year, with a value of 2,439 million $€, 4.4 \%$ more than in 2015 , and a per capita annual consumption of $13.2 \mathrm{~kg}(+4.3 \%)$. The most notable consumption is associated with soups and creams $(5 \mathrm{~kg}$ per person and year). In the Region of Murcia, $54.3 €$ per capita/year was spent on prepared meals, which corresponds to $4.1 \%$ of total expenditure on food (MAGRAMA, 2017).

Over the last 5 years, the consumption of ready-to-eat meals has increased by $1.6 \mathrm{~kg}$ per person, and expenditure has increased by $7.2 €$ per capita. The evolution of the consumption of these products over the period 2012-2016 is shown in Figure 22. 


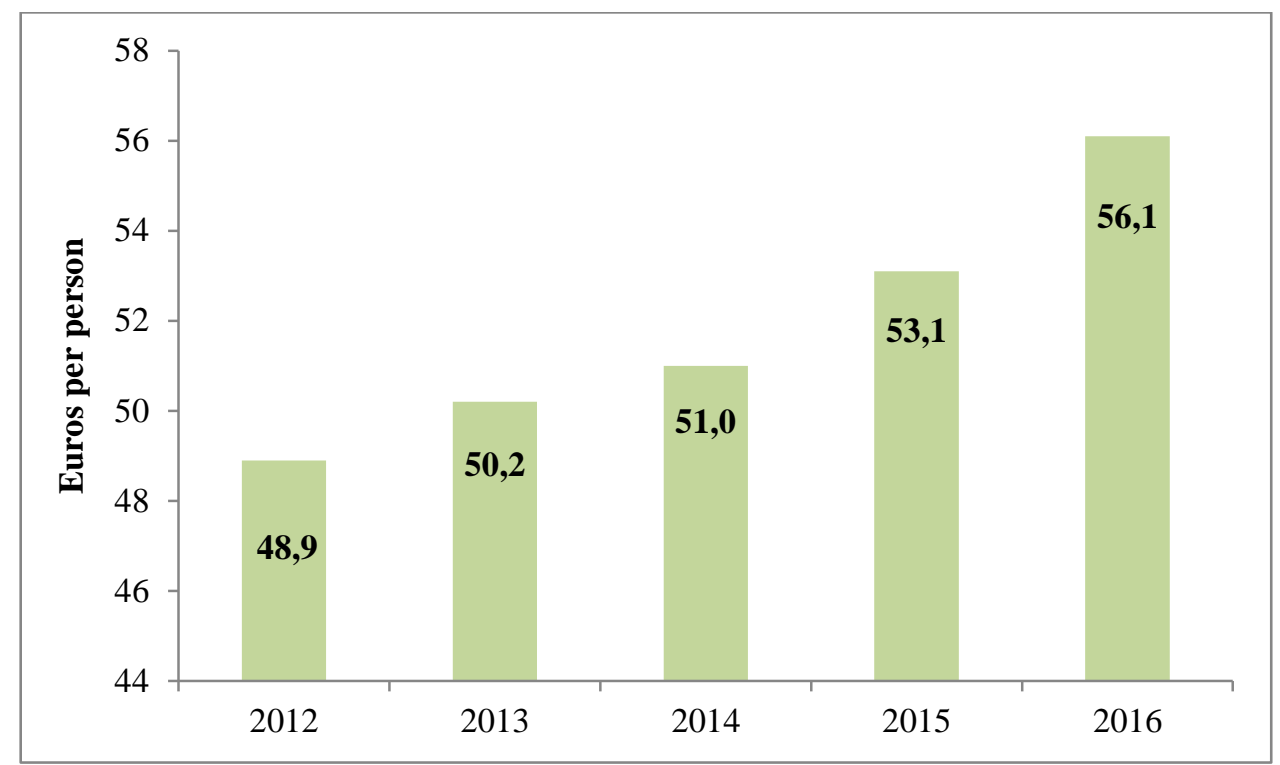

Figure 22. Evolution of the consumption ( $€$ per capita) of 'fifth range' products over the period 2012-2016 (MAGRAMA, 2017).

In relation to purchase place, households mainly used to purchase ready meals from supermarkets in 2016 (71.4\% of the market share). Hypermarkets account for $16.2 \%$ of these products and specialized shops (3.6\%). Home sales account for 1.4\%, while other forms of commerce account for 7.4\% (MAGRAMA, 2017).

The acceptance of 'fifth range' products in Spain is influenced by factors like (Alimarket, 2017; MAGRAMA, 2017):

- People under 35 years

- High purchasing power

- Residents in towns $>500,000$ inhabitants

- Families $\leq 2$ members

- Perception: homemade and natural dish, similar to the one cooked at home, if compared with other prepared dishes (frozen, canned, crystal, room temperature, etc.).

- Convenient meal (ready-to-eat) 


\subsection{Safety aspects of the 'fifth range' vegetables}

The damage from spoilage and contamined food affects the food industry and consumers. Microbial growth involves many and complex mechanisms that can be provocate the food spoilage and decrease the acceptance of sensory attribute of foods and consequently the reject by consumers. The presence of visible growth as colonies can change the texture of the products and the perception of off-odors and off-flavors may indicate spoilage by microorganisms (bacteria and molds). On the other hand, the development, crosscontamination and toxin production of pathogenic microorganisms damage the food safety and impose a risk to health of consumers (Lorenzo et al., 2018).

The ingestion and colonization of pathogen microorganisms in human digestive tract usually cause gastroenteritis, with symptoms like diarrhea, intestinal cramps, nauseas, fever, etc. (Lorenzo et al., 2018). The main agents involved in gastroenteritis related to vegetables are bacteria, like Escherichia coli, Salmonella spp. and Listeria monocitogenes. Outbreaks of foodborne and cross-contamination with bacteria are associated with a diversity of foodstuff due to inadequate equipment design, reduced sanitation practices, inadequate thermal processing, deficient control of ingredients, etc.

The actual EU Regulation 1441/2007 (EC_1441/2007, 2007) establishes some pathogenic microorganisms as the unique microbiological criteria. Then, fresh-cut and fruit and vegetables beverages with mild heat treatments or non-thermal treatments are regulated by such Regulation. Table 7 includes the applicable microbial criteria of the latter Regulation for fresh-cut fruit and vegetables or minimally processed horticultural produce. 
Table 7. Food safety criteria applied to the fresh-cut products (Regulation EC 1441/2007, 2007).

\begin{tabular}{|c|c|c|c|c|c|}
\hline \multirow[t]{2}{*}{ Food category } & \multirow[t]{2}{*}{ Microorganism } & \multicolumn{2}{|c|}{$\begin{array}{l}\text { Sampling } \\
\text { plan }^{1}\end{array}$} & Limits $^{2}$ & \multirow[t]{2}{*}{$\begin{array}{l}\text { Stage where the } \\
\text { criterion applies }\end{array}$} \\
\hline & & $\mathbf{n}$ & c & $\mathbf{M}$ & \\
\hline $\begin{array}{l}\text { Pre-cut fruit and vegetables } \\
\text { (ready-to-eat). }\end{array}$ & E. coli & 5 & 2 & $\begin{array}{l}1,000 \\
\mathrm{CFU} \mathrm{g}\end{array}$ & $\begin{array}{l}\text { Manufacturing } \\
\text { process. }\end{array}$ \\
\hline $\begin{array}{l}\text { Pre-cut fruit and vegetables } \\
\text { (ready-to-eat). }\end{array}$ & Salmonella & 5 & 0 & Absence in $25 \mathrm{~g}$ & $\begin{array}{l}\text { Products placed on } \\
\text { the market during } \\
\text { their shelf- life. }\end{array}$ \\
\hline \multirow{2}{*}{$\begin{array}{l}\text { Ready-to-eat foods able to } \\
\text { support the growth of } \\
\text { Listeria monocytogenes, } \\
\text { other that those intended } \\
\text { for infants and for special } \\
\text { medical purposes. }\end{array}$} & \multirow[t]{2}{*}{ L. monocytogenes } & \multirow[t]{2}{*}{5} & \multirow[t]{2}{*}{0} & $100 \mathrm{CFU} \mathrm{g}^{-13}$ & $\begin{array}{l}\text { Products placed on } \\
\text { the market during } \\
\text { their shelf- life. }\end{array}$ \\
\hline & & & & Absence in $25 \mathrm{~g}^{4}$ & $\begin{array}{l}\text { Before the food has } \\
\text { left the immediate } \\
\text { control of the food } \\
\text { business operator. }\end{array}$ \\
\hline
\end{tabular}

(1) $\mathrm{n}=$ number of units comprising the sample; $\mathrm{c}=$ number of sample units giving values between $\mathrm{m}$ and $\mathrm{M} / /$ (2) For points $1.1-1.25 ; \mathrm{m}=\mathrm{M}$. // (3) This criterion shall apply if the manufacturer is able to demonstrate, to the satisfaction of the competent authority, that the product will not exceed the limit $100 \mathrm{CFU} / \mathrm{g}$ throughout the shelf-life. The operator may fix intermediate limits during the process that must be low enough to guarantee that the limit of $100 \mathrm{CFU} / \mathrm{g}$ is not exceeded at the end of shelf-life. // (4) This criterion shall apply to products before they have left the immediate control of the producing food business operator, when he is not able to demonstrate, to the satisfaction of the competent authority, that the product will not exceed the limit of $100 \mathrm{CFU} / \mathrm{g}$ throughout the shelf-life.

\section{CONVENTIONAL AND INNOVATIVE QUALITY PRESERVATION METHODS}

\subsection{Conventional heat treatment}

Traditional pasteurization refers to heat foods below $100^{\circ} \mathrm{C}$ to destroy microorganisms of public health significance. Pasteurization processes used in the industry do not kill all microorganisms in foods; they only target pertinent pathogens and lower levels of spoilage organisms that may grow during storage and distribution (Silva and Gibbs, 2010). Within the different processing systems (pasteurization / sterilization), certain aspects should be taken into account. For example if the food to be treated is packaged or not, if the process will be continuous or not, or if the heating will take place directly or indirectly (heat exchanger equipment, steam injection, etc.) can make great differences between the different equipment (Richardson, 2001). Due to the diversity of industrial systems currently available for food heat treatment, consideration should be given to equipment aspects such as (i) the type of 
heating medium (water or steam), (ii) whether mechanical agitation can be applied during treatment and (iii) whether heating will take place directly or indirectly. Finally, it is also important to take into account the specific characteristics of each food such as: (i) composition, (ii) thermal properties (specific heat, enthalpy associated with phase transitions, diffusivity, conductivity), (iii) geometric properties (density, porosity and dimensions), and (iv) rheological properties (consistency and viscosity) (Wang and Sun, 2012).

\subsection{Microwave treatment}

The use of domestic and industrial MW are constantly increased in foods, textiles, medical applications, rubber, wood products, organic/inorganic synthesis, polymerization, and cellular breakdown. Furthermore, MW technology has demonstrated to be source of heat/energy for integrated remedial methodologies and an efficient alternative for contaminated soil remediation and medical waste treatment $(\mathrm{Wu}, 2008)$. Also a potential application of MW could be in food processing, which are increasingly used, being optimized for blanching, cooking, pasteurization, sterilization, dehydration, tempering, vacuum drying, freeze-drying, baking, roasting and extraction (Krishnaswamy et al., 2013; Orsat et al., 2016). Thus, the limit for human exposure, which is generally considered safe, is at a level of 1 $\mathrm{mW} / \mathrm{cm}^{2}$ body surface in most countries. As is the case for ionizing radiation, also for MW it becomes common to express the exposure or absorption by humans through the value of the specific absorption rate (SAR), which is defined as the quotient of the incident power and body weight. For MW, the International Commisson on Non-Ionizing Radiation Protection (ICNIRP, 1998; IRPA, 1988) recommends a value for the SAR to be set to $0.4 \mathrm{~W} / \mathrm{kg}$.

\subsubsection{Principal of microwave}

MW is a form of non-ionizing electromagnetic radiation with a frequency band between $300 \mathrm{MHz}$ to $300 \mathrm{GHz}$, higher than ordinary radio waves but lower than infrared light (Figure 23) corresponding to wavelength from $1 \mathrm{~mm}$ to $1 \mathrm{~m}$ (Hoogenboom et al., 2009). MW directly affects molecules by ionic conduction and dipole rotation with heating occurring mainly at 915 and $2450 \mathrm{MHz}$. Whereas $915 \mathrm{MHz}$ has some considerable advantages for industrial applications, domestic MW ovens use a frequency of $2450 \mathrm{MHz}$ (Regier et al., 2016). MW power penetration is greater at $915 \mathrm{MHz}(8-22 \mathrm{~cm})$ than at $2,450 \mathrm{MHz}(3-8 \mathrm{~cm})$ so it is more suitable for heating thick masses of materials. 


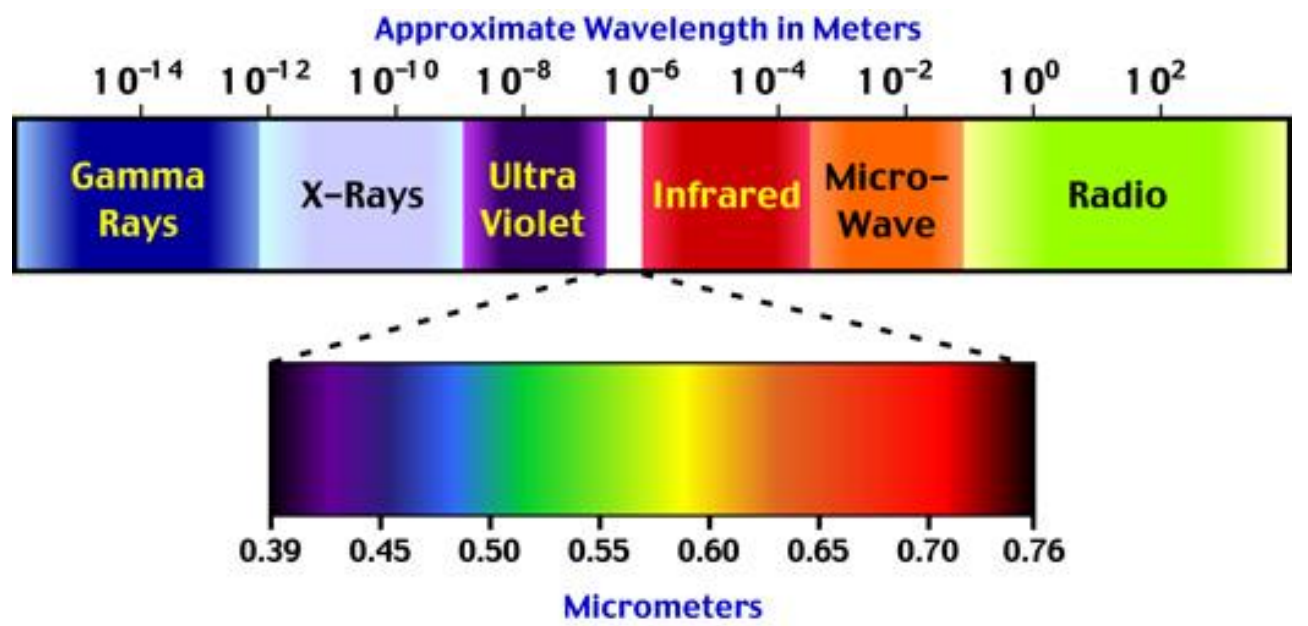

Figure 23. Electromagnetic waves spectrum (www. eoearth.org)

When MW heating is applied, energy penetrates the material, within which the friction between the polar molecules produces internal heat. Heating is due to an increase in molecular kinetic energy (i.e., an increased movement of permanent dipoles within the material as they try to reorient themselves with the oscillating, electrical, field of the incident wave), as well as associated molecular friction (Meda et al., 2016). A schematic representation of a semiindustrial MW oven equipment is shown in Figure 24. 


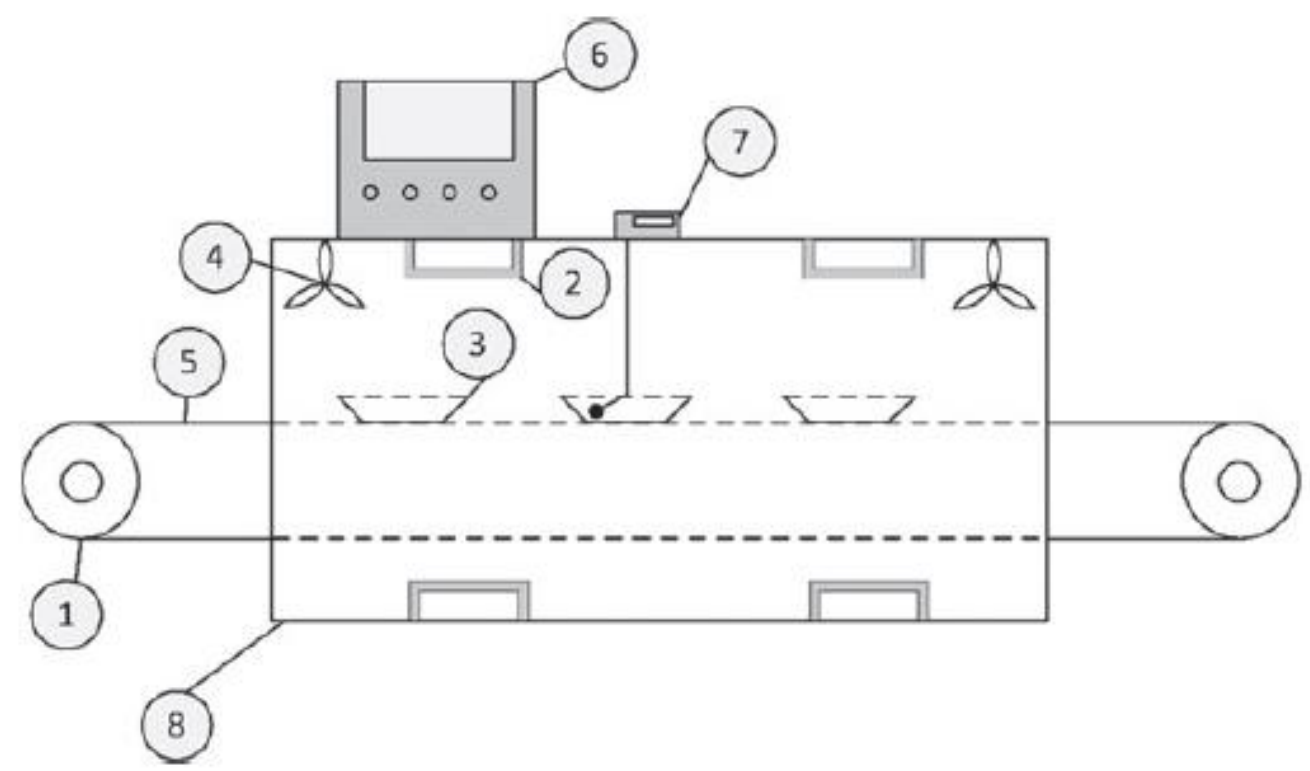

Figure 24. Semi-industrial microwave oven, process diagram: 1, motor; 2, magnetron; 3, sample; 4, fan; 5 , conveyor belt; 6 , control process; 7 , fibre-optic temperature sensor; 8, microwave chamber (Arjmandi et al., 2017a)

MWs can pass through materials like glass, paper, plastic and ceramics, and be absorbed by foods and water. However, they are reflected by metals and cannot penetrate them (Hill, 1998). The dielectric properties of materials have effective role on the absorption of the MW energy and its conversion to heat. These properties determine both the energy propagation within the product and the transformation of the MW energy into heat inside the dielectric element (Puligundla, 2013). When MWs impinge on a dielectric material, part of the energy is transmitted, part is reflected, and part is absorbed by the material, where it is dissipated as heat (Meda et al., 2016). The ability of a material to interact with MWs is dependent on the dielectric constant $\left(\varepsilon^{\prime}\right)$ and dielectric loss $\left(\varepsilon^{\prime \prime}\right)$. The dielectric constant is a measure of a samples ability to obstruct the MW energy as it passes through, and the loss factor measures the samples ability to dissipate that energy. The word 'loss' is used to indicate the amount of input MW energy that is lost to the sample by being dissipated as heat. Knowledge of the dielectric properties of the material heated is of great importance in MW processing, since these properties describe the ability of a material to absorb, transmit, and reflect electromagnetic energy (Puligundla, 2013). 
Aspects related to the design and characteristics of each MW equipment can influence the uniformity of the electromagnetic field, and, as a consequence, on the greater or lesser homogeneity of heating. As is the case of (i) the dimensions of the equipment, (ii) the power and location of the magnetron, (iii) the design and location of the magnetron, and (iv) good functioning of the applicators. On the other hand, the characteristics of the (i) composition, especially in terms of moisture and moisture salt content, (ii) thermal properties (diffusivity and conductivity), (iii) dielectric properties (storage factor and loss factor), (iv) geometric properties (density, porosity, shape and dimensions) and (v) rheological properties (consistency and viscosity), influence their interaction. with the electromagnetic field, affecting the amount of radiation absorption and heat dissipation, consequently, the distribution of heat and food temperatures are also affected (Chandrasekaran et al., 2013). Furthermore, consideration relating to the process such as: (i) the initial temperature of the product, (ii) if it is a continuous or discontinuous process, (iii) treatment time, and (iv) MW power should be considered (Salazar-González et al., 2012).

\subsubsection{Advantages of microwave technology}

MW processing offers some advantages compared to conventional methods including (Chandrasekaran et al., 2013; Salazar-González et al., 2012; Ahmed and Ramaswamy, 2007):

- Reduction of the processing time and energy. MW penetrates inside the food materials and, consequently, cooking takes place throughout the whole volume of food internally, uniformly and rapidly.

- MW heating is considered selective, since the electromagnetic field interacts mainly with the water molecules in the food, producing an increase in their temperature, while the other components receive heat indirectly, i.e. by conduction.

- Nutrients and vitamin contents, as well as sensory characteristics of food are preserved because the heat transfer is fast.

- Energy saving. The high-power magnetrons (85\% at $900 \mathrm{MHz}, 80 \%$ at 2,450 MHz) are efficiency, so the overall efficiency of MW system is very high.

- MW equipment is suitable for cleaning-in-place system, low cost system maintenance, and environmentally clean processing, since MW generation does not produce exhaust gas or toxic waste 
- Suitable for heat-sensitive, high-viscous, and multiphase fluids

- Flat radial temperature profile for most products

- MW could be combined with other technologies, such as regenerative heat exchangers and infrared heating for better process performance

\subsubsection{Limitations and solutions of microwave technology}

Several major drawbacks limiting the application of MW technology are (Ahmed and Ramaswamy, 2007; Chandrasekaran et al., 2013):

- Non availability of actual temperature profiles. Measurement of temperature at few locations does not guarantee the real temperature distribution of the product during MW heating, as the heating pattern can be uneven and difficult to predict, and change during heating

- Non-uniform temperature distribution resulting in hot and cold spots in MW-heated products

- Application of MW has an inherent non-uniformity of the electromagnetic field within a MW cavity.

- It is not always true that the MW process results in better quality retention of product. The gradation kinetics of either quality, sensory, or nutrient depend on many factors like nature of the product, product geometry, and dielectric properties of the product which significantly vary during heat processing.

Some interacting factors influence the heating uniformity in a MW oven like the design of the waveguide, cavity and applicator system, the geometry and size of the food material, as well as its dielectric and thermal properties. Furthermore, the package composition and geometry will influence the heating result, as will the spacing between neighboring products if several items are heated simultaneously. Additionally, not only electromagnetic field pattern, and heat conduction, but also water transport in the food may influence the overall temperature distribution (Raaholt and Isaksson, 2016).

The methods for improving MW heating uniformity can be largely divided into two approaches: the uniformity of an electromagnetic field in the MW cavity and the uniformity of MW energy absorption within the materials. Several approaches of the former can be 
widely utilized based on mode-stirrer configurations (Plaza-González et al., 2005), various MW sources with different frequencies, or a rotary table in MW cavity (Watanabe et al., 2010), a micro strip transducer (Javier et al., 2015). While the latter depends on the dielectric and thermal properties of the material and its size or the moisture content and distribution (Castillejo et al., 2017).

Furthermore, some of them provided industrial solutions for continuous flow liquids, such as skim milk or apple or tomato sauce, were calculated the transient Maxwell's equations, that are solved by the finite difference time domain method to describe the electromagnetic field in the MW cavity and the waveguide (Zhu et al., 2007). Industrial ovens with a continuous belt carrying the samples and including water circulation in the cavities to help to level power distribution and as a result improve the heating uniformity (Resurrección et al., 2013).

\subsection{High hydrostatic pressure treatment}

HHP is a non-thermal food processing technology that has a great potential and can be advantageous in different types of products. This technology can inactivate pathogenic and spoilage microorganisms and enzymes, producing microbiologically safety products, while maintaining their sensory and nutritional quality (Oey et al., 2008).

The Table 8 list several HHP's process conditions and their effects on the nutritional properties of any vegetables products. HHP process can cause changes on the biochemical characteristics of a product, for example, altering the structures of membranes and secondary, tertiary and quaternary structures of proteins. Additionally, this technology can induce molecules like starch to gelatinization. Nevertheless, for vitamins, flavor molecules, amino acids, diverse studies suggesting that these compounds can remain unaffected during HHP process (Considine et al., 2008). Another use of the HHP is the process named high pressure assisted thermal processing (HPTP), which can be used for pasteurization or sterilization as a function of temperature of treatment. HPTP uses moderate initial temperatures between 60 and $90^{\circ} \mathrm{C}$, where both pressure and compression heat contribute to the treatment (García-Parra et al., 2016). 
Table 8. HHP's process conditions and their effects on the nutritional properties of some vegetables products.

\begin{tabular}{|c|c|c|c|}
\hline Product & $\begin{array}{l}\text { Process } \\
\text { conditions }\end{array}$ & Effects & References \\
\hline $\begin{array}{l}\text { Carrot and tomato } \\
\text { puree }\end{array}$ & $\begin{array}{l}400-600 \mathrm{MPa}, \\
15 \min / 20^{\circ} \mathrm{C}\end{array}$ & $\begin{array}{l}\text { Retention of ascorbic acid (90\%) } \\
\text { Increase carotein content }(58 \%) \\
\text { Higher antioxidant activity }\end{array}$ & (Patras et al., 2009) \\
\hline Apple puree & $\begin{array}{l}400-600 \mathrm{MPa} \\
5 \mathrm{~min} / 20^{\circ} \mathrm{C}\end{array}$ & Vit $\mathrm{C}$ retention $(93.5 \%-600 \mathrm{MPa})$ & (Landl et al., 2010) \\
\hline Pumpkin puree & $\begin{array}{l}600 \mathrm{MPa} \\
1 \mathrm{~min} / 70^{\circ} \mathrm{C}\end{array}$ & $\begin{array}{l}\text { Increase total phenolic compound } \\
\text { (TPC) }(65 \%)\end{array}$ & $\begin{array}{l}\text { (García-Parra et al., } \\
\text { 2016) }\end{array}$ \\
\hline Mango pulp & $\begin{array}{c}550 \mathrm{MPa}, \\
4 \min / 59{ }^{\circ} \mathrm{C}\end{array}$ & Increase ТPC (34\%) & $\begin{array}{l}\text { (Camiro-Cabrera et } \\
\text { al., 2017) }\end{array}$ \\
\hline Pea puree & $\begin{array}{l}550 \mathrm{MPa}, \\
5 \mathrm{~min} / 20^{\circ} \mathrm{C}\end{array}$ & $\begin{array}{l}\text { Improved the rheological properties } \\
\text { during storage. Reduction of } \\
\text { polygalacturonase activity }\end{array}$ & (Klug et al., 2017) \\
\hline $\begin{array}{l}\text { Chickpea flour } \\
\text { puree }\end{array}$ & $\begin{array}{c}\text { 600MPa, } \\
15 \min / 50^{\circ} \mathrm{C}\end{array}$ & Increase in $\mathrm{G}^{\prime}$ and $\mathrm{G}^{\prime \prime}$ values & $\begin{array}{l}\text { (Álvarez et al., } \\
\text { 2017) }\end{array}$ \\
\hline Strawberry puree & $\begin{array}{c}600 \mathrm{MPa} \\
15 \mathrm{~min} / 25^{\circ} \mathrm{C}\end{array}$ & $\begin{array}{l}\text { Increase }(10 \%) \text { TPC } \\
\text { Retention anthocyanin content }\end{array}$ & (Patras et al., 2009) \\
\hline
\end{tabular}

\subsubsection{Process principles}

HHP involves the application of hydrostatic pressure in the range of 100-900 MPa for 1-30 minutes, which is instantaneously and uniformly distributed throughout the packaged or non-packaged food product with or without the assistance of thermal treatment. There are two general scientific principles, which are of direct relevance to the use of HHP in food processing. The first is the Le Chatelier's principle, which states that when a system at equilibrium is disturbed, the system responds in a way that tends to minimize the disturbance. 
This means that the increase in pressure causes a decrease in the product volume affecting biological structures, reactions and processes. Second, the isostatic principle rule states that the pressure is instantaneously and uniformly transmitted throughout a sample under pressure, whether the sample is remain in direct contact with the pressurizing medium or in a hermetically sealed pressure-transmitting container, irrespective of the size or geometry of the product (Norton and Sun, 2008).

A schematic representation of HHP equipment is shown in Figure 25. The packed food product is placed in a basket and then transferred to the pressure chamber containing the pressure-transmitting medium. Compression of the pressure-transmitting fluid by the action of a pump or a piston is used to pressure increase. After treatment time, the vessel is decompressed, and the product is removed. HHP can be achieved without heating, but during the pressure build-up adiabatic heating takes place due to the heat of compression of the used pressure-transmitting fluid (often water). (Barba et al., 2017).

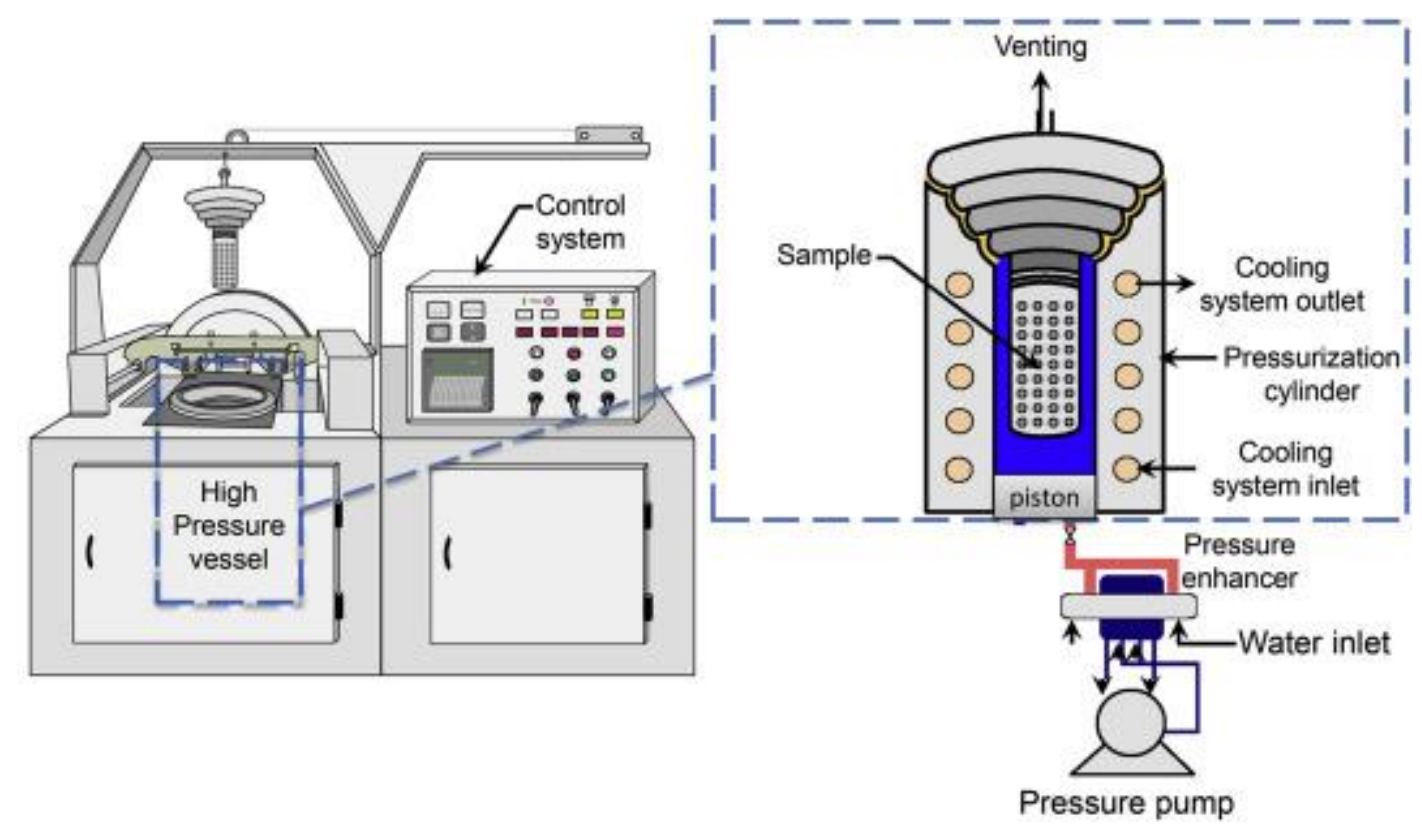

Figure 25. Schematic representation of high pressure processing equipment (Barba et al., 2016). The pressure build-up is generated by a direct method. 
HHP is characterized by three parameters: final pressure level $(\mathrm{P})$, temperature $(\mathrm{T})$, and pressure duration time $(\mathrm{t})$. HHP treatment is a uniform and instantaneous process, independent of the size and geometry of the product, where different types of food matrices (liquid or solid) can be processed. The action of HHP is based on a decrease in molecular volume changes, which may induce chemical reactions and physical transformations, which can be highly effective in modifying the integrity of cells walls and membranes, thus promoting the extractability of the intracellular bioactive compound and facilitating its solubilization (Heinz and Buckow, 2010).

\subsubsection{Applications in foods: biochemical changes}

As hydrogen bonds are stabilized by high pressure, and as their formation involves a volume decrease, pressure does not generally affect covalent bonds. Consequently, HHP can disrupt large molecules of or microbial cell structures, such as enzymes, proteins, lipids and cell membranes, and leave small molecules such as vitamins and flavour components unaffected. HHP only affects noncovalent bonds (i.e. ionic, hydrophobic and H bonds), which suggesting that primary structure and low-molecular-weight molecules, such as those responsible for the sensory and nutritional qualities of food, are left intact (Considine et al., 2008). In accordance, Patras et al. (2009) observed that HHP treatments at moderate temperatures can maintain the vitamin content and anthocyanins in strawberry and blackberry purees. On the other hand, it was observed that high pressures can produced changes in membrane permeability and disruption of cell walls favoring the bioactive compounds releasing from tissue or alteration their chemical structure to conversion of insoluble phenolic into more soluble forms and, in consequence, improving their extractability (Dini et al., 2013).

The application of high pressures on a food product can influence their physicalchemical and structural properties that are observed through a change in the volume of the system and the structure of proteins, as well as changes in enzyme activity and inactivation of microorganisms. Structural changes are related to physical and chemical changes in the morphology of food tissue, cell organelles and membranes, including at the molecular level. Changes in the cell wall are due to modifications in lipid, protein or polysaccharide fractions of the wall during high pressure processing. The high pressure induces changes in the 
polysaccharides, as well as in the structure of the polysaccharides, proteins (deployment, aggregation, gelling) and crystallization of fats. All this can affect its functionality, texture and structure of the plant tissue (Galazka et al., 1996).

HHP treatment (at low and moderate temperatures) has a limited effect on pigments responsible for the colour of fruits and vegetables (e.g. chlorophyll, carotenoids, anthocyanins, etc.). In many cases, the green colour of vegetables not changed after HHP treatment. Accordingly, Wang et al., (2013) observed that HHP (600 MPa, $15 \mathrm{~min}$ ) processing delayed the green color deterioration of spinach puree. Several studies on HHP showed this technological process helpful for retaining the green color by chlorophyll content changes after treatment and during the storage due to the inactivation of enzymes, inhibition of senescence and thylakoid membrane disintegration (Wang et al., 2013). However, at elevated temperature, the colour can changed, for example, in a pumpkin puree after a HHP treatment (650 $\left.\mathrm{MPa}, 60^{\circ} \mathrm{C}, 10 \mathrm{~min}\right)$ (García-Parra et al., 2016).

Due to cell disruption, HHP processing facilitates the occurrence of enzymatic and non-enzymatic reactions. Substrates, ions and enzymes which are located in different compartments in the cells can be liberated and interact with each other during HHP treatment. High pressures inactivate enzymes by altering the secondary and tertiary structures of proteins, changing the functional integrity, biological activity, and susceptibility to proteolysis. The mechanism of enzyme inactivation can be hypothesized similar to protein denaturation. The application of pressure may induce reservible or irreversible changes in the native structure of the enzyme (Chakraborty et al., 2014). Therefore, the effect of high pressures on enzyme activity can be twofold, relatively low pressures can produce activation of enzymes, while high pressures can contribute to inactivation of the enzymes. Cao et al. (2011) studied PPO and POD activities in strawberry pulp after HHP (400 to $600 \mathrm{MPa} / 25$ $\mathrm{min} / 25^{\circ} \mathrm{C}$ ) and reported $48 \% \mathrm{PPO}$ inactivation at $600 \mathrm{MPa} / 5 \mathrm{~min} / 25^{\circ} \mathrm{C}$ and $64 \% \mathrm{POD}$ inactivation at $600 \mathrm{MPa} / 5 \mathrm{~min} / 25^{\circ} \mathrm{C}$. On the other hand, in strawberry puree treated at 200 $\mathrm{MPa} / 5 \mathrm{~min} / 29^{\circ} \mathrm{C}$ was observed an activation about $110 \%$ of PPO, and $91 \%$ PPO inactivation was obtained in severe conditions $\left(600 \mathrm{MPa} / 71^{\circ} \mathrm{C}\right)$ (Sulaiman and Silva, 2013).

HHP treatment can affect the rheological properties of food products such as puree, pulp and juice of fruits and vegetables. Ahmed et al. (2005) reported that the viscosity of 
mango pulp increased after HHP treatments at 100 or $200 \mathrm{MPa}\left(20{ }^{\circ} \mathrm{C} / 15\right.$ or $\left.30 \mathrm{~min}\right)$, while a reduction in viscosity was observed after $\mathrm{HHP}$ treatments at 300 and $400 \mathrm{MPa}\left(20{ }^{\circ} \mathrm{C} / 15\right.$ or $30 \mathrm{~min}$ ). The observed effects are dependent on the conditions of the HHP process and the type of fruit and vegetable.

Inactivation of microorganisms by HHP is due to a number of explanations including changes in cell wall, cell morphology and cell membrane lipids, dissociation of ribosome, loss of genetic functions and altered biochemical reactions (Ritz et al., 2000). Pressure resistance by vegetative microorganisms is species-dependent. Molds and yeasts are less resistance to pressure and often inactivated at pressures below $300 \mathrm{MPa}$. Gram-negative bacteria are often more sensitive to HHP treatment than Gram-positive bacteria. However, there are numerous exceptions to this statement. Guan et al. (2006) observed that some strains of Escherichia coli O157: $\mathrm{H} 7$ present a greater resistance, reaching $600 \mathrm{MPa}$, and even being necessary to apply temperature for its complete inactivation. The growth phase of bacteria also plays a role in determining their pressure sensitivity/resistance. Cells in the stationary phase of growth are normally more pressure resistant than those in the exponential phase (Hayman et al., 2007). Furthermore, moderate temperature $\left(40-60^{\circ} \mathrm{C}\right)$ combined HHP treatment can also enhance microbial inactivation. García-Parra et al. (2016) observed in a pumpkin puree that the inactivation of native microorganisms increased proportionally with pressure and temperature.

\subsubsection{Advantages and limitations}

One of the major advantages of using HHP in food processing is the maintained of the original sensory properties of fresh produce (Patras et al., 2009), which is in accordance with the consumer demand for healthy, nutritional and safety food products. HHP technology leads to a shorter processing time regarding a batch thermal treatment as the pressure treatment is independent of the product's dimension (Norton and Sun, 2008). And finally, HHP is an environmentally friendly technology, since the pressure is usually generated with the use of high-pressure intensifiers that use electricity to produce the pressure, once the pressure has been reached, no additional energy is required to maintain the pressure. This is in contrast to a thermal treatment, where energy needs to be constantly provided for the duration of the treatment. 
In relation to limitations of the use of HHP, is necessary a deeper insights of the process to bacterial inactivation. Some aspects still need to be studied in more details (like $\mathrm{pH}$, rates of compression, and decompression, etc.). Additionaly, selection of process parameters is mainly dependent on type of matrix and target bacteria. Furthermore, the sensitivities of enzymes are unpredictable and very much specific to the product, which leads to different pressure stabilities at various temperatures and vice versa. The deeper knowledge of these parameters is important to the sensory quality of the HHP treated products. Additionally, since most foods are pressure-treated after packaging, it is necessary to study food and package interactions with the HHP or with the HPTP, including effects of the pressure transmitting fluid, because the literature on the effects of pressure-processing technologies on these compounds is still incomplete (Escobedo-Avellaneda et al., 2011).

\subsection{Sous vide treatment}

Sous vide is French for 'under vacuum' and sous vide cooking is defined as 'raw materials or raw materials with intermediate foods, that are cooked under controlled conditions of temperature and time inside heat-stable vacuum pouches' (Schellekens, 1996).

The sous vide technique is used to process thermally or minimally treated ready-to-eat products, as well as fresh products. It could be a reasonable choice, as sous vide allows to obtain products with an extensive shelf life and a quality similar to that of fresh food (Muizniece-brasava et al., 2016). Microbial safety of sous vide products is determined by the following factors: i) heat treatment intensity, ii) cooling speed after thermal treatment, and iii) temperature control during the refrigerated storage (González-Fandos et al., 2004)

The selection of the temperature/time binomial is very important during the cooking of the food products to achieve a good sensory quality and safety. In particular, this binomial acquires a crucial suggestion in the sous vide method since the relatively low cooking temperatures used maybe suitable for microorganism growth. Lower temperatures (between $65-70^{\circ} \mathrm{C}$ ) are often used for more delicate foods, such as fish, while higher temperatures (90$100^{\circ} \mathrm{C}$ ) are applied to vegetables. The shelf life of the sous vide products may vary from 6 to 45 days (Villarino-Rodríguez, 2009). One the most important aspects of sous vide cooking is rapid chilling (or immediately consumption) and refrigeration of heat treated products to prevent the germination of microorganism spores and subsequent outgrowth and 
multiplication of microorganisms, as spores are heat-tolerant at temperature below $100^{\circ} \mathrm{C}$. It is suggested that the food should be cooled within $1 \mathrm{~h}$ after cooking (Baldwin, 2012).

Products in sous vide packaging can be heat treated in different environments: in water bath, in hot air or saturated water steam, or in hot water flow. Pasteurizing in water can be performed in water baths or autoclaves, for heat treatment in steam/air environment autoclaves and convection ovens are suitable. Sous vide cooking differs from traditional cooking methods in two fundamental ways: the raw food is vacuum-sealed in heat-stable, food-grade plastic pouches and the food is cooked using precisely controlled heating. The food inside a vacuum-sealed package has many advantages: it allows heat to be efficiently transferred from the water (or steam) to the food; it increase the shelf life of the food due to elimination of the risk of recontamination during storage; its inhibits off-flavors from oxidative and prevents evaporative losses of flavor volatiles and moisture during cooking (Baldwin, 2012).

Recently, the sous vide cooking method possesses a lot of advantages such as unique textural characteristics, lower lipid oxidation derived from the vaccum conditions, lower moisture loss, and modifications of profile of volatile flavor compounds. Iborra-Bernad et al. (2013) also compared sous vide method for green bean pods. Green beans cooked with sous vide had higher greenness flavor and overall preference compare to traditional cooking. Sous vide packaging prevents the direct contact between food and $\mathrm{O}_{2}$, so, can reduces the oxidation of colour pigments such as chlorophyll and carotenoids.

The sous vide cooking is a possible strategy to avoid loss of nutrients. Indeed, different studies observed that the loss of molecules in vegetables, like ascorbic acid and polyphenols were lower applying sous vide conditions (Martínez-Hernández et al., 2013a; Renna et al., 2014). As a result, thus this food presents a higher antioxidant activity regarding the one cooked with traditional pasteurization. Koç et al. (2017) observed that total phenolic content of carrots was highly protected when cooked in sous vide method compare to conventional treatment. Sous vide cooking provides advantages associated to nutritional values and to the sensorial satisfaction of consumers (Iborra-Bernad et al., 2013; Renna et al., 2014). Indeed, vegetables were more aromatic and tastier than the ones cooked via boiling method. 


\subsection{Other technologies}

Ohmic heating process is created on the passage of alternating electrical current through food system that works as an electrical resistance where heat is generated. Ionic substances in food, such as acids and salts, has electrical conductivity, thus when the food is subjected to electrical pulses, a molecular polarization is produced, resulting in an increase of the movement of ionic substances and consequently an increase of the temperature (Escajeda et al., 2018). Mercali et al. (2015) reported the effect of ohmic heating in jaboticaba juice and no significant differences were found between degradation rates of anthocyanins for ohmic and conventional heating at temperature ranging from 70 to $90^{\circ} \mathrm{C}$. Furthermore, ohmic heating process has some advantages like the lower maintenance costs and no negative environmental impact. However, a common problem that occurs during ohmic heating is fouling. For example, Tumpanuvatr and Jittanit (2012) described problems with the use of ohmic heating in orange and pineapple juices. The authores reported that the treatment caused vit $\mathrm{C}$ degradation, as well as the color and flavor changes of the juices, because of the metal ions migration from the corrosion of the electrodes into the samples. This problem can be avoided by using higher frequencies (about $10 \mathrm{kHz}$ ) and correct electrode materials ( $\mathrm{Al}, \mathrm{Ti}$, platinized-titanium) ( Escajeda et al., 2018).

Another non-thermal technique is the pulse electric field (PEF) system. The basic principle of this technology is the application of short pulses of high electric fields (voltage intensity in the order of $20-80 \mathrm{kV} / \mathrm{cm}$ ) with duration of micro- to milliseconds distributed to a product placed between a set of two electrodes. These pulses induce adverse changes in microorganisms and tissues present in the food matrix (Morales-de la Peña et al., 2011). Geveke et al. (2015) reported that the populations of E. coli were reduced $7.3 \mathrm{log}$ in strawberry puree at $24 \mathrm{kV} / \mathrm{cm}$ and $52.5^{\circ} \mathrm{C}$. Also, Timmermans et al. (2014) studied the PEF for the inactivation of Salmonella Panamá in apple juice and found that inactivation was due to the high initial kinetic energy that promote cell susceptibility to PEF at an electric field strength of $20 \mathrm{kV} / \mathrm{cm}$. Temperature increases with PEF are low and normally not more than $40^{\circ} \mathrm{C}$, but if needed, cooling systems can be attached to the usual equipment. PEF inactivates microorganisms by induction and alterations in different electric potentials between each side of the membrane. 
Furthermore, the effect of PEF on the bioaccessibility of carotenoids in fruit mixture combinations has been studied. Regarding untreated samples an increase of $79 \%$ in cisviolaxanthin and neoxanthin bioaccessibility for beverages based on fruit juice mixture (orange, kiwi, pineapple and mango) combined with water, milk or soymilk after applying PEF treatments $(35 \mathrm{kV} / \mathrm{cm}, 4 \mu \mathrm{s}$ bipolar pulses, $200 \mathrm{~Hz}, 1800 \mu \mathrm{s})$ was found (RodríguezRoque et al., 2016).

\section{ALTERNATIVE TECHNIQUES FOR INNOVATIVE MINIMAL PROCESSING OF VEGETABLES JUICES}

\subsection{Use of cyclodextrins}

Cyclodextrins (CDs) are natural high molecules consisting of cyclic oligosaccharides with six $(\alpha-C D)$, seven $(\beta-C D)$ and eight $(\gamma-C D)$ glucopyranose units, bound by $\alpha-(1-4)$ linkages forming a truncated conical structure. The preparation process of CDs consists of four principal phases: (i) culturing of the microorganism that produces the CD glucosyl transferase enzyme (CGT-ase); (ii) separation, concentration and purification of the enzyme from the fermentation medium; (iii) enzymatical conversion of prehydrolyzed starch in mixture of cyclic and acyclic dextrins; and (iv) separation of CDs from the mixture, their purification and crystallization. CGT-ase enzymes degrade the starch and produce intramolecular reactions without the water participation. In the process, cyclic and acyclic dextrins are originated, which are oligosaccharides of intermediate size. The cyclic resulting products or CDs are formed by the link among units of glucopyranose that constitute the dextrins. The union is made through glycosidic $\mathrm{O}_{2}$ bridges by a $(1,4)$ bonds (Figure 26) (Astray et al., 2009). 


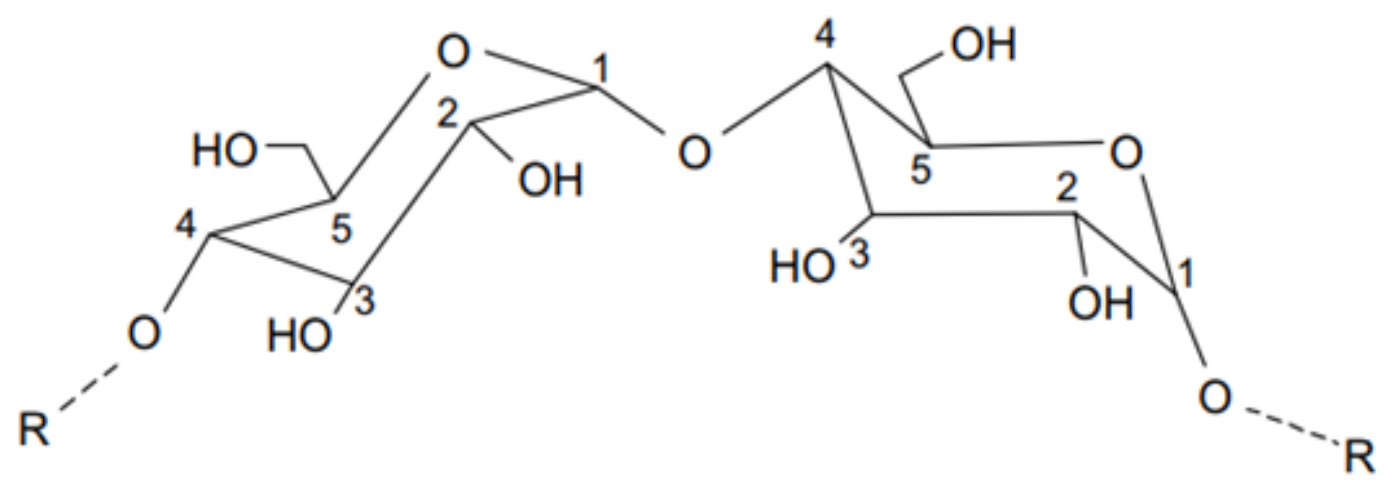

Figure 26. Glycosidic oxygen bridge $\alpha(1,4)$ between two molecules of glucopyranose. (Astray et al., 2009).

CD structure provides a hydrophilic outer surface and hydrophobic interior deep. The inner part of CDn molecules is made apolar by glycosidic $\mathrm{O}_{2}$ and methine protons, while the external surface is polar by presence of secondary and primary hydroxyls at the edge of the ring. As a result, CDs are able to form inclusion complexes with a large number of hydrophobic compounds. CDs has been studied due to potential use in the food industry as additives for a wide range of applications such as stabilization of flavours, protection of nutritional/health-promoting compounds (vitamins, phenolic compounds, etc.), elimination of undesired tastes and browning reactions, and to avoid microbiological contaminations, among other applications (Hu et al., 2012; Wilkowska et al., 2016).

The most important $\mathrm{CDs}$ at industrial level are $\alpha \mathrm{CD}, \beta \mathrm{CD}$ and $\gamma \mathrm{CD}$ are listed in the GRAS list of the FDA for use as a food additive. The recommendation of Joint FAO/WHO Expert Committee on Food Additives (JECFA, 2016) for a maximum level of b-CDs in foods is $5 \mathrm{mg} / \mathrm{kg}$ per day. For $\alpha$ - and $\gamma$-CDs no Acceptable Daily Intake (ADI) was defined because of their favorable toxicological profiles.

Some studies shown that the use of CDs significantly improved the color of pasteurized fruit juices, such as peach and pear (López-Nicolás et al., 2007c and 2009), without having negative effects on other important organoleptic attributes, such as odor and/or aroma. The enzymatic browning of juices can be slowed down using CDs $(\alpha, \beta$, and $\gamma)$ 
at different concentrations because CDs are able to complex the phenolic compounds and therefore avoid their oxidation by the enzyme polyphenoloxidase.

\subsection{Spherification}

Spherification is a technique used in avant-garde and modernist cuisine, which was invented by Peschardt in 1946 and carried forward by 'El Bulli', one of the most distinguished restaurants in the world (Vega and Castells, 2012). In modern cuisine, this technique is central to the formation of faux caviar, eggs, gnocchi and ravioli.

Spherification techniques can be divided into two types depending on the preparing method: basic spherification and reverse spherification. Basic spherification is a method where a liquid containing sodium alginate is submersed into the calcium solution. This causes calcium ions to permeate into the sodium alginate droplet, and calcium alginate is formed from the surface to inside the droplet (Figure 27a). On the other hand, in reverse spherification, a liquid containing calcium solution is submersed into sodium alginate, causing calcium ions to diffuse from the calcium solution to the surrounding sodium alginate, and a calcium alginate outer layer is formed (Figure 27b) (Lee and Rogers, 2012). 

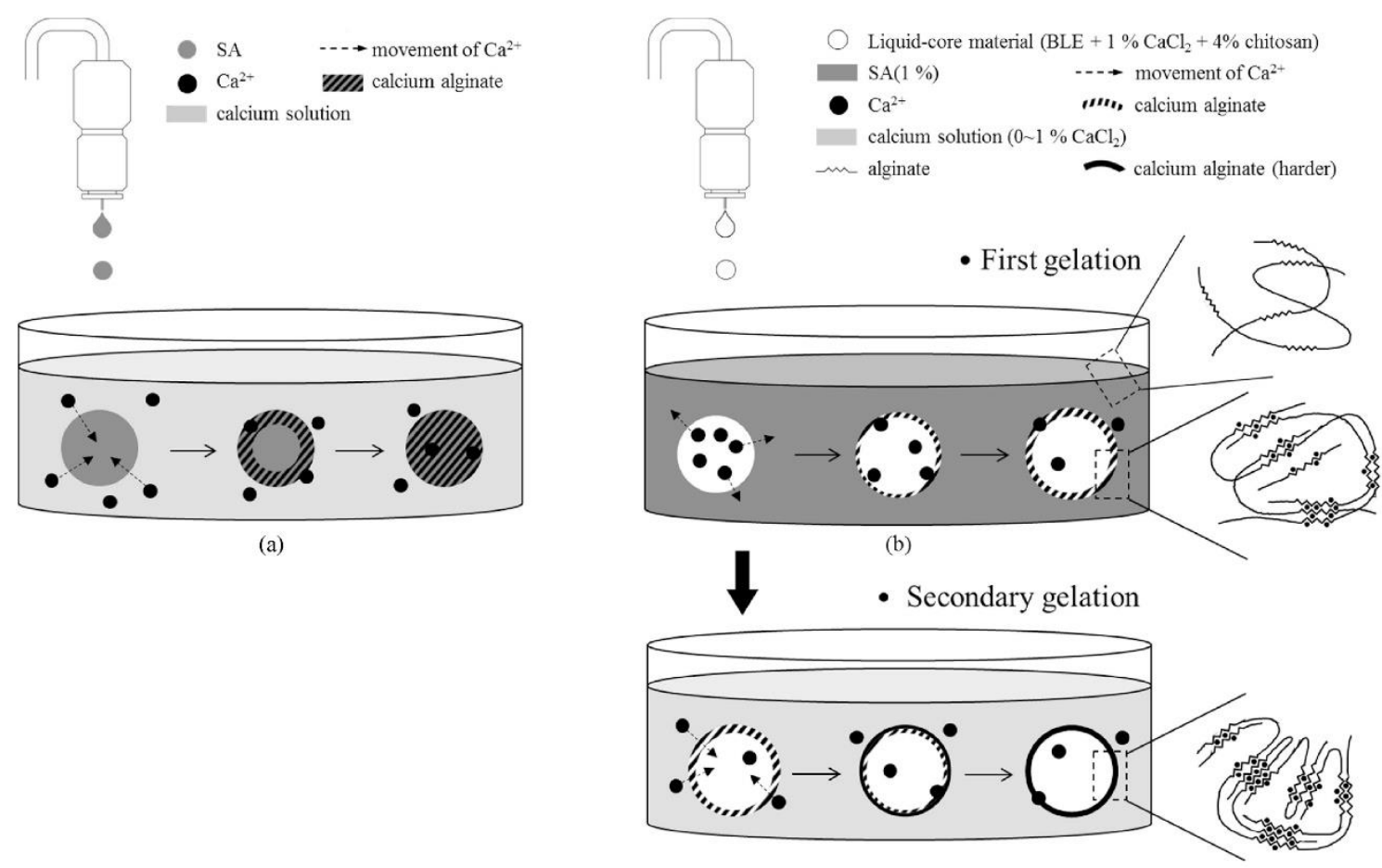

(c)

Figure 27. Gelation mechanism of (a) basic spherification; (b) first gelation of reverse spherification; (c) secondary gelation of reverse spherification (Tsai et al., 2017a)

There are few studies about the development of vegetable spherification. Tsai et al. (2017a) develop spheres of burdock leaf extracts by reverse spherification. Furthermore, a functional food with soursop (65\% water, $33 \%$ pulp, $0.7 \%$ splenda, $0.8 \%$ alginate and $0.5 \%$ xanthan gum) was developed by basic spherification, which provided a good sensory acceptance (Ibarra, 2017). The main goal of spherification of foods is to innovate and design dishes with new textures and flavors that promote new sensations in consumers.

\subsection{Other presentation and techniques}

The consumption of vegetables can be promoted through the development of attractive ready-to-eat products that should be processed with non-aggressive treatments to preserve as much as possible the quality and nutritional parameters of the raw materials (Artés et al., 2009). In this context, smoothies beverages made of fresh blended vegetables are alternative to increase the vegetables intake. Smoothies are non-alcoholic beverages prepared from fresh 
or frozen fruit and/or vegetables, which are blended without filtering and usually mixed with crushed ice to be immediately consumed. The smoothies could be produced with other components like milk, ice-cream, yogurt, lemonade or tea. They have a milk shake-like consistency (Castillejo et al., 2016). Accordingly, a red fruit-based smoothies was developed treated with HHP $\left(350 \mathrm{MPa}, 5 \mathrm{~min}, 10{ }^{\circ} \mathrm{C}\right)$. This treatment controlled the microbial quality of the smoothies during chilling storage at $4^{\circ} \mathrm{C}$ (Hurtado et al., 2017). Furthermore, an innovative formulation of smoothie (12\% beet, $45 \%$ purple grapes, $35 \%$ cucumber and $8 \%$ broccoli) treated with mild heat-treated $\left(90{ }^{\circ} \mathrm{C} / 45 \mathrm{~s}\right)$ was studied and modelled throughout storage $\left(5,15\right.$ and $\left.25^{\circ} \mathrm{C}\right)$. The sensory quality data estimated smoothie shelf-life of 55 (at $5^{\circ} \mathrm{C}$ ), 12 (at $15^{\circ} \mathrm{C}$ ) and 5.8 days (at $25^{\circ} \mathrm{C}$ ) (González-Tejedor et al., 2017).

Another alternative innovative minimal processing technique is the ready-to-blend formulation, defined as a fresh-cut (which involves correspondent plant material preparation, sanitizing treatments and MAP combined with chilling temperature) fruit, vegetable, or a mix of them, which is packaged under specific proportions ready for domestic blending. ArtésHernández et al. (2017) developed a ready-to-blend fruit/vegetable mix (melon, pineapple and carrot), fortified with vit B12, where a coating of chitosan was applied. The shelf life of these products was 9 days at $5^{\circ} \mathrm{C}$ showing the prepared beverages good quality during subsequent storage for $48 \mathrm{~h}$ at $5^{\circ} \mathrm{C}$. 


\section{OBJECTIVES}

The general objective of this Thesis was to develop innovative vegetables-based formulations such as purees, juices, sauces and hummus prepared as 'fifth range' products with high quality and bioactive compounds content and prolonged refrigerated shelf life by using emerging sustainable minimal processing techniques.

Such general objective was achieved by the following specific objectives:

- Optimization of the innovative vegetables-based formulations according to sensory tests.

- Study and optimization of the use of processing techniques (industrial MW, HHP and sous vide), to extend the shelf life of 'fifth range' vegetable products with lowered quality degradation meeting food safety regulations.

- Study and optimization of the encapsulation of glucoraphanin in broccoli juice with cyclodextrins.

- Optimization of kale spherification with stevia.

- Optimization of the reverse spherification process of kale spheres with lowered degradation of nutritional and bioactive compounds content during shelf life. 


\section{CHAPTER I}

\section{Improving quality of an innovative pea puree by high hydrostatic pressure}

Tâmmila Venzke Klug, ${ }^{1}$ Ascensión Martínez-Sánchez, ${ }^{1,2}$ Perla A Gómez, ${ }^{2}$ Elena Collado, ${ }^{2}$ Encarna Aguayo, ${ }^{1,2}$ Francisco Artés ${ }^{1,2}$ and Francisco Artés-Hernández ${ }^{1,2}$

1 Postharvest and Refrigeration Group. Department of Food Engineering. Universidad Politécnica de Cartagena. Paseo Alfonso XIII, 48, 30203 Cartagena, Murcia, Spain.

${ }^{2}$ Institute of Plant Biotechnology. Universidad Politécnica de Cartagena. Campus Muralla del Mar, 30202 Cartagena, Murcia, Spain.

Reference: Journal of Food Science and Technology. 2017. 97, 4362-4369. 


\section{I.1. INTRODUCTION}

The food industry is continuously developing new products with increased health benefits and consumer's acceptance. Previous studies have described the positive effect on health of consuming plant-based diets with increased intake of legumes (McCrory et al., 2010: Lima et al., 2016). Particularly, green peas intake has shown healthy properties such as reduced risk of cardiovascular diseases, colon cancer (Busambwa et al., 2016), diabetes, osteoporosis, hypertension, gastrointestinal disorders, and reduction of cholesterolaemia (Parolini et al., 2013). Moreover, green peas have a high nutritional value being an significant source of protein (ca. 24\%), complex carbohydrates, vitamins and minerals for diet (Dahl et al., 2012). Despite of this, the actual intake of legumes in Europe and USA is low. According to National Health and Nutrition Examination Survey (NHANES) data, on any given day, only about 8\% of adults consume dry legumes and peas (Mitchell et al., 2009). This may be attributed, in part, due to life style of consumers which are demanding appetizing ready to eat products. To satisfy this trend, the food industry is developing new products like high quality blended fruit and vegetables prepared as smoothies or purees, which could or not receive a mild thermal treatment. These smoothies present different soft textures and represent an excellent and convenient alternative to promote the daily consumption of fruit and vegetables (Castillejo et al., 2016).

Furthermore, besides sensory quality, the rheological and/or textural properties of a puree is a very important quality factor that should be controlled during processing as well as its evolution (firmness and stickiness) throughout the storage period (Piteira et al., 2006). In addition, another important factor is the particle size, which has shown a positive correlation with viscosity (Sato and Rosiane, 2009: Bi et al., 2015). Therefore, for a vegetable puree, particle concentration, size and type have been found to be the key structural parameters controlling the rheological properties (Moelants et al., 2013).

Among the conventional cooking methods, boiling is the most widely applied by the industry. However, the instability of the viscosity during storage and the relative low consistency, due to residual activity of enzymes, represent a problem (Krebbers et al., 2003). On the other hand, new emerging technologies such as HHP could be an alternative to be used both alone or combined with traditional treatments (Terefe et al., 2010; García-Parra et al., 2014). 
Furthermore, HHP technology has the advantage of producing foods with novel textures (Álvarez et al., 2014), whose rheological properties depend on the pressure-time parameters applied during treatment (Opazo-Navarrete et al., 2012). In some cases, HHP causes a volume reduction, modifying the interactions with water molecules and protein unfolding (Neeto et al., 2014), which can improve texture as well as maintain the texture during the storage. However, the application of a blanching technique at the early stage of the processing to reduce microbial growth and the activity of some enzymes has been shown to be necessary before the HHP treatment in pumpkin, apple and plum purees (Landl et al., 2010; Contador et al., 2012; Gonzalez-Cebrino et al., 2012).

The pea puree here presented is a healthy innovative product and, being based on peas, includes the legume's health benefits. The development of this new 'ready-to-eat' pea puree is an alternative that is being demanded by different population segments and consumers, and would help in increasing the intake of legumes. Moreover, the aim of this study was the development of an innovative legume puree, basically made of frozen peas, thermally treated and processed under HHP treatment (550 MPa for 5 or $10 \mathrm{~min}$ ). Enzymatic activity, stability of apparent viscosity and particle size, and microbial and sensory quality throughout 36 days at $5{ }^{\circ} \mathrm{C}$ were monitored.

\section{I.2. EXPERIMENTAL}

\section{I.2.1. Plant material and puree preparation}

The puree formulation was constituted by frozen peas (Pisum sativum L.), olive oil (5.6\%), salt $(0.3 \%)$, lemon juice (3\%), pepper $(0.008 \%)$ and dried onion $(0.1 \%)$. All ingredients were purchased at a local supermarket located in Cartagena (Murcia, Spain). The formulation was previously optimized based on acceptability quality tests performed by a trained panel $(n=7)$ as later described.

\section{I.2.2. Treatments and storage conditions}

Frozen peas were boiled in a $3.7 \mathrm{~L}$ processor Robot Cook $^{\circledR}$ (Robot Coupe, Montceau-enBourgogne, France) with water $\left(100^{\circ} \mathrm{C}\right)$ for $10 \mathrm{~min}$. After the conventional thermal treatment, the liquid was removed and the remaining ingredients were added and blended in the 
processor for $2 \mathrm{~min}$ at $1,450 \mathrm{~g}^{-1}$. Pea puree (200 g) was packed in embossed polyethylene bags, sealed vacuum (Egarvac, Barcelona, Spain) and immersed in ice to reduce the temperature from $50^{\circ} \mathrm{C}$ to $15^{\circ} \mathrm{C}$. A group of 18 bags were stored at $5{ }^{\circ} \mathrm{C}$ in darkness conditions (CTRL). The remaining bags were pressurized at $550 \mathrm{MPa}$ using a High Pressure Iso-Lab System (Stansted Fluid Power LTD, UK). Two pressurization times were assayed: 5 min (HHP-5) and 10 min (HHP-10). Fresh blended frozen peas plus remaining ingredients, which were not boiled or HHP treated, were also evaluated (NB).

All samples were stored at $5^{\circ} \mathrm{C}$ in darkness conditions and analyzed at 0 (immediately after treatments on processing day), 7, 14, 21, 28 and 36 days of storage, except NB samples, which were only evaluated on day 0 . Three replicates per treatment and sampling day were evaluated.

\section{I.2.3. Rheological properties of purees}

Rheological analyses were performed using an ARG2 stress-controlled rheometer (TA Instruments, New Castle, DE, USA) equipped with serrated (to prevent wall depletion phenomena) plate-plate geometry $(20 \mathrm{~mm}$, gap $2 \mathrm{~mm})$. A solvent trap saturated with water was used to avoid evaporation. For every measurement the puree sample was transferred to the rheometer geometry and then it was allowed to equilibrate between the plates at $25{ }^{\circ} \mathrm{C}$ for $1 \mathrm{~min}$. The measurements were made with and increasing shear rate from 1 to $100 \mathrm{~s}^{-1}$. After $36 \mathrm{~d}$ at $5^{\circ} \mathrm{C}$ modulus $\left(\mathrm{G}^{\prime}\right)$ and loss modulus (G') were determined in a frequency range of 100 to $0.2 \mathrm{~Hz}$. The strain value was obtained by preliminary strain sweep oscillatory trials to determine the linear viscoelastic region. The strain sweep oscillatory tests were carried out at a frequency of $1 \mathrm{~Hz}$ and in a range of shear strain of 0.01 to $10 \%$. Flow tests were also used to cover shear rate range between $10^{-2}$ and $10^{2} \mathrm{~s}^{-1}$. Three repetitions of the dynamic-mechanical experiments were performed for each puree sample.

\section{I.2.4. Particle size distribution (PSD) measurement}

Pea puree samples $(0.4 \mathrm{~g})$ were diluted (1:500) in distilled water. The PSD of the samples was determined by a Mastersizer 2000 device (Malvern Instruments, Malvern, UK) with a watercontinuous diluting accessory (2000 Hydro-G). The surface mean diameter $D[3,2]$ and volume mean diameter $D[4,3]$ for all samples were determined. Moreover, the $10 \%, 50 \%$ and 
$90 \%$ of particles under a determined particle size were represented as $d(0.1), d(0.5)$ and $d(0.9)$, respectively. Five readings were made for each sample and the average of the readings was calculated.

\section{I.2.5. Polygalacturonase (PG) and pectin methylesterase (PME) activities}

For PG analyses, samples were extracted using the method of Aguiló-Aguayo et al. (2008) with some modifications. A puree sample of $0.5 \mathrm{~g}$ was homogenized (orbital shaker, Stuart, Staffordshire, UK) at low speed with $15 \mathrm{~mL}$ of cold acetone at $4{ }^{\circ} \mathrm{C}$ for $30 \mathrm{~min}$. Subsequently, the homogenate was centrifuged at $20,000 \times g$ for $10 \mathrm{~min}$ at $4{ }^{\circ} \mathrm{C}$ and then the supernatant was discarded. The pellet was resuspended with $10 \mathrm{~mL}$ of cold acetone for $15 \mathrm{~min}$ at $4{ }^{\circ} \mathrm{C}$, then the homogenate was centrifuged at $20,000 \times g$ for $15 \mathrm{~min}$ at $4{ }^{\circ} \mathrm{C}$ and the supernatant was discarded, using the pellet for enzyme determination. The PG activity was quantified according to the method described by Gross (1982). One unit (U) of PG activity was defined as the amount of enzyme that yielded $1 \mathrm{mmol} \mathrm{L}^{-1}$ reducing groups $\mathrm{min}^{-1}$.

PME activity was determined according to Ratner et al. (1969), with some modifications. Puree samples $(2.5 \mathrm{~g})$ were homogenized with $10 \mathrm{~mL}$ of $0.2 \mathrm{~mol} \mathrm{~L}^{-1}$ sodium chloride. The filtered homogenate $(2.5 \mathrm{~mL})$ was mixed with $15 \mathrm{~mL}$ pectin $\left(10 \mathrm{~g} \mathrm{~L}^{-1}\right)$ and the $\mathrm{pH}$ was adjusted at 7.0 with $1 \mathrm{~mol} \mathrm{~L}^{-1} \mathrm{NaOH}$. Finally, the $\mathrm{pH}$ was kept at 7.0 for 10 min using 0.01 mol L ${ }^{-1} \mathrm{NaOH}$. One PME $\mathrm{U}$ was expressed as the amount of enzyme that produces nmol g ${ }^{-1}$ $\min ^{-1}$ at $\mathrm{pH} 7.0$ and $22^{\circ} \mathrm{C}$.

The residual PG or PME activity was defined as the percentage of the specific activity after each treatment respect to the specific activity of control samples. Three replicates were use per treatment and each replicate was measured by triplicate.

\section{I.2.6. Sensory analyses}

Sensory analyses were performed according to international standards (ASTM STP 913, 1986). Discrimination of samples according to their sensory quality was carried out by a sensory panel (seven people aged between 22-68 years) previously trained in discriminative quality attributes. Samples (about $30 \mathrm{~g}$ ) were served at room temperature $\left(24{ }^{\circ} \mathrm{C}\right.$ ) in transparent glasses coded with three random digit numbers. Still mineral water was used as 
palate cleanser. The panel screened for sensory ability (color, flavor, texture, taste, consistency) on a 5-point structured hedonic scale (5, excellent; 4, good; 3, limit of acceptability; 2, poor; 1, extremely bad) and overall quality was evaluated on a 9-point structured hedonic scale (9, extremely like; 8 , like very much; 7 , like moderately; 6 , like slightly; 5, limit of acceptability; 4, dislike slightly; 3, dislike moderately; 2, dislike very much; 1, extremely dislike).

\section{I.2.7. Physiochemical analyses}

A pH-meter was used to analyze the $\mathrm{pH}$ (Crison $2001 \mathrm{pH}$ meter, Crison Instruments SA, Barcelona, Spain). Color was determined using a colorimeter (Minolta CR-300 Series, Japan). Total color differences $(\Delta \mathrm{E})$ throughout storage of pea puree samples were compared to their respective initial values according to equations previously described (Walkling-Ribeiro et al., 2010).

The color differences $(\Delta \mathrm{E})$ were expressed as follows:

$$
\left.\left.\Delta \mathrm{E}=\sqrt{(}\left(L_{0}-L^{*}\right)^{2}+\left(a_{0}-a^{*}\right)^{2}+\left(b_{0}-b^{*}\right)^{2}\right\rfloor\right)
$$

\section{I.2.8. Microbial analyses}

To determine the mesophilic, psychrophilic, enterobacterial, and yeast and mould growth, standard enumeration methods were used. Samples of $10 \mathrm{~g}$ were homogenized in $90 \mathrm{~mL}$ of sterile peptone saline solution ( $\mathrm{pH} 7$; Scharlau Chemie SA, Barcelona, Spain) for $30 \mathrm{~s}$ in a sterile stomacher bag (model 400 bag 6141, Seward Medical, London, UK) using a masticator (Colwort Stomacher 400 Lab, Seward Medical). For the enumeration of each microbial group, tenfold dilution series were prepared in $9 \mathrm{~mL}$ of sterile peptone saline solution. Mesophilic, enterobacteria and psychrotrophic were pour plated, and yeast and mould were spread plated. The following media and incubation conditions were used: plate count modified agar (PCA) (Scharlau Chemie) for mesophilic and psychrotrophic aerobic bacteria, incubated at $30{ }^{\circ} \mathrm{C}$ for $48 \mathrm{~h}$ and at $5{ }^{\circ} \mathrm{C}$ for 7 days, respectively; violet red bile dextrose agar (Scharlau Chemie) for enterobacteria, incubated at $37{ }^{\circ} \mathrm{C}$ for $48 \mathrm{~h}$; and rose Bengal agar (Scharlau Chemie) for yeasts and moulds, incubated for $3-5$ days at $22{ }^{\circ} \mathrm{C}$. All microbial counts were reported as log 
colony-forming units per gram of product $\left(\log \mathrm{CFU} \mathrm{g}{ }^{-1}\right)$. Each of the three replicates was analyzed by duplicate.

\section{I.2.9. Statistical analysis}

An analysis of variance (ANOVA) was performed for comparing different treatments and storage times at a significant level of $P \leq 0.05$ using PASW Statistics 22 for Windows (SPSS Inc., Chicago, IL, USA). In some cases, when significant differences were observed, Tukey's HSD (Honestly Significant Difference) test was applied. Bilateral correlations were determined by Pearson's correlation coefficient with a confidence interval established at 95\%.

\section{I.3. RESULTS}

\section{I.3.1. Viscosity}

Apparent viscosity of all samples decreased as shear rate increase from 1 to $100 \mathrm{~s}^{-1}$, suggesting that the samples followed a pseudo-plastic flow behavior (Fig. I.1). At low shear rates (up to $10 \mathrm{~s}^{-1}$ ), large viscosity differences between samples were observed and at high shear-rates minor differences were detected. The effective shear rate range in the mouth is 40 $50 \mathrm{~s}^{-1}$, which would have implied actual sensory consistency (Bourne, 2002). On the processing day, the viscosity at a shear rate of $50 \mathrm{~s}^{-1}$ on NB samples (1.91 $\mathrm{Pa} \mathrm{s}$ ) was significantly $(P<0.05)$ higher than for CTRL $(0.30 \mathrm{~Pa} \mathrm{~s})$, HHP-5 (0.60 Pa s) and HHP-10 (0.40 Pa s).

After 21 days of storage, CTRL and HHP-5 samples showed a decrease in viscosity at low share rates and an increase at $50 \mathrm{~s}^{-1}$ (around 0.72 and $0.84 \mathrm{~Pa} \mathrm{~s}$ for CTRL and HHP-5 respectively), while HHP-10 showed a similar viscosity as on day 0 (around $0.33 \mathrm{~Pa}$ s at 50 $\mathrm{s}^{-1}$ ), without significant differences among treatments (Fig. I.1).

After $36 \mathrm{~d}$ at $5{ }^{\circ} \mathrm{C}$, the viscosity at low shear rate was maintained for HHP-5 samples. However, in CRTL and HHP-10 samples it significantly decreased (Fig. I.1). At $50 \mathrm{~s}^{-1}$ the viscosity was $0.63,0.62$ and $0.59 \mathrm{~Pa}$ s for CRTL, HHP-5 and HHP-10, respectively. The behavior of the samples after 36 days of storage was also observed in relation to G' and G'. The $G^{\prime}$ was larger than the $G^{\prime \prime}$ in the oscillatory frequency $(\omega)$ range evaluated for all studied 
samples. Moreover, it was found that $\mathrm{G}^{\prime}$ values for HHP-5 samples were higher than for the other treatments (Fig. I.2).

\section{I.3.2. Particle size distribution}

The average particle size distribution of the pea puree samples is shown in Table I.1. At day 0 , HHP treatments showed a significant decrease in $D[3,2]$, which was higher with longer HHP treatment time $(P<0.001)$. A similar trend was found in $\mathrm{D}[4,3]$ parameter, but in this case, all treatments showed significant differences regarding NB samples. In addition, after heat treatment, CRTL samples presented an increase for $d(0.1)$ and a decrease for $d(0.9)$, resulting in the generation of smaller particles regarding NB samples. $D[3,2]$ increased throughout storage, which was also found for $D[4,3], d(0.1)$ and $d(0.9)$. On the other hand, $d(0.5)$ decreased during the same time at $5{ }^{\circ} \mathrm{C}$.

After 36 days at $5^{\circ} \mathrm{C}$, HHP treatments showed significant higher values in $D[4,3], D[3,2]$, $d(0.5)$ and $d(0.9)$ when compared to CTRL treatment.

\section{I.3.3. Polygalacturonase (PG) and pectin methylesterase (PME) activities}

The effect of different treatments in PG activity was evaluated and the residual activity is shown in Fig. I.3. After treatments, an initial inactivation of $16 \%, 15 \%$ and $21 \%$ was found in CTRL, HHP-5 and HHP-10, respectively, without significant differences between CTRL and HHP-5 $(P>0.05)$. The residual activity of PG remained low until day 21 , when it started to increase for all the treatments. However, after 29 days at $5{ }^{\circ} \mathrm{C}$, the residual PG activity of CTRL samples continued increasing and this trend was maintained until the end of storage. Conversely, residual PG activity was reduced for all HHP treatments, HHP-10-treated samples showing the lowest PG residual activity. In addition, after 36 days at $5{ }^{\circ} \mathrm{C}$ a significant negative correlation $(\mathrm{P}<0.01)$ was found between $\mathrm{PG}$ and $D[4,3], d(0.5)$ and $d(0.9)$, Pearson's values being $-0.972,-0.931$ and -0.981 , respectively.

The PME activity of NB samples was $2599 \pm 354.8 \mathrm{nmol} \mathrm{g}^{-1} \mathrm{~min}^{-1}$ after blending. However, no PME activity was detected in CTRL and HHP treatments, indicating that the enzyme was completely inactivated by the thermal treatment. 


\section{I.3.4. Sensory quality}

Overall quality was maintained during 2 weeks of storage, but after 21 days a significant decrease was detected $(\mathrm{P}<0.001)$ (Table I.2). A similar trend was observed for texture (Table I.2). Color, taste and flavor showed a significant decrease after 14 days of storage. No significant differences were found among treatments regarding taste, consistency and overall quality ( $\mathrm{P}>0.05$ ) (Table I.2). The shelf life of pea purees was determined based on the overall quality after 36 days of storage. Sensorial evaluations did not show any significant difference among treatments, and all samples showed an acceptable overall quality after 36 days at $5^{\circ} \mathrm{C}$.

\section{I.3.5. Physico-chemical quality attributes}

The physicochemical parameters evaluated on day 0 are shown in Table I.3. Non significant $\mathrm{pH}$ changes after processing (Table I.3) and throughout storage were observed (data not shown). When compared to NB samples, a slight increase in luminosity ( $\mathrm{L}^{*}$ values) after boiling was observed (Table I.3), without differences among HHP treatments. The characteristic green color of peas ( $\mathrm{a}^{*}$ value) and ${ }^{\circ} \mathrm{h}$ value decreased after the thermal treatment in CTRL regarding NB samples, with no differences among the HHP treatments (Table I.3). However nonsignificant differences were found in $\mathrm{b}^{*}$ values. The $\Delta E$ values showed significant color changes in CTRL and HHP treatments compared to NB, while no significant differences were found between HHP treatments and between these treatments respect to CTRL.

\section{I.3.6. Microbial analyses}

After boiling and HHP treatments, all samples showed low mesophilics counts $(<3 \log \mathrm{CFU}$ $\mathrm{g}^{-1}$ ) during storage, with no differences among them (Fig. I.4). This indicates that the initial boiling was effective for reducing the original natural microflora contamination. Psychrotrophic, enterobacteria and molds and yeasts counts were maintained below the detection limit $\left(<1 \log \mathrm{CFU} \mathrm{g} \mathrm{g}^{-1}\right.$ for bacterial and $<2 \log \mathrm{CFU} \mathrm{g} \mathrm{g}^{-1}$ for molds and yeasts) (data not shown). 


\section{I.4. DISCUSSION}

The rheological properties of a puree are crucial in the development of new products by the food industry. Often, these attributes determine the functional properties and moreover they are involved in several processes like quality control, treatments (mechanical behaviour), unit operations design (pumping, blending and packaging), storage / physical stability and even in the time to consumption (texture). The decrease in viscosity in the pea puree with high shear rate $\left(>50 \mathrm{~s}^{-1}\right)$ found after blending boiled samples (CTRL) could be related to the decrease in particle size. This reduction was high after HHP treatments, and mainly with the 10 min treatment. These results can be appreciated in relation to $D[3,2]$ and $D[4,3]$, where the volume-based particle size parameter $D[4,3]$ was highly influenced by large particles, whereas $D[3,2]$ was more sensitive to the fraction of small particles present as described by LópezSánchez et al. (2012). Accordingly, previous results from López-Sánchez et al. (2011), reported that the smallest particle size measured by $D[3,2]$ was obtained after thermal treatment $\left(90^{\circ} \mathrm{C} \pm 40 \mathrm{~min}\right)$ with combined application of high pressure of homogenization (60 MPa) in broccoli-based and carrot based suspensions. The decrease of viscosity was also associated with the reducing particle size in avocado puree treated by ultrasounds (Bi et al., 2015).

During storage there was an increase in particle size of pea puree, mainly for HHP treatments. After 36 days at $5{ }^{\circ} \mathrm{C}$, the higher viscosity at small shear rate $\left(1 \mathrm{~s}^{-1}\right)$ compared to a shear rate around $50 \mathrm{~s}^{-1}$ of HHP-5 samples (Fig. I.3) was associated with a significant increase of particle size parameters such as $d(0.1)$ and $D[3,2]$ compared to remaining treatments (Table I.1). It has been described that large and irregular-shaped particles contribute to high viscosity, causing a higher hindrance to the flow than finer and regular-shaped particles, as reported in apple purees by Espinosa-Muñoz et al. (2012). Larger particles can occupy a larger volume in the sample than an aggregate of small particles due to less efficient particle packing of larger particles and as the result of an increase in flow resistance (López-Sanchez, 2011). In addition, the higher $\left(\mathrm{G}^{\prime}\right)$ in relation to $\left(\mathrm{G}^{\prime \prime}\right)$ showed a dominant contribution of the elastic component respect to the viscoelasticity of pea puree samples, like a characteristic viscoelastic solid behavior. López-Sánchez et al. (2011) reported that a large yield stress, storage $\left(\mathrm{G}^{\prime}\right)$ and loss $\left(\mathrm{G}^{\prime \prime}\right)$ modulus were linked to a larger particle size in carrot puree. Furthermore, Carreau et al. (2002) described that the higher storage modulus value indicates 
either a strong particle-particle interaction or a network type structure in a stabilized form, or both. This means that the attractive forces become dominant due to the strong hydrogen bonding and hydrophobic association (Basu et al., 2011).

On the other hand, the residual PG activity during the storage could explained the decrease in particle size for CTRL samples (lower $d(0.5), d(0.9), D[3,2]$ and $D[4,3]$ ) at the end of storage and the decrease of viscosity by the degradation of the attractive forces. PG has been pointed to induce loss of structural integrity of tissue systems and also may cause a viscosity or consistency loss in pastes and purees of plant sources (Crelier et al., 2001). For pea puree, this enzyme was more thermo-resistant than PME, and could be used as an indicator of HHP efficiency. This result agrees to those reported by Arjmandi et al. (2017a) who found that PG was the more thermo-resistant enzyme in tomato puree.

The negative correlation described between PG and $d(0.5), d(0.9)$ and $D[4,3]$ could explain the effect of this enzyme reducing the particle size and then decreasing the viscosity. Furthermore, a high PG inactivation detected in HHP samples could increase the viscosity. Rovere et al. (1997) described an increased viscosity in tomato puree after HHP treatment (700-900MPa) with a factor 2-3 compared to heated material due to compacting effects or protein-tissue coagulation. However, the lower viscosity in HHP-10 respect to HHP-5 could be explained by the effect of the significantly lower $d(0.5)$ particle size found in HHP-10.

Panelists did not observe significant differences among treatments in relation to consistency. In addition, no significant differences were detected in viscosity at shear rate $50 \mathrm{~s}^{-1}$ among treatments. Related to this, Appelqvist et al. (2015) suggested that only large variation in viscosity could be detected in the mouth, viscosity being the contribution of thickness, structure and particle-particle interactions.

Moreover, after thermal treatment the decrease in color as loss of greenness, mainly represented by a decrease in $\mathrm{a}^{*}$, might be caused by the degradation of chlorophyll, which is the main pigment responsible for the green color in peas. Visible color changes in food caused by thermal treatment was previously reported by Icier et al. (2006), who found a reduction in $\mathrm{a}^{*}$ values from -12.12 to -18.99 in a pea puree after water blanching $\left(100^{\circ} \mathrm{C}, 5 \mathrm{~min}\right)$. Regarding $\Delta E$ values, which represent the perceptible color change by consumers, an important $\Delta E$ (around 11) was found after treatments, the color being more affected by boiled 
treatment than by HHP. Medina-Meza et al. (2015) reported a $\Delta \mathrm{E}$ around 12-13 in an oilbased spinach sauce with thermal treatment $\left(70^{\circ} \mathrm{C}, 10 \mathrm{~min}\right)$ and $\mathrm{HHP}(400 \mathrm{MPa}, 5 \mathrm{~min})$ without significant differences between treatments. However, during the storage slight changes of $\Delta E$ were found.

The $\mathrm{pH}$ was stable during the storage, in agreement with the low counts detected for all analyzed microorganisms, since high microbiological counts might alter the $\mathrm{pH}$ of a product. In fact the microbial load does not reduce the shelf life of pea purees, due to the efficacy of thermal treatment among other factors like good manufacture practices and storage conditions. Vacuum packaging of samples could also contribute to maintaining the initial low counts of microorganisms during storage and, additionally, those microorganisms that were damaged after the thermal treatment could not be recovered during the storage. García-Parra et al. (2014) evaluated the microbial stability (mesophilic, psychrotropic and molds and yeasts) of nectarine after thermal treatment $\left(85^{\circ} \mathrm{C}, 10 \mathrm{~min}\right)$ and $\mathrm{HHP}(400 \mathrm{MPa}$ or $600 \mathrm{MPa}, 5$ $\mathrm{min}$ ) and the microbial counts were significantly reduced by 2-3 $\log \mathrm{CFU} \mathrm{g} \mathrm{g}^{-1}$. In some cases, the HHP treatments could not inactivate microorganisms completely. Relating to this, JacoboVelásquez et al. (2010) described that the residual aerobic microorganisms were able to reinstate their functionality after around 40 days of storage, generating a sudden increase on their population between day 40 and 45 in avocado pulps treated under HHP (600MPa, 3 $\min )$.

\section{I.5. CONCLUSIONS}

HHP treatments increased the viscosity of pea puree at low shear rate, which can be perceived by consumers, but decrease the viscosity at high shear rate helping to industrial processing to be the puree more fluid. Furthermore, HHP treatments improved the rheological properties in pea-based puree, in which the consistency properties are very important for consumer acceptance, without changes in sensorial properties such as color or taste. Further studies are required to determine the effect of this new technology on nutritional and antinutritional compounds in this kind of legume puree. 


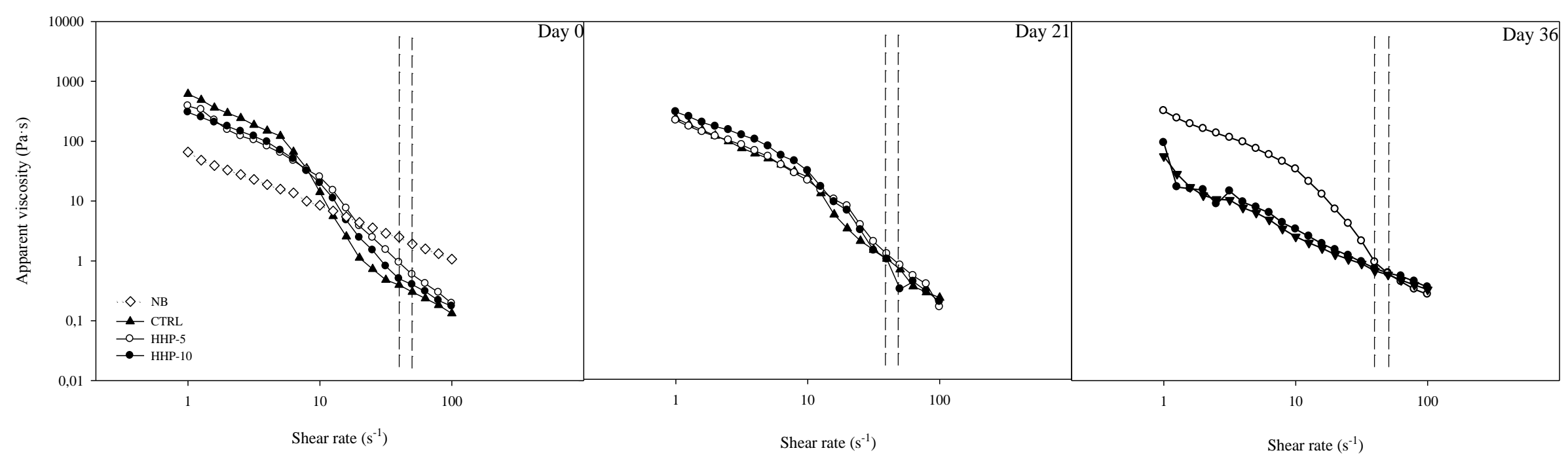

Figure I.1. Apparent viscosity (Pa s) at a shear rate of $1-100 \mathrm{~s}^{-1}$ of pea puree samples after NB, CTRL and HHP treatments during storage at $5{ }^{\circ} \mathrm{C}$. Apparent viscosity (Pa s) versus shear rate $\left(\mathrm{s}^{-1}\right)$ for different pea puree samples (NB, non-boiled samples; CTRL, boiled-thermal treatment; HHP-5, boiled-thermal treatment plus $550 \mathrm{MPa} 5 \mathrm{~min}$; HHP-10, boiled-thermal treatment plus $550 \mathrm{MPa} 10 \mathrm{~min}$ ) during storage at $5{ }^{\circ} \mathrm{C}$. The effective shear rate range in the mouth $\left(40-50 \mathrm{~s}^{-1}\right)$ is represented by vertical lines. 


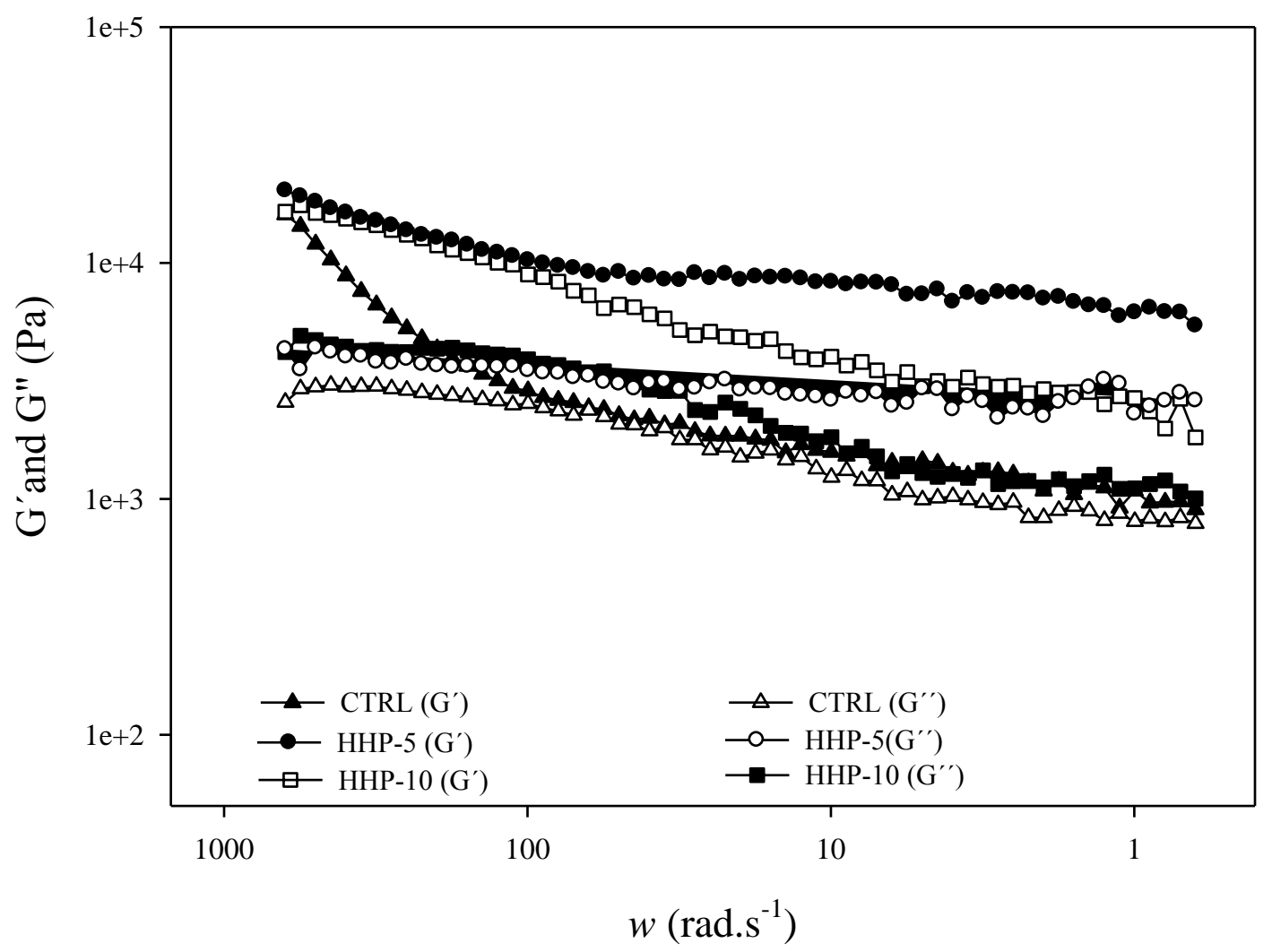

Figure I.2. Storage modulus $\left(\mathrm{G}^{\prime}\right)$ and loss modulus $\left(\mathrm{G}^{\prime \prime}\right)$ as a function of frequency $(w)$ of pea puree samples after boiled-thermal treatment (CTRL), boiled-thermal treatment plus $550 \mathrm{MPa} 5 \mathrm{~min}$ (HHP5) and boiled-thermal treatment plus $550 \mathrm{MPa} 10 \mathrm{~min}$ (HHP-10) at 36 days of storage at $5{ }^{\circ} \mathrm{C}$. 


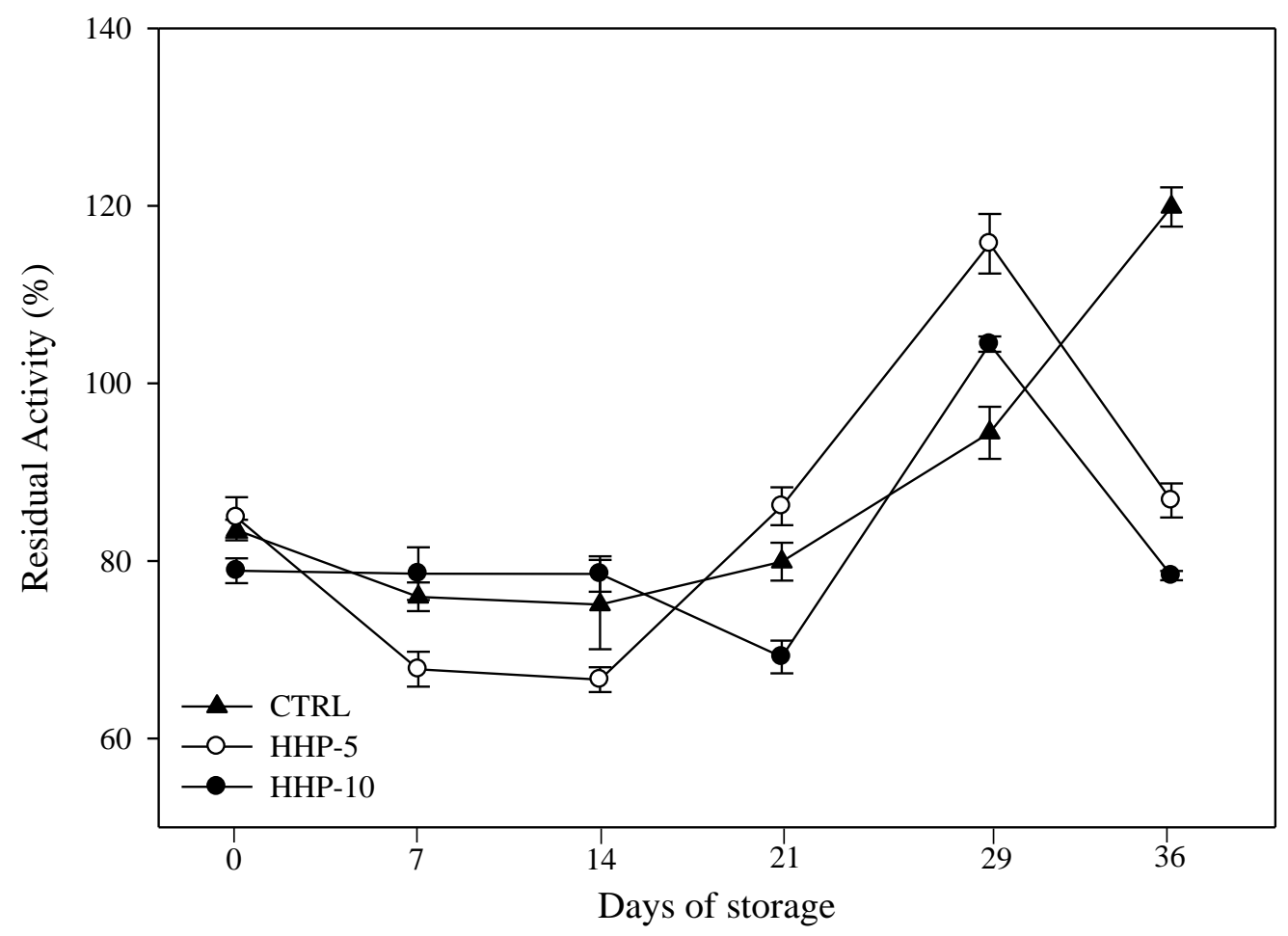

Figure I.3. Residual activity (\%) of polygalacturonase in pea puree samples after boiled-thermal treatment (CTRL), boiled-thermal treatment plus $550 \mathrm{MPa} 5 \mathrm{~min}$ (HHP-5) and boiled-thermal treatment plus $550 \mathrm{MPa} 10 \mathrm{~min}$ (HHP-10) during storage at $5{ }^{\circ} \mathrm{C}$. 


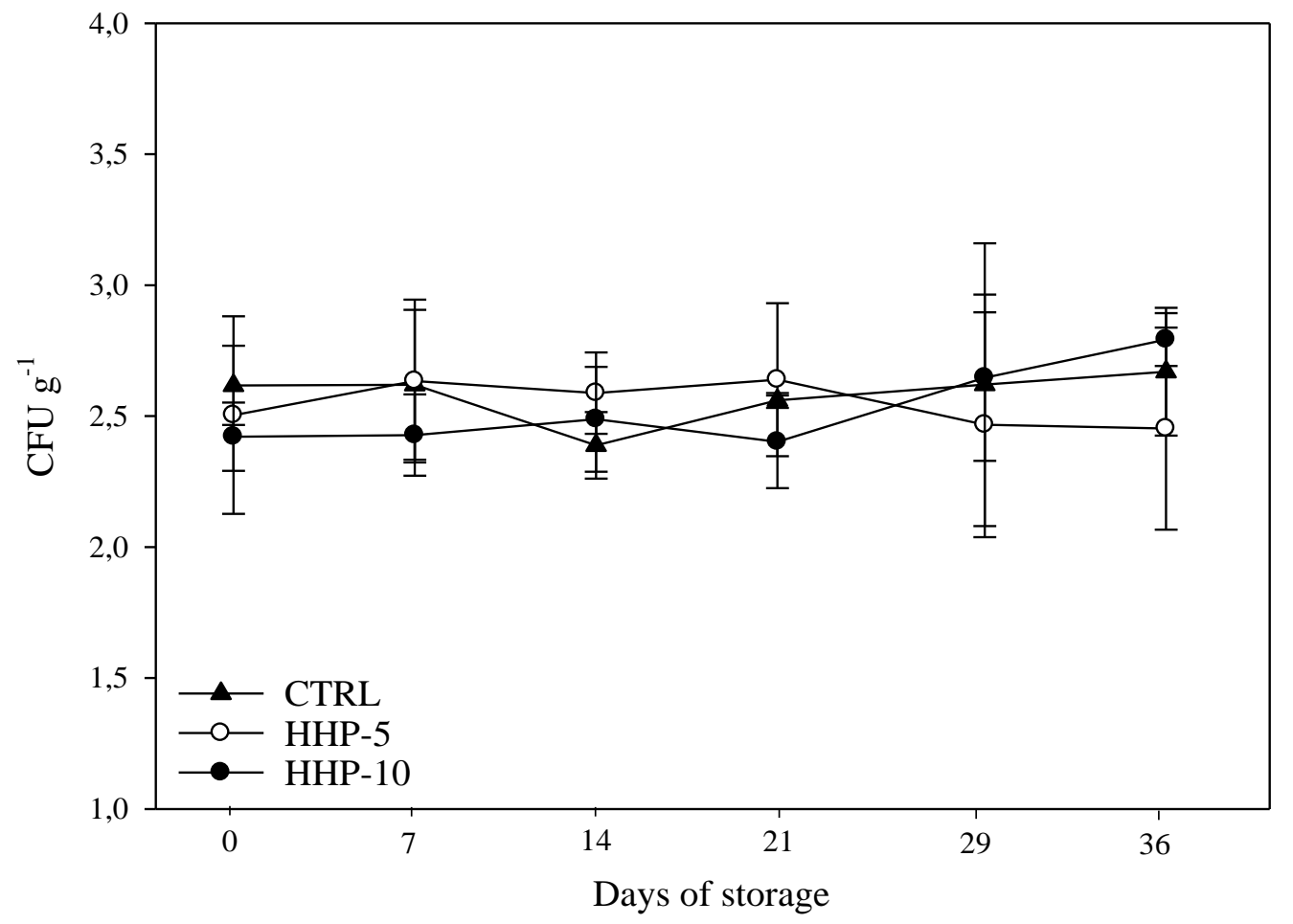

Figure I.4. Evaluation of mesophiles in pea puree samples after boiled-thermal treatment (CTRL), boiled-thermal treatment plus $550 \mathrm{Mpa} 5 \mathrm{~min}$ (HHP-5) and boiled-thermal treatment plus $550 \mathrm{Mpa} 10$ $\min$ (HHP-10) during storage at $5{ }^{\circ} \mathrm{C}$. 
Table I.1. Particle size parameters in pea puree samples on processing day (0) and after 21 and 36 days at $5{ }^{\circ} \mathrm{C}$.

\begin{tabular}{|c|c|c|c|c|c|c|}
\hline Day & Treatment & $D[3,2](\mu \mathrm{m})$ & $D[4,3](\mu \mathrm{m})$ & $d(0.1)(\mu \mathrm{m})$ & $d(0.5)(\mu \mathrm{m})$ & $d(0.9)(\mu \mathrm{m})$ \\
\hline \multirow[t]{4}{*}{0} & $\mathrm{NB}$ & $44.7 \pm 3.1^{\mathrm{a}}$ & $447.3 \pm 42.0^{\mathrm{a}}$ & $18.4 \pm 2.5^{\mathrm{c}}$ & $240.9 \pm 49.6^{\mathrm{ns}}$ & $1172.8 \pm 63.9^{\mathrm{a}}$ \\
\hline & CTRL & $41.5 \pm 1.4^{\mathrm{Bab}}$ & $333.2 \pm 10.7^{\mathrm{Ab}}$ & $24.9 \pm 2.2^{\mathrm{Aa}}$ & $225.0 \pm 19.2^{\mathrm{Ans}}$ & $789.3 \pm 14.5^{\mathrm{Ab}}$ \\
\hline & HHP-5 & $38.7 \pm 0.7^{\mathrm{Cb}}$ & $316.5 \pm 32.7^{\mathrm{Bb}}$ & $21.2 \pm 1.1^{\mathrm{Bab}}$ & $211.0 \pm 30.7^{\mathrm{NSns}}$ & $755.6 \pm 70.9^{\mathrm{Bb}}$ \\
\hline & HHP-10 & $32.9 \pm 2.9^{\mathrm{Cc}}$ & $302.6 \pm 22.6^{\mathrm{Bb}}$ & $20.3 \pm 3.9^{\mathrm{Bb}}$ & $191.1 \pm 16.6^{\mathrm{Ans}}$ & $738.8 \pm 48.7^{\mathrm{Bb}}$ \\
\hline \multirow[t]{3}{*}{21} & CTRL & $42.3 \pm 2.8^{\mathrm{ABns}}$ & $300.6 \pm 8.5^{\mathrm{Ba}}$ & $20.7 \pm 2.1^{\mathrm{Bb}}$ & $168.1 \pm 11.8^{\mathrm{Ba}}$ & $764.7 \pm 20.6^{\mathrm{Aa}}$ \\
\hline & HHP-5 & $45.8 \pm 3.7^{\mathrm{Bns}}$ & $299.7 \pm 12.9^{\mathrm{Ba}}$ & $24.5 \pm 4.1^{\mathrm{Ba}}$ & $171.2 \pm 16.8^{\mathrm{NSa}}$ & $763.4 \pm 20.5^{\mathrm{Ba}}$ \\
\hline & HHP-10 & $43.9 \pm 1.9^{\mathrm{Bns}}$ & $246.9 \pm 9.9^{\mathrm{Cb}}$ & $26.2 \pm 2.1^{\mathrm{ABa}}$ & $132.3 \pm 2.2^{\mathrm{Bb}}$ & $662.4 \pm 32.8^{\mathrm{Cb}}$ \\
\hline \multirow[t]{3}{*}{36} & CTRL & $45.7 \pm 2.3^{\mathrm{Ac}}$ & $225.1 \pm 10.7^{\mathrm{Ac}}$ & $27.7 \pm 3.2^{\mathrm{Ab}}$ & $129.0 \pm 1.4^{\mathrm{Cb}}$ & $585.4 \pm 44.4^{\mathrm{Bb}}$ \\
\hline & HHP-5 & $57.0 \pm 4.3^{\mathrm{Aa}}$ & $371.8 \pm 11.7^{\mathrm{Ab}}$ & $38.8 \pm 5.4^{\mathrm{Aa}}$ & $212.8 \pm 62.1^{\mathrm{NSa}}$ & $1191.9 \pm 216.9^{\mathrm{Aa}}$ \\
\hline & HHP-10 & $49.9 \pm 2.1^{\mathrm{Ab}}$ & $439.8 \pm 29.7^{\mathrm{Aa}}$ & $30.4 \pm 6.8^{\mathrm{Ab}}$ & $188.1 \pm 19.1^{\mathrm{Aa}}$ & $1234.6 \pm 60.1^{\mathrm{Aa}}$ \\
\hline \multicolumn{2}{|l|}{ Days } & $* * *$ & $* * *$ & $* * *$ & $* * *$ & $* * *$ \\
\hline \multicolumn{2}{|c|}{ Treatment } & $* * *$ & $* * *$ & $* *$ & $* *$ & $* * *$ \\
\hline \multicolumn{2}{|c|}{ Days $\mathrm{x}$ Treatment } & $* * *$ & **** & $* * *$ & $* * *$ & $* * *$ \\
\hline
\end{tabular}

Values correspond to average value $(n=3) \pm$ SE. Different lower case letters within the same column show significant differences between treatments. Different capital letters within the same column show significant differences between storage times. Control samples were only evaluated to test significant differences between pea puree treatments on processing day. NS, not significant; $* * * P \leq 0.001 ; * * P \leq 0.01$. 
Table I.2. Sensory quality (flavor, color, taste, consistency and overall quality) of pea puree samples after boiled-thermal treatment (CTRL), boiled-thermal treatment plus $550 \mathrm{Mpa} 5 \mathrm{~min}$ (HHP-5) and boiled-thermal treatment plus $550 \mathrm{Mpa} 10 \mathrm{~min}$ (HHP-10) during storage at $5{ }^{\circ} \mathrm{C}$.

\begin{tabular}{|c|c|c|c|c|c|c|}
\hline Day & Treatment & Flavour & Colour & Taste & Consistency & Overall Quality \\
\hline \multirow[t]{3}{*}{0} & CTRL & $4.90 \pm 0.00^{\mathrm{Ans}}$ & $4.83 \pm 0.29^{\mathrm{Ans}}$ & $4.80 \pm 0.10^{\mathrm{Ans}}$ & $4.67 \pm 0.29^{\mathrm{Ans}}$ & $8.73 \pm 0.21^{\text {Ans }}$ \\
\hline & HHP-5 & $4.83 \pm 0.15^{\text {Ans }}$ & $4.83 \pm 0.29^{\mathrm{Ans}}$ & $4.93 \pm 0.11^{\mathrm{Ans}}$ & $4.77 \pm 0.25^{\mathrm{Ans}}$ & $8.83 \pm 0.29^{\mathrm{Ans}}$ \\
\hline & HHP-10 & $4.95 \pm 0.07^{\text {Ans }}$ & $4.83 \pm 0.29^{\mathrm{Ans}}$ & $4.70 \pm 0.20^{\text {Ans }}$ & $4.83 \pm 0.29^{\mathrm{Ans}}$ & $8.57 \pm 0.49^{\mathrm{Ans}}$ \\
\hline \multirow[t]{3}{*}{7} & CTRL & $4.73 \pm 0.37^{\mathrm{ABns}}$ & $4.71 \pm 0.47^{\text {Ans }}$ & $4.57 \pm 0.36^{\mathrm{ABns}}$ & $4.53 \pm 0.46^{\mathrm{ABns}}$ & $8.25 \pm 0.65^{\mathrm{ABns}}$ \\
\hline & HHP-5 & $4.60 \pm 0.43^{\mathrm{ABns}}$ & $4.74 \pm 0.47^{\text {Ans }}$ & $4.61 \pm 0.42^{\mathrm{ABns}}$ & $4.73 \pm 0.42^{\mathrm{ABns}}$ & $8.56 \pm 0.43^{\mathrm{ABns}}$ \\
\hline & HHP-10 & $4.50 \pm 0.43^{\mathrm{ABns}}$ & $4.77 \pm 0.39^{\mathrm{Ans}}$ & $4.52 \pm 0.41^{\mathrm{ABns}}$ & $4.85 \pm 0.31^{\mathrm{ABns}}$ & $8.45 \pm 0.43^{\mathrm{ABns}}$ \\
\hline \multirow[t]{3}{*}{14} & CTRL & $4.25 \pm 0.51^{\mathrm{Bns}}$ & $4.27 \pm 0.47^{\text {Bns }}$ & $4.32 \pm 0.33^{\mathrm{BCns}}$ & $4.25 \pm 0.46^{\mathrm{BCns}}$ & $8.03 \pm 0.53^{\mathrm{Bns}}$ \\
\hline & HHP-5 & $4.21 \pm 0.47^{\mathrm{Bns}}$ & $4.17 \pm 0.25^{\text {Bns }}$ & $4.34 \pm 0.62^{\mathrm{BCns}}$ & $4.31 \pm 0.60^{\mathrm{BCns}}$ & $8.21 \pm 0.65^{\mathrm{Bns}}$ \\
\hline & HHP-10 & $4.22 \pm 0.32^{\mathrm{Bns}}$ & $4.43 \pm 0.35^{\mathrm{Bns}}$ & $4.09 \pm 0.44^{\mathrm{BCns}}$ & $4.42 \pm 0.44^{\mathrm{BCns}}$ & $8.17 \pm 0.26^{\mathrm{Bns}}$ \\
\hline \multirow[t]{3}{*}{21} & CTRL & $3.71 \pm 0.49^{\mathrm{Cns}}$ & $4.08 \pm 0.82^{\text {Bns }}$ & $3.75 \pm 0.42^{\mathrm{CDns}}$ & $3.78 \pm 0.57^{\mathrm{CDns}}$ & $7.40 \pm 0.42^{\mathrm{Cns}}$ \\
\hline & HHP-5 & $4.00 \pm 0.29^{\mathrm{Cns}}$ & $4.03 \pm 0.81^{\text {Bns }}$ & $3.96 \pm 0.33^{\mathrm{CDns}}$ & $4.07 \pm 0.19^{\mathrm{CDns}}$ & $7.61 \pm 0.56^{\mathrm{Cns}}$ \\
\hline & HHP-10 & $3.98 \pm 0.49^{\mathrm{Cns}}$ & $4.16 \pm 0.61^{\mathrm{Bns}}$ & $3.92 \pm 0.44^{\mathrm{CDns}}$ & $4.07 \pm 0.19^{\mathrm{CDns}}$ & $7.49 \pm 0.49^{\mathrm{Cns}}$ \\
\hline \multirow[t]{3}{*}{29} & CTRL & $3.85 \pm 0.35^{\mathrm{Cns}}$ & $3.98 \pm 0.54^{\text {Bns }}$ & $3.50 \pm 0.50^{\mathrm{Dns}}$ & $3.87 \pm 0.52^{\mathrm{CDns}}$ & $7.37 \pm 0.79^{\mathrm{Cns}}$ \\
\hline & HHP-5 & $3.98 \pm 0.39^{\mathrm{Cns}}$ & $4.05 \pm 0.52^{\mathrm{Bns}}$ & $3.90 \pm 0.49^{\text {Dns }}$ & $4.04 \pm 0.27^{\mathrm{CDns}}$ & $7.51 \pm 0.91^{\mathrm{Cns}}$ \\
\hline & HHP-10 & $4.13 \pm 0.63^{\mathrm{Cns}}$ & $4.20 \pm 0.60^{\mathrm{Bns}}$ & $4.00 \pm 0.70^{\mathrm{Dns}}$ & $4.35 \pm 0.62^{\mathrm{CDns}}$ & $7.57 \pm 0.72^{\mathrm{Cns}}$ \\
\hline \multirow[t]{3}{*}{36} & CTRL & $3.16 \pm 0.29^{\mathrm{Dns}}$ & $3.73 \pm 0.25^{\mathrm{Bns}}$ & $3.50 \pm 0.41^{\text {Dns }}$ & $3.80 \pm 0.27^{\text {Dns }}$ & $6.50 \pm 0.50^{\text {Dns }}$ \\
\hline & HHP-5 & $3.36 \pm 0.50^{\mathrm{Dns}}$ & $3.88 \pm 0.20^{\mathrm{Bns}}$ & $3.75 \pm 0.29^{\mathrm{Dns}}$ & $3.90 \pm 0.55^{\text {Dns }}$ & $7.00 \pm 0.00^{\mathrm{Dns}}$ \\
\hline & HHP-10 & $3.50 \pm 0.55^{\text {Dns }}$ & $3.87 \pm 0.20^{\mathrm{Bns}}$ & $3.83 \pm 0.26^{\mathrm{Dns}}$ & $3.83 \pm 0.41^{\mathrm{Dns}}$ & $6.92 \pm 0.30^{\mathrm{Dns}}$ \\
\hline \multicolumn{2}{|l|}{ Days } & **** & **** & **** & **** & *** \\
\hline \multicolumn{2}{|c|}{ Treatments } & NS & NS & NS & NS & NS \\
\hline \multicolumn{2}{|c|}{ Days *Treatment } & NS & NS & NS & NS & NS \\
\hline
\end{tabular}

Values correspond to average value $(\mathrm{n}=3) \pm \mathrm{SE}$. Different lower case letters within the same column show significant differences between treatments. Different capital letters within the same column show significant differences between storage times. Control samples were only evaluated to test significant differences between pea puree treatments on processing day. NS, not significant; *** $P \leq 0.001 ; * * P \leq 0.01$. 
Table I.3. Effect of control treatment and HHP treatments in $\mathrm{pH}$, color $\left(\mathrm{L}^{*} \mathrm{a}^{*} \mathrm{~b}^{*},{ }^{\circ} h\right.$ value and total color differences $(\Delta E))$ in pea purees on processing day.

\begin{tabular}{lllllll}
\hline Treatment & $\mathbf{p H}$ & $\mathbf{L}^{*}$ & $\mathbf{a}^{*}$ & $\mathbf{b}^{*}$ & ${ }^{\circ} \boldsymbol{h}$ value & \multicolumn{1}{c}{$\boldsymbol{E}$} \\
\hline NB & $5.6 \pm 0.3$ & $51.9 \pm 0.0^{\mathrm{a}}$ & $-23.3 \pm 0.0^{\mathrm{a}}$ & $36.7 \pm 0.0$ & $122.3 \pm 0.6 \mathrm{a}$ & \\
CTRL & $5.2 \pm 0.2$ & $57.3 \pm 0.4^{\mathrm{b}}$ & $-13.6 \pm 1.2^{\mathrm{b}}$ & $34.6 \pm 0.6$ & $111.5 \pm 1.9 \mathrm{~b}$ & $11.3 \pm 0.8$ \\
HHP-5 & $5.4 \pm 0.1$ & $57.4 \pm 0.6^{\mathrm{b}}$ & $-13.1 \pm 0.7^{\mathrm{b}}$ & $34.3 \pm 0.7$ & $110.9 \pm 1.3 \mathrm{~b}$ & $11.8 \pm 0.6$ \\
HHP-10 & $5.3 \pm 0.0$ & $57.5 \pm 0.4^{\mathrm{b}}$ & $-13.1 \pm 0.5^{\mathrm{b}}$ & $35.7 \pm 1.7$ & $110.3 \pm 0.5 \mathrm{~b}$ & $11.7 \pm 0.3$ \\
& & & & & & \\
Treatments & NS & $* * *$ & $* * *$ & NS & $* * *$ & NS \\
& & & & & & \\
\hline
\end{tabular}

Different lower case letters denote significant differences $(* * *(P \leq 0.001))$ among treatments $(\mathrm{n}=3 \pm \mathrm{SD})$. NS, not significant 


\section{CHAPTER II}

\section{Microwave and high hydrostatic pressure processing improved quality of a fresh pea seeds puree during shelf life}

Tâmmila Venzke Klug ${ }^{1}$, Ascensión Martínez-Sánchez ${ }^{1,2}$, Elena Collado², Perla A Gómez², Encarna Aguayo ${ }^{1,2}$, Francisco Artés ${ }^{1,2}$ and Francisco Artés-Hernández $z^{1,2}$

1 Postharvest and Refrigeration Group. Department of Food Engineering. Universidad Politécnica de Cartagena. Paseo Alfonso XIII, 48, 30203 Cartagena, Murcia, Spain.

${ }^{2}$ Institute of Plant Biotechnology. Universidad Politécnica de Cartagena. Campus Muralla del Mar, 30202 Cartagena, Murcia, Spain.

Submitted to a peer reviewed Journal included in the JCR of the ISI 


\section{II.1. INTRODUCTION}

Consumers are really interested in benefits from healthy diets like the 'Mediterranean Diet', which is mainly based of fruit and vegetables, grains, extra-virgin olive oil, and legumes, consuming moderate amounts of meat. However, the current lifestyle usually does not allow the time needed for the preparation of such meals. Thus, their consumption should be promoted through the development of convenient products processed under non-aggressive minimal treatments to preserve original quality as much as possible (Castillejo et al., 2016). Therefore, a legume-based 'ready to eat' product could positively influence the low legume consumption in the Europe, which is $2.56 \mathrm{~kg}$ per capita and year (FAOSTAT, 2013) while the world average is $7.21 \mathrm{~kg}$. Legumes are very important in the human diet due to their high nutritional value (high protein and fiber content, with low fat content) and high essential nutrients and bioactive compounds content (phenolic compounds, tocopherols, carotenes, fibers, etc.) which have beneficial effects in health (Boye et al., 2010; Aguilera et al., 2011; Wang et al., 2011; Alshikh et al., 2015). Therefore, food legumes have traditionally been an important part of human diet and we expect that in the future, they will be even more important due to their benefits.

The antioxidant activity of the seed legumes has been primarily associated with its phenolics content (Wang et al., 2011; Alshikh et al., 2015), which are in higher content in raw seeds. Peas are legumes with excellent nutritional and bioactive properties, mainly derived from polyphenols, phytosterols, non-digestible carbohydrates (Singh et al., 2017b), protein, vitamins and minerals (Dahl et al., 2012).

The main issue of processing 'ready-to-eat' products is their limited shelf-life, since they are susceptible to spoilage and quality degradation. Furthermore, unappropriated treatments during processing of legume-based products may alter the profile and bioavailability of some nutrients (Xu and Chang, 2008; Kim et al., 2015). In this sense, HHP is a useful non-thermal processing technique which may be considered as a suitable technique for this kind of products and new ones (Kirse et al., 2017). Food treated by HHP has been shown to preserve its original bioactive/nutritional compounds and to produce minimum sensory changes in terms of freshness, flavour, taste and colour (Andrés et al., 2016; Wang et al., 2013). Furthermore, HHP technology can improve texture and preserve it throughout refrigerated 
storage (Klug et al., 2017). In addition, some results have shown that HHP in combination with temperature, results in greater release of bioactive compounds causing higher measured levels when compared with untreated samples, probably due to the cellular disruption (García-Parra et al., 2016).

On the other hand, microwave (MW) pasteurization is a thermal technology considered as an alternative to conventional techniques which can preserve nutrients and the fresh taste of vegetables-based products, due to a combination of high power and short time (Arjmandi et al., 2017a). Castillejo et al. (2018) have recently reported that MW treatment can be used by the food industry with the specific modelling of a heating profile to obtain excellent homogeneous heating of brocoli-based beverages obtaining high levels of bioactive compounds during subsequent storage up to one month at $5{ }^{\circ} \mathrm{C}$. Picouet et al. (2009) reported that MW treatment at $652 \mathrm{~W}$ for $35 \mathrm{~s}$ followed by 15 days of storage at $5{ }^{\circ} \mathrm{C}$ resulted in $50 \%$ average loss of vitamin $\mathrm{C}$ in apple puree although the viscosity and titratable acidity were unaffected. According to this, Benlloch-Tinoco et al. (2015) showed a superior preservation of colour and bioactive compounds (57-67\%) when MW (1000 W, 340 s) heating was the technology selected to process the kiwifruit puree.

The aim of the present study was to develop an innovative puree made of fresh pea seeds and evaluate the effect of alternative MW and HHP (with and without temperature) processing treatments on the microbial and sensory quality, rheological properties and bioactive compounds contents, just after treatment and during 24 days at $5{ }^{\circ} \mathrm{C}$ in darkness conditions.

\section{II.2. MATERIALS AND METHODS}

\section{II.2.1. Puree preparation from fresh peas}

A pea puree $(94.4 \%$ fresh peas, $2.36 \%$ olive oil, $2.83 \%$ lemon juice, $0.21 \%$ salt, $0.16 \%$ dried onion, $0.04 \%$ pepper), was optimized based on sensory quality evaluations of a previously discriminative trained panel $(n=11)$ from the UPCT. All ingredients were purchased at a local supermarket from Cartagena (Murcia, Spain). The nutritional composition of the pea puree was determined with the software DIAL 1.0 (Ortega-Anta et al., 2008). 


\section{II.2.2. Treatments and Storage Conditions}

All ingredients were blended in a Robot Cook ${ }^{\circledR}$ (Robot Coupe, Montceau-en-Bourgogne, France) for $30 \mathrm{~s}$ at $1450 \mathrm{x}$. The obtained puree was packaged (50 g) under aseptic conditions in a sterile polyethylene bags embossed under aseptic conditions being kept cold $\left(5^{\circ} \mathrm{C}\right)$ in crushed ice until subsequent treatments. Pea puree samples were processed by:

HHP: high pressure processing treatment at room temperature. HHP was conducted placing puree samples ( 4 bags per each treatment run) in the sampling vessel of a high hydrostatic pressure equipment (HP Pilot Food Processor, Stansted Fluid Power Ltd., Essex, U.K.) at $550 \mathrm{MPa}$ for $10 \mathrm{~min}$ at $23{ }^{\circ} \mathrm{C}$. The selection of pressure and processing time and the equipment description is based in our previous findings and preliminary experiments (Klug et al., 2017).

HPTP: high pressure assisted thermal processing. HPTP was conducted in the same conditions of HHP, but at $60^{\circ} \mathrm{C}$ instead of $23^{\circ} \mathrm{C}$.

MW: semi-continuous microwave treatment. It consisted of an innovative semiindustrial prototype of a continuous microwave oven (SI-MAQ0101, Sairem Ibérica SL, Barcelona, Spain) which was previously described by Klug et al. (2018) with some modifications. MW treatment consisted of a semi-continuous mode with back-and-forth movement of $2 \mathrm{~m} \mathrm{~min}^{-1}$ belt speed at $9 \mathrm{~kW}(3+2+2+2 \mathrm{~kW})$ for $40 \mathrm{~s}$. MW treatment was previously optimized in order to achieve a fast heating of $85^{\circ} \mathrm{C}$, checked with a portable fiber optic thermometer (Neoptix NOMAD Fiber NMD, Neoptix, Quebec, Canada). Four puree packages were always treated at the same time in every treatment batch, reaching a temperature of $85 \pm 5^{\circ} \mathrm{C}$ according to Castillejo et al. (2018).

CTRL: blended but non-heated fresh samples were used as control.

Three packages (replicates) were prepared for each treatment and sampling time. HHP, HPTP and MW samples were immediately cooled down to $5{ }^{\circ} \mathrm{C}$. Packages from each sample batch (CTRL, MW, HHP and HPTP) were stored at $5{ }^{\circ} \mathrm{C}$ in darkness and evaluated on processing (day 0 ) and after 7, 12, 17 and 24 days. 


\section{II.2.3. Physicochemical Analyses}

Fresh samples were used to determine the $\mathrm{pH}$ by a pH-meter (Crison $2001 \mathrm{pH}$ meter, Crison Instruments SA, Barcelona, Spain). Colour was determined using a colourimeter (Minolta CR-300 Series, Japan) and the results were expressed as CIE L*a*b* colour space units. Total colour differences $(\Delta \mathrm{E})$ throughout storage were compared to their respective initial values according to equations previously described by (Walkling-Ribeiro et al., 2010). $\Delta \mathrm{E}$ were expressed as

$$
\Delta \mathrm{E}=1 / 2\left(\left[\left(\mathrm{~L}_{0}-\mathrm{L}^{*}\right)^{2}+\left(\mathrm{a}_{0}-\mathrm{a}^{*}\right)^{2}+\left(\mathrm{b}_{0}-\mathrm{b}^{*}\right)^{2}\right]\right)
$$

\section{II.2.4. Total Phenolic Contents}

Frozen pea puree samples (1.5 g) were placed in glass bottles and homogenized (Ultra-turrax T-25, Ika-Labortechnik, Staufen, Germany) with methanol (3 $\mathrm{mL})$ for $1 \mathrm{~min}$. The extracts were centrifuged at $15,000 \times g$ for $10 \mathrm{~min}$ at $4{ }^{\circ} \mathrm{C}$. The supernatant was used to determine the total phenolic content (TPC) by the Singleton et al. (1999) method, but with some modifications (Martínez-Hernández et al., 2011). Supernatant samples (19 $\mu \mathrm{L})$ and $29 \mu \mathrm{L}$ of 1 $\mathrm{N}$ Folin-Ciocalteu reagent were mix in a well plate and incubated for $3 \mathrm{~min}$ at room temperature in darkness conditions. Then, $192 \mu \mathrm{L}$ of a solution containing $\mathrm{Na}_{2} \mathrm{CO}_{3}(0.4 \%)$ and $\mathrm{NaOH}(2 \%)$ was added. After 45 min of incubation at room temperature in darkness conditions, the absorbance was measured at $750 \mathrm{~nm}$ and TPC was expressed as mg gallic acid equivalents (GAE) $\mathrm{kg}^{-1} \mathrm{fw}$.

\section{II.2.5. Individual Phenolic compounds}

Frozen samples (2.5 g) of pea puree were homogenized (Ultra-turrax T-25, Ika-Labortechnik, Staufen, Germany) for $1 \mathrm{~min}$ with $10 \mathrm{~mL}$ of a mixture of $\mathrm{MeOH} /$ water (80:20, v:v), containing 4mM NaF (Llorach et al., 2008). The extracts were centrifuged $(15,000 \times g, 10$ min, $4{ }^{\circ} \mathrm{C}$ ), and the supernatants were analyzed in an Ultra High-Performance liquid chromatography (UPLC) instrument (Shimadzu, Kyoto, Japan) equipped with aDGU-20A degasser, LC-30AD quaternary pump, SIL-30 AC autosampler,CTO-10AS column heater and SPDM-20A photodiode array detector was used. Chromatographic analyses were carried with a C18 column (Gemini NX $250 \mathrm{~mm} \times 4.6 \mathrm{~mm}, 5 \mu \mathrm{m}$; Phenomenex, Torrance CA, USA). The 
mobile phase was a mixture of (A) water with $5 \%$ formic acid and (B) methanol. The flow rate was $1 \mathrm{~mL}$ min-1 in a linear gradient starting with $10 \% \mathrm{~B}$ at $0 \mathrm{~min}$, reaching $20 \%$ at $0-25$ $\min , 50 \% \mathrm{~B}$ at $40 \mathrm{~min}$, kept $50 \%$ B for $5 \mathrm{~min}$, reaching $90 \% \mathrm{~B}$ at $45-47 \mathrm{~min}$, kept $90 \%$ B for 3 min and 10\% B for $10 \mathrm{~min}$. The chromatograms were recorded at 280 and $320 \mathrm{~nm}$ and the identification of phenolic compounds was carried out according to their UV spectra and retention times as compared with standards. Phenolic acids were quantified as equivalents of ferulic acid (Sigma, St Louis, MO, USA), p coumaric acid (Sigma, St Louis, MO, USA) and + catechin hydrate (Sigma, St Louis, MO, USA). Phenolics acids derivates were quantified as equivalents of p-coumaric acid and data are expressed as mg per $\mathrm{kg}$ of fresh weight.

\section{II.2.6. Vitamin C}

Total vitamin C, as ascorbic acid (AA) and dehydroascorbic acid (DHA), was measured according to the method of Zapata and Dufour (1992), with slight modifications. Frozen samples of $5 \mathrm{~g}$ of pea puree were homogenized (Ultra-turrax T-25, Ika-Labortechnik, Staufen, Germany) for $1 \mathrm{~min}$ in $5 \mathrm{~mL}$ of extraction medium prepared as previously described (Collado et al., 2017). The extracts were centrifuged at $15,000 \times g$ for $10 \mathrm{~min}$ at $4{ }^{\circ} \mathrm{C}$. Derivaticed samples $(20 \mu \mathrm{L})$ were injected onto a Gemini NX $(250 \mathrm{~mm} \times 4.6 \mathrm{~mm}, 5 \mu \mathrm{m}) \mathrm{C} 18$ column (Phenomenex, Torrance CA, USA), using an HPLC (Series 1100 Agilent Technologies, Waldbronn, Germany) equipped with a G1322A degasser, G1311A quaternary pump, G1313A autosampler, G1316A column heater and G1315B photodiode array detector. The HPLC system was controlled by the software Chem Station Agilent, v.08.03. AA and DHA were quantified using commercial standards (Sigma, St Louis, MO, USA). Total vitamin C, calculated as the sum of AA and DHA, was expressed as $\mathrm{mg} \mathrm{g}^{-1}$ fw. All samples were tested in triplicate.

\section{II.2.7. Total Antioxidant Capacity}

The same sample extracts to determine TPC were used to evaluate the antioxidant capacity (TEAC) by 2,2-diphenyl-1-picrylhydrazil (DPPH) (Brand-Williams et al., 1995) and ferric reducing antioxidant power (FRAP) (Benzie and Strain., 1999) assays. 
DPPH assay: the free radical scavenging activity using the free radical DPPH was evaluated by measuring the decrease in absorbance at $515 \mathrm{~nm}$ for $45 \mathrm{~min}$. A volume $(194 \mu \mathrm{L})$ of DPPH solution $(0.7 \mathrm{mM})$ was added to each extract sample $(21 \mu \mathrm{L})$.

FRAP assay: the freshly made up FRAP solution containing sodium acetate buffer (pH 3.6), $10 \mathrm{mM}$ TPTZ solution (in $40 \mathrm{mM} \mathrm{HCl}$ ) and $20 \mathrm{mM} \mathrm{FeCl} 3$ was prepared in a v/v/v proportion of 10:1:1. A volume $(198 \mu \mathrm{L})$ of FRAP solution was react to each extract sample $(6 \mu \mathrm{L})$ for $50 \mathrm{~min}$ at room temperature in darkness and increase of absorbance was determined at 593 $\mathrm{nm}$. The antioxidant activity for DPPH and FRAP assays was expressed as Trolox equivalent antioxidant capacity (TEAC) per $\mathrm{kg}^{-1} \mathrm{fw}$.

\section{II.2.8. Viscosity}

Viscous flow tests to measure the storage modulus $\left(\mathrm{G}^{\prime}\right)$ and loss modulus $\left(\mathrm{G}^{\prime \prime}\right)$ values were determined in triplicate with a controlled shear rate/stress rheometer (AR G2, TA Instruments, USA) at $20^{\circ} \mathrm{C}$ according to Klug et al. (2017). Stress sweep tests were run at $1 \mathrm{~Hz}$ with the shear stress of the input signal varying from 0.1 to $100 \mathrm{~Pa}$. Frequency sweeps were run, subjecting the samples to stress that varied harmonically with time at frequencies $(\omega)$ from 1 to $100 \mathrm{rad} \mathrm{s}^{-1}$.

\section{II.2.9. Sensory Analyses}

The sensory evaluation of the fresh pea puree was carried out by 11 members (aged 22-69 years) of a previously trained in discriminative quality attributes and the ability to communicate sensory descriptions of products according to Klug et al. (2018). The panel screened for sensory ability (colour, flavour, texture, taste, consistency, overall quality) on a 5-points structured hedonic scale (5: excellent, 4: good, 3: limit of acceptability, 2: poor, 1: extremely bad).

\section{II.2.10. Microbial Analyses}

To determine the mesophilic, Enterobacteriaceae, and yeast and mould growth in fresh pea puree, standard enumeration methods were used according to (Castillejo et al., 2016). The following media and incubation conditions were used: plate count modified agar (PCA) (Scharlau Chemie, Barcelona, Spain) for mesophilic and psychrotrophic aerobic bacteria, 
incubated at $37{ }^{\circ} \mathrm{C}$ for $48 \mathrm{~h}$ and at $5{ }^{\circ} \mathrm{C}$ for 7 days, respectively; violet red bile dextrose agar (Scharlau Chemie, Barcelona, Spain) for Enterobacteriaceae, incubated at $37{ }^{\circ} \mathrm{C}$ for $48 \mathrm{~h}$; and rose bengal agar (Scharlau Chemie, Barcelona, Spain) for yeasts and moulds, incubated for 3-5 days at $25{ }^{\circ} \mathrm{C}$. The presence of Salmonella spp., Listeria monocytogenes and generic Escherichia coli was monitored according to the European legislation (Regulation EC 1441/2007, 2007). All microbial counts were reported as log colony forming units per gram of product $\left(\log \mathrm{CFU} \mathrm{g}^{-1}\right)$. Each of the three replicates was analyzed by duplicate.

\section{II.2.11. Statistical Analysis}

An analysis of variance (ANOVA) was performed for comparing different treatments and storage times at a significant level of $\mathrm{P} \leq 0.05$ using PASW Statistics 22 for Windows (SPSS Inc., Chicago, IL, USA). In some cases, when significant differences were observed, the Tukey's HSD (Honestly Significant Difference) test was applied. Bilateral correlations were determined by Pearson's correlation coefficient with a confidence interval established at $95 \%$.

\section{II.3. RESULTS AND DISCUSSION}

\section{II.3.1 Phsysicochemical quality}

Colour is the first attribute that determines product quality and plays an important role for its acceptability. Table II. 1 represents color value changes throughout storage at $5{ }^{\circ} \mathrm{C}$. The colour of pea puree was affected by treatments. After treatments, an increase in lightness $\left(\mathrm{L}^{*}\right)$ was observed regarding CTRL samples, indicating a lighter colour in the different treated purees. Such increase in $\mathrm{L}^{*}$ values for HHP-treated fruit purees and pulps has been previously reported (Landl et al., 2010; Sánchez-Moreno et al., 2006). Previous work had showed an increase in $\mathrm{L}^{*}$ related to degradative loss of total pigments (chlorophyll and xanthophyll) during heating by MW (1000W, 200 s) of kiwifruit puree (Benlloch-Tinoco et al., 2012). However, the increase in lightness in MW, HHP and HPTP-treated samples in this work could be due to the pigment cell disruption at the pea puree surface resulting in a higher lightness value more than a pigment degradation associated to $a^{*}$ value. According to this, Ahmed et al. (2000) described an increase in $L^{*}$ and $b^{*}$ values with increased fineness in green chili pureed. Additionally, colour changes are also reported as $\Delta \mathrm{E}$ parameter that represents the perceptible colour variation by consumers. The highest $\Delta \mathrm{E}$ was observed in HPTP samples, 
regarding MW and HHP samples, that showed similar colour changes. A $\Delta \mathrm{E}$ value higher than 3 determine perceptible to the human eye differences; thus, visible colour difference was only found in HPTP treatment. García-Parra et al. (2016) also reported that the greatest colour changes of pumpkin puree ocurred with a combined treatment of high pressure and mild temperature $\left(600 \mathrm{MPa} / 60^{\circ} \mathrm{C}\right)$. However, the higher $\Delta \mathrm{E}$ was observed after 7 days of storage, mainly in CRTL and HPTP samples (Table II.1). It could be due to mainly the increase in a* values. Previous work demonstrated that $a *$ value can be an optimal indicator of green pea puree quality change and could be applicable for pasteurization process quality quantification and evaluation (Bornhorst et al., 2017b).

The $\mathrm{a}^{*}$ value tended to increase during storage in all the samples. HHP samples showed the most greenness puree at the end of storage and maintained the yellowness colour. Moreover, HHP showed the lowest $\Delta \mathrm{E}$ values after 24 days at $5{ }^{\circ} \mathrm{C}$. HHP and MW processing, delayed the green color deterioration of pea puree. The chromatic $a^{*}$ index showed an important decrease (44\%) after HPTP treatment on processing day, with significant differences between other treatments. However, HPTP treatment showed the highest $a^{*}$ and $b^{*}$ values, indicating significantly decreased sample greenness and increased yellowness regarding the remaining treatments (HHP, MW and CTRL samples). During thermal processing of green vegetables, chlorophylls are converted to pheophytins, causing a change from bright green to olive-brown (Ihl et al., 1998). Such greenness loss in green vegetable puree after high pressure with temperature might be caused by chlorophylls degradation.

During storage, a decrease $(11 \%)$ in $\mathrm{L}^{*}$ was observed in HPTP samples. The chromatic $\mathrm{b}^{*}$ index showed a different behavior among treatments and also throughout storage. According to these results, $b^{*}$ values increased when treatment intensity increased in MW-treated (1000W, 200 s) kiwifruit puree (Benlloch-Tinoco et al., 2012). After 12 days of storage, HHP and MW samples showed a decrease around $0.2 \%$ and $16.2 \%$ in $b^{*}$ values, respectively, regarding the processing day. Finally, HHP treated samples showed a slight decrease in $b^{*}$ values throughout storage, showing a decrease of $3 \%$ at the end of storage, respect to the $21 \%$ observed in MW samples. As result, HHP samples registred the lowest $\Delta \mathrm{E}$ values after 24 days. Accordingly, the quality parameters $\left(\mathrm{a}^{*} / \mathrm{b}^{*}\right)$ evaluated in a cantaloupe puree treated by HHP (500 MPa, $5 \mathrm{~min}$ ) remained unchanged during storage indicating the minimal effect of HHP on pigments (Mukhopadhyay et al., 2017). Several studies on HHP showed this 
technlogical process helpful for retaining the green color by chlorophyll content changes after treatment and during the storage due to the inactivation of enzymes, inhibition of senescence and thylakoid membrane disintegration (Wang et al., 2013; Hendrickx et al., 1998). The pH values were around $5.0 \pm 0.3$, without remarkable differences between treatments and storage time (data not shown).

\section{II.3.2. Total Phenolics Content (TPC)}

CTRL samples showed a TPC of $334.5 \pm 24.8 \mathrm{mg} \mathrm{GAE} \mathrm{kg}^{-1}$ fw. After MW and HHP treatments, a decrease of $19 \%$ and $14 \%$, respectively, with significant ( $p>0.05)$ differences between MW and CTRL samples was observed (Table II.2). Our results are in agreement with previous studies where MW treatment $(1000 \mathrm{~W}, 1 \mathrm{~min})$ showed a decrease of $17 \%$ in TPC regarding untreated samples of pea seeds (Turkmen et al., 2005) or when kiwifruit puree was microwaved ( $2 \mathrm{~W} / \mathrm{g}, 340 \mathrm{~s})$ and the TPC was reduced by $28.8 \%$ (Benlloch-Tinoco et al., 2015). Moreover, Linsberger-Martin et al. (2013) showed a decrease of $6 \%$ in TPC of dry split peas after HHP (600MPa, $30 \mathrm{~min}, 20^{\circ} \mathrm{C}$ ). Additionally, (Wang et al., 2013) observed a TPC decreased in spinach puree samples treated by HHP at $600 \mathrm{MPa}$ compared to the control samples. The decrease in TPC content in MW and HHP samples could be due to the partial degradation of TPC by thermal treatment as well as the linking of TPC to other molecules, being these complex undetermined as TPC methodology (Volf et al., 2014). On the other hand, HPTP samples showed the highest TPC, with a $15 \%$ of increment compared to CTRL samples (Table II.2). It is in agreement with previous works where HHP combined with temperature showed a synergic effect. García-Parra et al. (2016) described that pumpkin puree samples showed the highest TPC after HPTP at $600 \mathrm{MPa} / 70{ }^{\circ} \mathrm{C}$ with a $65 \%$ of increment compared to control puree. Furthermore, Camiro-Cabrera et al. (2017) showed that mango puree treated with HPTP $\left(550 \mathrm{MPa} / 59{ }^{\circ} \mathrm{C} / 4 \mathrm{~min}\right)$ increase TPC in concentration up to $34 \%$ as compared with the initial content. This increased could be enhanced by the combination of both treatments (temperature and HHP). These results suggested that treatments might produce changes in antioxidant extractability, like cellular disruption and dissociation of some phenolic compounds from biological structures or alteration their chemical structure to conversion of insoluble phenolic into more soluble forms (Dini et al., 2013). 
After 7 days at $5^{\circ} \mathrm{C}$, an increase in TPC was observed in CTRL and HHP samples, while TPC was maintained in MW and HPTP samples (Table II.2). MW samples showed the lowest TPC after treatments and after 24 days at $5{ }^{\circ} \mathrm{C}$, with significant different between other treatments $(\mathrm{p}<0.05)$ (Table II.2). It may be explained by the heat nature of this treatment, contrary to the used HHP or HPTP, which could lead to the heat degradation of these bioactive compounds or chemical rearrangements such as the binding of phenolics with other organic substances (Volf et al., 2014). Nevertheless, MW samples still retained $70 \%$ of their initial TPC after 24 days at $5{ }^{\circ} \mathrm{C}$. On the other hand, CTRL samples could have active enzymes which cause the liberation or destruction of some phenolic compounds in others. On the contrary, the hydrogen bonds between the polyphenol hydroxyl groups and hydrogen atoms of polysaccharides created during the treatments can encapsulate phenolic compounds and make their extraction difficult (Faller and Fialho, 2010; Xie et al., 2017). These hydrogen bonds could be instable and change during the storage.

\section{II.3.3. Individual phenolic content}

The major individual phenolic compounds identified were catechin, $p$ coumaric, phenolic acids derivatives and ferulic acid (Table II.3). The total concentration of phenolic acids determined in CTRL pea puree at the day 0 were $949.7 \pm 97.3 \mathrm{mg} \mathrm{kg}^{-1}$ fw. These phenolics accounted $12.88 \%, 28.5 \%, 58.6 \%$ and $0.02 \%$ of catechin, $p$ coumaric, phenolic acids derivative and ferulic acid, respectively. Similar individual phenolic compounds of pea seeds has been previously reported being $\mathrm{p}$ coumaric and their derivatives the major phenolic compounds found (Yao et al., 2011; Carbonaro et al., 2015). In this study, $p$ coumaric contents of untreated pea puree were equal to $270.82 \pm 15.73 \mathrm{mg} \mathrm{kg}^{-1} \mathrm{fw}$ (Table II.3). A lower level of coumaric acid was determined by Yao et al. (2011) that reported pea seeds cv. DingWan No.1 contained levels of coumaric acid $\left(61.2 \mathrm{mg} \mathrm{kg}^{-1}\right)$. Ferulic acid content was the minor phenolic compounds found, with values of $0.23 \mathrm{mg} \mathrm{kg}^{-1} \mathrm{fw}$ in CTRL samples. Giusti et al. (2017) reported values of ferulic acid content in splitted green peas of $0.9 \mathrm{mg} \mathrm{kg}^{-1}$ of dry weight sample. Additional Parmar et al. (2016) showed a catechin content of $390 \mathrm{mg} \mathrm{kg}^{-1}$ in raw field peas.

After 7 days at $5{ }^{\circ} \mathrm{C}$, an increase in phenolic content was observed in all samples, except in MW samples. The phenolic content was mainly increased in CTRL samples. The levels of 
(+)-catechin of CTRL pea purees greatly increased 6.2 times after 7 days at $5{ }^{\circ} \mathrm{C}$ and after that remained unchanged until the end of the storage (Table II.3). After 12 days at $5{ }^{\circ} \mathrm{C}$, an increase in catechin levels of 2.2, 3.2 and 1.7 times in MW, HHP and HPTP-treated samples was observed, respectively, regarding values on processing days (Table II.3). Additionally, after 12 days at $5{ }^{\circ} \mathrm{C}$, MW and HPTP samples showed an increase of $29 \%$ and $32 \%$ in $p$ coumaric contents, respectively, regarding values on processing days.

After 24 days at $5{ }^{\circ} \mathrm{C}$, CTRL samples showed the highest phenolics content and no significant differences were observed between treatments. This increase was due to the increase in the catechin content during the first 12 days of storage in all samples, but mainly in CTRL ones. Some phenolics could suffer chemical rearrangements, such as the binding of phenolics with other organic substances, during processing (Volf et al., 2014) and then, such compounds could be free during the subsequent storage. Additionally, the differences between results of individuals' polyphenols and TPC detected in pea puree could be associated to the unspecific method to determine TPC which could have determined the changes of other compounds that presented absorbance at the same wavelength that TPC was determined.

\section{II.3.4 Vitamin C content}

The highest total vitamin C content (AA + DHAA) was observed in CTRL samples, where the $99 \%$ was DHAA (37.28 mg per $100 \mathrm{~g} \mathrm{fw})$ and $1 \%$ was AA $(0.38 \mathrm{mg}$ per $100 \mathrm{~g} \mathrm{fw})$. These values are lower than the vitamin $\mathrm{C}$ content in pea seeds (643 to $707 \mathrm{mg} \mathrm{kg}^{-1}$ total vitamin C) previously reported by Collado et al. (2017). However, in our study, pea seeds were processed and could be easily oxidized, in agreement with the high percentage observed of DHAA (Fig. II.1). AA is easily oxidised by the enzymes ascorbate oxidase and ascorbic acid peroxidase to DHAA which exhibits antioxidant properties in addition to antiscorbutic activity equivalent to that of AA (Munyaka et al., 2010). During pea puree preparation blending disrupts plant cells allowing enzymes to access their substrates located in different plant cell locations. Consequently, lower AA values were detected in pea puree CTRL or treated samples on processing day due to rapid ascorbic acid to DHA enzymatic conversion. MW and HHP treatments significantly decrease vitamin C, reducing its content around 47\% and $49 \%$, respectively, while HPTP treatment reduced around $90 \%$ the vitamin C content regarding CTRL samples (Fig II.1). Although MW treatment was relatively short (40 s), the 
temperature reached for pasteurization $\left(85^{\circ} \mathrm{C}\right)$ could be responsible of the reduction in vitamin C. Moreover, the extended time treatment (10 min) used for HHP can decrease the vitamin C content of samples. On the contrary, Sánchez-Moreno et al. (2005) described vitamin $\mathrm{C}$ losses lower than $9 \%$ in orange juice after $\mathrm{HHP}$ at $400 \mathrm{MPa} / 40{ }^{\circ} \mathrm{C}$ for $1 \mathrm{~min}$. Additional previous authors showed a better vitamin $\mathrm{C}$ retention in fruit and vegetable processed after HHP at ambient temperature conditions compared to TP (Oey et al., 2008; Landl et al., 2010; Yi et al., 2016). Furthermore, the temperature $\left(60^{\circ} \mathrm{C}\right)$ and the long time treatment $(10 \mathrm{~min})$ for HPTP samples showed a negative synergic effect in pea puree in the thermolabile vitamin C. According to this, Sánchez-Moreno et al. (2003) observed that combined treatment of HHP/temperature is dependent mainly on temperature intensity, thus orange juice treated by HHP treatment at $400 \mathrm{MPa} / 40{ }^{\circ} \mathrm{C} / 1$ min showing losses in vitamin $\mathrm{C}$ content, but not after $350 \mathrm{MPa} / 30^{\circ} \mathrm{C} / 2.5 \mathrm{~min}$.

During the storage, significant losses of vitamin $\mathrm{C}$ were observed in all treatments. After 7 days at $5{ }^{\circ} \mathrm{C}$, a reduction around $63 \%$ was described in CTRL samples, while in the remaining treatments, the losses in vitamin $\mathrm{C}$ content were around $81 \%$ and $64 \%$ in MW and HHP-treated samples, respectively. On the other hand, HPTP samples maintained the vitamin $\mathrm{C}$ content, but decreasing the percentage of the reduced form (AA). After 12 days at $5{ }^{\circ} \mathrm{C}$, the vitamin C content was decreased in CTRL and MW samples, observed the lowest vitamin C content in MW samples. Finally, after 17 days of storage, the vitamin C content was very low in all treatments and mainly in MW samples, while after 24 days at $5{ }^{\circ} \mathrm{C}$ was close to the limit of detection. The degradation of vitamin $\mathrm{C}$ during the storage could be explained by the possible existence of other anti or pro-oxidants, pressure-induced enzyme activation (cytochrome oxidase, ascorbic acid oxidase and peroxidase), aerobic and non-enzymatic anaerobic reactions (Polydera et al., 2005; Sánchez-Moreno et al., 2005; Zhou et al., 2014)

\section{II.3.5. Antioxidant capacity}

The antioxidant capacity of pea puree was evaluated by two different assays, FRAP and DPPH (Table II.2). In FRAP assay, the initial TEAC value of CTRL samples was $268.9 \pm 9.8$ mg TEAC kg-1 fw. Is was according to previously data reported by Collado et al. (2017) where the antioxidant capacity of fresh cut peas treated with acidified sodium chlorite evaluated by FRAP assay reported values of $280 \pm 10 \mathrm{mg} \mathrm{TEAC} \mathrm{kg}^{-1} \mathrm{fw}$. After treatments, 
the antioxidant capacity showed an increase of $94 \%, 48 \%$ and $34 \%$ after HPTP, HHP and MW samples, respectively, regarding CTRL samples (Table II.2). The increase in the antioxidant capacity after HPTP treatment could be related to cellular disruption, e inactivation of antioxidant enzymes, due to the treatment facilitates extraction of these compounds or to disruption of weak bounds between dietary fiber and phenolic compounds that, in addition to covalent bounds, interact by electrostatic forces and hydrogen bonds (Palafox-Carlos et al., 2011). The extracted phenolic content and antioxidant activity in onions (cv. Doux) treated with HHP increased at pressures of 300 or $600 \mathrm{MPa}(1-3 \mathrm{~min} / 25$ ${ }^{\circ} \mathrm{C}$ ) increased the phenolic content extracted and the antioxidant capacity due to HHP produced changes in membrane permeability and disruption of cell walls favoring the release of phenolic compounds from tissue and, in consequence, improving their extractability (Vázquez-Gutierrez et al., 2013). Another possibility is that HHP treatment induced covalent bond breaking can depolymerize polyphenols, giving free polyphenolic monomers (Paciulli et al., 2016). At the same time, ascorbic acid can act both as pro- and anti-oxidant, depending on the considered food matrix and processing conditions (Davey et al., 2000).

These results are according to the TPC described, except to CTRL samples. The FRAP values observed in CTRL samples are lower that it could be expected. CTRL samples showed the highest vitamin $\mathrm{C}$ and high TPC values. TEAC by FRAP assays of all treatments showed a constant decrease throughout storage, with decreases $35 \%, 26 \%$ and $16 \%$ in HPTP, MW and HHP, respectively, during these last 12 days of storage. At the contrary, untreated samples showed an increase of $38 \%$ after 12 days of storage, regarding values on processing days (Table II.2). This increase was related to the previously discussed TPC increase. In addition, CTRL samples showed the highest increased in catechin content after 12 days of storage. Previous reports show the different antioxidant activity of several polyphenolic compounds, report a higher activity in catechin respect to p-coumaric (Dávalos et al., 2004; Soobrattee et al., 2005). At the end of storage the lowest FRAP values were observed in MW treatment, which is in according to the lowest TPC, catechin and vitamin C content.

On the other hand, the TEAC evaluated by DPPH assay showed the highest antioxidant capacity after HPTP treatment, but no significant differences were observed between MW and HHP treatments and CTRL samples (Table II.2). However, at 12 days of storage, MW treated samples showed the lowest DPPH values, and the rest of treatments not showed significant 
differences with CTRL samples (Table II.2). Such high TEAC decrease in MW samples may be explained due to high vitamin $\mathrm{C}$ degradation that was maximized by thermal treatment. At the end of storage, CTRL samples showed the highest antioxidant capacity, as in agreement of TPC data, and no significant differences were observed between the different treatments.

\section{II.3.6 Rheological characteristics}

The frequency dependence of storage or elastic modulus $\left(\mathrm{G}^{\prime}\right)$ and loss or viscous $\left(\mathrm{G}^{\prime \prime}\right)$ modulus of pea puree samples are presented in Figure II.2. $G^{\prime}$ predominates over $G^{\prime \prime}$ in the frequency range of 1-100 $\mathrm{rad} \mathrm{s}^{-1}$ for all treatments, indicating a solid-like or weak-gel behavior. G' is directly related to the cross-link density of the network in a gel. The shape of the rheological spectrum is similar to that reported by Álvarez et al. (2017a) for a commercial Spanish hummus. Also, a similar predominating solid-like behavior has been reported for pea puree (Klug et al., 2017) and rocket puree (Ahmed et al., 2013).

After treatments, $\mathrm{G}^{\prime}$ of HPTP and MW treatments were greater than HHP and CTRL treated samples (Fig II.2). In relation to MW treated samples, the increase in viscosities of microwave treated starches might due to the rupture of the starch granules and reassociation of the amylopectin molecules which gelatinized gradually as function of the vibration motion of the polar molecules during microwave treatment (Deka \& Sit, 2016). On the other hand, (Álvarez et al., 2017b) showed an increase in $\mathrm{G}^{\prime}$ and $\mathrm{G}^{\prime \prime}$ values of a ready-to-eat chickpea flour puree samples after a pressurization treatment at $600 \mathrm{MPa}, 50{ }^{\circ} \mathrm{C}, 15 \mathrm{~min}$ due to the weakening of the starch granule integrity by hot (Ikegwu et al., 2013). High values of viscosity after HPTP treatments, probably reflecting HHP-induced starch gelatinization and unfolding of proteins (Álvarez et al., 2017b), and a further factor to be taken into account is that denaturation of the protein component could also affect the rheological properties of the HHP-treated samples. In accordance with our results, (Liu et al., 2013) observed that both $G^{\prime}$ and $G^{\prime \prime}$ values increased with frequency for Chousa mango pulp as a result of HHP treatment at 100 and $200 \mathrm{MPa}$ (both 15 and $30 \mathrm{~min}$ ). Furthermore, Leite et al. (2017) described that high pressure process can affect the pea starch. Pea starch was treated with HHP (500 and $600 \mathrm{MPa}, 15 \mathrm{~min}$ ) and was observed that after pressurization at $500 \mathrm{MPa}$, the sediment phase presented a higher volume, and, after process at $600 \mathrm{MPa}$, it was clearly 
observed a gel phase. This indicates that HHP can lead to formation of pea starch gel at room temperature, and this process can be called ‘cold-gelatinization' (Leite et al., 2017).

During the storage, changes in the rheological properties of samples were observed (Fig II.2). After 24 days of storage, the viscosity of HPTP-treated samples decreased resulting in the formation of a weaker gel matrix after heating. The higher storage modulus value show either a strong particle-particle interaction or a network type structure in a stabilized form, or both (Carreau et al., 2002). Therefore, the attractive forces become dominant due to the strong hydrogen bonding and hydrophobic association (Basu et al., 2011), could be lost in HPTP samples during the storage. However, the viscosity increased in CTRL samples, while HHP and MW samples maintained the viscosity during the storage. Furthermore, HHP and MW treatments provided more stable pea puree in relation to rheological properties.

\section{II.3.7 Sensory quality}

In sensory quality, significant differences were observed among treatments on processing day (Fig II.3). According to panellist's observations, colour and texture were the main quality parameters that determined the overall quality of the pea puree. As result, the overall quality of MW and HHP samples was better scored than HPTP and CTRL samples on processing day and throughout storage. In relation to colour, HPTP provided pea puree samples with a noticeable loss of greenness due to the combination of pressure and mild temperature. However, the panelist no observed significant differences in colour between CTRL, HHP and MW treatments on processing day. Although, during the storage HHP samples showed the best colour (Fig II.3). On the other hand, MW samples provided the best texture to pea puree (Fig II.3), which is in agreement with the rheological parameters evaluated. (Zhou et al., 2016) studied the viscosity of defatted avocado puree treated by MW (11.0 W/g, $80 \mathrm{~s})$ and showed that the viscosity of this product increased after MW treatment. Also, Klug et al. (2018) showed that a faba beans pesto sauce treated with MW (11 kW, $30 \mathrm{~s})$ was better accepted by panelist than a sauce treated by a conventional treatment $\left(85^{\circ} \mathrm{C}, 5 \mathrm{~min}\right)$ because it higher sensory viscosity. The slightly higher creamy perceptions of MW-treated samples may be beneficial for those consumers that prefer products with more homogeneous textures. After 24 days of storage, the different treatments (MW, HHP and HPTP) led pea puree samples over the limit of acceptance after 24 days of storage at $5{ }^{\circ} \mathrm{C}$ (Fig II.3). HHP and MW 
treated samples showed better overall quality compared to HPTP samples with scores of 7.7, 7.4 and 7.1, respectively. However, CTRL samples were rejected at 12 days of storage by the off-colours and off-odours appreciated (data not shown).

\section{II.3.8 Microbial Analyses}

All samples showed low aerobic mesophilic counts $\left(<4 \log \mathrm{CFU} \mathrm{g} \mathrm{g}^{-1}\right)$ during storage, without differences between treatments and storage time (data not shown). Enterobacteriaceae and molds and yeasts counts were maintained below the detection limit $\left(<1 \log \mathrm{CFU} \mathrm{g}{ }^{-1}\right.$ for bacterial and $<2 \log \mathrm{CFU} \mathrm{g}{ }^{-1}$ for molds and yeasts) (data not shown). No Salmonella spp., Listeria monocytogenes and generic Escherichia coli presence was detected throughout storage according to Regulation EC 1441/2007 (2007). According to our results, (Marszałek et al., 2016) evaluated the microbial stability (total microbial count and molds and yeasts) of strawberry puree preserved with continuous MW processing (10 s) and conventional pasteurization $\left(15 \mathrm{~min}\right.$ ), both treatments reaching the temperature of $90 \pm 1{ }^{\circ} \mathrm{C}$ and the microbial counts remained in 2-3 $\log \mathrm{CFU} \mathrm{g}{ }^{-1} \mathrm{fw}$ and $<1 \log \mathrm{CFU} \mathrm{g} \mathrm{g}^{-1}$ fw for molds and yeasts counts, respectively, until the end of the storage. Furthermore, Klug et al. (2018b) observed low mesophilic counts (below 4 log units) during storage of a b broccoli hummus after HHP treatment $\left(550 \mathrm{MPa}, 10 \mathrm{~min}, 23^{\circ} \mathrm{C}\right)$.

\section{II.5. CONCLUSIONS}

A fresh pea-based puree may be enhanced by alternative processing treatments maintaining the sensory quality of the raw material and preserving the main quality attributes during 24 days at $5{ }^{\circ} \mathrm{C}$. Thermal treatments (MW and HPTP) affected thermolabile compounds such as vitamin C. However, color was more affected by HPTP than in MWtreated samples. In this study, MW-treated samples (9 kW; $40 \mathrm{~s})$ showed similar color than non-thermal HHP-treated ones (550 MPa, $10 \mathrm{~min}$ ) which was perceived by the sensory panel, although a decrease in greenness was detected in MW samples after 24 days at $5{ }^{\circ} \mathrm{C}$. The apparent viscosity was higher in MW samples than in others and it was also perceived in the sensory test. Nevertheless, although colour and texture are important parameters, both HHP and MW treatments obtained the best sensory quality score. HHP is preferred in order to achieve more stabilized phenolics compounds with related total antioxidant capacity. 
Therefore, according to these results, HHP and MW treatments could be two alternative processing treatments to for improving quality of a pea puree. 
Table II.1. $L^{*}, a^{*}, b^{*}$ and $\Delta E$ color value changes of pea puree samples untreated (CTRL), or treated (MW, HHP, HPTP) stored at $5^{\circ} \mathrm{C}$.

\begin{tabular}{|c|c|c|c|c|c|}
\hline Day & Treatment & $\mathbf{L}^{*}$ & $\mathbf{a}^{*}$ & $\mathbf{b}^{*}$ & $\Delta \mathbf{E}$ \\
\hline \multirow[t]{4}{*}{0} & CTRL & $52.00 \pm 0.33 \mathrm{Ba}$ & $-17.45 \pm 0.32 \mathrm{Aa}$ & $34.68 \pm 1.01 \mathrm{ABa}$ & - \\
\hline & MW & $53.76 \pm 1.12 \mathrm{Ans}$ & $-16.34 \pm 0.72 \mathrm{Aa}$ & $33.55 \pm 1.32 \mathrm{Ba}$ & $2.81 \pm 0.31 \mathrm{Bc}$ \\
\hline & HHP & $53.57 \pm 0.21 \mathrm{Abc}$ & $-16.64 \pm 0.10 \mathrm{Aa}$ & $33.07 \pm 0.30 \mathrm{Bb}$ & $2.41 \pm 0.20 \mathrm{Bd}$ \\
\hline & НРТP & $54.08 \pm 0.42 \mathrm{Aa}$ & $-9.81 \pm 1.79 \mathrm{Ba}$ & $36.37 \pm 0.53 \mathrm{Aa}$ & $8.16 \pm 1.46 \mathrm{Aa}$ \\
\hline \multirow[t]{4}{*}{7} & CTRL & $50.04 \pm 0.33 \mathrm{Cb}$ & $-6.27 \pm 0.28 \mathrm{Bb}$ & $32.89 \pm 0.69 \mathrm{Bab}$ & $11.50 \pm 0.43 \mathrm{Ac}$ \\
\hline & MW & $54.67 \pm 1.67 \mathrm{ABns}$ & $-9.13 \pm 0.11 \mathrm{Ab}$ & $31.39 \pm 0.53 \mathrm{Bab}$ & $9.44 \pm 0.46 \mathrm{Bb}$ \\
\hline & HHP & $56.92 \pm 1.30 \mathrm{Aa}$ & $-9.28 \pm 0.40 \mathrm{Ab}$ & $36.08 \pm 1.49 \mathrm{Aa}$ & $9.77 \pm 0.52 \mathrm{Bc}$ \\
\hline & НРТP & $51.53 \pm 0.75 \mathrm{BCb}$ & $-5.93 \pm 0.23 \mathrm{Bb}$ & $33.45 \pm 0.69 \mathrm{ABb}$ & $11.62 \pm 0.29 \mathrm{Ab}$ \\
\hline \multirow[t]{4}{*}{12} & CTRL & $49.54 \pm 0.32 \mathrm{Db}$ & $-4.95 \pm 0.10 \mathrm{Cc}$ & $31.25 \pm 0.38 \mathrm{Bbc}$ & $13.20 \pm 0.25 \mathrm{Ab}$ \\
\hline & MW & $52.76 \pm 0.34 \mathrm{Bns}$ & $-6.00 \pm 0.29 \mathrm{Bc}$ & $28.10 \pm 0.28 \mathrm{Cbc}$ & $13.23 \pm 0.37 \mathrm{Aa}$ \\
\hline & HHP & $54.20 \pm 0.09 \mathrm{Abc}$ & $-7.01 \pm 0.23 \mathrm{Ac}$ & $33.02 \pm 0.15 \mathrm{Ab}$ & $10.80 \pm 0.22 \mathrm{Cb}$ \\
\hline & HPTP & $50.68 \pm 0.34 \mathrm{Cb}$ & $-5.43 \pm 0.15 \mathrm{Cb}$ & $32.86 \pm 0.83 \mathrm{Abc}$ & $12.24 \pm 0.21 \mathrm{Bab}$ \\
\hline \multirow[t]{4}{*}{17} & CTRL & $49.43 \pm 0.54 \mathrm{Bb}$ & $-4.89 \pm 0.26 \mathrm{Bc}$ & $31.07 \pm 1.35 \mathrm{ABbc}$ & $13.36 \pm 0.64 \mathrm{NSb}$ \\
\hline & MW & $53.92 \pm 0.89$ Ans & $-5.70 \pm 0.76 \mathrm{ABc}$ & $27.02 \pm 2.68 \mathrm{Bc}$ & $14.27 \pm 1.92 \mathrm{NSa}$ \\
\hline & HHP & $55.74 \pm 0.57 \mathrm{Aab}$ & $-6.32 \pm 0.06 \mathrm{Ad}$ & $33.07 \pm 1.11 \mathrm{Ab}$ & $11.89 \pm 0.18 \mathrm{NSa}$ \\
\hline & HPTP & $49.54 \pm 1.38 \mathrm{Bbc}$ & $-4.88 \pm 0.28 \mathrm{Bb}$ & $33.00 \pm 0.57 \mathrm{Ab}$ & $12.96 \pm 0.62 \mathrm{NSab}$ \\
\hline \multirow[t]{4}{*}{24} & CTRL & $47.56 \pm 0.45 \mathrm{Bc}$ & $-3.96 \pm 0.13 \mathrm{Dd}$ & $29.45 \pm 0.33 \mathrm{Bc}$ & $15.13 \pm 0.34 \mathrm{Aa}$ \\
\hline & MW & $53.20 \pm 0.49$ Ans & $-5.30 \pm 0.29 \mathrm{Bc}$ & $26.47 \pm 1.01 \mathrm{Cc}$ & $14.72 \pm 0.73 \mathrm{Aa}$ \\
\hline & HHP & $53.02 \pm 0.31 \mathrm{Ac}$ & $-6.31 \pm 0.12 \mathrm{Ad}$ & $32.06 \pm 0.39 \mathrm{Ab}$ & $11.50 \pm 0.22 \mathrm{Bab}$ \\
\hline & HPTP & $48.14 \pm 0.70 \mathrm{Bc}$ & $-4.52 \pm 0.21 \mathrm{Cb}$ & $31.22 \pm 0.52 \mathrm{Ac}$ & $13.94 \pm 0.43 \mathrm{Aa}$ \\
\hline \multicolumn{2}{|c|}{ Treatments } & $* * *$ & $* * *$ & $* * *$ & $* * *$ \\
\hline \multicolumn{2}{|l|}{ Days } & $* * *$ & $* * *$ & $* * *$ & $* * *$ \\
\hline \multicolumn{2}{|c|}{ Days x Treatments } & $* * *$ & $* *$ & $* * *$ & $* * *$ \\
\hline
\end{tabular}

Values correspond to average value $(n=3) \pm$ SD. Different capital letters within the same column show significant differences between treatments. Different lower case letters within the same column show significant differences between storage times. NS: not significant; *** $(\mathrm{p}<0.001) ; * *(\mathrm{p}<0.01) ; *(\mathrm{p}<0.05)$. 
Table II.2. Total antioxidant capacity (FRAP and DPPH methods) and total phenolics compounds (TPC) of pea puree samples untreated (CTRL), or treated (MW, HHP, HPTP) stored at $5^{\circ} \mathrm{C}$.

\begin{tabular}{|c|c|c|c|c|}
\hline Day & Treatment & $\begin{array}{l}\text { FRAP } \\
\left(\mathrm{mg} \mathrm{TEAC} \mathrm{kg}^{-1} \mathrm{fw}\right)\end{array}$ & $\begin{array}{l}\text { DPPH } \\
\left(\mathrm{mg} \mathrm{TEAC} \mathrm{kg}^{-1} \mathrm{fw}\right)\end{array}$ & $\begin{array}{l}\text { TPC } \\
\left(\mathrm{mg} \mathrm{GAE} \mathrm{kg}^{-1} \mathrm{fw}\right)\end{array}$ \\
\hline \multirow[t]{4}{*}{0} & CTRL & $268.9 \pm 9.8 \mathrm{Cb}$ & $255.6 \pm 1.3 \mathrm{Bb}$ & $334.5 \pm 24.8 \mathrm{Bb}$ \\
\hline & MW & $360.6 \pm 19.1 \mathrm{Ba}$ & $289.9 \pm 19.5 \mathrm{ABa}$ & $271.0 \pm 14.5 \mathrm{Cab}$ \\
\hline & HHP & $398.1 \pm 11.6 \mathrm{Ba}$ & $285.1 \pm 22.5 \mathrm{ABa}$ & $288.8 \pm 12.3 \mathrm{BCb}$ \\
\hline & НРТP & $521.9 \pm 13.6 \mathrm{Aa}$ & $349.3 \pm 29.6 \mathrm{Aa}$ & $384.3 \pm 11.1$ Ans \\
\hline \multirow[t]{4}{*}{7} & CTRL & $295.2 \pm 10.5 \mathrm{Cb}$ & $274.4 \pm 8.6 \mathrm{ABab}$ & $562.1 \pm 24.4 \mathrm{Aa}$ \\
\hline & MW & $311.6 \pm 6.9 \mathrm{Cb}$ & 249.2 $\pm 27.7 \mathrm{Bab}$ & $217.5 \pm 0.8 \mathrm{Cab}$ \\
\hline & HHP & $360.8 \pm 15.6 \mathrm{Bab}$ & $272.4 \pm 15.9 \mathrm{ABab}$ & $376.1 \pm 4.8 \mathrm{Ba}$ \\
\hline & НPTP & $410.6 \pm 16.2 \mathrm{Ab}$ & $322.1 \pm 26.7 \mathrm{Aa}$ & $402.4 \pm 14.1 \mathrm{Bns}$ \\
\hline \multirow[t]{4}{*}{12} & CTRL & $371.8 \pm 5.2 \mathrm{Aa}$ & $301.9 \pm 4.9 \mathrm{Aa}$ & $564.7 \pm 28.6 \mathrm{Aa}$ \\
\hline & MW & $266.1 \pm 6.8 \mathrm{Cc}$ & $246.8 \pm 2.2 \mathrm{Bab}$ & $284.5 \pm 30.9 \mathrm{Ca}$ \\
\hline & HHP & $333.5 \pm 6.6 \mathrm{Bbc}$ & $291.1 \pm 10.7 \mathrm{Aa}$ & $363.9 \pm 3.1 \mathrm{Ba}$ \\
\hline & НРТP & $339.9 \pm 7.4 \mathrm{Bc}$ & 287.1土7.3 Aab & $424.3 \pm 15.5 \mathrm{Bns}$ \\
\hline \multirow[t]{4}{*}{17} & CTRL & $369.5 \pm 18.7 \mathrm{Aa}$ & $291.9 \pm 4.5 \mathrm{Aab}$ & $576.1 \pm 29.6 \mathrm{Aa}$ \\
\hline & MW & $241.0 \pm 9.5 \mathrm{Cc}$ & $187.3 \pm 17.5 \mathrm{Cc}$ & $280.5 \pm 62.2 \mathrm{Ca}$ \\
\hline & HHP & $308.9 \pm 8.3 \mathrm{Bc}$ & $248.3 \pm 3.4 \mathrm{Bab}$ & $381.6 \pm 23.1 \mathrm{BCa}$ \\
\hline & НРТР & $291.6 \pm 1.6 \mathrm{Bd}$ & $245.5 \pm 11.2 \mathrm{Bbc}$ & $411.4 \pm 15.5 \mathrm{Bns}$ \\
\hline \multirow[t]{4}{*}{24} & CTRL & $352.2 \pm 28.1 \mathrm{Aa}$ & $297.1 \pm 21.3 \mathrm{Aa}$ & $603.6 \pm 12.6 \mathrm{Aa}$ \\
\hline & MW & $199.3 \pm 5.5 \mathrm{Cd}$ & $198.6 \pm 14.0 \mathrm{Bbc}$ & $190.8 \pm 7.4 \mathrm{Cb}$ \\
\hline & HHP & $261.4 \pm 27.7 \mathrm{Bd}$ & $231.1 \pm 17.0 \mathrm{Bb}$ & $377.9 \pm 5.6 \mathrm{Ba}$ \\
\hline & НРТP & $250.3 \pm 14.8 \mathrm{BCe}$ & $216.9 \pm 23.0 \mathrm{Bc}$ & $399.9 \pm 7.1 \mathrm{Bns}$ \\
\hline \multicolumn{2}{|c|}{ Treatments } & $* * *$ & $* * *$ & $* * *$ \\
\hline \multicolumn{2}{|l|}{ Days } & $* * *$ & $* * *$ & $* * *$ \\
\hline \multicolumn{2}{|c|}{ Days $x$ Treatments } & $* * *$ & $* * *$ & $* * *$ \\
\hline
\end{tabular}

FRAP: ferric reducing antioxidant power; DPPH: 2,2-diphenyl-1-picrylhydrazil; TEAC: Trolox equivalent antioxidant capacity; GAE: gallic acid equivalents. Values correspond to average value $(n=3) \pm$ SD. Different capital letters within the same column show significant differences between treatments. Different lower case letters within the same column show significant differences between storage times. NS: not significant; *** $(\mathrm{p}<$ $0.001) ; * *(\mathrm{p}<0.01) ; *(\mathrm{p}<0.05)$. 


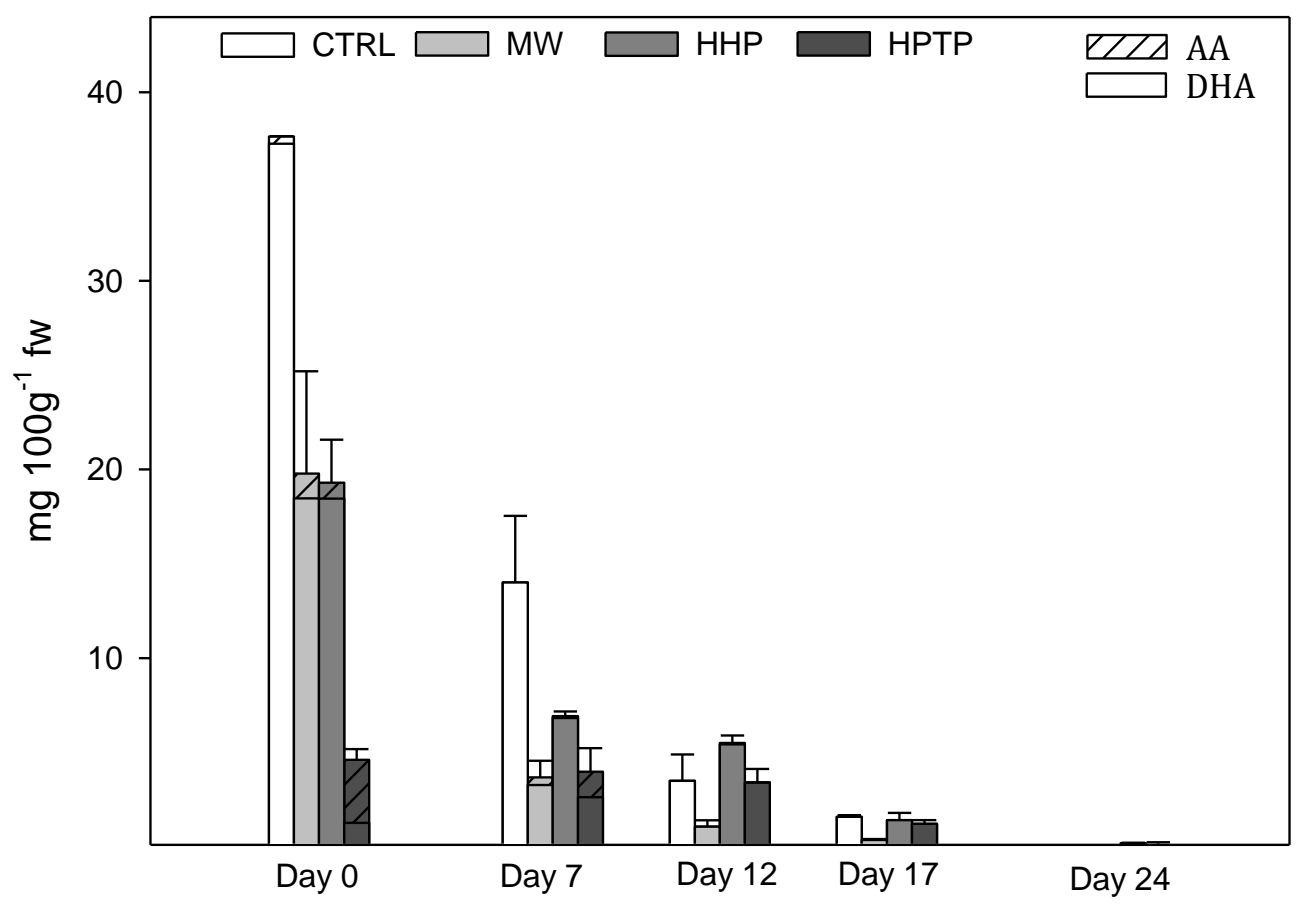

Figure II.1. Evolution of vitamin C (AA + DHA) in pea puree samples untreated (CTRL), or treated (MW, HHP, HPTP) stored at $5{ }^{\circ} \mathrm{C}$. (DHA, dehydroascorbic acid; AA, ascorbic acid). Data are mean \pm standard deviation $(n=3)$. 


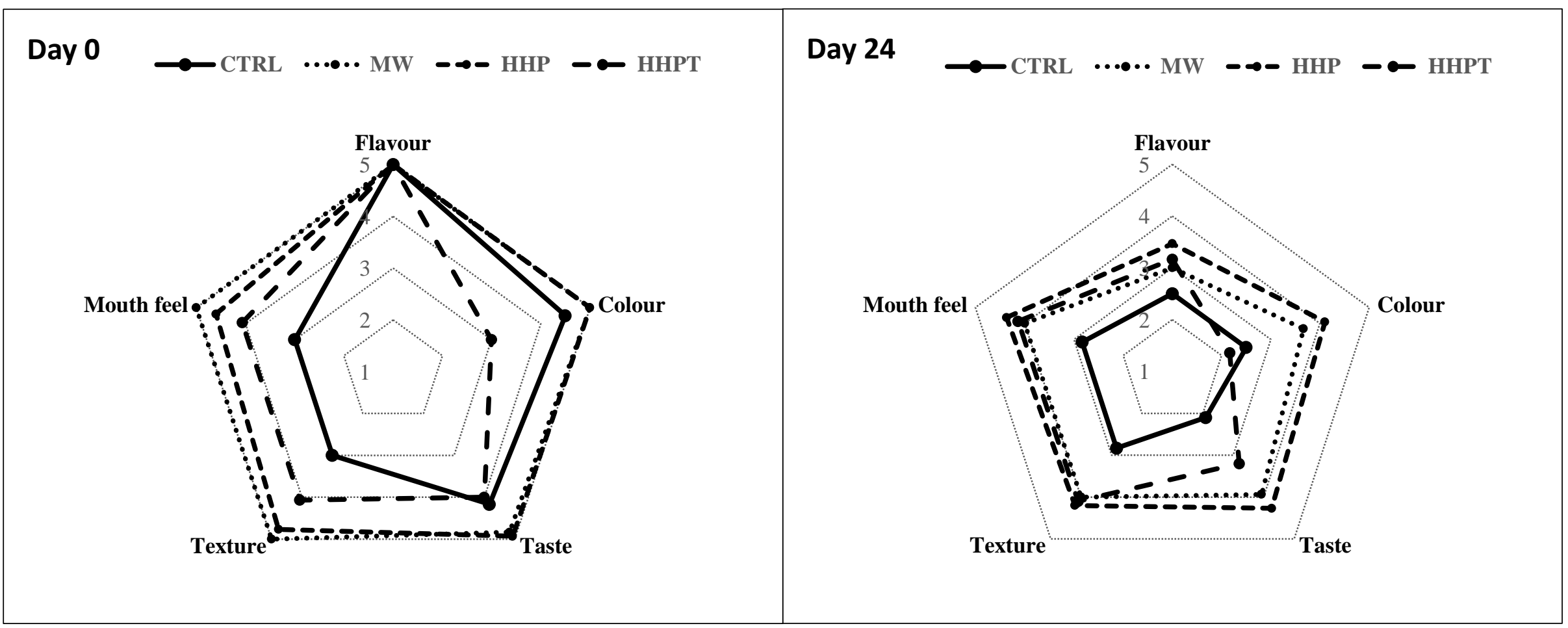

Figure II.3. Sensory scores of pea puree samples untreated (CTRL), or treated (MW, HHP, HPTP) at the day 0 and day 24 of storage at $5{ }^{\circ} \mathrm{C}$. 


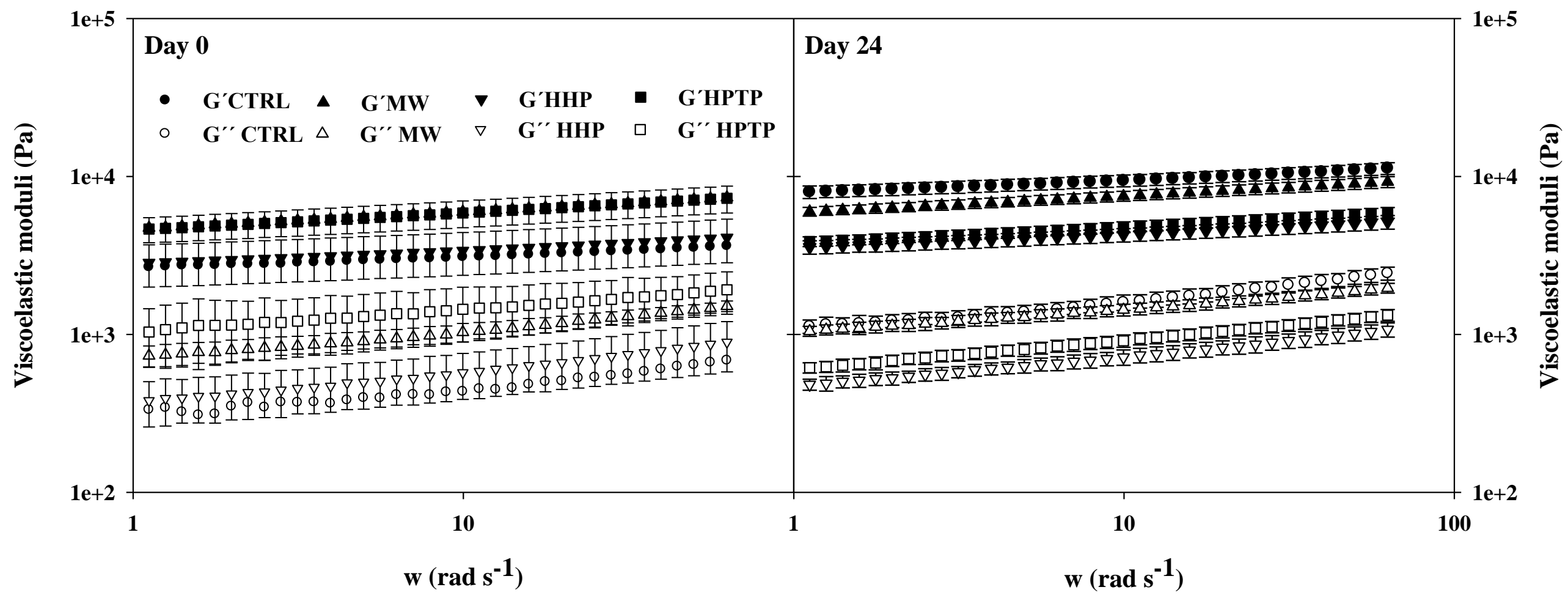

Figure II.2. Storage modulus $\left(\mathrm{G}^{\prime}\right)$ and loss modulus $\left(\mathrm{G}^{\prime \prime}\right)$ as a function of frequency (w) of pea puree samples untreated (CTRL), or treated (MW, HHP, HPTP) at the day 0 and day 24 of storage at $5{ }^{\circ} \mathrm{C}$. 
Table II.3. Individual phenolic contents of pea puree samples untreated (CTRL), or treated (MW, HHP, HPTP) stored at $5{ }^{\circ} \mathrm{C}$.

\begin{tabular}{|c|c|c|c|c|c|c|}
\hline Day & Treatment & $\begin{array}{c}\text { Catechin } \\
\left(\mathrm{mg} \mathrm{kg}^{-1} \mathbf{f w}\right)\end{array}$ & $\begin{array}{l}\text { p coumaric } \\
\left(\mathrm{mg} \mathrm{kg}^{-1} \mathrm{fw}\right)\end{array}$ & $\begin{array}{l}\text { Phenolic acids derivatives } \\
\qquad\left(\mathrm{mg} \mathrm{kg}^{-1} \mathrm{fw}\right)\end{array}$ & $\begin{array}{l}\text { Ferulic acid } \\
\left(\mathrm{mg} \mathrm{kg}^{-1} \mathbf{f w}\right)\end{array}$ & $\begin{array}{c}\text { Total } \\
\left(\mathrm{mg} \mathrm{kg}^{-1} \mathrm{fw}\right)\end{array}$ \\
\hline \multirow[t]{4}{*}{0} & CTRL & $122.36 \pm 2.95 \mathrm{Ab}$ & $270.82 \pm 15.73$ Ans & $556.27 \pm 32.61 \mathrm{NSb}$ & $0.23 \pm 0.09$ Ans & $949.7 \pm 97.3 \mathrm{NSb}$ \\
\hline & MW & $82.47 \pm 3.42 \mathrm{Cbc}$ & $224.53 \pm 9.23 \mathrm{Bb}$ & $550.65 \pm 19.79 \mathrm{NSb}$ & $0.07 \pm 0.01 \mathrm{Bab}$ & $857.7 \pm 32.3 \mathrm{NSb}$ \\
\hline & HHP & $69.57 \pm 2.05 \mathrm{Cd}$ & $245.49 \pm 11.94 \mathrm{ABns}$ & $578.62 \pm 27.15 \mathrm{NSb}$ & $0.05 \pm 0.01 \mathrm{Bb}$ & $893.7 \pm 41.1 \mathrm{NSb}$ \\
\hline & HPTP & $100.91 \pm 8.71 \mathrm{Bc}$ & $220.97 \pm 12.50 \mathrm{Bb}$ & $541.33 \pm 27.27 \mathrm{NSb}$ & $0.12 \pm 0.08 \mathrm{ABns}$ & $863.3 \pm 47.3 \mathrm{NSb}$ \\
\hline \multirow[t]{4}{*}{7} & CTRL & $763.62 \pm 101.82 \mathrm{Aa}$ & $290.16 \pm 44.77 \mathrm{NSns}$ & $578.94 \pm 2.08 \mathrm{NSa}$ & $0.34 \pm 0.06$ Ans & $1633.1 \pm 12.1 \mathrm{Aa}$ \\
\hline & MW & $59.46 \pm 0.15 \mathrm{Bc}$ & $255.47 \pm 28.83 \mathrm{NSab}$ & $575.34 \pm 33.30 \mathrm{NSa}$ & $0.11 \pm 0.07 \mathrm{Bab}$ & $890.4 \pm 96.2 \mathrm{Bb}$ \\
\hline & HHP & $148.66 \pm 20.08 \mathrm{Bc}$ & $241.71 \pm 36.57 \mathrm{NSns}$ & $614.17 \pm 10.85 \mathrm{NSa}$ & $0.11 \pm 0.03 \mathrm{Ba}$ & $1004.6 \pm 25.3 \mathrm{Ba}$ \\
\hline & HPTP & $133.05 \pm 5.34 \mathrm{Bbc}$ & $278.45 \pm 17.88 \mathrm{NSa}$ & $616.54 \pm 30.52 \mathrm{NSa}$ & $0.19 \pm 0.01 \mathrm{Bns}$ & $1028.3 \pm 50.6 \mathrm{Ba}$ \\
\hline \multirow[t]{4}{*}{12} & CTRL & $693.12 \pm 10.60 \mathrm{Aa}$ & $267.44 \pm 4.54 \mathrm{NSns}$ & $595.40 \pm 12.52 \mathrm{NSa}$ & $0.23 \pm 0.01$ Ans & $1556.2 \pm 8.7 \mathrm{Aa}$ \\
\hline & MW & $183.26 \pm 11.00 \mathrm{BCa}$ & $289.84 \pm 21.72 \mathrm{NSa}$ & $610.16 \pm 40.91 \mathrm{NSa}$ & $0.18 \pm 0.02 \mathrm{BCa}$ & $1083.4 \pm 73.5 \mathrm{Ba}$ \\
\hline & HHP & $220.46 \pm 7.63 \mathrm{Bb}$ & $271.34 \pm 15.11 \mathrm{NSns}$ & $613.72 \pm 5.55 \mathrm{NSa}$ & $0.16 \pm 0.01 \mathrm{Ca}$ & $1105.7 \pm 13.1 \mathrm{Ba}$ \\
\hline & HPTP & $175.00 \pm 27.87 \mathrm{Ca}$ & $291.73 \pm 17.92 \mathrm{NSa}$ & $646.52 \pm 14.24 \mathrm{NSa}$ & $0.22 \pm 0.02 \mathrm{ABns}$ & $1113.5 \pm 22.4 \mathrm{Ba}$ \\
\hline \multirow[t]{4}{*}{17} & CTRL & $666.05 \pm 30.95 \mathrm{Aa}$ & $243.37 \pm 26.21 \mathrm{NSns}$ & $596.33 \pm 43.37 \mathrm{NSb}$ & $0.21 \pm 0.06 \mathrm{NSns}$ & $1505.9 \pm 99.5 \mathrm{Aa}$ \\
\hline & MW & $129.96 \pm 40.91 \mathrm{Cab}$ & $263.22 \pm 10.31 \mathrm{NSab}$ & $543.66 \pm 29.22 \mathrm{NSb}$ & $0.10 \pm 0.06 \mathrm{NSab}$ & $936.9 \pm 43.5 \mathrm{Bab}$ \\
\hline & HHP & $220.96 \pm 28.13 \mathrm{Bb}$ & $243.78 \pm 13.23 \mathrm{NSns}$ & $538.20 \pm 39.15 \mathrm{NSb}$ & $0.13 \pm 0.02 \mathrm{NSa}$ & 1003.1 $\pm 77.6 \mathrm{Bab}$ \\
\hline & HPTP & $172.36 \pm 13.95 \mathrm{BCab}$ & $257.87 \pm 4.55 \mathrm{NSab}$ & $573.05 \pm 16.61 \mathrm{NSb}$ & $0.13 \pm 0.07 \mathrm{NSns}$ & $1003.4 \pm 28.8 \mathrm{Ba}$ \\
\hline \multirow[t]{4}{*}{24} & CTRL & $730.71 \pm 36.54 \mathrm{Aa}$ & $262.75 \pm 14.61 \mathrm{NSns}$ & $591.64 \pm 42.04 \mathrm{NSa}$ & $0.21 \pm 0.04$ Ans & $1585.2 \pm 87.3 \mathrm{Aa}$ \\
\hline & MW & $84.48 \pm 3.55 \mathrm{Dbc}$ & $303.07 \pm 24.83 \mathrm{NSa}$ & $612.16 \pm 49.03 \mathrm{NSa}$ & $0.04 \pm 0.00 \mathrm{Bb}$ & $999.7 \pm 74.9 \mathrm{Bab}$ \\
\hline & HHP & $272.71 \pm 6.26 \mathrm{Ba}$ & $252.29 \pm 3.22 \mathrm{NSns}$ & $575.13 \pm 8.28 \mathrm{NSa}$ & $0.15 \pm 0.01 \mathrm{Aa}$ & $1100.3 \pm 17.2 \mathrm{Ba}$ \\
\hline & HPTP & $205.84 \pm 5.47 \mathrm{Ca}$ & $278.33 \pm 26.09 \mathrm{NSa}$ & $601.53 \pm 31.08 \mathrm{NSa}$ & $0.20 \pm 0.03 \mathrm{Ans}$ & $1085.9 \pm 52.3 \mathrm{Ba}$ \\
\hline
\end{tabular}




\begin{tabular}{|c|c|c|c|c|c|}
\hline Treatment & $* * *$ & NS & NS & $* * *$ & $* * *$ \\
\hline Days & $* * *$ & $* * *$ & ** & $* * *$ & $* * *$ \\
\hline Days $x$ Treatment & $* * *$ & $*$ & NS & ** & $* * *$ \\
\hline
\end{tabular}

Values correspond to average value $(n=3) \pm$ SD. Different capital letters within the same column show significant differences between treatments. Different lower case letters within the same column show significant differences between storage times. NS: not significant; $* * *(\mathrm{p}<0.001)$; $* *(\mathrm{p}<$ $0.01) ; *(\mathrm{p}<0.05)$. 
Supplementary Table: Nutritional composition of the pea puree (100g) (Software DIAL 1.0)

\begin{tabular}{|c|c|}
\hline Nutrient & $100 \mathrm{~g}$ \\
\hline Calories (kcal) & 107.785 \\
\hline Protein $(\mathrm{g})$ & 6.539 \\
\hline Carbohydrates (g) & 10.783 \\
\hline Fibre (g) & 4.659 \\
\hline Fat $(\mathrm{g})$ & 3.271 \\
\hline $\mathrm{B} 1(\mathrm{mg})$ & 0.275 \\
\hline B2 (riboflavin) (mg) & 0.152 \\
\hline Niacin (mg) & 3.879 \\
\hline B6 (mg) & 0.162 \\
\hline Folic acid $(\mu \mathrm{g})$ & 71.273 \\
\hline Vitamin C (mg) & 22.128 \\
\hline Vitamin A $(\mu \mathrm{g})$ & 57.130 \\
\hline Eq. Carotene $(\mu \mathrm{g})$ & 342.782 \\
\hline Calcium (mg) & 24.498 \\
\hline Magnesium (mg) & 31.935 \\
\hline Potassium (mg) & 238.267 \\
\hline Phosphorus (mg) & 107.266 \\
\hline
\end{tabular}




\section{CHAPTER III}

\section{Cowpea puree: different eco-innovative technologies as alternative in the minimal processing}

Tâmmila Venzke Klug ${ }^{1}$, Ascensión Martínez-Sánchez ${ }^{1,2}$, Elena Collado², Perla A Gómez ${ }^{2}$, Encarna Aguayo ${ }^{1,2}$, Francisco Artés ${ }^{1,2}$ and Francisco Artés-Hernández ${ }^{1,2}$

1 Postharvest and Refrigeration Group. Department of Food Engineering. Universidad Politécnica de Cartagena. Paseo Alfonso XIII, 48, 30203 Cartagena, Murcia, Spain.

${ }^{2}$ Institute of Plant Biotechnology. Universidad Politécnica de Cartagena. Campus Muralla del Mar, 30202 Cartagena, Murcia, Spain.

Submitted to a peer reviewed Journal included in the JCR of the ISI 


\section{III.1. INTRODUCTION}

Grain legumes have high potential as novel ingredients for the nutritional quality improvement of foods due to their high protein and fiber content, antioxidant potential, low glycemic index, as well as functional properties like water binding capacity and fat absorption (Watts, 2011). This would contribute to diversify and increase the consumption of legumes as valuable and healthy sources of dietary proteins. In this regard, cowpea (Vigna unguiculata L. Walp) represents a legume specie contributing to the European agro-food system, displaying several agro-ecological benefits due to its features as a low-demanding crop (Martos-Fuentes et al., 2015). In addition to the agronomic advantages associated with cowpea culture, this legume is known to be an excellent source of protein being also rich in important vitamins (folic acid and vit B), minerals (iron and zinc), and soluble and insoluble dietary fiber (Carvalho et al., 2012). Furthermore, similar to other legumes, cowpea starch is extremely beneficial to human health, since is more slowly digested than starch from cereals, producing less abrupt changes in plasma glucose and insulin upon ingestion (Gonçalves et al., 2016). The consumption of cowpea has been related to the prevention of diverse metabolic diseases and carcinogenic pathologies (Frota et al., 2008; Xu and Chang, 2012). So, the development of a new 'ready-to-eat' cowpea puree would help in increasing the intake of legumes.

As consumers of ready to eat products prefer products without preservatives but with adequately shelf-life, appropriated processing treatments used during industrial processing of legume products must be considered, since the treatments may alter the profile and bioavailability of some nutrients (Xu and Chang, 2008). In this sense HHP processing, as a non-thermal process, is an alternative to preserve foods containing heat sensitive compounds. HHP causes a partial unfolding of proteins during the process and upon the release of the pressure, which leads to the inactivation of microorganisms and enzyme mechanisms (Considine et al., 2008). Food treated by HHP has been shown to kept high phenolics levels during storage and to produce minimum sensory changes in terms of freshness and colour (Cao et al., 2011). HHP is a promising technology to satisfy the need of the consumers by healthy, convenient, and has potential for new products, like vegetable-based spreads (Kirse et al., 2017). 
On the other hand, thermal technologies that preserve or enhance its original bioactive/nutritional compounds could be alternatives to conventional techniques. MW pasteurization can preserve nutrients and the fresh taste of vegetables products (BenllochTinoco et al., 2015). Arjmandi et al., (2017a) found continuous-flow MW heating to be more effective at inactivating POD and preserving nutritional properties in tomato puree than conventional thermal treatment.

Sous-vide (SV) treatment is a pasteurization technology where products are packaged in heat vacuumized pouches and then heat treated in water (bath) or air (oven) at a controlled temperature and time regime (Baldwin, 2012), followed by rapid cooling to avoid the risk of microbial growth. Recent studies have investigated the effects of sous-vide processing on vegetables reporting that the loss ascorbic acid and polyphenols were lower and provide advantages in the sensorial satisfaction of consumers (Iborra-Bernad et al., 2015; Renna et al., 2014).

The aim of the present study was to develop a cowpea puree and evaluate the effect of MW, HHP and SV treatments on the microbial and sensory quality, rheological properties and on the nutritional and bioactive compounds contents, just after treatments and also during 21 days at $5^{\circ} \mathrm{C}$.

\section{III.2. MATERIALS AND METHODS}

\section{III.2.1. Plant material}

Cowpea was harvested in the UPCT Agri-food Experimental Station Tomás Ferro (La Palma, Cartagena, Spain) at immature physiological stage. Selected variety of cowpea and the harvest season were based on previous experiences (Martos-Fuentes et al., 2017). Cowpeas were transported under chilling conditions $\left(5 \pm 1^{\circ} \mathrm{C}, 20 \mathrm{~min}\right)$ to the Pilot Plant where they were kept in darkness at $4{ }^{\circ} \mathrm{C}$ and $90-95 \% \mathrm{RH}$. Other ingredients were purchased at a local supermarket from Cartagena (Murcia, Spain). The next day, cowpea pods were shelled by hand in a cold room $\left(5^{\circ} \mathrm{C}\right)$ and the obtained seeds were immersed in cold water at $4 \pm 1^{\circ} \mathrm{C}$. These seeds were sanitized by immersion in $\mathrm{NaOCl}\left(150 \mathrm{mg} \mathrm{L}^{-1}, \mathrm{pH} 6.5,2 \mathrm{~min}, 4^{\circ} \mathrm{C}\right)$, and subsequent rinsing in cold tap water for $1 \mathrm{~min}$. 


\section{III.2.2. Puree from Cowpea}

A new cowpea puree (78.8\% cowpea seeds, $9.8 \%$ olive oil, $4.7 \%$ lemon juice, $5.5 \%$ water, $0.4 \%$ dried onion, $0.4 \%$ dried garlic, $0.12 \%$ cumin, $0.22 \%$ salt, $0.06 \%$ pepper), was previously optimized based on sensory quality evaluations of a discriminative trained panel $(n=8)$ from the UPCT.

\section{III.2.3. Treatments and storage conditions}

The sanitized cowpea seeds were bleaching with hot water $\left(100^{\circ} \mathrm{C}, 5 \mathrm{~min}\right)$ before the blending to obtain the puree. All ingredients were blended in a Robot Cook ${ }^{\circledR}$ (Robot Coupe, Montceau-en-Bourgogne, France) for $90 \mathrm{~s}$ at $1.450 \mathrm{~g}^{-1}$. The obtained puree was packaged (50 g) under aseptic conditions in a sterile embossed PE bags $(150 \times 250 \mathrm{~cm})(\mathrm{G} 1525$, Tav Food Packing SL, Madrid, Spain) under aseptic conditions being kept cold $\left(5^{\circ} \mathrm{C}\right)$ in crushed ice until subsequent treatments. Cowpea puree samples were treated by three different treatments: HHP, SV and by semi-continuous MW.

HHP was conducted placing puree samples (4 bags per each treatment run) in the sampling vessel of a high hydrostatic pressure equipment (HP Pilot Food Processor, Stansted Fluid Power Ltd., Essex, U.K.) at $550 \mathrm{MPa}$ for $10 \mathrm{~min}$ at $23^{\circ} \mathrm{C}$. Immediately after the samples were cooled down to the storage temperature $\left(5^{\circ} \mathrm{C}\right)$. The latter HHP treatment was selected according to our previous studies to obtain legume spreads with optimal quality (Klug et al., 2017).

Cowpea puree samples were pasteurized in a water bath (JP Selecta, Spain) for 3 min at $80.0 \pm 1.0{ }^{\circ} \mathrm{C}$ (core temperature $76.0 \pm 1.0^{\circ} \mathrm{C}$.) which was followed by immediately cooled down to $5^{\circ} \mathrm{C}$ and $\mathrm{SV}$ treatment was carried out.

MW treatment was applied in a semi-industrial prototype continuous-flow MW oven (Model SI MAQ0101, Sairem Iberica S.L., Barcelona, Spain) fully described in Castillejo et al. (2018). Briefly, this oven consisted of 4 adjustable magnetrons $(0.5-3.0 \mathrm{~kW} ; 2450 \mathrm{MHz})$, a polytetrafluoroethylene feed belt able to work on continuous or back-and-forth movement mode (semi-continuous), an optimized heating chamber, new energy economizing filters, a computer interface and a fibre optic slip ring for online temperature measurements inside the 
oven. MW treatment consisted of a semi-continuous mode with back-and-forth movement of $2 \mathrm{~m} \mathrm{~min}-1$ belt 151 speed at $8 \mathrm{~kW}(2+2+2+2 \mathrm{~kW})$ for $35 \mathrm{~s}$. This treatment was selected in order to achieve a fast heating to $80 \pm 2{ }^{\circ} \mathrm{C}$ checked with a portable fibre optic thermometer (Neoptix NOMAD-Fiber NMD, Neoptix, Quebec, Canada) since this treatment has been reported to induce good quality in a MW-treated legume puree (Klug et al., 2017). Four puree packages were treated at the same time in every treatment batch and the samples were immediately cooled down to $5^{\circ} \mathrm{C}$ after treatment.

Finally, untreated samples were used as control (CTRL). Packages from each sample batch (CTRL, HHP, SV and MW) were stored at $5{ }^{\circ} \mathrm{C}$ in darkness and evaluated on processing (day 0) and after 7, 14 and 21 days. Three packages (replicates) were prepared for each treatment and sampling time.

\section{III.2.4. Physicochemical analyses}

Fresh samples were used to determine the $\mathrm{pH}$ (Crison $2001 \mathrm{pH}$ meter, Crison Instruments SA, Barcelona, Spain). Colour was determined using a colorimeter (Minolta CR-300 Series, Japan) and results were expressed as CIE L*a*b* colour space units. Total colour differences $(\Delta \mathrm{E})$ throughout storage were compared to their respective initial values according to equations described by (Walkling-Ribeiro et al., 2010). $\Delta \mathrm{E}$ were expressed as:

$$
\Delta \mathrm{E}=1 / 2\left(\left\lfloor\left(L_{0}-L^{*}\right)^{2}+\left(a_{0}-a^{*}\right)^{2}+\left(b_{0}-b^{*}\right)^{2}\right\rfloor\right)
$$

\section{III.2.5. Total phenolic contents}

Frozen cowpea puree samples $(0.5 \mathrm{~g})$ were placed in glass bottles and homogenized (Ultraturrax T-25, Ika-Labortechnik, Staufen, Germany) with methanol (3 mL) for $1 \mathrm{~min}$. The extracts were centrifuged at $15,000 \times \mathrm{g}$ for $10 \mathrm{~min}$ at $4{ }^{\circ} \mathrm{C}$. The supernatant was used to determine the total phenolic content (TPC) by the Singleton and Rossi (1965) method with some modifications (Martínez-Hernández et al., 2011). Supernatant samples (19 $\mu \mathrm{L})$ and 29 $\mu \mathrm{L}$ of $1 \mathrm{~N}$ Folin-Ciocalteu reagent were mix in a well plate and incubated for $3 \mathrm{~min}$ at room temperature in darkness conditions. Then, $192 \mu \mathrm{L}$ of a solution containing $\mathrm{Na}_{2} \mathrm{CO}_{3}(0.4 \%)$ and $\mathrm{NaOH}(2 \%)$ was added. After $45 \mathrm{~min}$ of incubation at room temperature in darkness 
conditions, the absorbance was measured at $750 \mathrm{~nm}$ and TPC was expressed as mg gallic acid equivalents (GAE) $\mathrm{kg}^{-1} \mathrm{fw}$.

\section{III.2.6. Total antioxidant capacity}

The same sample extracts to determine TPC were used to evaluate the antioxidant capacity (TAC) by DPPH (Brand-Williams et al., 1995), ABTS (Cano et al., 1998) and FRAP (Benzie and Strain., 1999) assays early described. DPPH method was conducted by measuring the decrease in absorbance at $515 \mathrm{~nm}$ for $30 \mathrm{~min}$. A volume $(194 \mu \mathrm{L})$ of DPPH solution $(\approx 0.7$ $\mathrm{mM}$ and adjusted to $\left.\mathrm{Abs}_{517}=1.1 \pm 0.02\right)$ was added to each extract sample $(21 \mu \mathrm{L})$ and allowed to react for $30 \mathrm{~min}$. FRAP method was conducted by measuring the increase in absorbance at $593 \mathrm{~nm}$ for $45 \mathrm{~min}$. The freshly made-up FRAP solution (prepared in 10:1:1 v:v:v proportion of sodium acetate buffer, $\mathrm{pH} 3.6 ; 10 \mathrm{mM}$ TPTZ solution in $40 \mathrm{mM} \mathrm{HCl}$; and $20 \mathrm{mM} \mathrm{FeCl}$, respectively, and preincubated at $37^{\circ} \mathrm{C}$ for $2 \mathrm{~h}$ ) was added $(198 \mu \mathrm{L})$ to each extract sample (6 $\mu \mathrm{L}$ ) and allowed to react for $45 \mathrm{~min}$. ABTS method was conducted by measuring the increase in absorbance at $734 \mathrm{~nm}$ for $45 \mathrm{~min}$. A volume $(280 \mu \mathrm{L})$ of ABTS solution $\left(14 \mathrm{mM} \mathrm{ABTS}{ }^{+}\right.$ and $4.9 \mathrm{mM} \mathrm{K}_{2} \mathrm{~S}_{2} \mathrm{O}_{8}$ by $\left.1: 1(v: v)\right)$ was added to each extract sample $(6 \mu \mathrm{L})$ and allowed to react for $45 \mathrm{~min}$. The antioxidant activity for DPPH, ABST and FRAP assays was expressed as Trolox equivalent antioxidant capacity (TEAC) per $\mathrm{kg}^{-1} \mathrm{fw}$.

\section{III.2.7. Viscosity}

Viscous flow tests to measure the storage modulus $\left(\mathrm{G}^{\prime}\right)$ and loss modulus $\left(\mathrm{G}^{\prime \prime}\right)$ values were determined in triplicate with a controlled shear rate/stress rheometer (AR G-2, TA Instruments, UK) at $20{ }^{\circ} \mathrm{C}$. Stress sweep tests were run at $1 \mathrm{~Hz}$ with the shear stress of the input signal varying from 0.1 to $100 \mathrm{~Pa}$. Frequency sweeps were run, subjecting the samples to stress that varied harmonically with time at frequencies $(\omega)$ from 1 to $100 \mathrm{rad} \mathrm{s}^{-1}$.

\section{III.2.8. Sensory analyses}

The sensory evaluation of the fresh pea puree was carried out by 11 members (aged 22-70 years) of a previously trained in discriminative quality attributes and the ability to communicate sensory descriptions of products according to Klug et al. (2017). The panel screened for sensory ability (colour, flavour, texture, taste, consistency, overall quality) on a 
5-points structured hedonic scale (5: excellent, 4: good, 3: limit of acceptability, 2: poor, 1: extremely bad).

\section{III.2.9. Microbial analyses}

To determine the mesophilic, psychrotrophic, anaerobic Enterobacteriaceae counts, and yeast and mould growth in fresh cowpea puree, standard enumeration methods were used according to Klug et al. (2017). The presence of Salmonella spp., Listeria monocytogenes and generic Escherichia coli was monitored according to the European legislation (Regulation EC 1441/2007, 2007). All microbial counts were reported as $\log$ CFU g ${ }^{-1}$. Each of the three replicates was analyzed by duplicate.

\section{III.2.10. Statistical analysis}

An ANOVA was performed for comparing different treatments and storage times at a significant level of $\mathrm{p} \leq 0.05$ using PASW Statistics 22 for Windows (SPSS Inc., Chicago, IL, USA). In some cases, when significant differences were found, the Tukey's HSD (Honestly Significant Difference) test was applied. Bilateral correlations were determined by Pearson's correlation coefficient with a confidence interval established at $95 \%$.

\section{III.3. RESULTS}

\section{III.3.1 Phsysicochemical quality}

A light $\mathrm{pH}$ increase of cowpea puree after 14 days at $5{ }^{\circ} \mathrm{C}$ was observed. An increase in TA was also found in all samples during storage (Table III.1).

It was observed that the treatments had a significant $(\mathrm{p}<0.05)$ effect on the colour of cowpea puree samples, mainly in the $a^{*}$ value (Table III.1). HHP samples showed the most greenness colour at day 0 and maintained the yellowness colour, without significant differences with CTRL samples. Accordingly, Wang et al., (2013) observed that HHP (600 MPa, 15 min) processing delayed the green color deterioration of spinach puree. After SV and MW treatments, a decrease of $20.6 \%$ and $7.5 \%$ in $a^{*}$ values respectively was observed. During thermal processing of green vegetables chlorophylls are converted to pheophytins, causing a change from bright green to olive-brown (Ihl, et al., 1998; Artés et al., 2002). The highest $\Delta \mathrm{E}$ 
(3.75) was observed in SV samples at day 0, respect to MW and HHP samples (data not shown). A value higher than 3 in $\Delta \mathrm{E}$ determines differences perceptible to the human eye; thus, visible colour difference was only found in SV treatment. Similar results were reported by Kirse et al., 2017 , that observed in a maple pea spread $\mathrm{SV}$ treated $\left(80^{\circ} \mathrm{C}, 15 \mathrm{~min}\right)$ a higher increase on the $\Delta \mathrm{E}$ (2.95) in comparison to control. On the other hand, a color stability ( $\Delta \mathrm{E}<$ 3) was obtained for HHP-treated samples, which was also reported for apple puree (Landl et al., 2010). These can be attributed to the fact that HHP application does not initiate any pigment degradation or browning reaction which is more likely to be accelerated at higher temperatures like 60 or $70{ }^{\circ} \mathrm{C}$ (García-Parra et al., 2016).

The $\mathrm{a}^{*}$ value tended to increase during storage in all the samples, without significant differences among treatments. The higher $\Delta \mathrm{E}$ was observed after 12 days of storage, mainly in CRTL and SV samples (data not shown). It could be mainly due to the increase in $\mathrm{a}^{*}$ values. A previous work demonstrates that a* value can be an optimal indicator of green pea puree quality change and could be applicable for pasteurization process quality quantification and evaluation (Bornhorst et al., 2017b). After 21 days, an increase L* values was observed in HHP and MW treated samples (data not shown). Accordingly, increase in $\mathrm{L}^{*}$ values for pressure treated vegetable purees have been reported (Sánchez-Moreno et al., 2006; Landl et al., 2010). Furthermore, Klug et al. (2018) observed an increase in $L^{*}$ values during cold storage (20 days) of a faba beans pesto sauce MW treated (11 kW, $30 \mathrm{~s})$ and conventional pasteurization $\left(85{ }^{\circ} \mathrm{C}, 5 \mathrm{~min}\right)$. This might be due to cell disruption at the puree surface resulting a higher lightness values after HHP and MW treatments. Non-significant differences were found in $b^{*}$ values in all samples during storage (data not shown).

\section{III.3.2. Total phenolics content}

The initial TPC of cowpea puree was $572.30 \pm 9.95 \mathrm{mg} \mathrm{GA} \mathrm{kg}^{-1}$ (Figure III.1). High phenolic levels have been reported for different varieties of cowpeas seeds, with TPC values between $60 \mathrm{mg} \mathrm{GAE} \mathrm{kg}{ }^{-1}$ and $14.000 \mathrm{mg} \mathrm{GAE} \mathrm{kg}{ }^{-1}$ (Zia-Ul-Haq et al., 2013; Adjei-Fremah et al., 2015; Siddhuraju and Becker, 2006). In general, the TPC content of cowpea puree was unchanged $(\mathrm{p}<0.05)$ after any of the applied treatments. Nevertheless, the TPC of the cowpea puree increased a $6 \%$ after MW treatment. The same trend was observed for HHP and SV treated samples, but it was not significant. 
After 7 days of storage, a decrease (6.4 \%) in HHP-treated samples was observed, with significant differences among treatments (Figure III.1). Cao et al. (2011) studied the TPC in strawberry pulp and found that the content decreased when the pulp was treated at $400 \mathrm{MPa}$ for 5-25 min, probably be due to higher residual activity of PPO and POD in HHP-treated strawberry pulps at $400 \mathrm{MPa}$. Saikaew et al. (2018) also reported a decrease in TPC in pressurized (550 MPa, $30 \mathrm{~min}$ ) purple kernels might due to inefficient HHP conditions that not completed the inactivate enzymes, or instead release or activate oxidative enzymes.

The decrease of TPC continue during storage in all treated samples, with decreases of $9.0 \%$, $5.4 \%$ and $6.7 \%$ in HHP, MW and SV, respectively, after 21 days of storage in comparison with the initial value. At the end of storage, no significant differences among treatments were found. Xu et al. (2016) observed a significant loss of TPC (19\%) in the HHP-processed (550 $\mathrm{MPa}, 10 \mathrm{~min}$ ) banana puree, during 20 days of refrigerated storage, that was attributed to residual activity of PPO (19.41\%). The loss of TPC during storage might be hypothesized by the oxidation degradation of phenolic compounds, polymerization of phenolic compounds with proteins (Cao et al., 2011) or condensation reactions through covalent association with phenolic compounds (Chakraborty et al., 2015).

\section{III.3.3. Total Antioxidant Capacity}

In FRAP assay, the initial TEAC value of CTRL samples was $2166 \pm 15.3 \mathrm{mg} \mathrm{TEAC} \mathrm{kg}^{-1} \mathrm{fw}$ (Figure III.2). After treatments, the TEAC showed an increase of $10 \%$ and $6 \%$ after SV and MW samples, respectively, regarding CTRL samples. It has been suggested that food processing such as heating might improve the extractability of antioxidant compounds by breaking down cell walls (Gärtner and others 1997). Klug et al. (2018) showed a different behavior in a faba beans pesto sauce MW treated $(11 \mathrm{~kW} ; 30 \mathrm{~s})$, where a decrease of $14 \%$ was observed after treatment. On the other hand, the HHP samples showed a little decrease of $3 \%$ regarding the initial values. During storage, was not observed a significant decrease in treated samples, except in SV ones, which showed a $12 \%$ decrease after 14 days of storage.

Generally, the TEAC evaluated by DPPH assay showed a similar trend that FRAP assay values to treated samples and throughout storage, except to CTRL samples, that showed a decrease during storage of $17 \%$ regarding initial values (Figure 2). The antiradical capacity values of cowpea seeds varieties from Pakistan against DPPH • ranged from 25.1 to $32.5 \mu \mathrm{mol}$ 
Trolox/g (Zia-Ul-Haq et al., 2013) and Moreira-Araújo et al. (2017) reported DPPH values in

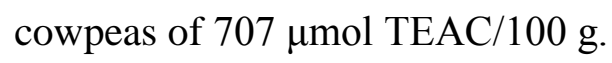

The TEAC evaluated by ABTS assay indicated different mechanisms for the antioxidant capabilities of the compounds. The highest antioxidant capacity were found after MW and SV treatments, with increases of $2.6 \%$ and $7.4 \%$, respectively, regarding control samples (Figure III.2), probably due to heat extractability previously discussed in FRAP increase. However, after 21 days of storage, MW and SV samples showed a decrease of $12 \%$ and $15 \%$, respectively (Figure III.2), with significant different among other treatments. It may be explained by the heat nature of these treatments, contrary to the used HHP, which could also lead to the heat degradation of bioactive compounds or chemical rearrangements such as the binding of phenolics with other organic substances (Volf et al., 2014), which can interfere in the TEAC by ABTS assay. On the contrary, at the end of storage CTRL and HHP samples showed an increase of $25 \%$ and $9 \%$, respectively, regarding values on processing day (Figure 2). CTRL and HHP-treated samples could have active enzymes which cause the liberation or destruction of some phenolic compounds in others.

The correlation coefficients between DPPH and FRAP were positive and significant (0.758, $\mathrm{p}$ $<0.001)$, between FRAP and TPC were positive and significant $(0.689, \mathrm{p}<0.001)$ and between DPPH and TPC were positive and significant $(0.479, \mathrm{p}<0.001)$. Although several bioactive compounds present in cowpea pods (chlorophyll, carotenoids, ascorbic acid, etc.) exhibit considerable antioxidant properties, the results of this study suggest that the high concentration of phenolic may determine the antioxidant activity of cowpea puree.

\section{III.3.4. Rheological characteristics}

The frequency dependence of storage or elastic modulus $\left(\mathrm{G}^{\prime}\right)$ and loss or viscous $\left(\mathrm{G}^{\prime \prime}\right)$ modulus of cowpea puree samples are presented in Figure III.3. $\mathrm{G}^{\prime}$ predominates over $\mathrm{G}^{\prime \prime}$ in the frequency range of 1-100 $\mathrm{rad} \mathrm{s}^{-1}$ for all treatments, indicating a solid-like or weak-gel behavior. G' is directly related to the cross-link density of the network in a gel. The shape of the rheological spectrum is similar to that reported in a pea puree (Klug et al., 2017) and rocket puree (Ahmed et al., 2013). 
After treatments, $\mathrm{G}^{\prime}$ of SV and MW treated samples were greater than that of HHP treated samples (Fig. III.3). Also, after HHP treatment, an increase in the G'and G" parameters regarding CTRL was found. Leite et al. (2017) observed that when a pea starch was pressurizated at $600 \mathrm{MPa}$, a gel phase was detected. This 'cold-gelatinization' shows that HHP can lead to formation of pea starch gel at room temperature. Aditionally, Saikaew et al. (2018) showed that HHP can enhances the swelling of starch granule causing gelatinization, since HHP (550-700 MPa, $30 \mathrm{~min}$ ) treated samples of kernels was completed gelatinized.

After 21 days of storage, a decreased in the viscosity of SV and HHP-treated samples was observed (Fig. III.3). In relation to HHP samples, the decrease in viscosity could be related to polygalacturonase (PG) enzyme inactivation, like observed in a pea puree (Klug et al., 2017). PG has been indicated to induce loss of structural integrity of tissue systems and also may cause a viscosity or consistency loss in pastes and purees of plant sources (Crelier et al., 2001). For pea puree, this enzyme was more thermo-resistant than PME, and could be used as an indicator of HHP efficiency. The decrease in viscosity, corroborated with the decrease in TPC contents, suggest that the HHP (550 MPa, $10 \mathrm{~min}$ ) failed to completely inactivate the enzymes responsible to loss in viscosity or phenolic contents.

The loss in viscosity observed in SV samples at the end of storage was mainly attributed to a loss of the integrity of the samples, because the samples turned breakable during cold storage. The viscosity was maintained in MW samples, probably due to the efficiency of the treatment in relation to inactivation of enzymes. Arjmandi et al. (2017a) reported that PG was the more thermo-resistant enzyme in tomato puree MW treated, where the major reduction (71\%) was found in $3150 \mathrm{~W} / 150 \mathrm{~s}$ treatment, whereas only $52 \%$ inactivation was reached at $390 \mathrm{~W} / 848$ s, so high power/short time seems to improve viscosity. These authors observed that viscosity was strongly influenced by the reduction in PG enzyme activity.

\section{III.3.5. Sensory}

According to panellist's observations, texture was the main quality parameter that determined the overall quality of the cowpea puree, since other parameters like colour, flavour and taste not showed significant differences (data not shown). As result, the overall quality of HHP samples was better scored than the others ones on processing day. HHP samples provided the best texture to cowpea puree (Fig. III.4), which is in agreement with the rheological 
parameters evaluated, since MW and SV treatments showed high apparent viscosity, which diminished the characteristic of a puree smear. On the contrary, Klug et al. (2018) showed that a faba beans pesto sauce MW treated $(11 \mathrm{~kW}, 30 \mathrm{~s})$ was better accepted by panelist than a sauce conventionaly treated $\left(85^{\circ} \mathrm{C}, 5 \mathrm{~min}\right)$ because it higher sensory viscosity. On the other hand, the panelist not observed significant differences in colour among CTRL, HHP, SV and MW treatments on processing day (data not shown), despite differences in a* values of HHP treated samples in relation to the other treatments (Table III.1).

After 21 days of storage, HHP and MW samples showed better overall quality with scores of $7.73 \pm 0.21$ and 7.20 \pm 0.26 , respectively, what led cowpea puree samples over the limit of acceptance after 21 days at $5{ }^{\circ} \mathrm{C}$ (Figure 4). The SV treatment was rejected at 14 days because of the loss of characteristic of spreading, what turned out the viscosity of the product breakable, showing overall quality score of $3.83 \pm 0.30$. This loss in viscosity was observed in $G^{\prime}$ and G"' values of the SV samples (Fig. III.3). In HHP- treated samples was also observed a reduction in $\mathrm{G}^{\prime}$ and $\mathrm{G}^{\prime \prime}$ values (Fig. III.3), but this reduction was not perceived by the panellist's in relation to characteristic of spreading of the cowpea puree.

\section{III.3.6. Microbial analyses}

The microbiological quality (mesophilic and anaerobic counts) of cowpea puree samples is shown in Figure 5. All samples showed similar initial mesophilic and anaerobic counts of 2.3-2.8 and 1.5-2.3 $\log \mathrm{CFU} \mathrm{g}^{-1}$ respectively (Fig. III.5) and psychrophilic, Enterobacteriaceae, and $\mathrm{Y}+\mathrm{M}$ loads $\left(<1 \log \mathrm{CFU} \mathrm{g}^{-1}\right)$ (data not shown). Lower Enterobacteriaceae levels were reported in our study compared to $4 \log \mathrm{CFU} \mathrm{g}{ }^{-1}$ reported in an untreated chickpea puree (Álvarez et al., 2017) probably owed to more efficient good manufacturing practices (processing in a cold room, sanitizing of all used material, etc.) hereby used.

As expected, a high microbial growth was found during storage of CTRL samples, with mesophilic/anaerobic increases of about $0.4 / 1.1 \log$ units after 7 days. The mesophilic loads of treated samples were below $4 \log$ units after 21 days while psychrophilic, Enterobacteriaceae and $\mathrm{Y}+\mathrm{M}$ loads were $<1 \log$ unit. No high microbial growth rates differences among HHP, MW and SV-treated samples were found during storage. Therefore, final mesophilic, total anaerobic bacteria, psychrophilic, and Y+M loads of HHP, MW and 
SV treated samples ranged between 2.1-3.4, 2.2-2.9, $<1 \log$ and $<1 \log$ CFU g ${ }^{-1}$, respectively, after 21 days at $5^{\circ} \mathrm{C}$.

\section{III.4. CONCLUSIONS}

The alternative treatments applied by different technologies showed differences in sensory quality of the cowpea puree. HHP and MW treatments were able to preserve consistency, texture and taste. SV samples showed loss of the apparent viscosity during storage and it was also perceived in the sensory test. Physicochemical properties, especially colour, were greatly influenced by heat treatments, in where HHP treatment was able to preserve greenness. However, TPC and TAC were more affected by HHP than MW-treated samples. Therefore, according to these results, HHP and MW treatments could be two alternative processing treatments to improving quality of a cowpea puree. 
Table III.1. pH, total titratable acidity (TTA) and color ( $\left.\mathrm{a}^{*}\right)$ changes during storage at $5{ }^{\circ} \mathrm{C}$ of untreated (CTRL), high hydrostatic pressure (HHP), microwave (MW) and sous vide (SV) treated cowpea puree.

\begin{tabular}{|c|c|c|c|c|}
\hline Day & Treatment & pH & TTA & $\mathbf{a}^{*}$ \\
\hline \multirow[t]{4}{*}{0} & CTRL & $5.03 \pm 0.06 \mathrm{~b}$ & $0.49 \pm 0.05 \mathrm{NSa}$ & $-6.40 \pm 0.35 \mathrm{Aba}$ \\
\hline & HHP & $5.03 \pm 0.06 \mathrm{~b}$ & $0.49 \pm 0.05 \mathrm{NSb}$ & $-6.75 \pm 0.36 \mathrm{Aa}$ \\
\hline & MW & $4.80 \pm 0.10 b$ & $0.41 \pm 0.08 \mathrm{NSb}$ & $-5.92 \pm 0.21 \mathrm{Ba}$ \\
\hline & SV & $4.83 \pm 0.12 b$ & $0.44 \pm 0.12 \mathrm{NSb}$ & $-5.08 \pm 0.14 \mathrm{Ca}$ \\
\hline \multirow[t]{4}{*}{7} & CTRL & $4.90 \pm 0.00 \mathrm{~b}$ & $0.63 \pm 0.03 \mathrm{ABab}$ & $-4.04 \pm 0.10 \mathrm{NSc}$ \\
\hline & HHP & $4.87 \pm 0.06 \mathrm{~b}$ & $0.68 \pm 0.02 \mathrm{Aab}$ & $-3.60 \pm 0.16 \mathrm{NSc}$ \\
\hline & MW & $4.80 \pm 0.10 b$ & $0.53 \pm 0.08 \mathrm{Bab}$ & $-3.97 \pm 0.49 \mathrm{NSb}$ \\
\hline & SV & $4.83 \pm 0.12 b$ & $0.53 \pm 0.06 \mathrm{Bab}$ & $-3.82 \pm 0.23 \mathrm{NSb}$ \\
\hline \multirow[t]{4}{*}{14} & CTRL & $5.00 \pm 0.10 \mathrm{ab}$ & $0.49 \pm 0.02 \mathrm{NSb}$ & $-4.45 \pm 0.11 \mathrm{NSbc}$ \\
\hline & HHP & $4.93 \pm 0.06 \mathrm{ab}$ & $0.66 \pm 0.16 \mathrm{NSab}$ & $-4.44 \pm 0.71 \mathrm{NSb}$ \\
\hline & MW & $4.93 \pm 0.06 \mathrm{ab}$ & $0.54 \pm 0.16 \mathrm{NSb}$ & $-4.45 \pm 0.21 \mathrm{NSb}$ \\
\hline & SV & $4.93 \pm 0.06 \mathrm{ab}$ & $0.73 \pm 0.08 \mathrm{NSa}$ & $-4.18 \pm 0.60 \mathrm{NSab}$ \\
\hline \multirow[t]{4}{*}{21} & CTRL & $5.07 \pm 0.21 \mathrm{a}$ & $0.78 \pm 0.11 \mathrm{NSa}$ & $-4.89 \pm 0.43 \mathrm{NSb}$ \\
\hline & HHP & $5.10 \pm 0.10 \mathrm{a}$ & $0.82 \pm 0.08 \mathrm{NSa}$ & $-4.45 \pm 0.10 \mathrm{NSb}$ \\
\hline & MW & $4.93 \pm 0.06 \mathrm{a}$ & $0.72 \pm 0.02 \mathrm{NSa}$ & $-4.04 \pm 0.26 \mathrm{NSb}$ \\
\hline & SV & $5.10 \pm 0.17 \mathrm{a}$ & $0.73 \pm 0.04 \mathrm{NSa}$ & $-4.17 \pm 0.66 \mathrm{NSab}$ \\
\hline \multicolumn{2}{|c|}{ Treatment } & $*$ & $* *$ & $* * *$ \\
\hline \multicolumn{2}{|l|}{ Days } & $* *$ & $* * *$ & $* * *$ \\
\hline \multicolumn{2}{|c|}{ Days $\mathrm{x}$ Treatment } & NS & $*$ & $* *$ \\
\hline
\end{tabular}

Values correspond to average value $(n=3) \pm$ SD. Different capital letters within the same column show significant differences among treatments. Different lower case letters within the same column show significant differences among storage time. NS: not significant; *** $(\mathrm{p}<0.001)$; ** $(\mathrm{p}<0.01)$; $(\mathrm{p}<0.05)$. 


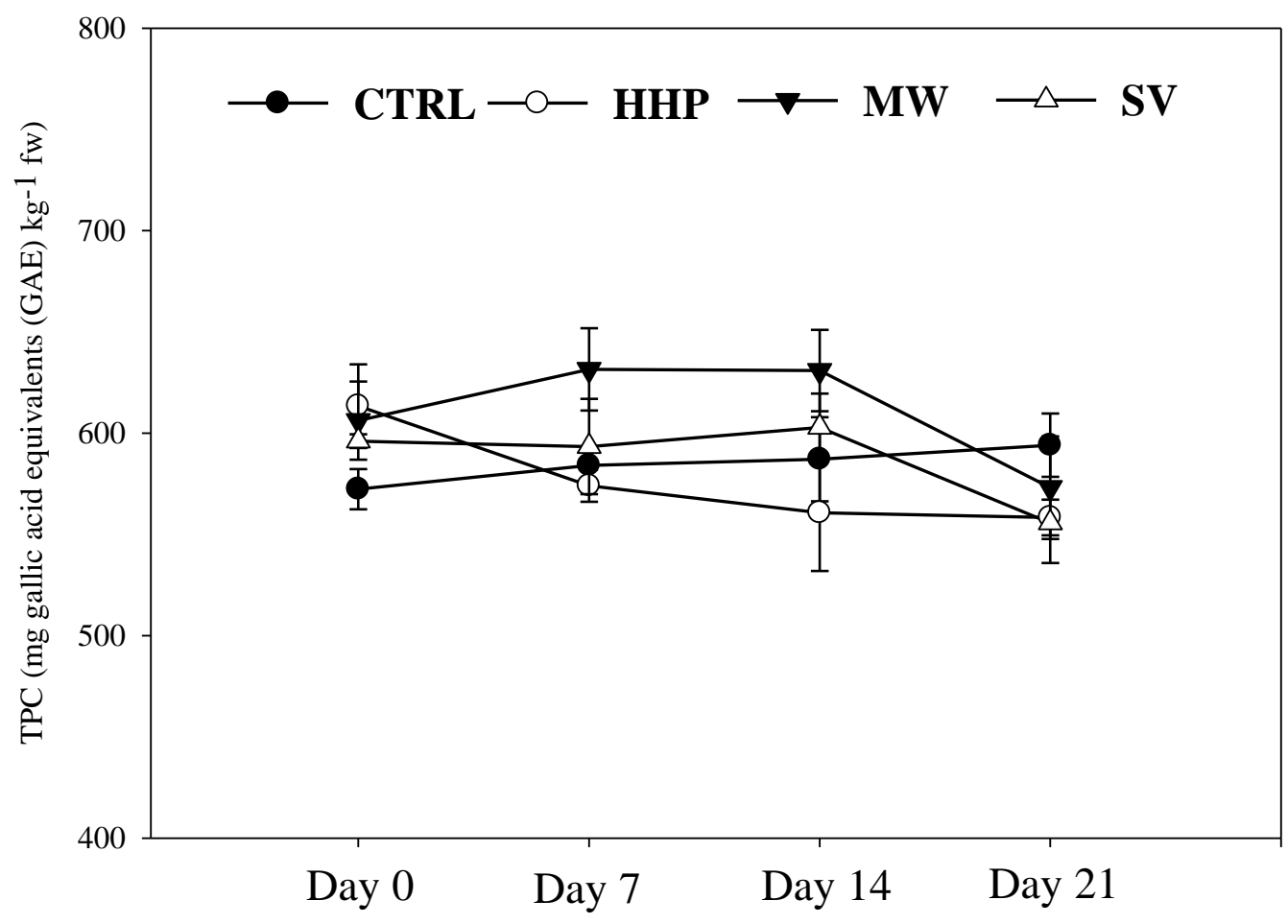

Figure III.1. Total phenolic content changes during storage at $5{ }^{\circ} \mathrm{C}$ of untreated (CTRL), high hydrostatic pressure (HHP), microwave (MW) and sous vide (SV) treated cowpea puree. 


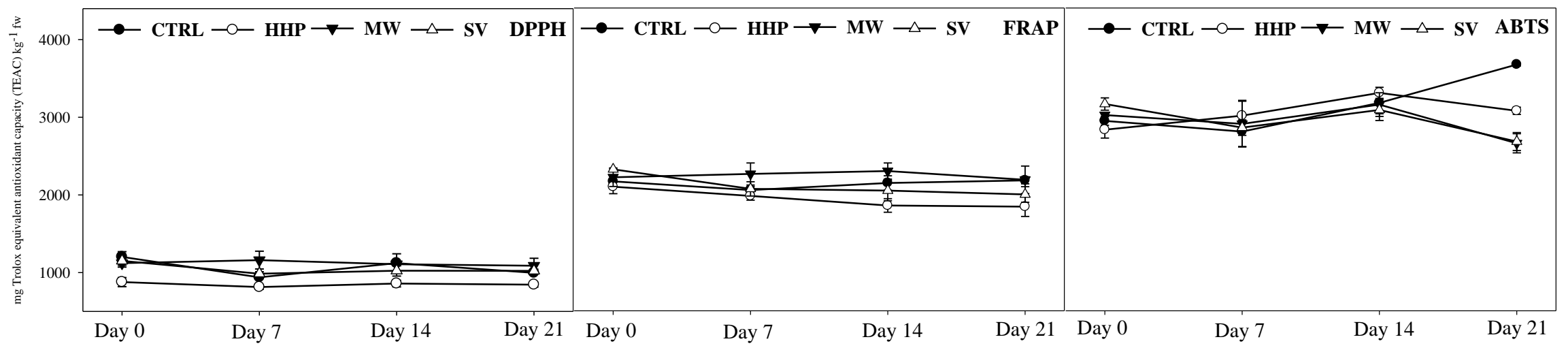

Figure III.2. Total antioxidant capacity (DPPH, FRAP and ABTS methods) changes during storage at $5{ }^{\circ} \mathrm{C}$ of untreated (CTRL), high hydrostatic pressure (HHP), microwave (MW) and sous vide (SV) treated cowpea puree. (FRAP: ferric reducing antioxidant power; DPPH: 2,2-diphenyl-1-picrylhydrazil; TEAC: Trolox equivalent antioxidant capacity; GAE: gallic acid equivalents). 


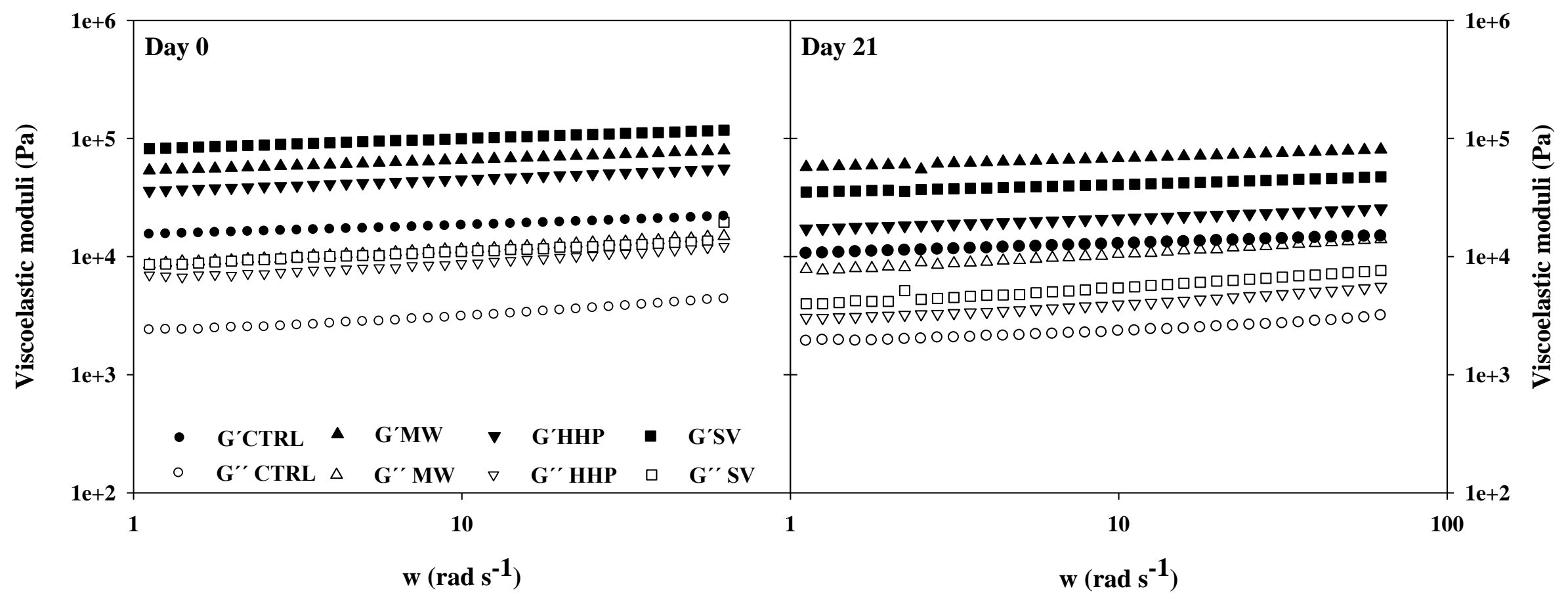

Figure III.3. Rheological parameters changes during storage at $5{ }^{\circ} \mathrm{C}$ of untreated (CTRL), high hydrostatic pressure (HHP), microwave (MW) and sous vide (SV) treated cowpea puree. 


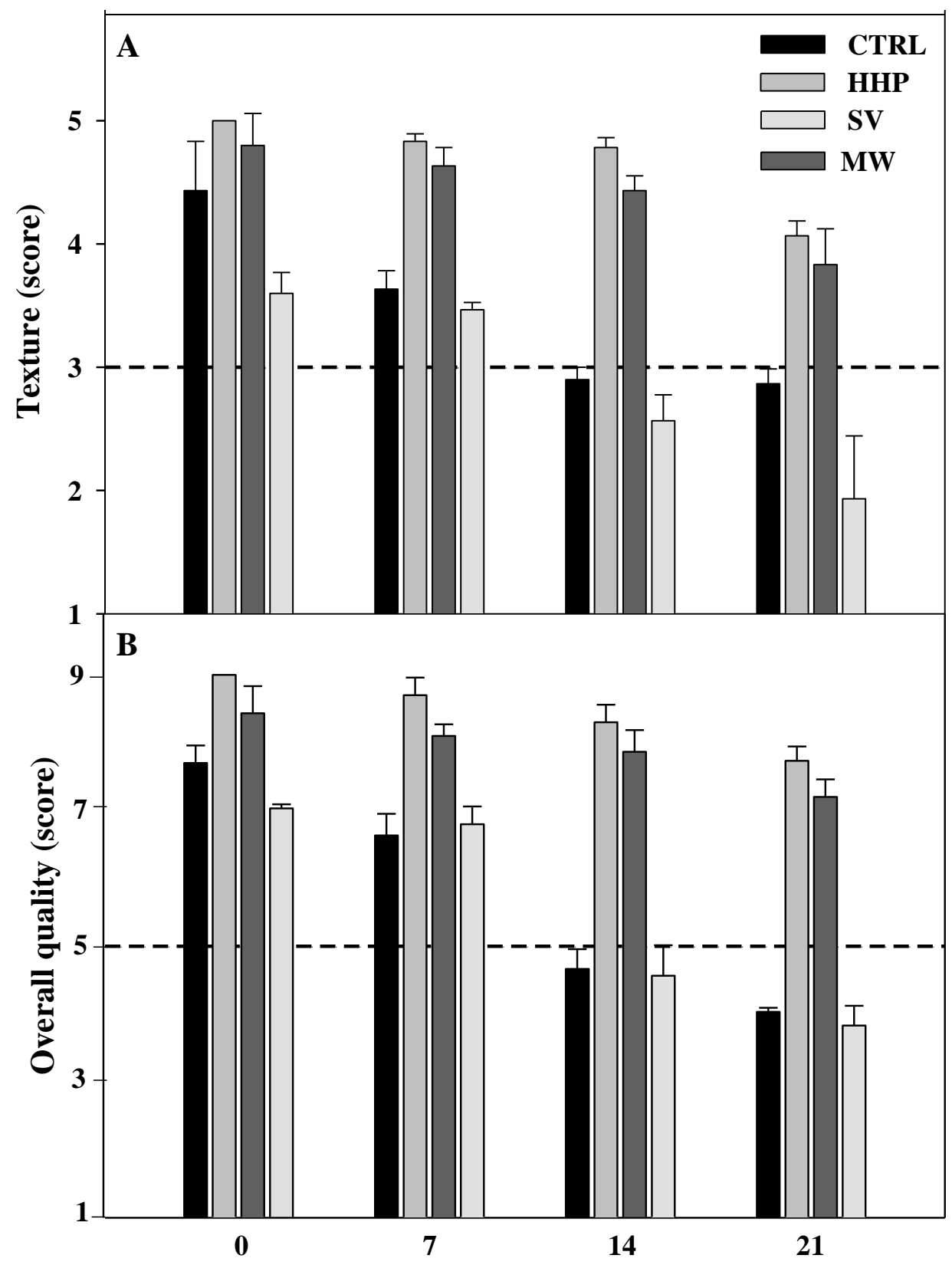

Figure III.4. Sensory consistency (A) and overall quality (B) changes during storage at $5{ }^{\circ} \mathrm{C}$ of untreated (CTRL), high hydrostatic pressure (HHP), microwave (MW) and sous vide (SV) treated cowpea. 


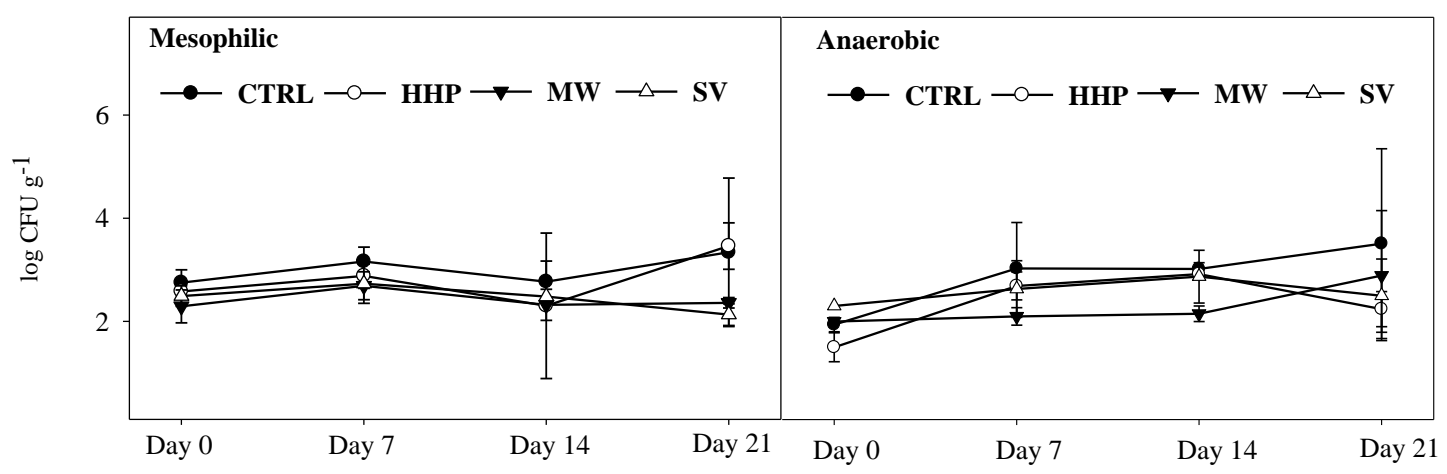

Figure III.5. Mesophilic and anaerobic counts during storage at $5{ }^{\circ} \mathrm{C}$ of untreated (CTRL), high hydrostatic pressure (HHP), microwave (MW) and sous vide (SV) treated cowpea puree 


\section{CHAPTER IV}

\section{Innovative Quality Improvement by Continuous Microwave Processing of a Faba Beans Pesto Sauce}

Tâmmila Venzke Klug ${ }^{1}$, Elena Collado ${ }^{2}$, Ascensión Martínez-Sánchez ${ }^{1,2}$, Perla A Gómez ${ }^{2}$, Encarna Aguayo ${ }^{1,2}$, Mariano Otón ${ }^{2}$, Francisco Artés ${ }^{1,2}$ and Francisco Artés-Hernández ${ }^{1,2}$

1 Postharvest and Refrigeration Group. Department of Food Engineering. Universidad Politécnica de Cartagena. Paseo Alfonso XIII, 48, 30203 Cartagena, Murcia, Spain.

2 Institute of Plant Biotechnology. Universidad Politécnica de Cartagena. Campus Muralla del Mar, 30202 Cartagena, Murcia, Spain.

Reference: Food and Bioprocess Technology. 2018. 11(3), 561-571. 


\section{IV.1. INTRODUCTION}

There is an actual trend towards increasing the consumption of healthy foods due to consumers are really concern about the influence of diet on health and well-being. Therefore, the food industry needs to produce healthy innovative ready-to-eat high quality and safety products to satisfy the demand of consumers. Previous studies have described a positive association between plant-based diets with increased intake of legumes and health (Lima et al., 2016). Particularly, the development of new legumes-based elaborates, like faba beans, could be an interesting market since i.e., faba bean seeds contain $22.4-36 \%$ protein, $57.8-61 \%$ carbohydrates, $12 \%$ fiber and 1.2-4\% lipids (Hedley 2001). In addition, faba beans can be recommended as a good folate source, as a $100 \mathrm{~g}$ portion of green faba bean seeds provides $120 \mu \mathrm{g}$ of dietary folate equivalents (Hefni et al., 2015). Furthermore, an important phenolics content and antioxidant activity of faba beans have been previously reported (Baginsky et al., 2013). Moreover, a therapeutic potential to treat Parkinson's disease has been described since faba beans provides L-3,4-dihydroxyphenylalanine (L-DOPA), the precursor to the neurotransmitter catecholamine (Randhir and Shetty 2004). Therefore, previous studies showed faba beans as an interesting food to develop innovative food products due to its beneficial health implications.

Processing technologies which can guarantee safety and stability while offer high quality products, may be the key to prolong the shelf-life and satisfy the current consumers demand (Picouet et al., 2009). MW pasteurization is a thermal technology considered as an interesting alternative to conventional techniques. MW heating has a number of quantitative and qualitative advantages over conventional heating techniques (Marszalek et al., 2015; Bornhorst et al., 2017a). The main advantage is that heat is generated inside the product itself. Therefore, it can be heated in a shorter time and even with more temperature diffusion. Such advantages, often increased yield and production rate and/or led to an improved product quality.

Previous studies have evaluated the microbial and sensory quality, as well as the nutrient content and bioactive compounds associated to MW cooking. Arjmandi et al. (2017a) showed that MW treatment with high power/short time (1900 W/180 s, $2700 \mathrm{~W} / 160 \mathrm{~s}$ and 3150 $\mathrm{W} / 150 \mathrm{~s}$ ) in tomato puree improved the viscosity, lycopene extraction and better decreased 
the enzyme residual activity (PG and PME) than conventional heated. Benlloch-Tinoco et al. (2015) studied the impact of MW (1000W/340 s) and conventional pasteurization on the shelf life of a kiwifruit puree and observed a higher preservation of bioactive compounds (57-67\%) in MW-treated samples regarding conventional pasteurization. In addition, Arjmandi et al. (2017b) reported a better colour retention of an oranged-coloured smoothie after an alternative pasteurization treatment provided by MW at $90 \pm 2{ }^{\circ} \mathrm{C}$ for $35 \mathrm{~s}$. Similar results were reported by Guzmán et al. (2002), who observed a greener colour in avocado puree treated with MW power density for a shorter time $(31.65 \mathrm{~W} / \mathrm{g}, 30 \mathrm{~s})$.

The aim of the present study was to develop an innovative pesto sauce, made of fresh faba beans seeds, and evaluate the effect of an alternative MW processing treatment on the microbial, sensory and nutritional quality changes, as well as on the bioactive compounds content during the storage for 20 days at $5{ }^{\circ} \mathrm{C}$ in darkness.

\section{IV.2. MATERIALS AND METHODS}

\section{IV.2.1. Pesto sauce from Faba Beans}

A new pesto sauce (73\% fresh faba beans (Vicia faba L. var. minor cv. Palenca), $22 \%$ olive oil, $3.63 \%$ lemon juice, $0.55 \%$ vinegar, $0.4 \%$ salt, $0.4 \%$ sugar, $0.02 \%$ garlic powder; $\mathrm{pH}=5.0$ ), was previously optimized based on sensory quality evaluations of a previously discriminative trained panel $(n=11)$ from the UPCT. All ingredients were purchased at a local supermarket from Cartagena (Murcia, Spain).

\section{IV.2.2. Treatments and storage conditions}

All ingredients were blended in a Robot Cook $^{\circledR}$ (Robot Coupe, Montceau-en-Bourgogne, France) for $30 \mathrm{~s}$ at $1.450 \mathrm{x} g$ (control treatment, CTRL). Then, pesto sauce samples (approximately $1 \mathrm{~kg}$ ) were heated in the same blender for conventional pasteurization (CP) at $85 \pm 2{ }^{\circ} \mathrm{C}$ during $5 \mathrm{~min}$ while samples (approximately $1 \mathrm{~kg}$ ) for MW treatment were packed in polyethylene bags embossed (100 g) and treated for $30 \mathrm{~s} / 11 \mathrm{~kW}$ in an innovative semiindustrial prototype of continuous microwave oven (SI-MAQ0101, Sairem Ibérica SL, Barcelona, Spain) which was previously described (Arjmandi et al. 2017b; Castillejo et al. 2018). Briefly, the microwave oven consisted of 4 adjustable magnetrons $(0.5-3.0 \mathrm{~kW} ; 2450$ 
$\mathrm{MHz}$ ), a polytetrafluoroethylene (PTFE) feed belt able to work on continuous or back-and-forth movement mode (semi-continuous), an optimized heating chamber, new energy economizing filters, a computer interface and a fibre optic slip ring for online temperature measurements inside the microwave oven. MW consisted of a semi-continuous mode with back-and-forth movement of $2 \mathrm{~m} \mathrm{~min}^{-1}$ belt speed at $11 \mathrm{~kW}(3+3+3+2 \mathrm{~kW})$ for 30 s. MW treatment was previously optimized in order to achieve a fast heating of $85^{\circ} \mathrm{C}$, checked with a portable fibre optic thermometer (Neoptix NOMAD-Fiber NMD, Neoptix, Quebec, Canada)). The reflected power from each magnetron was $360 \mathrm{~W}$ resulting in a final MW power of $9.56 \mathrm{~kW}(2.64+2.64+2.64+1.64 \mathrm{~kW})$. After MW treatment, samples reached a temperature of $85 \pm 5{ }^{\circ} \mathrm{C}$. As CTRL samples, non-heated blended samples were used. Immediately after processing (CTRL, CP and MW), samples of $100 \mathrm{~g}$ were vacuum sealed (Egarvac, Barcelona, Spain) and cooled up to $5{ }^{\circ} \mathrm{C}$ in ice-water bath. Packages were stored at $5{ }^{\circ} \mathrm{C}$ in darkness condition. Three packages from each sample batch (CTRL, CP and MW) of faba beans pesto sauce were evaluated immediately after processing (day 0 ) and after 5, 8, 14 and 20 days of storage for physicochemical, sensory and microbial analyses. The rest of analyses were carried out in frozen samples at $-80^{\circ} \mathrm{C}$.

\section{IV.2.3. Physicochemical analyses}

Samples were used to determine the $\mathrm{pH}$ by a pH-meter (Crison $2001 \mathrm{pH}$ meter, Crison Instruments SA, Barcelona, Spain). Titratable acidity (TA) was determined by the titration of $5 \mathrm{~g}$ of samples $+45 \mathrm{~mL}$ of distilled water with $0.1 \mathrm{~mol} \mathrm{~L}^{-1} \mathrm{NaOH}$ to $\mathrm{pH} 8.1$ (T50, Mettler Toledo, Milan, Italy) and expressed as g malic acid $100 \mathrm{~mL}^{-1}$. Color was determined using a colorimeter (Minolta CR-300 Series, Japan) and the results were expressed as CIE L*a*b* color space units. Total color differences $(\Delta \mathrm{E})$ throughout storage were compared to their respective initial values according to equations previously described by Walkling-Ribeiro et al. (2010). $\Delta \mathrm{E}$ were expressed as

$$
\Delta \mathrm{E}=1 / 2\left(\left\lfloor\left(L_{0}-L^{*}\right)^{2}+\left(a_{0}-a^{*}\right)^{2}+\left(b_{0}-b^{*}\right)^{2}\right\rfloor\right)
$$

\section{IV.2.4. Total carotenoids and chlorophylls content}

The sample preparation for chlorophyll determination was conducted as previously reported Rodríguez-Hidalgo et al. (2010), with light modifications, in where the total chlorophyll 
pigments were extracted with hexane. Briefly, frozen samples $(0.5 \mathrm{~g})$ were mixed with hexane $(9 \mathrm{~mL})$ and $15 \mathrm{~mL}$ of a mixture of methanol-acetone $(1: 2, \mathrm{v} / \mathrm{v})$. The extraction was carried out by using an orbital shaker (Stuart, Staffordshire, UK) at $200 \times \mathrm{g}$ at $4{ }^{\circ} \mathrm{C}$ for $4 \mathrm{~h}$ in darkness. After extraction, $25 \mathrm{~mL}$ of $1 \mathrm{M} \mathrm{NaCl}$ was added and samples were vortex mixed. The upper layer was used to determine the chlorophyll and carotenoid content. The absorbance (A) at 662, 644 and $470 \mathrm{~nm}$ was measured using a UV-visible spectrophotometer (Hewlett Packard, model 8453, Columbia, USA) in sample extracts $(1 \mathrm{~mL})$. The equations developed by Wellburn (1994) were used to determine the individual content of chlorophyll a $(\mathrm{Ca}=10.05 \mathrm{x}$ A662-0.766 x A644), chlorophyll b ( $\mathrm{Cb}=16.37$ x A644-3.14 x A662), total chlorophylls (Ca $+\mathrm{Cb})$ and total carotenoids $[\mathrm{Cx}+\mathrm{c}=(1000 \times \mathrm{A} 470-1.28 \times \mathrm{Ca}-56.7 \times \mathrm{Cb}) / 205]$. Chlorophylls and total carotenoids contents were expressed as $\mathrm{mg} \mathrm{kg}^{-1} \mathrm{fw}$. All measurements were made in triplicate.

\section{IV.2.5. Sugar and organic acids contents}

The sucrose content and organic acids (citric and malic) were calculated according to Flores et al. (2012) with some modifications. Frozen pesto sauce samples ( $3 \mathrm{~g}$ ) were homogenized (Ultra-turrax T-25, Ika-Labortechnik, Staufen, Germany) with cold water (10 mL) for $1 \mathrm{~min}$. The extracts were filtrated with a cheesecloth and centrifuged at 12,000 $\times g$ for $20 \mathrm{~min}$ at 4 ${ }^{\circ} \mathrm{C}$. The supernatant was purified by passing through a column of solid phase extraction in a parallel Strata C18-E column (55um, 70 A; Phenomenex, Macclesfield, UK) and samples were filtered through a $0.45 \mu \mathrm{m}$ PTFE syringe filter. Chromatographic analyses were carried out on an ultra-high-performance liquid chromatography instrument -UHPLC- (Shimadzu, Kyoto, Japan) equipped with a DGU-20A degasser, LC-30AD quaternary pump, SIL-30AC autosampler, CTO-10AS column heater and SPDM-20A photodiode array detector. The UHPLC system was controlled by the software LabSolutions (Shimadzu, v5.42 SP5). Chromatographic analyses were carried out onto a RAM-Carbohydrate Ag+ (Phenomenex, Macclesfield, UK) column. The column temperature was maintained at $25{ }^{\circ} \mathrm{C}$. Sulfuric acid $0.001 \mathrm{~N}$ as the mobile phase was used with an isocratic flow rate of $1.0 \mathrm{~mL} \mathrm{~min}^{-1}$, and the injection volume $20 \mu \mathrm{L}$. Quantification and assignment of peaks was based on the peak areas and retention times of known standard curves for purified sucrose, acid citric and acid malic (Sigma, St Louis, MO, USA). The results were expressed as $\mathrm{mg} \mathrm{kg}^{-1} \mathrm{fw}$. 


\section{IV.2.6. Determination of condensed tannins}

Frozen samples (3 g) were homogenized (Ultra-turrax T-25, Ika-Labortechnik, Staufen, Germany) with methanol $(6 \mathrm{~mL})$ for $1 \mathrm{~min}$ and the extraction was carried out in an orbital shaker (Stuart, Staffordshire, UK) for $20 \mathrm{~min}$ at $200 \times g$. The extracts were centrifuged at $15,000 \times g$ for $10 \mathrm{~min}$ at $4{ }^{\circ} \mathrm{C}$.

The condensed tannins were colorimetrically assayed by the method of vanillin- $\mathrm{HCl}$ according to Price et al. (1978). To $1 \mathrm{~mL}$ of supernatant, $2.5 \mathrm{~mL}$ of $1 \%$ vanillin reagent and $2.5 \mathrm{~mL}$ of solution $\mathrm{HCl} 8 \%$ were added and incubated for $20 \mathrm{~min}$ in a water bath at $30{ }^{\circ} \mathrm{C}$ under continuous agitation. The samples absorbance was read at $500 \mathrm{~nm}$. Methanol was used as a blank and catechin (+; Sigma Chemical Co., St Louis, MO) was used as standard to made the calibration curves. The condensed tannins content was expressed as mg catechin equivalents (CE) $\mathrm{kg}^{-1} \mathrm{fw}$.

\section{IV.2.7. Total phenolics content}

Frozen pesto sauce samples $(0.5 \mathrm{~g})$ were placed in glass bottles and homogenized (Ultraturrax T-25, Ika-Labortechnik, Staufen, Germany) with methanol (3 $\mathrm{mL})$ for $1 \mathrm{~min}$. The extracts were centrifuged at $15,000 \times g$ for $10 \mathrm{~min}$ at $4{ }^{\circ} \mathrm{C}$. The supernatant was used to determine the total phenolic content (TPC) by the Singleton and Rossi (1965) method, but with some modifications (Martínez-Hernández et al., 2011). Supernatant samples (19 $\mu$ L) and $29 \mu \mathrm{L}$ of $1 \mathrm{~N}$ Folin-Ciocalteu reagent were mix in a well plate and incubated for $3 \mathrm{~min}$ at room temperature in darkness conditions. Then, $192 \mu \mathrm{L}$ of a solution containing $\mathrm{Na}_{2} \mathrm{CO}_{3}$ $(0.4 \%)$ and $\mathrm{NaOH}(2 \%)$ was added. After $45 \mathrm{~min}$ of incubation at room temperature in darkness conditions, the absorbance was measured at $750 \mathrm{~nm}$ and TPC was expressed as $\mathrm{mg}$ gallic acid equivalents (GAE) $\mathrm{kg}^{-1}$ fw.

\section{IV.2.8. Total antioxidant capacity}

The same sample extracts to determine TPC were used to evaluate the antioxidant capacity (TEAC) by 2,2-diphenyl-1-picrylhydrazil (DPPH) (Brand-Williams et al., 1995) and ferric reducing antioxidant power (FRAP) (Benzie and Strain 1999) assays. 
DPPH assay: the free radical scavenging activity using the free radical DPPH was evaluated by measuring the decrease in absorbance at $515 \mathrm{~nm}$ for $30 \mathrm{~min}$. A volume $(194 \mu \mathrm{L})$ of DPPH solution $(0.7 \mathrm{mM})$ was added to each extract sample $(21 \mu \mathrm{L})$.

FRAP assay: the freshly made up FRAP solution containing sodium acetate buffer (pH 3.6), $10 \mathrm{mM}$ TPTZ solution (in $40 \mathrm{mM} \mathrm{HCl}$ ) and $20 \mathrm{mM} \mathrm{FeCl} 3$ was prepared in a v/v/v proportion of 10:1:1. A volume $(198 \mu \mathrm{L})$ of FRAP solution was react to each extract sample $(6 \mu \mathrm{L})$ for $45 \mathrm{~min}$ at room temperature in darkness and increase of absorbance was determined at 593 $\mathrm{nm}$. The antioxidant activity for DPPH and FRAP assays was expressed as Trolox equivalent antioxidant capacity (TEAC) $\mathrm{kg}^{-1} \mathrm{fw}$.

\section{IV.2.9. Sensory analyses}

Sensory analyses were performed according to international standards (ASTM 1986). Tests were conducted in a standard room (ISO 2007) equipped with ten individual taste boxes using the white light. Samples (about $20 \mathrm{~g}$ ) were served at room temperature in transparent glasses coded with 3 random digit numbers. Still mineral water was used as palate cleanser. The sensory evaluation of the faba beans pesto sauce was carried out by 11 members (aged 22-69 years) of a previously trained in discriminative quality attributes and the ability to communicate sensory descriptions of products according to Klug et al. (2017). The panel screened for sensory ability (colour, flavour, texture, taste, consistency, overall quality) on a 5-points structured hedonic scale (5: excellent, 4: good, 3: limit of acceptability, 2: poor, 1: extremely bad).

\section{IV.2.10. Microbial analyses}

To determine the mesophilic, psychrophilic, Enterobacteriaceae, and yeast and mould growth, standard enumeration methods were used according to Castillejo et al. (2016). The following media and incubation conditions were used: plate count modified agar (PCA) (Scharlau Chemie, Barcelona, Spain) for mesophilic and psychrotrophic aerobic bacteria, incubated at $37{ }^{\circ} \mathrm{C}$ for $48 \mathrm{~h}$ and at $5{ }^{\circ} \mathrm{C}$ for 7 days, respectively; violet red bile dextrose agar (Scharlau Chemie, Barcelona, Spain) for enterobacteria, incubated at $37{ }^{\circ} \mathrm{C}$ for $48 \mathrm{~h}$; and rose bengal agar (Scharlau Chemie, Barcelona, Spain) for yeasts and moulds, incubated for 3-5 days at $25{ }^{\circ} \mathrm{C}$. The presence of Salmonella spp., Listeria monocytogenes and generic 
Escherichia coli was monitored according to the European legislation (Regulation EC 1441/2007 2007). All microbial counts were reported as log colony forming units per gram of product $\left(\log \mathrm{CFU} \mathrm{g}^{-1}\right)$. Each of the three replicates was analyzed by duplicate.

\section{IV.2.11. Statistical analysis}

An analysis of variance (ANOVA) was performed for comparing different treatments and storage times at a significant level of $\mathrm{P} \leq 0.05$ using PASW Statistics 22 for Windows (SPSS Inc., Chicago, IL, USA). In some cases, when significant differences were observed, the Tukey's HSD (Honestly Significant Difference) test was applied. Bilateral correlations were determined by Pearson's correlation coefficient with a confidence interval established at 95\%.

\section{IV.3. RESULTS AND DISCUSSION}

\section{IV.3.1. Effect of thermal treatments on physicochemical quality attributes}

Faba beans pesto sauce showed a $\mathrm{pH}$ decrease just after heat treatments and a subsequent light $\mathrm{pH}$ decrease and TA increase after 14 days at $5{ }^{\circ} \mathrm{C}$ (Table IV.1). MW samples showed the lowest $\mathrm{pH}$ decrease (around 0.03 units) and the lowest increase in TA (around 0.14 units). On the other hand, colour of the pesto sauce was affected by treatments. After thermal treatments, a lightness ( $\left.\mathrm{L}^{*}\right)$ decrease was observed regarding CTRL samples (Fig. IV.1B), without differences between MW and CP treatments. This trend was maintained during storage.

However, at the end of storage, an increase in $\mathrm{L}^{*}$ was observed in all samples (CTRL, CP and MW) (Fig. IV.1B). The chromatic $a^{*}$ and $b^{*}$ index showed a different behavior among treatments and also throughout storage. Thermal treatments increased $\mathrm{a}^{*}$ values, with the highest value detected in CP-samples, while MW treatment showed the highest $b^{*}$ value. As a result, processed samples slightly changed to less yellow tones. The color of faba beans pesto sauce after microwave treatment changed from light green to dark green $\left(a^{*}\right.$ and $b^{*}$ increasing). MW treatment preserved the pigments improving the appearance to that obtained with CP treatment. The increase of chromatic $a^{*}$ index and decrease of $b^{*}$ has been previously reported by Benlloch-Tinoco et al. (2014), where more luminous kiwifruit puree was obtained under MW treatment (1000W / 340 s), due to the preservation of pigments instead of to the typical browning reactions in heating processes. Throughout storage, a* chromatic index 
increased after 5 days at $5{ }^{\circ} \mathrm{C}$ (Fig. IV.1A), while a decrease in $\mathrm{b}^{*}$ index was observed after 8 days at $5{ }^{\circ} \mathrm{C}$ (data not shown). All treatments showed relevant colour differences $(\Delta \mathrm{E})$ from day 8, and this trend was maintained until the end of storage (Fig. IV.1C). According to our results, Marszalek et al. (2015) found minor colour changes in strawberry puree after two continuous MW treatments $\left(90 \pm 1^{\circ} \mathrm{C}\right.$, at atmospheric pressure or at $120 \pm 1{ }^{\circ} \mathrm{C}$ and $0.35 \mathrm{MPa}$ with a holding time of $10 \mathrm{~s}$ ). De Ancos et al. (1999) also reported that MW heating induced slight colour changes in strawberry puree. A high significant $(\mathrm{p}<0.01)$ negative correlation was observed between $\mathrm{a}^{*}$ index and $\mathrm{pH}(-0.597)$ and between $\mathrm{a}^{*}$ index and TA $(-0.742)$.

\section{IV.3.2. Effect of thermal treatments on total carotenoids and chlorophylls}

The initial total chlorophylls content of CTRL samples was $31.6 \pm 5.7 \mathrm{mg} \mathrm{kg}^{-1}$ fw (Table IV.2). Chlorophyll a represents around $77 \%$ of total chlorophyll content of pesto sauce of faba beans. Petzold et al. (2014) showed that broad beans seeds (Vicia faba L) var. major cv. Aguadulce contained $19.4 \pm 0.9 \mathrm{mg} \mathrm{kg}^{-1}$ of total chlorophylls and that $68.5 \%$ was reported to be chlorophyll a. After treatments, total chlorophylls content was significantly $(\mathrm{p}<0.01)$ lower in CP samples than in MW samples, without significant differences between CTRL and MW treatments (Table IV.2). Significant differences in total chlorophylls content were due to changes in chlorophyll a, in accordance with Zhao et al. (2013). Chlorophyll b was maintained after pasteurization treatments and during the storage (data not shown). Chlorophylls can be degradated under low pH conditions (Cano 1991) and by thermal processing. According to the literature, losses of chlorophylls brought about by thermal processing vary from 12 to $66 \%$ depending on the species, the usable part of the plant and the treatment time/temperature binomial (Lisiewska et al., 2004; Murcia et al., 2000). At the end of storage, CP samples showed losses around $12 \%$ in the total chorophylls content, while MW samples showed an increase around 14\% (Table IV.2).

On the other hand, MW-treated samples showed a higher total carotenoids content than CP samples, while carotenoids content in pasteurized samples (MW and CP) did not showed significant differences regarding CTRL samples (Table IV.2). Total carotenoids content after MW treatment $\left(8.9 \pm 0.7 \mathrm{mg} \mathrm{kg}^{-1} \mathrm{fw}\right)$ remained quite constant throughout the storage and showed highest values compared to $\mathrm{CP}$ samples $\left(8.0 \pm 2.3 \mathrm{mg} \mathrm{kg}^{-1} \mathrm{fw}\right)$. Arjmandi et al. (2017a) showed that $\beta$-carotene content of tomato puree was also affected by heating method, 
and increased after continuous MW pasteurization regarding unheated CTRL samples by breaking down the cellulose structure of the plant cell walls (Van het Hof et al. 2000). At the end of storage, CP samples showed around 13\% losses while MW samples reported around $8 \%$ losses (Table IV.2).

A significant $(\mathrm{p}<0.01)$ negative correlation was observed between $\Delta \mathrm{E}$ and the pigments determined in the faba bean pesto sauce, reporting - 0.447 with total chlorophylls content and 0.436 with total carotenoids content. The higher $\Delta \mathrm{E}$ value observed in $\mathrm{CP}$ treatment regarding MW treatment could be attributed to the highest $\mathrm{a}^{*}$ index, and mostly to the highest decrease in chlorophylls and carotenoids content.

\section{IV.3.3. Effect of thermal treatments on sugar and organic acids}

After treatments, no significant differences were observed between samples in the citric acid content (Fig. IV.2B). After 5 days of storage at $5{ }^{\circ} \mathrm{C}$, a significant decrease $(\mathrm{p}<0.001)$ was observed in the citric acid content from all samples, although the highest decrease was observed in CTRL samples (27\%) and the lowest decrease in MW samples (17\%) (Fig. IV.2B). After this, citric acid content was maintained until the end of storage in all samples. On the contrary, malic acid was unaffected by treatments and was quite stable throughout the storage time (Fig. IV.2C).

The sucrose content of faba beans pesto sauce was lower than previous data reported in raw faba beans and this could be due to different preharvest factors. Vidal-Valverde et al. (1998) evaluated the sucrose content in faba beans seeds (Vicia faba, L. major), which described values of $38.3 \pm 1.2 \mathrm{~g} \mathrm{~kg}^{-1}$ of dry matter $(\mathrm{dm})$. Few data have been published reporting the effects of processing on the soluble sugars of faba beans. In our study, sucrose content increased after CP (63.4\%) and MW (77.2\%) treatments regarding CTRL samples (Fig. IV.2A). According to our results, Shimelis and Rakshit (2005) evaluated sucrose content in common bean after MW treatment until $10 \mathrm{~min}$ and showed that the sucrose content was increased in the MW-heated samples. On the contrary, Vidal-Valverde et al. (1998) showed that the content of sucrose of faba beans seeds after citric acid soaking plus cooking $\left(100^{\circ} \mathrm{C}\right.$, $35 \mathrm{~min}$ ) was reduced by $72 \%$. After 5 days at $5{ }^{\circ} \mathrm{C}$, a decrease was observed in all samples, in where CTRL samples showed the highest decrease with losses around $72 \%$, while CP samples and MW samples showed losses around $27 \%$ and 39\%, respectively. MW and CP samples 
showed lower sucrose content than CTRL ones after 20 days at $5{ }^{\circ} \mathrm{C}$ (Fig. IV.2A). According to Rao and Belavady (1978) a part of oligosaccharides could be present in bound form to proteins or to other macromolecules and thermal treatments may affect these bonds releasing the oligosaccharides.

\section{IV.3.4. Effect of thermal treatments on condensed tannins, total phenolics content (TPC) and total antioxidant capacity (TEAC)}

Condensed tannins content of untreated CTRL pesto sauce was $5942 \pm 390 \mathrm{mg} \mathrm{CE} \mathrm{kg}^{-1} \mathrm{fw}$. Almeida et al. (2008) described a ranged for condensed tannins from 1.95 to $2.87 \mathrm{~g}$ eq. catechin (CE) $\mathrm{kg}^{-1} \mathrm{dm}$ in Vicia faba cultivars. Variety with high tannins content (for example, var. Bobas) and variety with low tannins content (for example, var. Amulet) showed values of 7840 and $760 \mathrm{mg} \mathrm{CE} \mathrm{kg}^{-1} \mathrm{dm}$, respectively (Przywitowski et al., 2016). A 20\% decrease of the condensed tannins content, just after MW treatment on processing day and regarding CTRL samples, was observed (Table IV.2). On the contrary, CP treatment did not affect the condensed tannins content (Table IV.2). Tannins can be considered as antinutritional factors, leading to reduced nutrient absorption, mineral availability and protein digestibility (DíazBatalla et al., 2006), so the reduction of tannins content is an important point to be considered in a legume-based product. Similar results, have been recently reported by Deng et al. (2015), which evaluated tannins content in buckwheat grains after MW treatment $(850 \mathrm{~W} ; 30 \mathrm{~min})$ reporting a decrease of $27.5 \%$ after the treatment. A possible explanation to this reduction could be related to heat labile nature of such compounds (Rakic et al., 2007). After 5 days at 5 ${ }^{\circ} \mathrm{C}$, the tannins content decreased in CTRL and CP samples without differences regarding MW samples. This trend was observed until the end of storage.

The total phenolics content of CTRL samples was higher $\left(2980 \pm 213 \mathrm{mg} \mathrm{GAE} \mathrm{kg}^{-1} \mathrm{fw}\right)$ than the one reported by Baginsky et al. (2013) in several varieties of faba beans immature seeds $\left(817.02 \pm 71.05\right.$ to $\left.1337.82 \pm 84.22 \mathrm{mg} \mathrm{GAE} \mathrm{kg}^{-1}\right)$. After thermal treatments, a reduction around $12 \%$ or $16 \%$ in CP and MW treatments, respectively, was observed (Table IV.2). In general, phenolic degradation may occur after thermal treatments and during storage due to enzymatic or chemical oxidation (Tomás-Barberán and Espín 2001). This trend was described by previous authors. Benlloch-Tinoco et al. (2015) detected that total phenolics content was reduced by $28.80 \%$ and $42.38 \%$ when kiwifruit puree was microwaved ( $2 \mathrm{~W} / \mathrm{g}, 340 \mathrm{~s}$ ) and 
conventionally heat treated $\left(97^{\circ} \mathrm{C}, 30\right.$ s), respectively. In the same way, Picouet et al. (2009) founded that apple puree samples heated under MW conditions (652 W, $35 \mathrm{~s}$ ), achieving maximum product temperature of $75.3 \pm 4.8{ }^{\circ} \mathrm{C}$, showed $26 \%$ loss of total phenolic content after 5 days of storage regarding the initial content. However, contradictory data to these results has also been reported. Zhou et al. (2016) observed that domestic MW oven treatments for 60 and $80 \mathrm{~s}$ at $11.0 \mathrm{~W} / \mathrm{g}$, reaching temperature of $100{ }^{\circ} \mathrm{C}$, increased total phenolic content by $12.8 \%$ and $29.0 \%$ in defatted avocado puree, respectively regarding untreated samples. After 20 days at $5{ }^{\circ} \mathrm{C}$, MW-treated samples showed $0.7 \%$ losses of TPC regarding values on processing day, while CP and CTRL- treated samples showed losses around $4.3 \%$ and 16\%, respectively (Table IV.2). During storage, total phenolics content was maintained, probably due to the PPO and POD enzymes inactivation, or because of samples were kept in vacuum bags and therefore PPO was not active to degrade the phenolic compounds. Benlloch-Tinoco et al. (2013) published that the inactivation of PPO and POD during microwave processing of kiwifruit puree was significantly faster in comparison with the conventional processes. Arjmandi et al. (2017a) found microwave heating to be more effective at inactivating POD and preserving nutritional properties in tomato puree than conventional thermal treatment.

TEAC of the faba beans pesto sauce evaluated by FRAP and DPPH assays are presented in Table IV.2. In FRAP assay, TEAC showed a decrease around 14\% in MW treatment regarding CTRL samples, although no differences between MW and CP samples were observed. After 5 days at $5{ }^{\circ} \mathrm{C}$, all samples reported a decrease of their antioxidant capacity, which was around $8 \%$ in MW treated samples, while CP and CTRL samples showed losses around 14\% (Table IV.2). However, at the end of storage, no differences were observed regarding the initial day in CTRL, CP and MW samples. On the other hand, the TEAC evaluated by DPPH assay, not showed differences among treatments, and it was well preserved during the 20 days of storage at $5{ }^{\circ} \mathrm{C}$ (Table IV.2). The different results observed between FRAP and DPPH assays were due to the different methodology based in both assays. DPPH test the free radical scavenging activity, while FRAP evaluate the ferric reducing capacity of extracts (Llorach et al., 2008).

The TPC and condensed tannins showed a high correlation in FRAP assay. The correlation coefficient between FRAP and TPC was positive and significant $(0.829, \mathrm{p}<0.001)$ and between FRAP and condensed tannins was positive and significant $(0.564, \mathrm{p}<0.01)$. 
However, no significant correlation was observed by DPPH assay. The correlation between FRAP assay and TPC corroborated with the results of Sinha et al. (2013) that reported high positive relationship between total phenols and antioxidant capacity in faba beans seeds and that the antioxidant activity reported was largely because of its condensed tannins. We observed that the reduction of tannins content is in agreement with the reduction in the TEAC by FRAP assay. The antioxidant activity of flavonoids depends on the number of hydroxyl groups in their molecules, so a high concentration of procyanidins, rich in hydroxyl groups, increased the antioxidant capacity (Oszmianski et al., 2008).

\section{IV.3.5. Effect of thermal treatments on sensory quality}

In sensory quality, no differences were observed among treatments on processing day. However, after 14 days at $5{ }^{\circ} \mathrm{C}$, thermally treated samples showed better taste than CTRL samples (Fig. IV.3A). In addition, CTRL samples were rejected by taste after 14 days at $5{ }^{\circ} \mathrm{C}$. A similar trend was observed in flavour, where MW samples and CP samples presented better flavour than CTRL samples (data not shown).

On the other hand, MW treated samples showed the best colour throughout storage, while CTRL samples showed the lowest score and CTRL samples were rejected by colour after 20 days (Fig. IV.3B). Similar results were observed in texture, where MW and CP treatments provided the best texture to pesto sauce samples, while CTRL samples showed the worst (Fig. IV.3C). Furthermore, consistency was lower in CTRL samples than in thermally treated CP and MW samples (data not shown). As result, the shelf life of CTRL samples was lower than 14 days at $5{ }^{\circ} \mathrm{C}$, meanwhile thermally treated samples presented a good acceptability up to 20 days at $5{ }^{\circ} \mathrm{C}$, mainly MW-treated samples (Fig. IV.3).

MW treatment provided a better ideal phases separation between oils and other components, like a typical pesto. In addition, a higher consistency of the product was observed during storage. In this way, among MW and CP heated samples, MW samples were more consistent and had a better texture than CP or CTRL samples. In terms of sensory quality, the higher viscosity was better scored as it gives better mouthfeel. Zhou et al. (2016) studied the viscosity of defatted avocado puree treated by MW (11.0 W/g, $80 \mathrm{~s})$ and showed that the viscosity of this product increased after MW treatment. The increase in viscosity of microwaved-treated samples could be attributed to the rupture of the starch granules and re- 
association of the amylopectin molecules which gradually gelatinized as function of the vibrational motion of the polar molecules during the microwave treatment (Bilbao-Sáinz et al., 2007).

The taste showed a high correlation with condensed tannins, citric acid and sucrose. The correlation coefficients between taste and condensed tannins were positive and significant $(0.464, \mathrm{p}<0.01)$, between taste and citric acid were positive and significant $(0.578, \mathrm{p}<$ $0.001)$ and between taste and sucrose were positive and significant $(0.681, \mathrm{p}<0.001)$.

Concerning sensory taste, we observed a better acceptability of thermally treated faba beans pesto sauce samples, mainly in MW samples. A possible reason could be the highest sucrose content and the lowest astringent taste, which could be related to the lowest condensed tannins content regarding CTRL samples. Troszynska et al. (2006) evaluated astringency and proteins precipitation activity from faba bean and broad bean extracts and was reported that phenolic extracts from these legume seeds have acted as effective astringents. Also Troszynska et al. (2006) observed that the extracts showed precipitation ability of the heterogeneous proteins which naturally existed in human salivary (HSPs) and in bovine serum albumin (BSA) protein, which indicates that their astringency was responsible for condensed tannins. Additionally, tannins content might also reduce food acceptance due to change in sensory quality as a result of alter astringency, bitterness and texture of food products.

\section{IV.3.6. Effect of thermal treatments on microbial analyses}

All samples showed low aerobic mesophilics counts $\left(<3 \log \mathrm{CFU} \mathrm{g}{ }^{-1}\right)$ during storage, without differences between treatments and storage time (Fig. IV.4). Psychrotrophic, enterobacteria and molds and yeasts counts were maintained below the detection limit $\left(<1 \log \mathrm{CFU} \mathrm{g} \mathrm{g}^{-1}\right.$ for bacterial and $<2 \log \mathrm{CFU} \mathrm{g}^{-1}$ for molds and yeasts) (data not shown). No Salmonella spp., Listeria monocytogenes and generic Escherichia coli presence was detected throughout storage according to Regulation EC 1441/2007 (2007). According to our results, Marszalek et al. (2016) evaluated the microbial stability (total microbial count and molds and yeasts) of strawberry puree preserved with continuous MW processing and $\mathrm{CP}$, both treatments reaching the temperature of $90 \pm 1{ }^{\circ} \mathrm{C}$, and the microbial counts remained in 2-3 log CFU g ${ }^{-1} \mathrm{fW}$ and < $1 \log \mathrm{CFU} \mathrm{g}{ }^{-1} \mathrm{fw}$ for molds and yeasts counts, respectively, until the end of the storage. 
In agreement with the low counts detected for all analyzed microorganisms, no $\mathrm{pH}$ alteration was detected. In fact, the microbial load does not reduce the shelf life of faba beans pesto sauce, due to the efficacy of the thermal treatment, among other factors like good manufacture practices and storage conditions. The vacuum packaging of the samples could also contribute to maintain the initial low counts of microorganisms during storage, and additionally, those microorganisms that were damaged after the thermal treatment could not be recovered during the storage.

\section{IV.4. CONCLUSIONS}

The alternative mild pasteurization applied by different technologies showed differences in sensory quality of the faba beans pesto sauce. Physicochemical properties, especially colour, were greatly influenced by heat treatments, in where MW treatment was able to preserve greenness, improve the consistency, texture and taste. In addition, degradation of condensed tannins by MW is an interesting alternative to conventional pasteurization for astringent cooked food. Therefore, MW is an efficient technology to apply in faba beans pesto sauce to improve its physicochemical, nutritional and sensorial quality regarding conventional pasteurization and maintaining the quality of the pesto sauce throughout 20 days at $5{ }^{\circ} \mathrm{C}$. 
Table IV.1. $\mathrm{pH}$ and titratable acidity (TA) changes during storage at $5{ }^{\circ} \mathrm{C}$ of untreated control (CTRL), conventional pasteurization (CP) and microwave (MW) treated faba beans pesto sauce.

\begin{tabular}{|c|c|c|c|}
\hline Day & Treatment & pH & $\begin{array}{l}\text { TA } \\
\left(\mathrm{g} \text { malic acid } 100 \mathrm{~mL}^{-1}\right)\end{array}$ \\
\hline \multirow[t]{3}{*}{0} & CTRL & $4.90 \pm 0.01 \mathrm{Aa}$ & $0.41 \pm 0.01 \mathrm{NSc}$ \\
\hline & $\mathrm{CP}$ & $4.83 \pm 0.06 \mathrm{Ca}$ & $0.41 \pm 0.03 \mathrm{NSb}$ \\
\hline & MW & $4.83 \pm 0.06 \mathrm{Ba}$ & $0.44 \pm 0.02 \mathrm{NSb}$ \\
\hline \multirow[t]{3}{*}{5} & CTRL & $4.86 \pm 0.06 \mathrm{Aab}$ & $0.41 \pm 0.01 \mathrm{NSc}$ \\
\hline & $\mathrm{CP}$ & $4.80 \pm 0.01 \mathrm{Cab}$ & $0.49 \pm 0.03 \mathrm{NSb}$ \\
\hline & MW & $4.80 \pm 0.01 \mathrm{Bab}$ & $0.47 \pm 0.02 \mathrm{NSb}$ \\
\hline \multirow[t]{3}{*}{8} & CTRL & $4.90 \pm 0.01 \mathrm{Aa}$ & $0.43 \pm 0.01 \mathrm{NSc}$ \\
\hline & $\mathrm{CP}$ & $4.83 \pm 0.06 \mathrm{Ca}$ & $0.52 \pm 0.09 \mathrm{NSab}$ \\
\hline & MW & $4.87 \pm 0.06 \mathrm{Ba}$ & $0.46 \pm 0.01 \mathrm{NSb}$ \\
\hline \multirow[t]{3}{*}{14} & CTRL & $4.87 \pm 0.06 \mathrm{Ab}$ & $0.58 \pm 0.02 \mathrm{NSa}$ \\
\hline & $\mathrm{CP}$ & $4.70 \pm 0.01 \mathrm{Cb}$ & $0.55 \pm 0.05 \mathrm{NSab}$ \\
\hline & MW & $4.80 \pm 0.01 \mathrm{Bb}$ & $0.58 \pm 0.04 \mathrm{NSa}$ \\
\hline \multirow[t]{3}{*}{20} & CTRL & $4.87 \pm 0.06 \mathrm{Ab}$ & $0.52 \pm 0.06 \mathrm{NSb}$ \\
\hline & $\mathrm{CP}$ & $4.70 \pm 0.01 \mathrm{Cb}$ & $0.68 \pm 0.15 \mathrm{NSb}$ \\
\hline & MW & $4.77 \pm 0.06 \mathrm{Bb}$ & $0.65 \pm 0.04 \mathrm{NSa}$ \\
\hline \multicolumn{2}{|c|}{ Treatment } & $* * *$ & $* *$ \\
\hline \multicolumn{2}{|l|}{ Days } & $* * *$ & $* * *$ \\
\hline \multicolumn{2}{|c|}{ Days $x$ Treatment } & NS & $*$ \\
\hline
\end{tabular}

Values correspond to average value $(n=3) \pm$ SD. Different capital letters within the same column show significant differences between treatments. Different lower case letters within the same column show significant differences between storage times. NS: not significant; $* * *(\mathrm{p}<0.001) ; * *(\mathrm{p}<0.01) ; *(\mathrm{p}<0.05)$. 
Table IV.2. Total carotenoids, total chlorophylls content changes, total antioxidant capacity (FRAP and DPPH methods), total phenolics compounds (TPC) and condensed tannins changes during storage at $5{ }^{\circ} \mathrm{C}$ of untreated control (CTRL), conventional pasteurization (CP) and microwave (MW) treated faba beans pesto sauce.

\begin{tabular}{|c|c|c|c|c|c|c|c|}
\hline Day & Treatment & $\begin{array}{l}\text { Total carotenoids } \\
\quad\left(\mathrm{mg} \mathrm{kg}^{-1} \mathrm{fw}\right)\end{array}$ & $\begin{array}{l}\text { Total chlorophylls (mg } \\
\left.\mathbf{k g}^{-1} \mathbf{f w}\right)\end{array}$ & $\begin{array}{c}\text { FRAP } \\
\left(m g \text { TEAC } \mathbf{k g}^{-1} \mathbf{f w}\right)\end{array}$ & $\begin{array}{c}\text { DPPH } \\
(m g \text { TEAC kg } \\
\left.\text { s }^{-1} \mathbf{f w}\right)\end{array}$ & $\begin{array}{c}\text { TPC } \\
\left(m g \text { GAE } \mathbf{~ k g}^{-1} \mathbf{f w}\right)\end{array}$ & $\begin{array}{l}\text { Condensed Tannins } \\
\quad\left(\mathrm{mg} \mathrm{CE} \mathrm{kg}^{-1} \mathrm{fw}\right)\end{array}$ \\
\hline \multirow[t]{3}{*}{0} & CTRL & $9.4 \pm 1.8 \mathrm{AB}$ & $31.6 \pm 5.7 \mathrm{~A}$ & $4146 \pm 109$ Аа & $1265 \pm 22 \mathrm{~b}$ & $2980 \pm 213 \mathrm{Aa}$ & $5942 \pm 390 \mathrm{Aa}$ \\
\hline & $\mathrm{CP}$ & $8.0 \pm 2.3 \mathrm{~B}$ & $29.5 \pm 3.4 \mathrm{~B}$ & $3672 \pm 119 \mathrm{ABa}$ & $1242 \pm 20 \mathrm{~b}$ & $2614 \pm 75 \mathrm{Ba}$ & $5838 \pm 64 \mathrm{Aa}$ \\
\hline & MW & $8.9 \pm 0.7 \mathrm{~A}$ & $31.5 \pm 4.0 \mathrm{~A}$ & $3564 \pm 210 \mathrm{Ba}$ & $1200 \pm 39 \mathrm{~b}$ & $2507 \pm 134 \mathrm{Ba}$ & $4730 \pm 210 \mathrm{Bns}$ \\
\hline \multirow[t]{3}{*}{5} & CTRL & $8.6 \pm 0.3 \mathrm{AB}$ & $32.5 \pm 0.9 \mathrm{~A}$ & $3548 \pm 13 \mathrm{Ab}$ & $1237 \pm 32 \mathrm{ab}$ & $2763 \pm 64 \mathrm{Aab}$ & $5048 \pm 26 \mathrm{NSab}$ \\
\hline & $\mathrm{CP}$ & $7.3 \pm 0.9 \mathrm{~B}$ & $24.3 \pm 5.2 \mathrm{~B}$ & $3178 \pm 207 \mathrm{ABb}$ & $1238 \pm 6 \mathrm{ab}$ & $2502 \pm 145 \mathrm{Bab}$ & $5331 \pm 525 \mathrm{NSab}$ \\
\hline & MW & $8.3 \pm 1.3 \mathrm{~A}$ & $30.0 \pm 1.2 \mathrm{~A}$ & $3275 \pm 58 \mathrm{Bb}$ & $1268 \pm 13 \mathrm{ab}$ & $2650 \pm 19 \mathrm{Bab}$ & $4770 \pm 400 \mathrm{NSns}$ \\
\hline \multirow[t]{3}{*}{8} & CTRL & $8.9 \pm 1.3 \mathrm{AB}$ & $30.8 \pm 0.1 \mathrm{~A}$ & $3509 \pm 59 \mathrm{Ab}$ & $1267 \pm 34 \mathrm{ab}$ & $2584 \pm 95 \mathrm{Aab}$ & $5815 \pm 677 \mathrm{NSa}$ \\
\hline & $\mathrm{CP}$ & $7.2 \pm 0.4 \mathrm{~B}$ & $25.0 \pm 0.1 \mathrm{~B}$ & $3425 \pm 132 \mathrm{ABb}$ & $1271 \pm 27 \mathrm{ab}$ & $2598 \pm 170 \mathrm{Bab}$ & $4407 \pm 519 \mathrm{NSbc}$ \\
\hline & MW & $8.5 \pm 1.9 \mathrm{~A}$ & $29.1 \pm 0.2 \mathrm{~A}$ & $3373 \pm 178 \mathrm{Bb}$ & $1274 \pm 33 \mathrm{ab}$ & $2537 \pm 137 \mathrm{Bab}$ & $4973 \pm 1041 \mathrm{NSns}$ \\
\hline \multirow[t]{3}{*}{14} & CTRL & $6.9 \pm 1.1 \mathrm{AB}$ & $29.4 \pm 5.6 \mathrm{~A}$ & $3512 \pm 155 \mathrm{Ab}$ & $1269 \pm 38 \mathrm{a}$ & $2588 \pm 175 \mathrm{Ab}$ & $4077 \pm 146 \mathrm{NSb}$ \\
\hline & $\mathrm{CP}$ & $6.9 \pm 0.2 \mathrm{~B}$ & $25.7 \pm 3.3 \mathrm{~B}$ & $3377 \pm 454 \mathrm{ABb}$ & $1250 \pm 4 \mathrm{a}$ & $2351 \pm 178 \mathrm{Bb}$ & $4050 \pm 14$ NSc \\
\hline & MW & $8.4 \pm 0.1 \mathrm{~A}$ & $28.2 \pm 6.0 \mathrm{~A}$ & $3130 \pm 134 \mathrm{Bb}$ & $1312 \pm 18 \mathrm{a}$ & $2359 \pm 171 \mathrm{Bb}$ & $4350 \pm 246 \mathrm{NSns}$ \\
\hline \multirow[t]{3}{*}{20} & CTRL & $7.3 \pm 0.3 \mathrm{AB}$ & $32.8 \pm 3.1 \mathrm{~A}$ & $3379 \pm 95$ Aab & $1266 \pm 23 \mathrm{ab}$ & $2500 \pm 239 \mathrm{Aab}$ & $4352 \pm 321 \mathrm{NSb}$ \\
\hline & $\mathrm{CP}$ & $7.0 \pm 0.9 \mathrm{~B}$ & $26.3 \pm 3.4 \mathrm{~B}$ & $3498 \pm 488 \mathrm{ABab}$ & $1247 \pm 15 \mathrm{ab}$ & $2501 \pm 291 \mathrm{Bab}$ & $4674 \pm 323 \mathrm{NSbc}$ \\
\hline & MW & $8.2 \pm 1.0 \mathrm{~A}$ & $35.8 \pm 3.0 \mathrm{~A}$ & $3500 \pm 692 \mathrm{Bab}$ & $1261 \pm 24 \mathrm{ab}$ & $2489 \pm 513 \mathrm{Bab}$ & $4074 \pm 98$ NSns \\
\hline \multicolumn{2}{|c|}{ Treatment } & $*$ & $* *$ & $*$ & NS & $*$ & $*$ \\
\hline \multicolumn{2}{|c|}{ Days } & NS & NS & $* *$ & $* *$ & $*$ & $* * *$ \\
\hline \multicolumn{2}{|c|}{ Days $x$ Treatment } & NS & NS & NS & $* *$ & NS & $* *$ \\
\hline
\end{tabular}

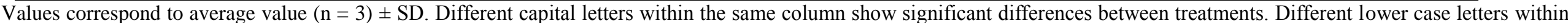

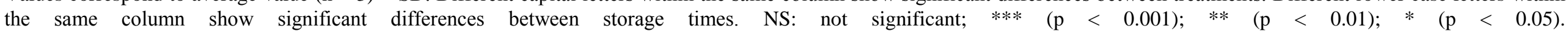




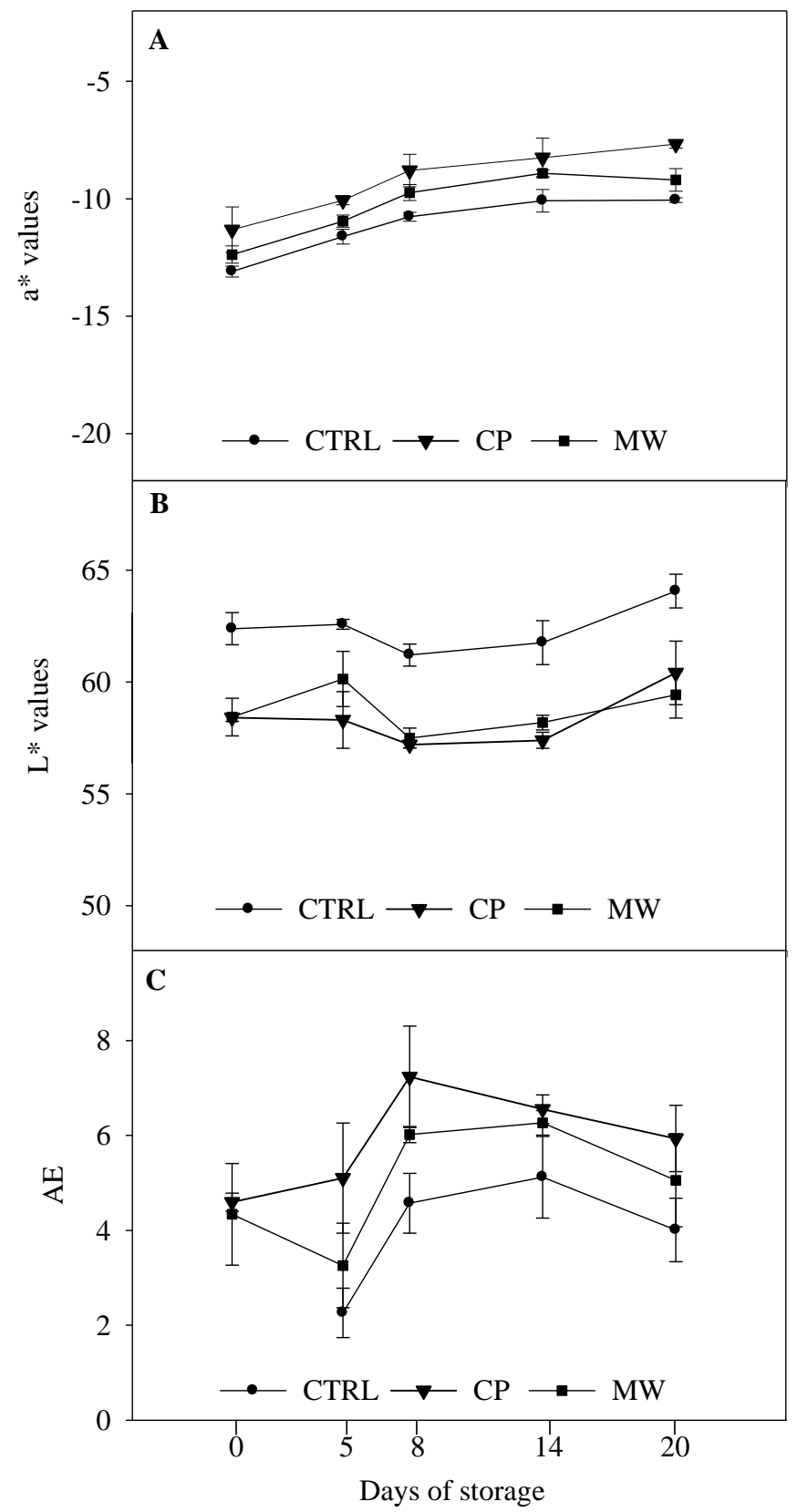

Figure IV.1. $\mathrm{a}^{*}(\mathrm{~A}), \mathrm{L}^{*}(\mathrm{~B})$ and $\Delta \mathrm{E}(\mathrm{C})$ color values changes during storage at $5{ }^{\circ} \mathrm{C}$ of untreated control (CTRL), conventional pasteurization (CP) and microwave (MW) treated faba beans pesto sauce. 


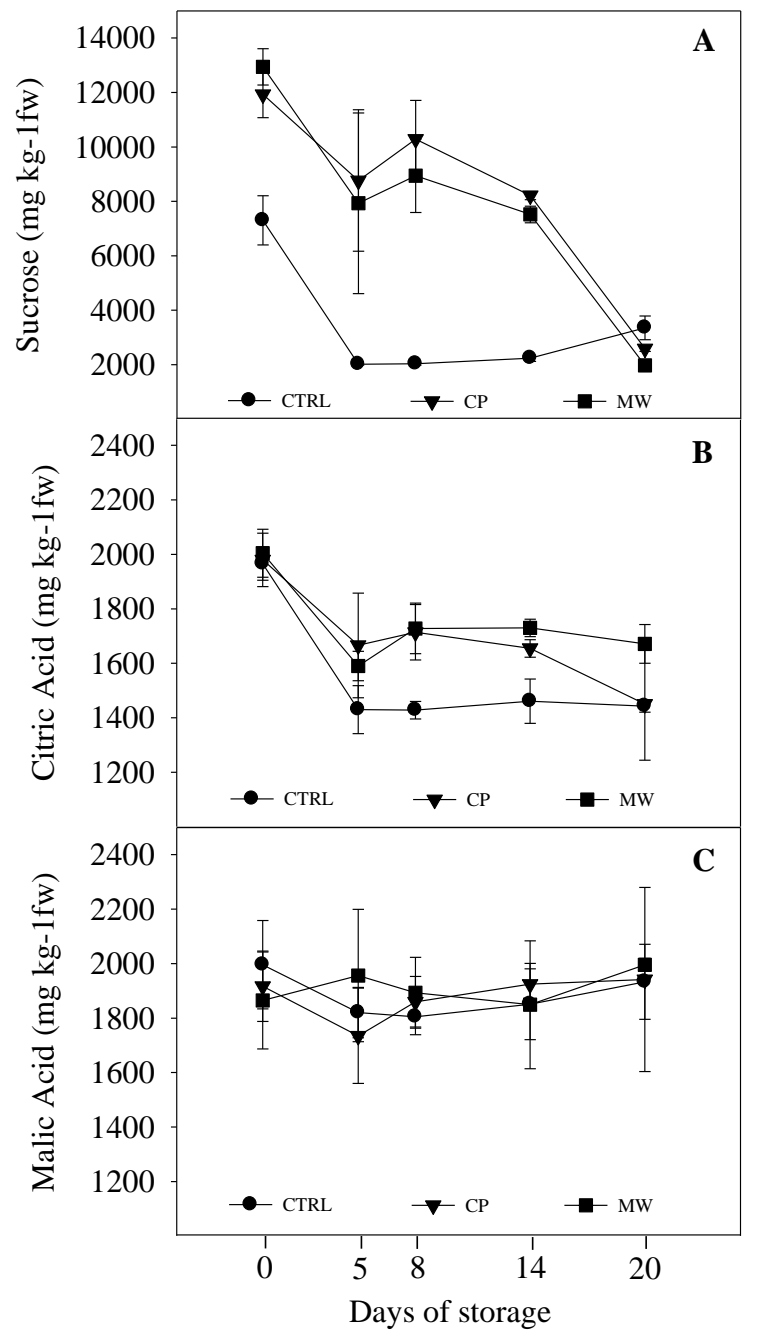

Figure IV.2. Sucrose content (A) and organic acids content [citric (B) and malic (C)] changes during storage at $5{ }^{\circ} \mathrm{C}$ of untreated control (CTRL), conventional pasteurization (CP) and microwave (MW) treated faba beans pesto sauce. 


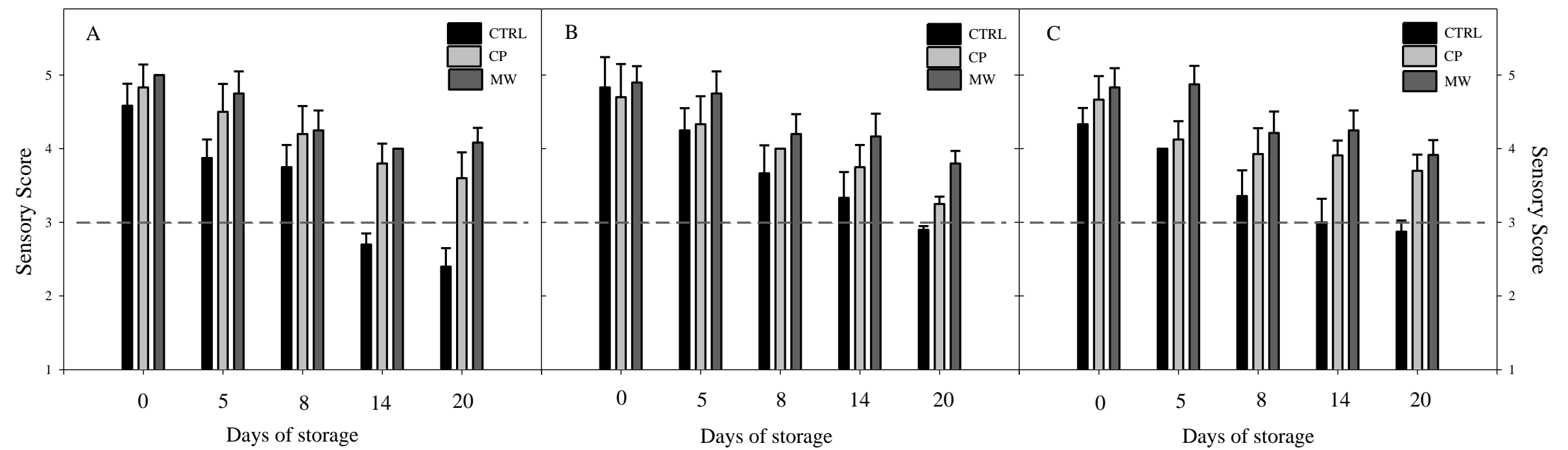

Figure IV.3. Sensory quality [taste (A), colour (B) and texture (C)] changes during storage at $5{ }^{\circ} \mathrm{C}$ of untreated control (CTRL), conventional pasteurization (CP) and microwave (MW) treated faba beans pesto sauce. 


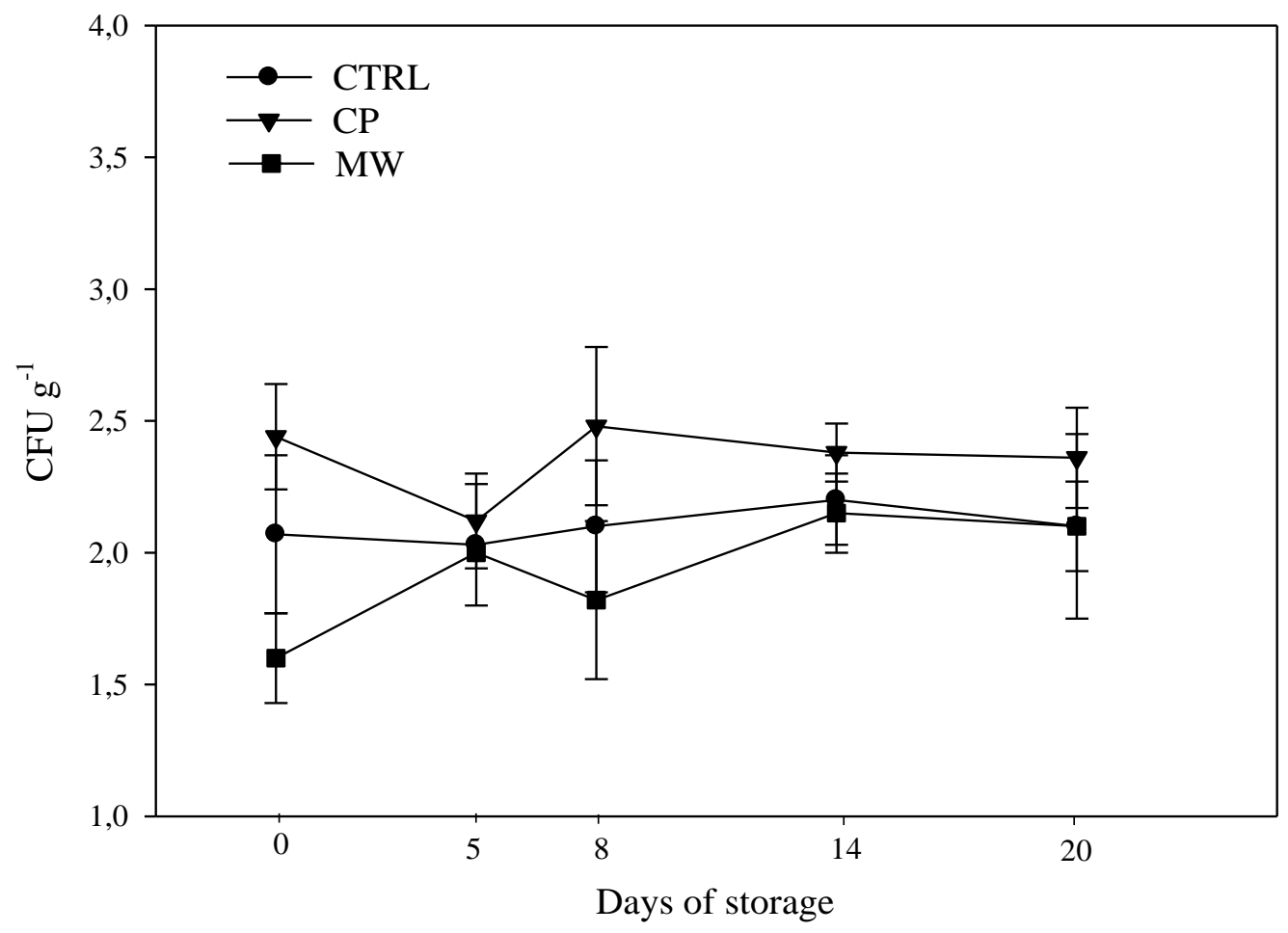

Figure IV.4. Evaluation of mesophiles during storage at $5{ }^{\circ} \mathrm{C}$ of untreated control (CTRL), conventional pasteurization (CP) and microwave (MW) treated faba beans pesto sauce. 


\section{CHAPTER V}

\section{Effect of microwave and high pressure processing on quality of an innovative broccoli hummus}

Tâmmila Venzke Klug ${ }^{1}$, Ginés Benito Martínez-Hernández ${ }^{1,2}$, Elena Collado ${ }^{2}$, Francisco Artés $^{1,2}$ and Francisco Artés-Hernández ${ }^{1,2}$

1 Postharvest and Refrigeration Group. Department of Food Engineering. Universidad Politécnica de Cartagena. Paseo Alfonso XIII, 48, 30203 Cartagena, Murcia, Spain.

${ }^{2}$ Institute of Plant Biotechnology. Universidad Politécnica de Cartagena. Campus Muralla del Mar, 30202 Cartagena, Murcia, Spain.

Reference: Food and Bioprocess Technology. 2018. 11, 1464-1477. 


\section{V.1. INTRODUCTION}

Hummus is a dip or spread made mainly with cooked mashed chickpeas blended with tahini, olive oil, lemon juice and salt. Hummus is an Arab dish adopted by Jews in Israel becoming a 'national dish', and a culinary cult, which was first industrialized in Israel in 1958 (Hirsch and Tene, 2013). The global consumption of hummus has increased by an average of $8.8 \%$ rate over the last few years, the Middle East and USA being the main consumption regions (MRF, 2017). Such augmenting interest in this product may be explained by the consumer recognition of the high nutritional quality of pulses (i.e., chickpeas) and their derived products. Hummus, because of its high chickpea content, is not only an important source of the main pulses nutrients (protein, dietary fibre, resistant starch, polyunsaturated fatty acids, vitamins and minerals) but also contains bioactive compounds like polyphenols (such as isoflavones) with high antioxidant potential, phytic acid, sterols and carotenoids, among others (Álvarez et al., 2017a; Jukanti et al., 2012; Wallace et al., 2016). In addition, chickpea/hummus consumption has been associated with better nutrient intake, diet quality and weight parameters in adults (O’Neil et al., 2014). A variety of hummus variants exist on the market in which part of chickpea proportion is replaced by other ingredients (i.e., eggplant, pepper, etc.) in order to diversify the product offer. Most of such hummuses variants show sensory characteristics far from those of the traditional hummus recipes.

Broccoli is a vegetable with excellent nutritional and bioactive properties that may be potentially used as an excellent ingredient to obtain an innovative hummus variant with high nutritional/bioactive quality. Broccoli has a characteristic bitter flavour, owed to its characteristic bioactive compounds containing sulphur (glucosinolates>isothiocyanates) which could potentially lead to the consumer rejection. In this sense, the use of new broccoli hybrids vegetables with milder taste (masking that bitterness with higher plant sugar contents) such as the kailan-hybrid broccoli $\left(\mathrm{Bimi}{ }^{\circledR}\right)$, but similar nutritional/bioactive properties (Martínez-Hernández et al., 2013b; Martínez-Hernández et al., 2015) could be an excellent alternative. The excellent health-promoting properties related with the broccoli consumption are potentially derived from specific sulphur-containing compounds (glucosinolates > isothiocyanates), polyphenols and vit $\mathrm{C}$ (both with high antioxidant activity), carotenoids, etc. (Martínez-Hernández et al., 2013d,, 2015; Vig et al., 2009). Glucosinolates are stored in the plant vacuole separately from enzyme myrosinase, but upon cell rupture, myrosinase comes 
into contact with the glucosinolates and the enzymatic degradation is almost instantly initiated, (Hanschen et al., 2014). Then, an intermediate aglycone is formed that may lead to different breakdown products (isothiocyanates, thiocyanates, nitriles, epithionitriles, oxazolidine-2-thiones) depending upon the side chain structures, reaction conditions ( $\mathrm{pH}, \mathrm{Fe}$ ions presence, water dilution, etc.) and protein factors (e.g. epithiospecifier protein (ESP)) (Fahey et al., 2001; Hanschen et al., 2017; Redovniković et al., 2012). Isothiocyanates are the glucosinolates products responsible of their known excellent health-promoting properties contrary to the rest of glucosinolates products without health-promoting properties. Glucoraphanin is one of the major broccoli glucosinolates that has been extensively studied due to the high health-promoting properties of its cognate isothiocyanate, sulforaphane. Sulforaphane has been reported to show a high potential to induce the activity of mammalian detoxication (phase 2) enzymes being considered as one of the most powerful anti-cancer phytochemicals (Traka and Mithen, 2008). Processing of Brassica products must be reoriented to inactivate ESP while avoiding complete myrosinase inactivation but meeting always the food safety aspects.

The main issue of processing these food products like vegetables dip or spreads is their limited shelf-life since they are susceptible to spoilage and quality degradation. Furthermore, unappropriated long thermal processing of food products may alter their nutritional/bioactive profile and the bioavailability of the compounds that configure that profile (Wallace et al., 2016). More efficient thermal application during such industrial processing is being constantly studied like the application of microwaves (MW) significantly reduce the treatment times (Castillejo et al., 2018). On the other side, non-thermal processing like high pressure processing (HPP) treatments has shown high microbicidal effects with low impact on sensory and nutritional/bioactive properties of fruit and vegetable products as reviewed (Oey et al., 2008; Rastogi et al., 2007).

The aim of this work was to study the effect of a high power-low treatment time semicontinuous MW treatment and a HPP on physicochemical, microbial, sensory and bioactive (glucoraphanin>sulforaphane, phenolic compounds and total antioxidant activity) quality of two broccoli cvs. hummuses (using two Brassica vegetables: 'Parthenon' and 'Bimi') during 28 days at $5^{\circ} \mathrm{C}$. 


\section{V.2. MATERIALS AND METHODS}

\section{V.2.1. Ingredients preparation}

Broccoli cv. Parthenon (Brassica oleracea Italica Group) and kailan-hybrid broccoli (B. oleracea Italica Group $\times$ Alboglabra Group; Bimi $\left.{ }^{\circledR}\right)$ were obtained from a local producer (Sacoje S.L., Lorca, Spain) on December 2016. Immediately after manual harvesting, plant material was pre-cooled with crushed ice and transported by car about $80 \mathrm{~km}$ to the Pilot Plant of our Research Group in the Universidad Politécnica de Cartagena. Then, it was stored at $2{ }^{\circ} \mathrm{C}$ and $90-95 \%$ relative humidity until next day when processing was conducted. Canned chickpeas (Hacendado, Valencia, Spain), tahini (made from brown sesame seeds; NaturGreen, Murcia, Spain), olive oil (extra virgin, $0.8 \%$ acidity; Hacendado, Valencia, Spain), and lemons (cv. Fino) were bought in a local supermarket in Cartagena (Spain).

Ingredients preparation was conducted in a disinfected cold room at $8{ }^{\circ} \mathrm{C}$. Broccoli cv. Parthenon florets were cut in small pieces $(\approx 2.5 \mathrm{~cm} \times 2.5 \mathrm{~cm})$ with a sharp stainless steel knife and kailan-hybrid florets were cut to a final length of approximately $15-18 \mathrm{~cm}$. Then, prepared plant material was washed with chlorinated water $(100 \mathrm{mg} \mathrm{L}-1$ free chlorine; $\mathrm{pH}$ $\left.6.5 ; 5^{\circ} \mathrm{C}\right)$ for $2 \mathrm{~min}$ and rinsed with cold $\left(5^{\circ} \mathrm{C}\right)$ tap water for $1 \mathrm{~min}$. Sanitized broccoli was placed in a glass container, covered and then blanched in a domestic MW oven (MWB-17AE, Fagor Industrial S. Coop., Valencia, Spain) at $750 \mathrm{~W}$ for $3 \mathrm{~min}$. The temperature in the centre of broccoli pieces after the latter microwave blanching was measured with a temperature probe with a value of $64.4 \pm 5.4{ }^{\circ} \mathrm{C}$. Such MW blanching parameters were selected as equivalents (Castillejo et al., 2018) to that of hot water blanching of $66^{\circ} \mathrm{C}$ for $5 \mathrm{~min}$ able to inactivate the epithiospecifier protein (ESP) while maintaining myrosinase activity (Matusheski et al., 2004). Blanched broccoli was immediately placed in plastic polyethylene (PE) bags and then cooled down in ice-water bath where they were kept until hummus preparation. Juice from lemon was extracted with a domestic hand-juicer. Canned chickpeas were drained discarding the brine and then they were rinsed under tap water for $20 \mathrm{~s}$.

\section{V.2.2. Hummus preparation}

Two types of hummuses were formulated based on related previous literature (Álvarez et al., 2017a; Hirsch and Tene, 2013) and sensory evaluations with eight habitual consumers of 
traditional hummus. These habitual consumers provided tips to obtain both hummuses with maximum broccoli content but retaining the essential characteristics of hummus. Broccoli proportions of each broccoli variety used to obtain both hummuses were optimized to be the same in order to facilitate data comparison between both hummuses. The optimized hummus composition was: $53 \%$ blanched broccoli (Pathenon or Bimi), $18 \%$ chickpeas, $12 \%$ water, 7 $\%$ tahini, $4.5 \%$ olive oil, $4.5 \%$ lemon juice and $1 \%$ salt. All hummus ingredients were blended in a semi-industrial food processor (Model Robot Cook ${ }^{\circledR}$, Robot Coupe, Vincennes Cedex, France) for $30 \mathrm{~s}$ at $1,450 \times g$ at room temperature. The obtained hummus was packaged $(50 \mathrm{~g})$ under aseptic conditions in sterile embossed PE bags $(150 \times 250 \mathrm{~cm})$ (G1525, Tav Food Packing SL, Madrid, Spain) being kept cold $\left(2{ }^{\circ} \mathrm{C}\right)$ in crushed ice until subsequent treatments.

\section{V.2.3. Hummus treatments and storage}

Packaged hummus samples were treated by semi-continuous MW treatment and a HPP treatment. A semi-industrial prototype continuous-flow MW oven (Model SI MAQ0101, Sairem Ibérica S.L., Barcelona, Spain) fully described in Castillejo et al. (2018) was used. Briefly, the MW oven consisted of 4 adjustable magnetrons $(0.5-3.0 \mathrm{~kW} ; 2450 \mathrm{MHz})$, a polytetrafluoroethylene (PTFE) feed belt able to work on continuous or back-and-forth movement mode (semi-continuous), an optimized heating chamber, new energy economizing filters, a computer interface and a fibre optic slip ring for online temperature measurements inside the MW oven. MW was set on the semi-continuous mode with back-and-forth movement of $2 \mathrm{~m} \mathrm{~min}^{-1}$ belt speed at $9 \mathrm{~kW}(3+2+2+2 \mathrm{~kW})$ for $40 \mathrm{~s}$. The reflected power from each magnetron was $360 \mathrm{~W}$ being automatically measured by the MW device through an internal directional coupler. Then, the applied MW power was $7.56 \mathrm{~kW}$ $(2.64+1.64+1.64+1.64 \mathrm{~kW})$, while the calculated power absorbed by the product, considering the specific heat of ingredients and power reflected by the MW chamber was $3.26 \mathrm{~kW}$. A complete modelling of the same heating treatment applied on plant products blends using this MW oven has been recently published by our Group (Castillejo et al., 2017). MW treatment was selected in order to achieve a fast heating to $85 \pm 2{ }^{\circ} \mathrm{C}$ (checked with a portable fibre optic thermometer (Neoptix NOMAD-Fiber NMD, Neoptix, Quebec, Canada) in the centre of the product) since this treatment has been reported to induce good quality in a MW-treated legume paste (Klug et al., 2017a). Heating profiles of the used MW power conditions were 
previously modelled in order to ensure homogeneous product heating (Castillejo et al., 2018). Four hummus packages were always treated at the same time in every treatment batch. Samples were immediately cooled down to the storage temperature $\left(5^{\circ} \mathrm{C}\right)$ after treatment.

HPP was conducted by placing hummus samples ( 4 bags per each treatment run) in the sampling vessel of a HPP equipment (HP Pilot Food Processor, Stansted Fluid Power Ltd., Essex, U.K.) at $550 \mathrm{MPa}$ for $10 \mathrm{~min}$ at $23{ }^{\circ} \mathrm{C}$. The latter HPP treatment was selected according to our previous studies to obtain legume pastes with maximum quality (Klug et al., 2017b).

Untreated samples were used as control (CTRL). Packages from each sample batch (CTRL, MW and HPP) were stored at $5{ }^{\circ} \mathrm{C}$ in darkness and evaluated on processing (day 0 ) and after 6, 15, 21 and 28 days. Three packages (replicates) were prepared for each treatment and sampling time.

\section{V.2.4. Microbial analyses}

Epiphytic microflora (mesophilic, psychrophilic, Enterobacteriaceae, and yeasts and moulds $(\mathrm{Y}+\mathrm{M}))$ growth was determined using standard enumeration methods and material as described (Castillejo et al., 2016). All microbial counts were reported as log colony forming units per gram of product $\left(\log \mathrm{CFU} \mathrm{g} \mathrm{g}^{-1}\right)$. Each of the three replicates was analysed in duplicate. The presence of Salmonella spp., Listeria monocytogenes and generic Escherichia coli was monitored according to the European legislation (Regulation, 2007). Each of the three replicates was analysed in duplicate.

\section{V.2.5. Physicochemical analyses}

Hummus samples were monitored during storage in relation to physicochemical quality according to $\mathrm{pH}$ and colour. $\mathrm{pH}$ was measured by a $\mathrm{pH}-$ meter (Crison $2001 \mathrm{pH}$ meter, Crison Instruments SA, Barcelona, Spain) by 1:3 dilution (distilled water:hummus; $v: w$ ). Colour was determined in plastic cuvettes (CM-A131, 50×37×13mm; $10 \mathrm{~mm}$ internal pass) using a colorimeter (Chroma Meter CR-400) coupled with a cuvette-holder (CR-400 cuvette holder; all colorimetric components were from Konica Minolta, Japan). The colorimeter was calibrated with a white reference plate (illuminant D65), $2^{\circ}$ observer and 8-mm viewing 
aperture. Colorimetric results were expressed as CIE L*a*b* colour space units. Total colour differences $(\Delta \mathrm{E})$ throughout storage were compared to their respective initial values according to equation (1):

$$
\Delta \mathrm{E}=1 / 2\left(\left\lfloor\left(L_{0}-L^{*}\right)^{2}+\left(a_{0}-a^{*}\right)^{2}+\left(b_{0}-b^{*}\right)^{2}\right\rfloor\right)(1)
$$

\section{V.2.6. Sensory analyses}

Sensory analyses were performed according to international standards (ASTM, 1986). Tests were conducted in a standard room (ISO, 2012) equipped with ten individual taste booths. Sensory evaluation of hummus samples were carried out by eight members sensory panel (aged 22-70 years) previously trained in discriminative quality attributes. Samples (about 20 g) were served at room temperature in transparent glasses coded with 3 random digit numbers. Still mineral water was used as palate cleanser. The panel screened for sensory ability (colour, flavour, texture, taste, consistency) on a 5-points structured hedonic scale (5: excellent, 4: good, 3: limit of acceptability, 2: poor, 1: extremely bad) and overall quality was evaluated on a 9-point structured hedonic scale (9: extremely like, 8: like very much, 7: like moderately, 6: like slightly, 5: limit of acceptability, 4: dislike slightly, 3: dislike moderately, 2: dislike very much, 1: extremely dislike).

\section{V.2.7. Total phenolics content}

Extraction to determine TPC and TAC was conducted as previously described (RodríguezVerástegui et al., 2015) but with slight modifications. Frozen fresh hummus samples of $0.5 \mathrm{~g}$ were homogenised (Ultra Turrax ${ }^{\circledR}$ model 18T, IKA-Werke GmbH \& Co. KG, Staufen, Germany) in $3 \mathrm{~mL}$ methanol for $30 \mathrm{~s}$. TPC/TAC extraction was conducted on an ice bed. TPC/TAC extraction was followed in an orbital shaker (Stuart, Staffordshire, UK) for $1 \mathrm{~h}$ at $200 \times g$ in darkness. Subsequently, supernatants from centrifuged extracts $(15,000 \times g, 10$ min, $4{ }^{\circ} \mathrm{C}$ ) were collected, kept in ice and analysed the same day for TPC and TAC.

TPC was determined based on Singleton et al. (1999) method, but with modifications described by Martínez-Hernández et al. (2011). Briefly, $19 \mu \mathrm{L}$ of TPC extract was placed on a flat-bottom polystyrene 96-well plate (Greiner Bio-One; Frickenhausen, BadenWürttemberg, Germany) and $29 \mu \mathrm{L}$ of $1 \mathrm{~N}$ Folin-Ciocalteu reagent was added. The latter 
mixture was incubated for $3 \mathrm{~min}$ in darkness at room temperature. Then, $192 \mu \mathrm{L}$ of a solution containing $\mathrm{Na}_{2} \mathrm{CO}_{3}(0.4 \%)$ and $\mathrm{NaOH}(2 \%)$ was added being samples incubated for $1 \mathrm{~h}$ at room temperature in darkness. Then, absorbance at $750 \mathrm{~nm}$ was measured using a Multiscan plate reader (Tecan Infininte M200; Männedorf, Meilen, Switzerland). TPC was expressed as gallic acid equivalents in $\mathrm{mg} \mathrm{kg}^{-1} \mathrm{fw}$. Each of the three replicates was analysed in duplicate.

\section{V.2.8. Total antioxidant capacity}

TAC was determined as described by Rodríguez-Verástegui et al. (2015) by three different methods: free radical scavenging capacity with 2,2-diphenyl-1-picrylhydrazil (DPPH) (Brand-Williams et al., 1995), ferric reducing antioxidant power (FRAP) (Benzie and Strain, 1999) and 2,20-azino-bis (3-ethylbenzothiazoline-6-sulphonic acid) (ABTS) (Cano et al., 1998). DPPH method was conducted by measuring the decrease in absorbance at $515 \mathrm{~nm}$ for 30 min. A volume $(194 \mu \mathrm{L})$ of DPPH solution $\left(\approx 0.7 \mathrm{mM}\right.$ and adjusted to $\left.\mathrm{Abs}_{515}=1.1 \pm 0.02\right)$ was added to each extract sample $(21 \mu \mathrm{L})$ and allowed to react for $30 \mathrm{~min}$. FRAP method was conducted by measuring the increase in absorbance at $593 \mathrm{~nm}$ for $45 \mathrm{~min}$. The freshly made-up FRAP solution (prepared in 10:1:1 v:v:v proportion of sodium acetate buffer, $\mathrm{pH}$ 3.6; $10 \mathrm{mM}$ TPTZ solution in $40 \mathrm{mM} \mathrm{HCl}$; and $20 \mathrm{mM} \mathrm{FeCl}_{3}$, respectively, and preincubated at $37^{\circ} \mathrm{C}$ for $2 \mathrm{~h}$ ) was added $(198 \mu \mathrm{L})$ to each extract sample $(6 \mu \mathrm{L})$ and allowed to react for 45 min. ABTS method was conducted by measuring absorbance at $734 \mathrm{~nm}$ for $60 \mathrm{~min}$. A volume $(280 \mu \mathrm{L})$ of ABTS solution $\left(14 \mathrm{mM} \mathrm{ABTS}^{+}\right.$and $4.9 \mathrm{mM} \mathrm{K}_{2} \mathrm{~S}_{2} \mathrm{O}_{8}$ by $\left.1: 1(v: v)\right)$ was added to each extract sample $(6 \mu \mathrm{L})$ and allowed to react for $60 \mathrm{~min}$. All TAC reactions were conducted at room temperature in darkness and absorbances were measured using the same microplate reader for TPC. TAC data were expressed as $\mathrm{mg}$ of Trolox equivalents $\mathrm{kg}^{-1} \mathrm{fw}$. Each of the three replicates was analysed in duplicate.

\section{V.2.9. Glucoraphanin analysis}

The content of 4-methylsulfinylbutyl glucosinolate (glucoraphanin) was analysed as previously described (Kiddle et al., 2001; Vallejo et al., 2002). Briefly, freeze-dried hummus powder $(0.2 \mathrm{~g})$ was weighed into glass screw-cap tubes $(10 \mathrm{~mL})$ and heated at $80{ }^{\circ} \mathrm{C}$ for 10 min using a shaking water bath. Then, $5 \mathrm{~mL}$ of methanol:water $(80: 20, v / v)$ was added to each sample and heating continued for $20 \mathrm{~min}$ at $80{ }^{\circ} \mathrm{C}$. Subsequently, $1 \mathrm{~mL}$ of hot $\left(100{ }^{\circ} \mathrm{C}\right)$ nanopure water was added to each sample being the heating bath continued for $30 \mathrm{~min}$. The 
extracts were centrifuged $\left(4,000 \times \mathrm{g}, 20 \mathrm{~min}, 4^{\circ} \mathrm{C}\right)$ and supernatants were decanted and stored on ice. The pellets were re-extracted as previously described with $2.5 \mathrm{~mL}$ methanol-water $(90: 10, v / v)$. Both supernatants were combined and made up to a final volume of $5 \mathrm{ml}$ with methanol-water $(90: 10, v / v)$. Desulphation of glucoraphanin was conducted using prepared DEAE Sephadex A25 (GE Healthcare, Uppsala, Sweden) mini-columns. The latter mini-columns were prepared by adding $0.5 \mathrm{ml}$ of nanopure water to a $3 \mathrm{~mL}$ reservoir (including a frit) leaving to drip the water. Then, $0.5 \mathrm{~mL}$ of DEAE Sephadex A25 (130 $\mathrm{g} \mathrm{L}^{-1}$ in $0.02 \mathrm{M}$ sodium acetate $(\mathrm{pH}$ 5.0) were added to the reservoir and it was allowed to settle to form an ion exchange filter of approx. $0.5 \mathrm{~cm}$. Finally, the prepared DEAE Sephadex A25 column was washed with another $0.5 \mathrm{~mL}$ nanopure water. Each methanol extract $(1 \mathrm{~mL})$ was loaded onto the prepared columns and the unbound material was removed using two washings with $0.5 \mathrm{ml}$ of nanopure water and two washings with $0.02 \mathrm{M}$ sodium acetate $(\mathrm{pH} 5.0$ ) per column. Purified sulfatase from Helix pomatia (EC 10.000 units; Sigma-Aldrich, St Louis, MO, USA) $(75 \mu \mathrm{l})$ was loaded onto each prepared column and desulphation was performed overnight (12 h) at room temperature. Desulphoglucoraphanin was eluted with three nanopure water washings $(0.5+0.5+0.25)$ and made up to a final volume of $1.5 \mathrm{~mL}$ with nanopure water.

The latter extracts were analysed using an ultra high-performance liquid chromatography (UHPLC) instrument (Shimadzu, Kyoto, Japan) equipped with a DGU-20A degasser, LC-30AD quaternary pump, SIL-30AC autosampler, CTO-10AS column heater and SPDM-20A photodiode array detector. Chromatographic analyses were carried out onto a Gemini C18 column (250mm x $4.6 \mathrm{~mm}, 2.6 \mathrm{~mm}$ particle size; Phenomenex, Macclesfield, UK) at $25^{\circ} \mathrm{C}$. Mobile phases were water (A) and acetonitrile (B). The flow rate was $1.5 \mathrm{~mL}$ $\min ^{-1}$ with a linear gradient eluent starting with $2 \%$ B to reach $20 \% \mathrm{~B}$ at 28 min and $2 \% \mathrm{~B}$ at $32 \mathrm{~min}$. Injection volume was $20 \mu \mathrm{L}$ and absorbance was registered at $229 \mathrm{~nm}$. Glucoraphanin was quantified using an external standard curve prepared with commercial desulphoglucoraphanin standard (Toronto Research Chemicals Inc., North York, Canada). Glucoraphanin was expressed in $\mathrm{mg} \mathrm{kg}^{-1} \mathrm{dw}$. Each of the three replicates was analysed in duplicate.

\section{V.2.10. Endogenous sulforaphane analysis}


The content of 1-isothiocyanato-4-(methylsulfinyl)butane (sulforaphane) was analysed according Ares et al. (2014) with slight modifications. Briefly, $0.25 \mathrm{~g}$ of freeze-dried hummus powder was mixed with $5 \mathrm{~mL}$ of acidic water $(\mathrm{pH} 6.0$ using $0.1 \mathrm{M}$ hydrochloric acid) in a glass screw-capped tube. The mixture was incubated in a heating bath at $45^{\circ} \mathrm{C}$ for 2 $\mathrm{h}$ to allow glucoraphanin conversion to sulforaphane. Then, $25 \mathrm{~mL}$ of methyl- $t$-butyhlether (MTBE) was added to the mixture and it was sonicated for $1 \mathrm{~min}$. Subsequently, the extract from the tube was dewatered using sodium sulphate $(5.5 \mathrm{~g})$ and the resulting extract was filtrated (Whatman 41). The collected filtrate was passed through an activated $(3 \mathrm{~mL}$ of MTBE $+3 \mathrm{~mL}$ ethyl acetate $+3 \mathrm{~mL}$ air) SI-1 silica cartridge (Phenomenex, Torrance CA, USA) and the eluent was discarded. Finally, sulforaphane was eluted from the cartridge with $2 \mathrm{~mL}$ methanol. Such methanolic extracts were evaporated to dryness in a rotary evaporator at $45^{\circ} \mathrm{C}$ being the dry residue resuspended in $1 \mathrm{~mL}$ acetonitrile followed by filtration with a PTFE $0.22-\mu \mathrm{m}$ syringe filter.

The sulforaphane extracts were analysed using the same UHPLC device as previously described. Chromatographic analyses were carried out onto a Gemini C18 column (250mm $\times 4.6 \mathrm{~mm}, 2.6 \mathrm{~mm}$ particle size; Phenomenex, Macclesfield, UK). The mobile phase was a mixture of $20 \mathrm{mM}$ ammonium formate in water and acetonitrile $(55: 45, v / v)$ and the injection volume of $5 \mu \mathrm{L}$ (draw speed of $50 \mu \mathrm{L} \mathrm{min}{ }^{-1}$ ). The flow rate was $0.6 \mathrm{~mL} \mathrm{~min}{ }^{-1}$, temperature at $25^{\circ} \mathrm{C}$ and the detection wavelength at $196 \mathrm{~nm}$. Sulforaphane was quantified using an external standard curve prepared with commercial DL-sulforaphane standard (Sigma-Aldrich, St. Louis MO, USA). The results were expressed as $\mathrm{mg} \mathrm{kg}^{-1} \mathrm{dw}$. Each of the three replicates was analysed in duplicate.

\section{V.2.11. Statistical analyses}

The experiment had a two-factor (treatment $\times$ storage time) design subjected to analysis of variance (ANOVA) using SPSS software (v.19 IBM, New York, USA). Statistical significance was assessed at $p=0.05$, and Tukey's multiple range test was used to separate the means. A hierarchical statistical analysis was conducted for bioactive compounds analyses where the two replicate measurements of each sample replicate were pooled as a first step, and then the three samples pooled as a second step. 


\section{V.3. RESULTS AND DISCUSSION}

\section{V.3.1. Sensory quality}

Bimi broccoli hummus showed better flavour scores than Parthenon broccoli hummus prior to treatments on processing day (Figure V.1). According to panellists' observations, flavour was the main quality parameter determining overall quality without high variations between the rest of parameters (colour, aroma, texture and consistency). Then, overall quality of CTRL Bimi broccoli hummus was better scored than Parthenon hummus on processing day. Sensory scores of both hummuses corresponding to CTRL showed good sensory scores on day 6 as observed in Figure V.1. Nevertheless, and according to the high microbial loads (described below), these untreated hummuses were not accepted by panellists on day 15 , primarily due to off-colours and off-odours (data not shown).

MW and HPP treatments led to higher sensory acceptation of both hummus types with better overall quality scores than CTRL samples as observed in Figure V.1. MW and HPP samples showed similar $(\mathrm{p}<0.05)$ flavour scores on processing day although texture was better scored in MW samples compared to HPP. Consumers characterise the texture of this dip product with different particle sizes rather than the homogeneous creamy texture common in other vegetable creams (according to the indications from eight hummus habitual consumers). According to panellists' observations, the latter finding was owed to a higher creamy texture of HPP samples which is attributed to the high pressures used during this treatment which lead to higher particle size as previously observed (Klug et al., 2017). Nevertheless, the slightly higher creamy perceptions of HPP hummus may be beneficial for those consumers that prefer products with more homogeneous textures opening to new age consumers' groups such as children.

MW and HPP treatments led to good sensory scores that were over the limit of acceptance after 28 days (Figure V.1). Particularly, Parthenon broccoli HPP hummus showed better overall quality compared to treated-MW one with scores of 7.1 and 6.0, respectively. No significant differences of sensory attributes between MW and HPP of Bimi broccoli hummus were observed after 28 days although HPP was scored with better flavour. 


\section{V.3.2. Physicochemical quality}

The acidic flavour of hummus (achieved with the addition of lemon juice) is one of the main, and expected, organoleptic characteristic of traditional hummus. In this sense, $\mathrm{pH}$ may be considered as an important physicochemical quality parameter of commercial hummus. The initial $\mathrm{pH}$ of both hummuses was 4.9-5.1 (Table V.1). The applied treatments did not alter $(\mathrm{p}<0.05)$ such initial $\mathrm{pH}$ values being correlated with the undetected $(\mathrm{p}<0.05)$ flavour differences in the sensory analyses of MW and HPP hummuses. In general, $\mathrm{pH}$ of all hummus samples was not highly changed after 28 days of storage with $\mathrm{pH}$ variations $<0.6 \mathrm{pH}$ units. Furthermore, all hummus samples showed $\mathrm{pH}$ values that ranged among 4.5-5.0 after 28 days being accepted by panellists. The acidic nature of the prepared hummus may favourably extend the commercial life of this product since the activities of degradative enzymes of some quality parameters (colour, texture, etc.) and the microbial growth may be highly reduced.

The prepared hummuses showed a pale green colour $\left(\mathrm{L}^{*}=55.2 / 51.9 ; \mathrm{a}^{*}=-6.6 /-5.9\right.$; $b^{*}=22.2 / 22.4$ ), without great differences between both hummus types. In general, hummus colour was not significantly changed $(\mathrm{p}<0.05)$ after treatments except greenness of Bimi broccoli hummus that was slightly increased (a* decrease) after MW treatment. Such colour change was not observed in MW Parthenon broccoli hummus. Bimi broccoli has higher tenderness related to younger plant cells compared to conventional broccoli varieties, which may lead to higher susceptibility of plant cells to disruption by the applied treatment. Accordingly, greenness change of Bimi broccoli hummus may be explained due to an improved chlorophylls extraction in this broccoli. Intense thermal treatments, boiling $\left(100^{\circ} \mathrm{C}\right)$ for $10 \mathrm{~min}$, in pea purée induced greenness loss ( $\mathrm{a}^{*}$ increase) while shorter boiling (10 min) of pea puree did not induced such greenness loss (Icier et al., 2006). Such greenness loss in green vegetable purees after intense thermal treatments might be caused by chlorophylls degradation (Klug et al., 2018). Colour changes are also reported as $\Delta \mathrm{E}$ parameter that represents the perceptible colour change by consumers. There were no significant $(\mathrm{p}<0.05)$ $\triangle \mathrm{E}$ differences between MW or HPP samples. Furthermore, panellist did not find colour differences among samples on processing day. During storage, no high colour changes of hummuses were observed $(\Delta \mathrm{E}$ changes $<6.9)$ with a general $\mathrm{a}^{*}$ increase, while $\mathrm{L}^{*}$ and $\mathrm{b}^{*}$ showed a general initial increase followed by a final decrease until day 28 . Nevertheless, such colour changes were not detected $(\mathrm{p}<0.05)$ by panellists in treated hummuses after 28 days. 


\section{V.3.3. Microbial analyses}

Microbiological quality of hummus samples is shown in Figure V.2. Both hummus types showed similar initial mesophilic, psychrophilic, Enterobacteriaceae, and $\mathrm{Y}+\mathrm{M}$ loads of 2.8-3.2, 3.0-3.7, 2.6-2.9 and 2.6-2.3 $\log$ CFU g ${ }^{-1}$, respectively. Lower Enterobacteriaceae levels were reported in our study compared to published loads ( $4 \log \mathrm{CFU} \mathrm{g}{ }^{-1}$ ) of an untreated chickpea purée (Álvarez et al., 2017b) probably owed to more efficient good manufacturing practices (processing in a cold room, sanitizing of all used material, etc.) hereby used. On the other hand, Y+M counts were similar to last authors' article $\left(2.4 \log \mathrm{CFU} \mathrm{g}{ }^{-1}\right)$.

MW treatment of Parthenon/Bimi hummuses reduced mesophilic, psychrophilic and Enterobacteriaceae loads by $0.5 / 0.9,0.2 / 0.8$ and $0.7 / 1.0$ log units, respectively, on processing day. Higher microbial reductions were achieved after HPP treatment with reductions of 1.6/1.9, 0.5/0.9 and 1.1/1.3, respectively. Better microbial reductions were observed in Bimi hummus compared to Parthenon hummus. The latter finding may be explained due to the higher content of phytochemical compounds with antimicrobial properties like phenolics, and other antioxidant compounds, and glucosinolates products (as shown later). As observed, HPP is an effective treatment to reduce microbial loads of hummus which may be explained by a pressure-disruption of microbial cell membranes (Yordanov and Angelova, 2010) as previously described in chickpea flour purée treated by HPP (Álvarez et al., 2017b). Attending to $\mathrm{Y}+\mathrm{M}$ counts, the low initial counts did not allow to find significant differences after application of such pasteurization treatments.

A high microbial growth was observed during storage of CTRL hummus samples, as expected, with mesophilic/psychrophilic increases of approximately 2.4/2.2-2.8/2.3 log units after 6 days. Furthermore, loads $\geq 6 \log$ CFU g ${ }^{-1}$ were observed in CTRL samples on day 15 . On the other hand, microbial quality of MW and HPP hummuses was highly maintained showing unchanged $(\mathrm{p}<0.05)$ microbial loads after 6 days. Mesophilic loads of treated samples were below 4 log units after 21 days while psychrophilic, Enterobacteriaceae and $\mathrm{Y}+\mathrm{M}$ loads were $<3 \log$ units. No significant differences were observed in the microbial growth rates between MW and HPP-treated samples during storage. Therefore, final mesophilic, psychrophilic, Enterobacteriaceae and $\mathrm{Y}+\mathrm{M}$ loads of both treated samples ranged between $3-6,3-6,1-3$ and $2-4 \log \mathrm{CFU} \mathrm{g}{ }^{-1}$, respectively, after 28 days at $5^{\circ} \mathrm{C}$. HPP has 
been proposed as an effective cold pasteurization treatment at $600 \mathrm{MPa}$ against vegetative forms but different findings have been found against inactivation of sporulated forms (Black et al., 2007; Téllez-Luis et al., 2001). Total anaerobic bacteria were also monitored at the end of storage. Low-moderate anaerobic loads in the HPP-treated hummus samples of 3.5-3.8 $\log$ CFU g ${ }^{-1}$ were registered at day 28 (data not shown). Accordingly, Álvarez et al. (2017b) reported that although germination of sulfite-reducing clostridia spores was triggered by HHP, such spores were able to continue germinating during the first weeks of storage but finally decreased since the spores were through outgrowth only slowly. On the other side, anaerobic counts of MW samples highly varied from 1.6 to $6.5 \mathrm{log}$ units. The latter variation may be probably owed to the heterogeneity of such industrial continuous microwave ovens as some sample bags could not be properly treated as recently modelled (Castillejo et al., 2018) being enough to control vegetative forms but no for sporulated ones. Lactic acid bacteria were also analysed on day 28 to monitor fermentation processes with levels of 4.0-4.5 log CFU $\mathrm{g}^{-1}$.

Conclusively, initial microbial loads of both hummus types were better reduced by HPP compared to MW. Although similar microbial growth was observed during storage using both treatments, HPP showed better processing homogeneity regarding anaerobic microflora loads after 28 days at $5{ }^{\circ} \mathrm{C}$ compared to MW.

\section{V.3.4. Glucoraphanin and sulforaphane contents}

Low glucoraphanin-sulforaphane conversion has been reported after broccoli cells disruption through different processes. Consequently, glucoraphanin-sulforaphane conversion has been optimized in broccoli products through acidification and blanching able to inactivate ESP but no myrosinase that has a higher thermal resistance (Hanschen et al., 2017; Matusheski et al., 2004). The reduced $\mathrm{pH}$ in hummus after lemon juice might lead to the observed sulforaphane formation, particularly for Parthenon broccoli hummus (Table V.2). Bimi broccoli hummus showed initial glucoraphanin content of $100.8 \mathrm{mg} \mathrm{kg}^{-1}$. Glucoraphanin content of approximately $347 \mathrm{mg} \mathrm{kg}^{-1} \mathrm{FW}$ has been reported in raw Bimi broccoli (Martínez-Hernández et al., 2013c) being glucoraphanin levels of Bimi broccoli hummus (53\% of Bimi broccoli) in the same range to those published data. Nevertheless, Parthenon broccoli hummus showed lower glucoraphanin contents $\left(1.94 \mathrm{mg} \mathrm{kg}^{-1}\right)$ than Bimi broccoli hummus. On the other side, 
Parthenon broccoli hummus presented initial sulforaphane contents of $81.8 \mathrm{mg} \mathrm{kg}^{-1}$ while Bimi broccoli hummus had a lower content with $18.52 \mathrm{mg} \mathrm{kg}^{-1}$. Myrosinase activity has been reported to highly vary between different plant parts, among other factors. In that way, myrosinase activity has been reported to be higher in broccoli floret compared to the stems (Dosz et al., 2014). On the other side, cold areas have been reported to remain during microwave heating (Castillejo et al., 2018). Conventional broccoli florets are more compact than Bimi florets (Martínez-Hernández et al., 2013b) which may result in a lower heat transfer during blanching treatment. Then, the higher myrosinase activity in conventional broccoli florets together with a probable lower heat-inactivation efficiency within florets of this broccoli variety may lead to the observed low glucoraphanin/high sulforaphane levels.

MW induced approximately $70 \%$ higher glucoraphanin levels in Bimi broccoli hummus compared to CTRL samples which may be explained by a higher glucosinolate extraction due to plant cells disruption by the applied heat. On the other side, the high pressures applied during HPP were more efficient to increase glucoraphanin extraction than MW with $110 \%$ higher levels of this glucosinolate. Furthermore, the possible heat glucoraphanin degradation occurred during MW is avoided using HPP which may also contribute to the observed higher glucoraphanin levels. The increased glucoraphanin levels were not observed $(p<0.05)$ on Parthenon broccoli hummus due to the low glucosinolate levels that avoided to observe significant differences.

Glucoraphanin levels of hummus decreased through storage possibly owed to different chemical reactions as observed in Bimi broccoli during storage at $5{ }^{\circ} \mathrm{C}$ (Martínez-Hernández et al., 2013c). However, increased glucoraphanin levels were observed after 21 days on MW and HPP Bimi broccoli hummuses. The latter de novo synthesis, especially higher for indole glucosinolates, has been reported to be initiated after tissue damage although these enzymatic reactions may be delayed depending of the cold storage temperature (Formica-Oliveira et al., 2017; Holst and Williamson, 2004; Martínez-Hernández et al., 2013c). Therefore, residual activities of several enzymes, more resistant to myrosinase, have been still reported in broccoli after heat treatments up to $96^{\circ} \mathrm{C}$ for $3 \mathrm{~min}$ (Dosz and Jeffery, 2013b). Furthermore, such enzymes can be protected from inactivation due to food complex matrixes such as that of this hummus including oil, pulses, etc. In this line, glucoraphanin biosynthesis during storage of broccoli products has been reported after 20 days of storage at $5{ }^{\circ} \mathrm{C}$ (Castillejo et al., 2018). 
Such glucoraphanin increase was not observed in CTRL Bimi broccoli hummus. The latter fact may be explained by a higher inactivation of enzymes responsible of this biosynthesis owed to the less compaction within the florets of this broccoli variety leading to a higher heat inactivation during blanching.

The initial sulforaphane levels of CTRL Parthenon broccoli hummus were unchanged $(\mathrm{p}<0.05)$ for the first 6 days of storage although it was highly degraded until undetectable levels $\left(<10 \mathrm{mg} \mathrm{kg}^{-1}\right)$ on day 15 . Nevertheless, such sulforaphane degradation was not observed in MW Parthenon broccoli hummus until day 21 probably due to heat inactivation of degradative enzymes, or other catalysts. In the same line, HPP Parthenon broccoli hummus samples showed the lowest sulforaphane stability during storage with $76 \%$ reduced levels on day 6. The last finding may be explained by higher plant cell disruption achieved with the high pressures processing which allowed higher kinetic rates of degradative reactions. Sulforaphane is a highly reactive compound, contrary to their relatively inert precursor glucoraphanin, which is very unstable in aqueous solutions, with its degradation rates increased as the storage temperature increases (Franklin et al., 2014; Lamy et al., 2011). The latter finding may result also from the balance with the previously commented de novo synthesis.

\section{V.3.5. Total phenolics content}

The initial TPC of hummuses were 363.0-440.2 $\mathrm{mg} \mathrm{GA} \mathrm{kg}^{-1}$ (Figures V.3A and V.3B), without differences $(\mathrm{p}<0.05)$ between both types. High phenolic levels have been reported for both broccoli varieties used (Martínez-Hernández et al., 2015). Chickpeas have also high phenolic contents although its quantity may be drastically reduced when commercialized in cans being more than half of the phenolics leached into the can brine (Bennink and Barrett, 2004). In general, the TPC content of both hummus types was not changed ( $p<0.05)$ after any of the applied treatments. Nevertheless, TPC of Parthenon broccoli hummus decreased by 22 $\%$ after MW treatment. The same trend was observed for MW-treated Bimi broccoli hummus but it was not significant $(\mathrm{p}<0.05)$. It may be explained by the heating applied with this treatment, contrary to HPP, which might lead to the observed heat degradation of these bioactive compounds. Contrary, TPC of CTRL hummus was enhanced during storage showing levels $20-27 \%$ higher on day 15 being maintained stable until the end of storage. 
Phenylalanine ammonia lyase (PAL) is considered the key enzyme of the phenylpropanoid pathways being then involved with the biosynthesis of phenolic compounds (Dixon and Paiva, 1995). Grinding of vegetables with the same food processor, and similar instrument working conditions, still resulted in $40 \%$ of viable cells of the resulted product. Furthermore, phenolic compounds accumulation after wounding, such as that occurred during grinding, has been related to PAL activation (Saltveit, 2000) and similarly reported in different grinded vegetable presentations (Artés-Hernández et al., 2017; Rodríguez-Verástegui et al., 2015). The observed TPC increment of CTRL hummus samples was not observed in MW and HPP samples since PAL could be probably inactivated after heat or high pressures, respectively. Nevertheless, MW and HPP samples still retained $62-80 \%$ of their initial TPC after 28 days at $5{ }^{\circ} \mathrm{C}$.

\section{V.3.6. Total antioxidant capacity}

TAC of Parthenon/Bimi broccoli hummuses determined by DPPH was 328.3/581.4 (Figure V.4A and V.4B) and 194.6/391.7 and 251.1/454.2 for ABTS and FRAP, respectively (data not shown). The initial TPC of samples were highly correlated $\left(\mathrm{R}^{2}=0.92\right)$ with TAC determined by DPPH, followed by FRAP $\left(\mathrm{R}^{2}=0.79\right)$ and ABTS $\left(\mathrm{R}^{2}=0.68\right)$ as shown in Figure 5. Then, TAC is discussed based on DPPH method. Furthermore, TPC-TAC correlations were improved when MW samples were removed from the correlations with $\mathrm{R}^{2}$ for DPPH, FRAP and ABTS of 0.99, 0.98 and 0.83, respectively (data not shown). Vit C has high antioxidant potential, and is also present at high levels in broccoli, but is very thermolabile as reported in heat-treated broccoli (Martínez-Hernández et al., 2013a). Then, the previous finding may be owed to a vit $\mathrm{C}$ degradation in MW samples that could lead to the observed higher $\mathrm{R}^{2}$ values when removed from TPC-TAC correlations. Accordingly, high vit $\mathrm{C}$ degradation was observed in broccoli-based beverages (Castillejo et al., 2018). Furthermore, vitamin $\mathrm{C}$ is degraded during food storage in a different grade compared to TPC depending of the nature and conditions of applied processing treatments. In that sense, TPC-TAC correlations during storage were very low when using data from storage (data not shown). Nevertheless, analysed TAC, by any of the methods, is an excellent indicator of the antioxidant potential of the hummus samples throughout storage mainly due to phenolic compounds and vit $\mathrm{C}$, the most important antioxidant compounds of the major ingredient: the broccoli. 
In general, TAC decreased during storage of hummus samples. A high TAC decrease was observed after 6 days showing CTRL samples the highest reductions of approximately $80 \%$. Such high TAC decrease in CTRL samples may be explained due to a high vit $\mathrm{C}$ degradation that was minimized in treated samples probably due to partial inactivation of degradative enzymes of this vitamin. Accordingly, higher vit $\mathrm{C}$ degradation rates have been reported in untreated green vegetables smoothies compared to treated samples (Castillejo et al., 2017). Nevertheless, a mild TAC enhancement was observed in CTRL samples from day 15 related to the previously discussed TPC increase although TAC showed a new decreasing trend on day 28. On the other side, treated samples showed more stable TAC levels from day 15 to the end of storage with TAC decreases $<31 \%$ during these last 13 days of storage.

\section{V.4. CONCLUSIONS}

Hummus consumption may be enhanced by new variants that incorporate in the composition other nutritive and complementary vegetables, whilst maintaining the characteristic sensory essence of the traditional hummus. Two broccoli hummuses (containing $53 \%$ blanched broccoli but still keeping the traditional hummus essence) were formulated with broccoli cv. Parthenon and other with the kailan-hybrid Bimi broccoli. Storage period at $5{ }^{\circ} \mathrm{C}$ was satisfactorily achieved for 28 days using innovative semi-continuous MW or HPP treatments. HPP is preferred in order to achieve higher microbial reductions and more stabilized phenolics compounds with related total antioxidant activity. On the other side, higher endogenous formation of the bioactive compound sulforaphane was observed in MW Bimi broccoli hummus during storage although its precursor glucoraphanin was better preserved in HPP samples. 


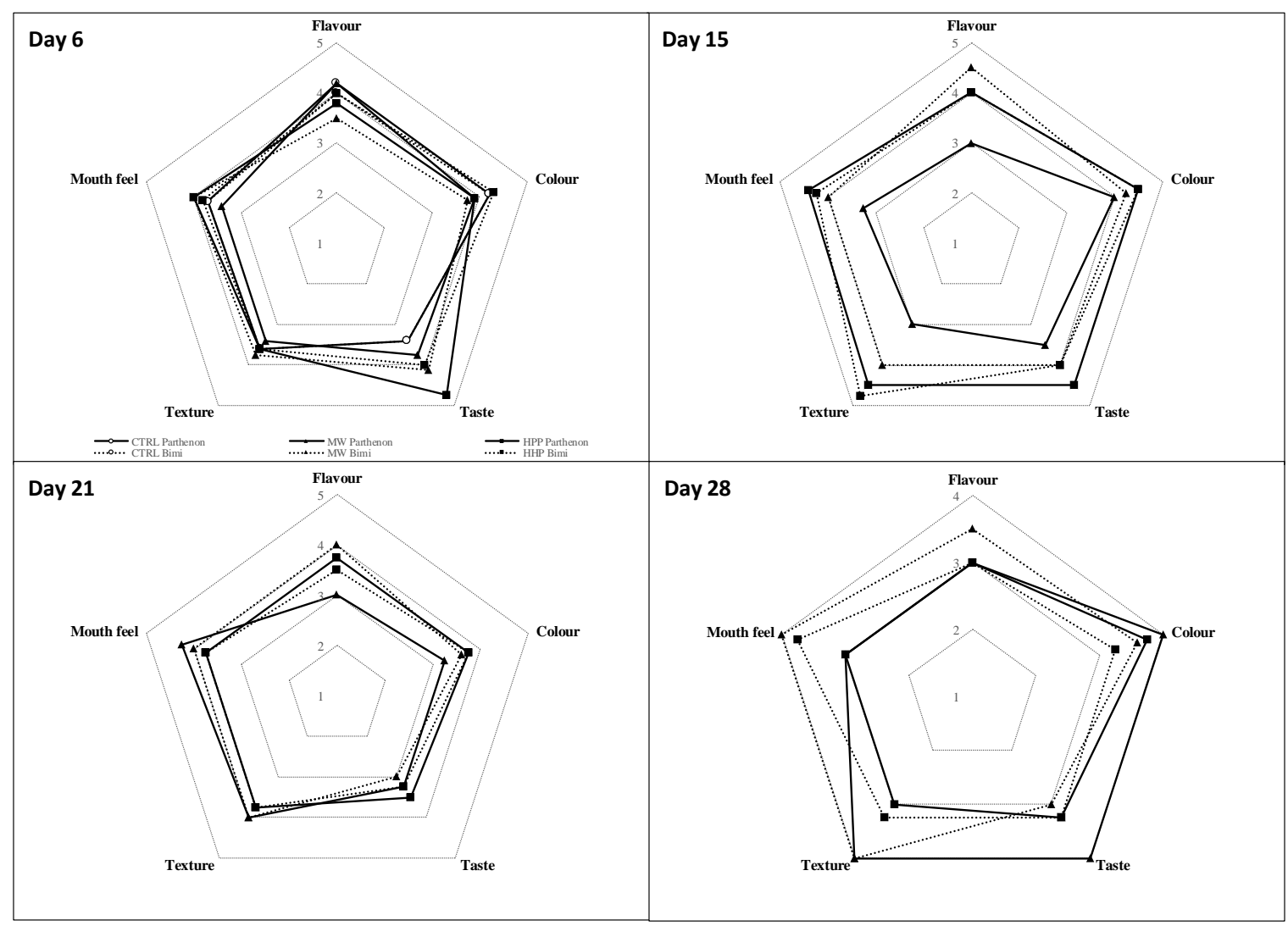

Figure V.1. Sensory scores of two broccoli (Parthenon; Bimi) hummus types untreated (CTRL), or treated (MW or HPP) after $6,15,21$ and 28 days at $5{ }^{\circ} \mathrm{C}(\mathrm{n}=3)$. 


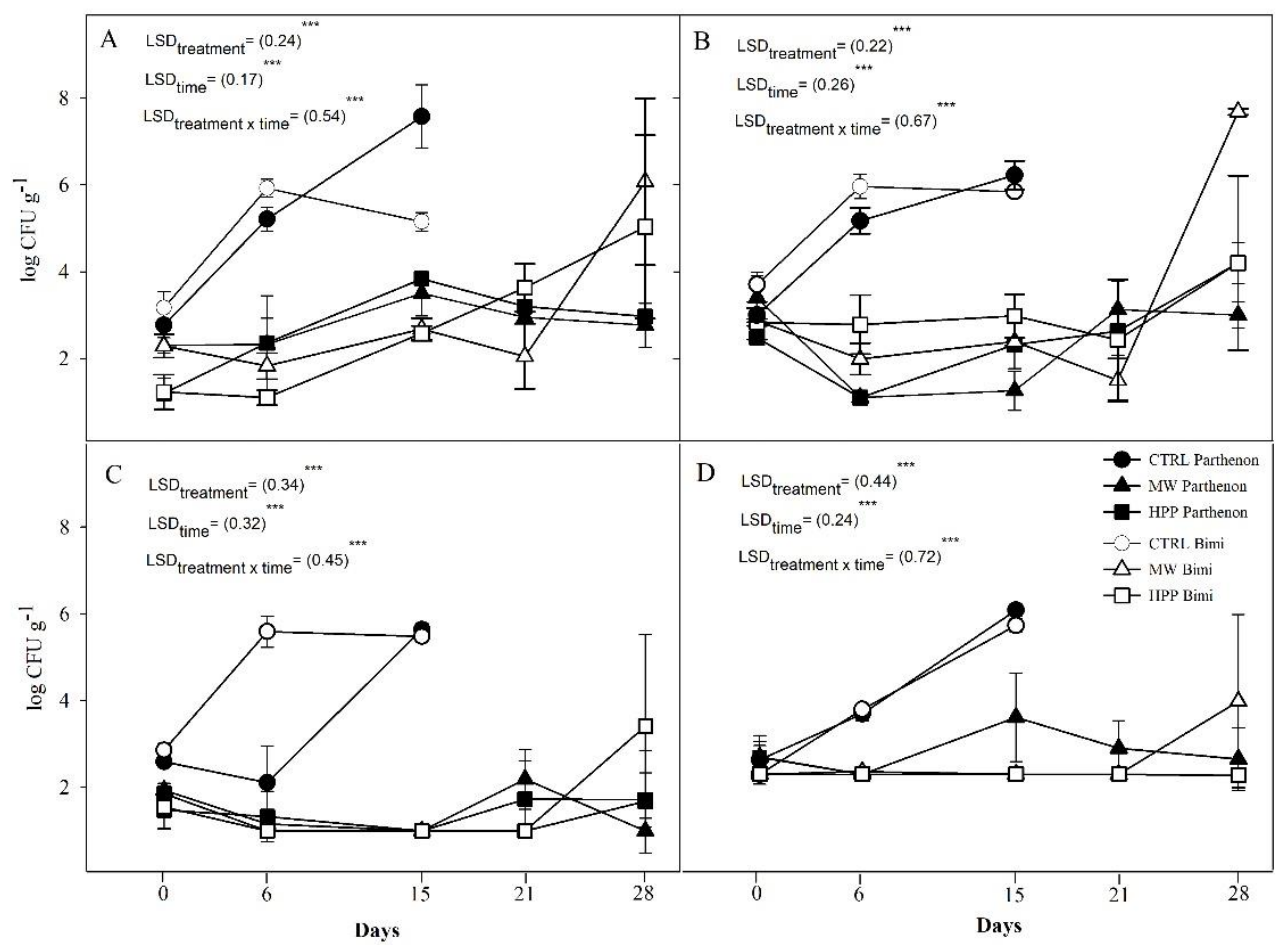

Figure V.2. Mesophilic (A), psychrophilic (B), Enterobacteriaceae (C) and yeast and moulds (D) counts ( $\log \mathrm{CFU} \mathrm{g} \mathrm{g}^{-1}$ ) of two broccoli hummus types untreated (CTRL), or treated (MW or HPP) stored at $5{ }^{\circ} \mathrm{C}(\mathrm{n}=3 \pm \mathrm{SD})$. Least significant differences (LSD) are expressed on each graph as a bar with the numerical value between parentheses. 


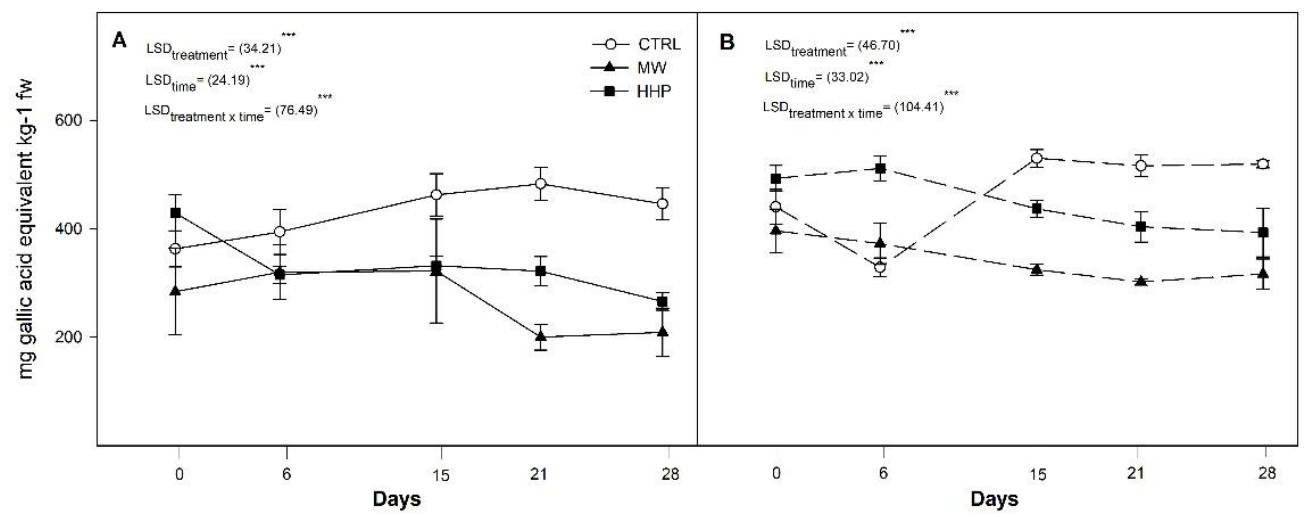

Figure V.3. Total phenolic contents of two broccoli (A, Parthenon; B, Bimi) hummus types untreated (CTRL), or treated (MW or HPP) stored at $5{ }^{\circ} \mathrm{C}(\mathrm{n}=3 \pm \mathrm{SD})$. Least significant differences (LSD) are expressed on each graph as a bar with the numerical value between parentheses. 


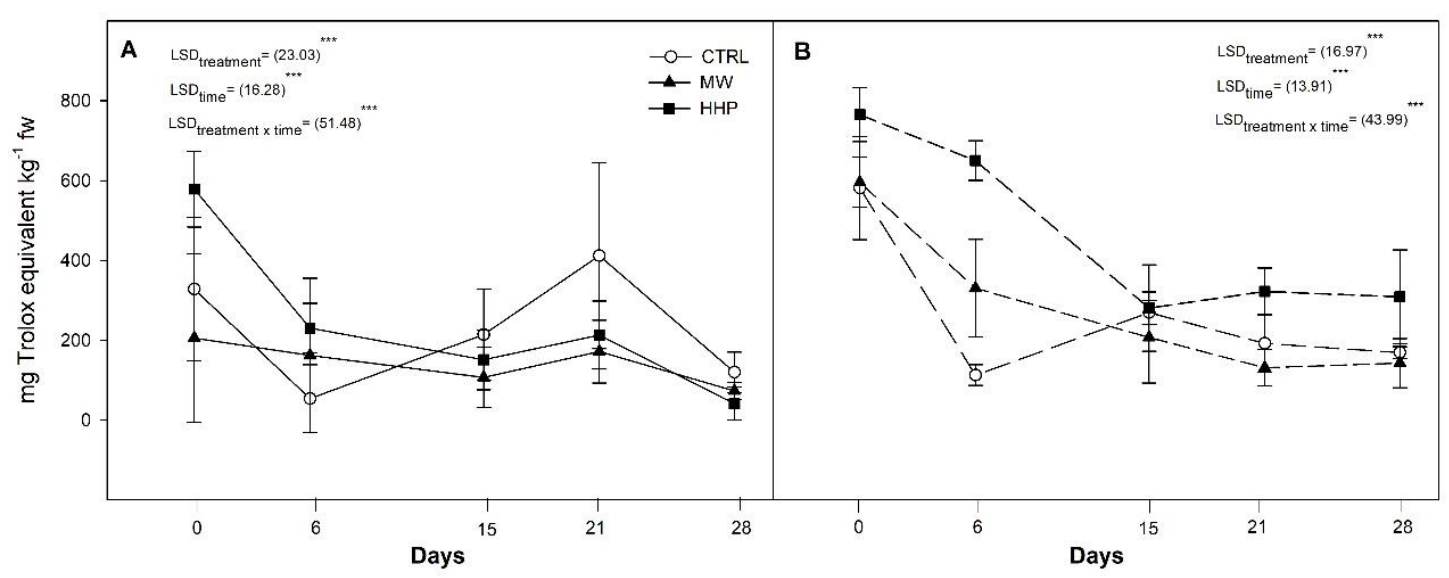

Figure V.4. Total antioxidant activity of two broccoli (A, Parthenon; B, Bimi) hummus types untreated (CTRL), or treated (MW or HPP) (determined by DPPH method) stored at $5{ }^{\circ} \mathrm{C}(\mathrm{n}=3 \pm \mathrm{SD})$. Least significant differences (LSD) are expressed on each graph as a bar with the numerical value between parentheses 


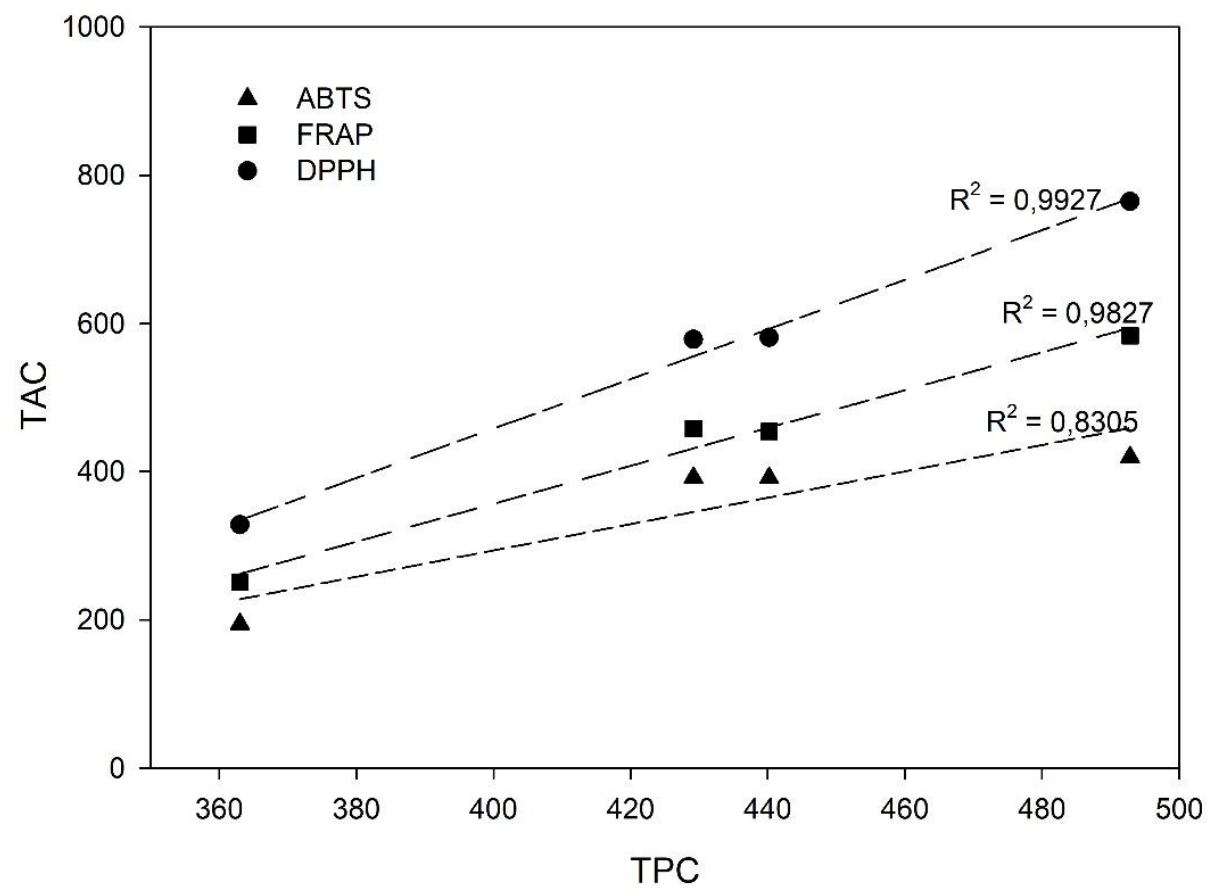

Figure V.5. Total phenolic contents (TPC)-Total antioxidant capacity (TAC) correlations of two broccoli hummus types untreated (CTRL), or treated (MW or HPP) on processing day. 
Table V.1. pH and colour parameters of two broccoli hummus types untreated (CTRL), or treated (MW or HPP) stored at $5^{\circ} \mathrm{C}(\mathrm{n}=3 \pm \mathrm{SD})$. Different capital letters denote significant differences $(P \leq$ 0.05 ) among different samples for the same sampling day. Different lowercase letters denote significant differences $(P \leq 0.05)$ among sampling days for the same sample. 


\begin{tabular}{|c|c|c|c|c|c|c|c|}
\hline Day & Broccoli & Treatment & $\mathbf{p H}$ & $\mathbf{L}^{*}$ & $\mathbf{a}^{*}$ & $\mathbf{b}^{*}$ & $\Delta \mathbf{E}$ \\
\hline \multirow[t]{6}{*}{0} & \multirow[t]{3}{*}{ CONV } & CTRL & $5.07 \pm 0.06 \mathrm{NSa}$ & $55.16 \pm 0.08 \mathrm{Aab}$ & $-6.65 \pm 0.13 \mathrm{ABa}$ & $22.24 \pm 1.13 \mathrm{NSb}$ & - \\
\hline & & MW & $5.07 \pm 0.12 \mathrm{NSns}$ & $53.04 \pm 0.06 \mathrm{ABbc}$ & $-5.76 \pm 0.29 \mathrm{BCa}$ & $22.71 \pm 0.73 \mathrm{NSab}$ & - \\
\hline & & HPP & $5.17 \pm 0.06 \mathrm{NSa}$ & $53.33 \pm 0.67 \mathrm{ABb}$ & $-5.59 \pm 0.86 \mathrm{BCa}$ & $21.19 \pm 0.47 \mathrm{NSns}$ & - \\
\hline & \multirow[t]{3}{*}{ BIMI } & CTRL & $4.90 \pm 0.26 \mathrm{NSa}$ & $51.89 \pm 1.58 \mathrm{Bb}$ & $-5.91 \pm 0.31 \mathrm{BCa}$ & $22.42 \pm 1.21 \mathrm{NSb}$ & - \\
\hline & & MW & $5.00 \pm 0.20 \mathrm{NSns}$ & $52.18 \pm 0.32 \mathrm{Bc}$ & $-7.67 \pm 0.54 \mathrm{Aa}$ & $22.54 \pm 0.40 \mathrm{NSns}$ & - \\
\hline & & HPP & $4.93 \pm 0.12 \mathrm{NSa}$ & $51.18 \pm 1.15 \mathrm{Bc}$ & $-5.29 \pm 0.12 \mathrm{Ca}$ & $22.36 \pm 0.49 \mathrm{NSbc}$ & - \\
\hline \multirow[t]{6}{*}{6} & \multirow[t]{3}{*}{$\mathrm{CONV}$} & CTRL & $4.90 \pm 0.03 \mathrm{ABa}$ & $56.71 \pm 3.12 \mathrm{ABab}$ & $-4.72 \pm 0.42 \mathrm{NSb}$ & $22.96 \pm 1.28 \mathrm{ABCab}$ & $3.58 \pm 1.53 \mathrm{Bns}$ \\
\hline & & MW & $5.02 \pm 0.02$ Ans & $59.74 \pm 2.64 \mathrm{Aa}$ & $-5.18 \pm 0.65 \mathrm{NSa}$ & $23.54 \pm 0.19 \mathrm{ABCa}$ & $6.83 \pm 2.50 \mathrm{ABns}$ \\
\hline & & HPP & $4.85 \pm 0.01 \mathrm{ABab}$ & $58.37 \pm 1.61 \mathrm{ABa}$ & $-4.72 \pm 0.10 \mathrm{NSab}$ & $20.79 \pm 0.20 \mathrm{Cns}$ & $5.14 \pm 1.58 \mathrm{ABns}$ \\
\hline & \multirow[t]{3}{*}{ BIMI } & CTRL & $4.60 \pm 0.10 \mathrm{Babc}$ & $56.29 \pm 1.20 \mathrm{ABa}$ & $-4.57 \pm 0.23 \mathrm{NSb}$ & $24.86 \pm 0.76 \mathrm{Aa}$ & $5.24 \pm 1.26 \mathrm{ABab}$ \\
\hline & & MW & $4.85 \pm 0.13 \mathrm{ABns}$ & $53.95 \pm 0.36 \mathrm{Bb}$ & $-4.33 \pm 0.24 \mathrm{NSb}$ & $21.80 \pm 1.77 \mathrm{BCns}$ & $4.13 \pm 0.24 \mathrm{ABb}$ \\
\hline & & HPP & $4.83 \pm 0.04 \mathrm{ABa}$ & $58.63 \pm 0.25 \mathrm{ABa}$ & $-4.56 \pm 0.20 \mathrm{NSb}$ & $24.06 \pm 1.16 \mathrm{ABab}$ & $7.74 \pm 0.34 \mathrm{Aa}$ \\
\hline \multirow[t]{6}{*}{15} & \multirow[t]{3}{*}{ CONV } & CTRL & $4.73 \pm 0.12 \mathrm{ABb}$ & $58.88 \pm 0.94 \mathrm{Aa}$ & $-4.66 \pm 0.07 \mathrm{Ab}$ & $24.96 \pm 1.28 \mathrm{Aab}$ & $5.07 \pm 1.31 \mathrm{ABns}$ \\
\hline & & MW & $4.97 \pm 0.06$ Ans & $52.53 \pm 2.84 \mathrm{Bc}$ & $-4.11 \pm 0.18 \mathrm{Bb}$ & $19.89 \pm 2.20 \mathrm{Bb}$ & $4.19 \pm 1.76 \mathrm{Bns}$ \\
\hline & & HPP & $4.50 \pm 0.01 \mathrm{BCb}$ & $58.46 \pm 0.17 \mathrm{Aa}$ & $-4.50 \pm 0.16 \mathrm{ABb}$ & $21.03 \pm 1.47 \mathrm{Bns}$ & $5.38 \pm 0.06 \mathrm{ABns}$ \\
\hline & \multirow[t]{3}{*}{ BIMI } & CTRL & $4.30 \pm 0.01 \mathrm{Cc}$ & $50.91 \pm 1.49 \mathrm{Bb}$ & $-4.14 \pm 0.12 \mathrm{Bbc}$ & $23.42 \pm 0.48 \mathrm{ABab}$ & $2.53 \pm 0.73 \mathrm{Bb}$ \\
\hline & & MW & $4.70 \pm 0.35 \mathrm{ABCns}$ & $53.69 \pm 0.72 \mathrm{Bbc}$ & $-4.17 \pm 0.13 \mathrm{Bb}$ & $22.22 \pm 1.56 \mathrm{ABns}$ & $4.07 \pm 0.36 \mathrm{Bb}$ \\
\hline & & HPP & $4.73 \pm 0.12 \mathrm{ABab}$ & $58.66 \pm 2.53 \mathrm{Aa}$ & $-4.54 \pm 0.26 \mathrm{ABb}$ & $25.56 \pm 0.69 \mathrm{Aa}$ & $8.21 \pm 2.44 \mathrm{Aa}$ \\
\hline \multirow[t]{6}{*}{21} & \multirow[t]{3}{*}{$\mathrm{CONV}$} & CTRL & $4.70 \pm 0.10 \mathrm{ABCb}$ & $57.08 \pm 0.27 \mathrm{Aab}$ & $-4.29 \pm 0.09 \mathrm{Abc}$ & $25.47 \pm 0.87 \mathrm{Aa}$ & $4.46 \pm 0.68 \mathrm{NSns}$ \\
\hline & & MW & $4.87 \pm 0.12 \mathrm{ABns}$ & $57.87 \pm 1.47 \mathrm{Aab}$ & $-4.16 \pm 0.28 \mathrm{ABb}$ & $21.93 \pm 0.64 \mathrm{Cab}$ & $5.22 \pm 1.24 \mathrm{NSns}$ \\
\hline & & HPP & $4.83 \pm 0.21 \mathrm{ABab}$ & $58.89 \pm 2.31 \mathrm{Aa}$ & $-4.12 \pm 0.10 \mathrm{ABb}$ & $22.35 \pm 0.75 \mathrm{Cns}$ & $5.93 \pm 2.22 \mathrm{NSns}$ \\
\hline & \multirow[t]{3}{*}{ BIMI } & CTRL & $4.40 \pm 0.17 \mathrm{Cbc}$ & $52.58 \pm 0.27 \mathrm{Bab}$ & $-3.72 \pm 0.20 \mathrm{Bcd}$ & $25.08 \pm 0.46 \mathrm{ABa}$ & $3.54 \pm 0.36 \mathrm{NSab}$ \\
\hline & & MW & $5.03 \pm 0.06$ Ans & $57.81 \pm 0.31 \mathrm{Aa}$ & $-4.18 \pm 0.15 \mathrm{ABb}$ & $23.51 \pm 0.69 \mathrm{BCns}$ & $6.73 \pm 0.10 \mathrm{NSa}$ \\
\hline & & HPP & $4.53 \pm 0.12 \mathrm{BCb}$ & $56.11 \pm 1.53 \mathrm{ABab}$ & $-3.69 \pm 0.23 \mathrm{Bc}$ & $23.04 \pm 0.62 \mathrm{Cbc}$ & $5.27 \pm 1.46 \mathrm{NSab}$ \\
\hline \multirow[t]{9}{*}{28} & \multirow[t]{3}{*}{ CONV } & CTRL & $4.50 \pm 0.01 \mathrm{NSc}$ & $53.89 \pm 1.36 \mathrm{Ab}$ & $-3.89 \pm 0.13 \mathrm{Ac}$ & $23.25 \pm 0.28 \mathrm{NSab}$ & $3.38 \pm 0.46 \mathrm{Bns}$ \\
\hline & & MW & $4.97 \pm 0.06 \mathrm{NSns}$ & $55.19 \pm 1.18$ Aabc & $-3.93 \pm 0.17 \mathrm{Ab}$ & $21.55 \pm 0.80 \mathrm{NSab}$ & $3.24 \pm 0.58 \mathrm{Bns}$ \\
\hline & & HPP & $4.57 \pm 0.29 \mathrm{NSb}$ & $55.90 \pm 0.39 \mathrm{Aab}$ & $-3.82 \pm 0.06 \mathrm{Ab}$ & $20.99 \pm 1.14$ NSns & $3.27 \pm 0.30 \mathrm{Bns}$ \\
\hline & \multirow[t]{3}{*}{ BIMI } & CTRL & $4.77 \pm 0.06 \mathrm{NSab}$ & $46.91 \pm 2.12 \mathrm{Bc}$ & $-3.19 \pm 0.11 \mathrm{Cd}$ & $22.65 \pm 0.34 \mathrm{NSb}$ & $5.76 \pm 1.84 \mathrm{Aa}$ \\
\hline & & MW & $4.67 \pm 0.29 \mathrm{NSns}$ & $53.00 \pm 1.05 \mathrm{Abc}$ & $-3.66 \pm 0.17 \mathrm{ABb}$ & $22.15 \pm 1.71 \mathrm{NSns}$ & $4.42 \pm 0.47 \mathrm{ABb}$ \\
\hline & & HPP & $4.67 \pm 0.12 \mathrm{NSab}$ & $52.68 \pm 0.91 \mathrm{Abc}$ & $-3.24 \pm 0.22 \mathrm{BCc}$ & $21.95 \pm 0.38 \mathrm{NSc}$ & $2.69 \pm 0.30 \mathrm{Bb}$ \\
\hline & \multicolumn{2}{|c|}{ Treatments } & $* * *$ & $* * *$ & $* * *$ & $* * *$ & $*$ \\
\hline & \multicolumn{2}{|c|}{ Days } & $* * *$ & $* * *$ & $* * *$ & $* * *$ & $* *$ \\
\hline & \multicolumn{2}{|c|}{ Days $x$ Treatments } & 0.001 & 0.000 & 0.000 & 0.000 & 0.000 \\
\hline
\end{tabular}


Table V.2. Glucoraphanin and sulforaphane contents of two broccoli hummus types untreated (CTRL), or treated (MW or HPP) stored at $5{ }^{\circ} \mathrm{C}(\mathrm{n}=3 \pm \mathrm{SD})$. Different capital letters denote significant differences $(P \leq 0.05)$ among different samples for the same sampling day. Different lowercase letters denote significant differences $(P \leq 0.05)$ among sampling days for the same sample.

\begin{tabular}{|c|c|c|c|c|}
\hline Day & Hummus & Treatment & Glucoraphanin $\left(\mathrm{mg} \mathrm{kg}^{-1} \mathrm{dw}\right)$ & Sulforaphane $\left(\mathrm{mg} \mathrm{kg}^{-1} \mathrm{dw}\right)$ \\
\hline \multirow[t]{6}{*}{0} & Parthenon & CTRL & $1.94 \pm 0.41 \mathrm{Db}$ & $81.77 \pm 17.15 \mathrm{Aa}$ \\
\hline & & MW & $8.22 \pm 2.93 \mathrm{Dc}$ & $55.20 \pm 6.37 \mathrm{Bab}$ \\
\hline & & HPP & $2.47 \pm 0.20 \mathrm{Dc}$ & $59.55 \pm 11.97 \mathrm{ABa}$ \\
\hline & Bimi & CTRL & $100.83 \pm 5.40 \mathrm{Ca}$ & $18.52 \pm 3.12 \mathrm{Ca}$ \\
\hline & & MW & $169.41 \pm 13.59 \mathrm{Ba}$ & ND Cns \\
\hline & & HPP & $209.24 \pm 23.72 \mathrm{Aa}$ & ND Cns \\
\hline \multirow[t]{6}{*}{6} & Parthenon & CTRL & $\mathrm{ND} C b$ & $74.77 \pm 10.12 \mathrm{Aa}$ \\
\hline & & MW & $5.77 \pm 0.83 \mathrm{Cc}$ & $51.63 \pm 12.88 \mathrm{Bab}$ \\
\hline & & HPP & $57.45 \pm 19.69 \mathrm{Bb}$ & $14.09 \pm 9.42 \mathrm{Cc}$ \\
\hline & Bimi & CTRL & $\mathrm{ND} \mathrm{Cb}$ & $12.71 \pm 4.23 \mathrm{Ca}$ \\
\hline & & MW & $145.58 \pm 12.49 \mathrm{Aa}$ & ND Cns \\
\hline & & HPP & $159.53 \pm 39.04 \mathrm{Aa}$ & ND Cns \\
\hline \multirow[t]{6}{*}{15} & Parthenon & CTRL & $86.59 \pm 7.09 \mathrm{Aa}$ & $5.78 \pm 1.07 \mathrm{Bb}$ \\
\hline & & MW & $5.92 \pm 0.20 \mathrm{Bc}$ & $58.34 \pm 21.05 \mathrm{Aa}$ \\
\hline & & HPP & $2.96 \pm 1.02 \mathrm{Bc}$ & $34.61 \pm 6.70 \mathrm{Ab}$ \\
\hline & Bimi & CTRL & $\mathrm{ND} \mathrm{Bb}$ & $\mathrm{ND} \mathrm{Bb}$ \\
\hline & & MW & $90.83 \pm 21.74 \mathrm{Ab}$ & ND Bns \\
\hline & & HPP & $75.37 \pm 49.99 \mathrm{Ab}$ & ND Bns \\
\hline \multirow[t]{6}{*}{21} & Parthenon & CTRL & $72.61 \pm 31.29 \mathrm{ABa}$ & $\mathrm{ND} C b$ \\
\hline & & MW & $98.85 \pm 104.47 \mathrm{Ab}$ & $53.98 \pm 8.84 \mathrm{Aab}$ \\
\hline & & HPP & $67.81 \pm 13.89 \mathrm{ABb}$ & $15.93 \pm 4.73 \mathrm{Bc}$ \\
\hline & Bimi & CTRL & $\mathrm{ND} \mathrm{Bb}$ & $\mathrm{ND} \mathrm{Cb}$ \\
\hline & & MW & $150.36 \pm 25.21 \mathrm{Aa}$ & ND Cns \\
\hline & & HPP & $147.92 \pm 28.14 \mathrm{Aa}$ & ND Cns \\
\hline \multirow[t]{9}{*}{28} & Parthenon & CTRL & $\mathrm{ND} \mathrm{Db}$ & $\mathrm{ND} \mathrm{Cb}$ \\
\hline & & MW & $204.76 \pm 15.43 \mathrm{Aa}$ & $28.50 \pm 2.08 \mathrm{Ab}$ \\
\hline & & HPP & $114.10 \pm 14.17 \mathrm{Ba}$ & $9.62 \pm 3.50 \mathrm{Bc}$ \\
\hline & Bimi & CTRL & ND Db & $\mathrm{ND} \mathrm{Cb}$ \\
\hline & & MW & $110.29 \pm 7.30 \mathrm{BCb}$ & ND Cns \\
\hline & & HPP & $71.43 \pm 23.80 \mathrm{Cb}$ & ND Cns \\
\hline & Treatments & & $* * *$ & $* * *$ \\
\hline & Days & & $* * *$ & $* * *$ \\
\hline & Days x Tre & ments & 0.000 & 0.000 \\
\hline
\end{tabular}




\section{CHAPTER VI}

\section{Effect of $\alpha-\beta-$ and maltosyl- $\beta$-cyclodextrins use on the glucoraphanin/sulforaphane system of broccoli juice}

Ginés Benito Martínez-Hernández ${ }^{1}$, Tâmmila Venzke Klug ${ }^{1}$, Maria del Mar CarriónMonteagudo ${ }^{1}$, Francisco Artés ${ }^{1}$, José Manuel López-Nicolás ${ }^{2}$ and Francisco Artés-Hernández ${ }^{1}$

1 Postharvest and Refrigeration Group. Department of Food Engineering. Universidad Politécnica de Cartagena. Paseo Alfonso XIII, 48, 30203 Cartagena, Murcia, Spain.

2 Department of Biochemistry and Molecular Biology-A, Faculty of Biology, University of Murcia, Campus de Espinardo, 30071, Murcia, Spain.

Reference: Journal of the Science of Food and Agriculture. 2018. In press.

Doi:10.1002/jsfa.9269 


\section{VI.1. INTRODUCTION}

Cyclodextrins (CDs) are large molecules of natural origin consisting of cyclic oligosaccharides with six $(\alpha-C D)$, seven $(\beta-C D)$ and eight $(\gamma-C D)$ glucopyranose units, bound by $\alpha-(1-4)$ linkages forming a truncated conical structure. After the CDs discovery such molecules were considered poisonous substances and its capacity for complexes formation was only considered a scientific curiosity (Astray et al., 2009). Latter research proved their non-toxicity, starting to be studied their potential use in the food industry as additives. In that sense, a wide range of industrial applications such as protection of nutritional/health-promoting compounds (vitamins, phenolic compounds, etc.), stabilization of flavours, elimination of undesired tastes and browning reactions, and to avoid microbiological contaminations, have been reported among other (Astray et al., 2009; Hu et al., 2012; Shao et al., 2014; Comunian and Favaro-Trindade, 2016). The most important CDs at industrial level are $\alpha-$ and $\beta-$ CDs being the last one the most used due to its low production cost. Nevertheless, $\beta-$ CD has low water solubility (almost nine times less soluble than $\alpha-$ and $\gamma-\mathrm{CDs}$ ) being necessary temperatures higher than $55^{\circ} \mathrm{C}$ to increase its solubility (Linerte et al., 1992). Substitution of the hydroxyl groups of CDs causes dramatic improvements in aqueous solubility and guest specificity, particularly in the case of $\beta-\mathrm{CD}$, providing substitution of the maltosyl group a more intense bonding with better stabilization of the inclusion (Acarturk et al., 1993; López-Nicolás et al., 1995; Veiga et al., 2002)

Broccoli (Brassica oleracea Italica Group) is a brassica vegetable that has been highly studied due to its high content in sulphur-containing compounds known as glucosinolates (GLS) (Traka and Mithen, 2008). Myrosinase (thioglucoside glucohydrolase) is largely stored in separate cell compartments from the GLS in brassica vegetables. Nevertheless, upon cell rupture (juicing, mastication, etc.) myrosinase comes rapidly into contact with the GLS starting to form an instable intermediate aglycone (thiohydroximate- $\mathrm{O}-$-sulfonate). Then, such aglycone may be further transformed in multiple compounds such as isothiocyanates (ITCs), nitriles, thiocyanates, epithionitriles and oxazolidine-2-thiones. The latter transformation may depend on several factors such as specifier proteins (i.e. epithiospecifier protein -ESP-), temperature, $\mathrm{pH}, \mathrm{Fe}^{2+}$ presence, water content, etc (Williams et al., 2010; Oliviero et al., 2014; Hanschen et al., 2017). However, ITCs are ideally preferred due to their high healthpromoting properties (Traka and Mithen, 2008; Cartea and Velasco, 2008; Williams et al., 
2010; Oliviero et al., 2014; Hanschen et al., 2017). Nevertheless, nitriles and epithionitriles have shown less health beneficial potential (Matusheski et al., 2001) being the ITCs formation preferred over the other compounds (Hanschen et al., 2017). Accordingly, GLS content of brassica vegetables has been recently recommended to be studied together with ITCs content as a GLS/ITCs system (Wu et al., 2017).

Glucoraphanin is one of the major broccoli GLS that has been extensively studied due to the high health-promoting properties of its cognate ITC, namely sulforaphane (4(methylsulphinyl) butyl ITC). Sulforaphane was identified as a potential chemopreventive compound due to its capacity to induce quinone reductase, a phase II detoxification enzyme, in Hepa lcl c7 cell culture (Zhang et al., 1992; Talalay et al., 1995; Juge et al., 2007). On the other side, myrosinase-like activity in animal and human gut microflora has been reported to be inefficient and highly variable (up to $40 \%$ ) in humans, contrary to previous studies (Bricker et al., 2014). Then, sulforaphane formation may be promoted in brassica vegetables by several strategies like ESP inactivation (while maintaining myrosinase activity (Matusheski et al., 2004)), pH modification and/or high water content as recently modelled (Hanschen et al., 2017). Among them, broccoli blanching ( $95^{\circ} \mathrm{C}, 4-5 \mathrm{~min}$ ) may inactivate ESP protein while still maintaining enough myrosinase activity levels to ensure high glucoraphanin>sulforaphane conversion (Ghawi et al., 2013). Nevertheless, sulforaphane is a very unstable compound in solution being then highly susceptible to degradation in brassica vegetables-including beverages. Then, it would be interesting to delay GLS>ITCs by GLS encapsulation. Accordingly, sulforaphane has been proposed to be protected by modified CDs according to studies using hydroxypropyl $-\beta-\mathrm{CD}$ within sulforaphane extracts purified from broccoli seeds (Wu et al., 2010; Wu et al., 2013; Fahey et al., 2017). However, latter studies were only conducted within purified sulforaphane extracts. Nevertheless, a complete study about the effects of most used CDs on the GLS>ITCs system in brassica beverages has not been conducted. The latter fact is very interesting since food matrix is considered as a potential interfering factor for the formation of inclusion complexes. 
According to such scenario, the aim of this study was to assess the effects of $\alpha-, \beta-$ and modified $\beta-C D$ (maltosyl $-\beta-C D$ ), addition to broccoli juice, at different concentrations, on the stability of the glucoraphanin/sulforaphane system of broccoli juice.

\section{VI.2. MATERIALS AND METHODS}

\section{VI.2.1. Chemicals and plant material}

Maltosyl- $\beta-$ CD was purchased from Alfa Chemistry (Stony Brook NY, USA) while the rest of reagents were from Sigma-Aldrich (St. Louis, MO, USA). Broccoli (B. oleracea Italica Group, var Parthenon) heads were obtained from a local producer (Campo de Lorca-Juan Marín S.L., Lorca, Spain). Broccoli was grown under open air cultivation in fields located in the Region of Murcia, in the Southeast Mediterranean Spanish area, in the winter growing cycle (planting in September) and were harvested randomly at the end of January 2017 (average temperature intervals of $4-27^{\circ} \mathrm{C}$ ). Plant material was grown according to integrated pest management cultural practices. Broccoli was hand-harvested at commercial maturity stage (about 350-400 g/head). Immediately after harvesting, broccoli heads were pre-cooled with crushed ice and transported by car about $80 \mathrm{~km}$ to the Pilot Plant of our Research Group in the Universidad Politécnica de Cartagena where were stored at $2{ }^{\circ} \mathrm{C}$ and $90-95 \% \mathrm{RH}$ until next day.

\section{VI.2.2. Juice preparation and cyclodextrins treatments}

Broccoli juice preparation was accomplished in a disinfected cold room at $8{ }^{\circ} \mathrm{C}$. Broccoli heads were carefully inspected selecting those free from defects and with similar visual appearance. Subsequently, plant material was sanitized with chlorinated water $\left(150 \mathrm{mg} \mathrm{L}^{-1}\right.$ free chlorine, $\mathrm{pH} 6.5,5^{\circ} \mathrm{C}$ ) for $2 \mathrm{~min}$, then rinsed with cold tap water $\left(5^{\circ} \mathrm{C}\right)$ and finally drained into a basket. The sanitized heads were cut into $5-\mathrm{cm}$ pieces with a sharp stainless knife and introduced (approximately $100 \mathrm{~g}$ ) in a plastic mesh. Subsequently, the mesh filled with broccoli pieces was blanched in a preheated water bath $\left(95 \pm 2{ }^{\circ} \mathrm{C}\right)$ for $5 \mathrm{~min}$. After blanching, meshes were quickly removed from the bath and introduced in an ice-water bath until the centre of the pieces reached $4{ }^{\circ} \mathrm{C}$ (registered with a temperature probe). 
Juice from blanched broccoli was obtained with a blender (Centrika Pro, Ariete, Spain). Broccoli juice was directly collected while juicing in a 1.5-L glass beaker, already containing the appropriate CDs quantity (described below) to achieve the desired concentrations, up to a final juice volume of $1 \mathrm{~L}$. The beaker containing CDs was placed on a magnetic stirrer to ensure a rapid CDs homogenization in the freshly blended juice.

CDs concentrations were chosen based on the maximum solubility of every CD in aqueous solutions at room temperature and previous uses in other plant beverages (López-Nicolás et al., 2007 a,b) $\alpha-, \beta-$ and maltosyl $-\beta-C D$ concentrations in the prepared juices were 10/30/40 $\mathrm{mM}, 3 / 6 / 10 \mathrm{mM}$ and 30/60/90 $\mathrm{mM}$, respectively. Broccoli juice without CDs was used as control (CTRL). Broccoli juices with CDs were further stirred up to $24 \mathrm{~h}$ at $22{ }^{\circ} \mathrm{C}$ with sampling times at $0,0.5,1$ and $3 \mathrm{~h}$, together with a long conservation of $24 \mathrm{~h}$. Such temperature was selected as the most favourable sulforaphane formation temperature as found in broccoli B. oleracea var. Italica BroccoCress (Hanschen et al., 2017) Juice samples were directly obtained at those sampling times in $50 \mathrm{~mL}-$ Falcon tubes being immediately frozen in liquid $\mathrm{N}_{2}$. Subsequently, samples were freeze-dried (LyoQuest, Telstar, Spain) and ground to a fine powder (Matusheski et al., 2001) using a mincer (IKA, A 11 basic, Berlin, Germany).

\section{VI.2.4. Glucoraphanin analysis}

Glucoraphanin was analysed according to literature with slight modifications (Kiddle et al., 2001; Vallejo et al., 2002). Briefly, freeze-dried juice powder (0.2 g) was weighed into glass screw-cap tubes $(10 \mathrm{~mL})$ and heated using a water bath $\left(80^{\circ} \mathrm{C}, 10 \mathrm{~min}\right)$ with constant shaking. Then, $5 \mathrm{~mL}$ of methanol:water $(80: 20, v: v)$ solution was added to each sample and heating was continued for $20 \mathrm{~min}$ at $80{ }^{\circ} \mathrm{C}$. Subsequently, $1 \mathrm{~mL}$ of hot $\left(100{ }^{\circ} \mathrm{C}\right)$ ultrapure water was added to each sample being the heating bath continued for further $30 \mathrm{~min}$. The obtained extracts were centrifuged $\left(4,000 \times \mathrm{g}, 20 \mathrm{~min}, 4{ }^{\circ} \mathrm{C}\right)$ and supernatants were decanted and stored on ice. Pellets were re-extracted as previously described with $2.5 \mathrm{~mL}$ methanolwater $(90: 10, v: v)$. Both supernatants were combined and made up to a final volume of $5 \mathrm{~mL}$ with methanol-water $(90: 10, v: v)$. Desulphation of glucoraphanin was conducted using prepared DEAE Sephadex A25 (GE Healthcare, Uppsala, Sweden) mini-columns. Columns were prepared by adding $0.5 \mathrm{~mL}$ of ultrapure water, $0.5 \mathrm{~mL}$ of DEAE Sephadex A25 followed by $0.5 \mathrm{~mL}$ of ultrapure water. Each methanolic extract $(1 \mathrm{~mL})$ was loaded onto the prepared 
columns and the unbound material removed using two washings with $0.5 \mathrm{~mL}$ of ultrapure water followed by two washings with $0.02 \mathrm{M}$ sodium acetate $(\mathrm{pH}$ 5.0) per column. Purified sulfatase from Helix pomatia (EC 10,000 units; Sigma-Aldrich, St Louis, MO, USA) (75 $\mu 1$ ) was loaded onto each column and desulphation was performed overnight (12 h) at room temperature. The desulphoglucoraphanin was eluted with three ultrapure water washings $(0.5+0.5+0.25 \mathrm{~mL})$ and made up to a final volume of $1.5 \mathrm{~mL}$ with ultrapure water.

The latter extracts were analysed using an ultra high-performance liquid chromatography (UHPLC) instrument (Shimadzu, Kyoto, Japan) equipped with a DGU-20A degasser, LC30AD quaternary pump, SIL-30AC autosampler, CTO-10AS column heater and SPDM-20A photodiode array detector. Chromatographic analyses were carried out onto a Gemini C18 column $(250 \mathrm{~mm} \times 4.6 \mathrm{~mm}, 2.6 \mu \mathrm{m}$ particle size; Phenomenex, Macclesfield, UK). The used mobile phases were water (A) and acetonitrile (B). The flow rate was $1.5 \mathrm{~mL} \mathrm{~min}^{-1}$ with a linear gradient eluent starting with $2 \% \mathrm{~B}$ to reach $20 \% \mathrm{~B}$ at $28 \mathrm{~min}$ and $2 \% \mathrm{~B}$ at $32 \mathrm{~min}$. Glucoraphanin was quantified using desulphoglucoraphanin standard (Toronto Research Chemicals Inc., North York, Canada). Glucoraphanin was expressed in $\mu \mathrm{mol} \mathrm{L}{ }^{-1} \mathrm{fw}$. Each of the five replicates was analysed in duplicate.

\section{VI.2.5. Sulforaphane analysis}

Sulforaphane was analysed according to Ares et al. (2014) with slight modifications. Briefly, $0.25 \mathrm{~g}$ of freeze-dried powder was mixed with $5 \mathrm{~mL}$ of acidic water $(\mathrm{pH} 6.0$ using $0.1 \mathrm{M}$ hydrochloric acid) in a glass screw-capped tube. The mixture was incubated in a heating bath at $45^{\circ} \mathrm{C}$ for $2 \mathrm{~h}$ to allow glucoraphanin conversion to sulforaphane. Then, $25 \mathrm{~mL}$ of methyl- $t-$ butyhlether (MTBE) was added to the mixture being then sonicated for 1 min. Subsequently, the latter extract was dewatered using sodium sulphate $(5.5 \mathrm{~g})$ being the resulting extract filtrated through a filter paper (Whatman 41). The collected filtrate was passed through an activated $(3 \mathrm{~mL}$ MTBE$+3 \mathrm{~mL}$ ethyl acetate $+3 \mathrm{~mL}$ air) SI-1 silica cartridge (Phenomenex, Torrance CA, USA) being discarded the eluent. Finally, sulforaphane was eluted from the cartridge with $2 \mathrm{~mL}$ of methanol. The latter methanolic extract was evaporated to dryness in a rotary evaporator at $45^{\circ} \mathrm{C}$ being the dry residue resuspended in $1 \mathrm{~mL}$ acetonitrile followed by filtration with a polytetrafluoroethylene $0.45-\mu \mathrm{m}$ syringe filter. 
Sulforaphane extracts were analysed using the above described UHPLC with the same C18 column. Mobile phase used was a mixture of $20 \mathrm{mM}$ ammonium formate in water and acetonitrile $(55: 45, v: v)$. The injection volume was $5 \mu \mathrm{L}$ (draw speed of $50 \mu \mathrm{L} \mathrm{min}{ }^{-1}$ ), flow rate $0.6 \mathrm{~mL} \mathrm{~min}^{-1}$, temperature at $25^{\circ} \mathrm{C}$ and detection wavelength at $196 \mathrm{~nm}$. Sulforaphane was quantified using DL-sulforaphane standard (Sigma-Aldrich, St. Louis MO, USA). Sulforaphane results were expressed as $\mu \mathrm{mol} \mathrm{g} \mathrm{L}^{-1} \mathrm{fw}$. Each of the five replicates was analysed in duplicate.

\section{VI.2.6. Statistical analyses}

A complete randomized design in triplicate with three-way ANOVA (cyclodextrin type $\times$ cyclodextrin concentration $\times$ time) was conducted. Statistical significance was assessed at the level $p=0.05$, and Tukey's multiple range test was used to separate means with SPSS software (v. 21, IBM, USA).

\section{VI.3. RESULTS AND DISCUSSION}

\section{VI.3.1. Glucoraphanin and sulforaphane levels after broccoli juicing}

Initial glucosinolate/sulforaphane content of 211.0/19.3 $\mu \mathrm{mol} \mathrm{L}^{-1}$ fw in CTRL juice just after juicing was found (Table VI.1). CTRL juice showed $340 \%$ higher sulforaphane contents after $3 \mathrm{~h}$ at $22^{\circ} \mathrm{C}$. Furthermore, glucoraphanin levels of CTRL juice seemed also to decrease after 3 $\mathrm{h}$ being confirmed a glucosinolate>sulforaphane conversion. Similarly, sulforaphane formation was reported in extracts of B. oleracea var. Italica BroccoCress at $22^{\circ} \mathrm{C}$ (Hanschen et al., 2017). Such endogenous myrosinase-sulforaphane formation is necessary since the previously reported glucoraphanin>sulforaphane conversion by the human colonic bacteria have low efficiency and high variability (from 1 to $40 \%$ ) (Clarke et al., 2011; Cramer et al., 2012; Fahey et al., 2012). Therefore, the used blanching of broccoli florets could inactivate ESP while maintaining myrosinase activity, as described in broccoli (Matusheski et al., 2004; Dosz and Jeffery, 2013a). Nevertheless, no sulforaphane levels were detected after $24 \mathrm{~h}$ (Table VI.1). The latter finding may be explained since sulforaphane is an inherently reactive ITC that is temperature-sensitive and degrades in many solvents including water while GLS are more resistant (Jin et al., 1999; Franklin et al., 2014). Accordingly, glucoraphanin levels of $19.3 \mu \mathrm{mol} \mathrm{L}^{-1} \mathrm{fw}$ were still observed after $24 \mathrm{~h}$ (Table VI.1). Glucoraphanin degradation 
may be also explained by its conversion to other non-ITC compounds at such endogenous broccoli $\mathrm{pH}$ (5.5-6.0). Accordingly, sulforaphane formation has been recommended to be increased in domestic preparation of broccoli juice by acidification with citric acid (i.e., from lemon) (Hanschen et al., 2017). Nevertheless, pH modification was avoided in this experiment in order to exclude additional experimental factors that would difficult data interpretation.

\section{VI.3.2. Effects of $\beta$-cyclodextrin use on broccoli juice}

Sulforaphane levels of broccoli juice with $3 \mathrm{mM} \beta-\mathrm{CD}$ were 5.6-fold higher than CTRL juice at $0 \mathrm{~h}$ (Table VI.1). The latter higher sulforaphane contents in $3 \mathrm{mM} \beta-\mathrm{CD}$ juice may be owed to the rapid sulforaphane encapsulation which preserved this compound from reported degradation processes ( $\mathrm{Wu}$ et al., 2010). Furthermore, $3 \mathrm{mM} \beta-\mathrm{CD}$ allowed to properly stabilize the progressively formed sulforaphane over time with 2.2 -fold higher levels after $3 \mathrm{~h}$ compared to initial levels of $3 \mathrm{mM} \beta$-CD samples (Table VI.1). On the other side, the highest $\beta-\mathrm{CD}$ concentration of $10 \mathrm{mM}$ was needed to stabilized glucoraphanin since unchanged $(\mathrm{p}<0.05)$ glucoraphanin contents were observed after $3 \mathrm{~h}$. Meanwhile, glucoraphanin levels decreased by 62 and $44 \%$ after $3 \mathrm{~h}$ using 3 and $6 \mathrm{mM} \beta-\mathrm{CD}$ concentrations, respectively. Likewise, other health-promoting molecules like vitamin $\mathrm{C}$ have been encapsulated with $\beta$ CD (Saha and Roy, 2017). Similar to glucoraphanin behaviour, $74 \%$ lower sulforaphane levels were found in broccoli juice with $10 \mathrm{mM} \beta-\mathrm{CD}$ at $3 \mathrm{~h}$ compared to samples with $3 \mathrm{mM}$ $\beta-\mathrm{CD}$ (Table VI.1). Nevertheless, sulforaphane encapsulation improvement using higher $\beta$ CD concentrations would be not possible to be studied due to the limited water solubility of this $\mathrm{CD}$ at $22^{\circ} \mathrm{C}\left(185 \mathrm{mg} \mathrm{L}^{-1}\right)$ (Chatjigakis et al., 1992). Nevertheless, the use of a modified $\beta-\mathrm{CD}$ (the maltosyl $-\beta-\mathrm{CD}$ ) would allow to use higher $\mathrm{CD}$ concentrations as presented in the next section.

\section{VI.3.3. Effects of maltosyl- $\beta$-cyclodextrin use on broccoli juice}

The used maltosyl $-\beta-\mathrm{CD}$ concentrations induced 40-60\% higher glucoraphanin contents than CTRL juice at $0 \mathrm{~h}$ (Table VI.1). The low-intermediate $(30-60 \mathrm{mM})$ maltosyl- $\beta-\mathrm{CD}$ concentrations showed a similar pattern to $\beta-\mathrm{CD}$ with high reductions of glucoraphanin content after 3 h. However, the highest maltosyl- $\beta-\mathrm{CD}$ concentration $(90 \mathrm{mM})$ retained $70 \%$ of the initial glucoraphanin content after $24 \mathrm{~h}$. Consequently, sulforaphane was not formed in 
those samples together with undetectable sulforaphane levels in the broccoli juice containing $90 \mathrm{mM}$ maltosyl- $\beta-\mathrm{CD}$ (Table VI.1). Hence, $90 \mathrm{mM}$ maltosyl- $\beta-\mathrm{CD}$ showed an excellent glucoraphanin retention after $24 \mathrm{~h}$, in contrast to the low retention showed by the highest $\beta$ CD concentration $(10 \mathrm{mM})$. The observed glucoraphanin retention using $90 \mathrm{mM}$ maltosyl- $\beta$ $\mathrm{CD}$ is highly interesting due to subsequent sulforaphane formation (catalysed by plant myrosinase which is still active) in the gastrointestinal tract after glucoraphanin release (Hirayama and Uekama 1999). Then, sulforaphane would probably be just formed in the gastrointestinal tract to be readily absorbed to the blood system with the subsequent potential health benefits.

Nevertheless, the use of such high maltosyl $-\beta-\mathrm{CD}$ concentration in the food industry would be not viable due to the high prices of this modified $\mathrm{CD}$ and possible human health effects of that high concentration. Accordingly, an intermediate solution between insufficient $\beta-\mathrm{CD}$ concentration and high prices of maltosyl $-\beta-\mathrm{CD}$ would be the use of $\alpha-\mathrm{CD}$.

\section{VI.3.4. Effects of $\alpha$-cyclodextrin use on broccoli juice}

The lowest $\alpha-C D$ concentration $(10 \mathrm{mM})$ showed $86 \%$ higher initial glucoraphanin retention compared to CTRL samples (Table VI.1). The increment of $\alpha-\mathrm{CD}$ concentration from 10 to $30 \mathrm{mM}$ did not induce $(p<0.05)$ higher initial glucoraphanin retention. The highest $\alpha-\mathrm{CD}$ concentration $(40 \mathrm{mM})$ achieved lower initial glucoraphanin retention than low-intermediate concentrations as similarly observed with the highest $\beta-C D$ concentrations $(6-10 \mathrm{mM})$. Similarly, high sulforaphane levels $\left(61.3 \mu \mathrm{mol} \mathrm{L}^{-1} \mathrm{fw}\right)$ were observed in samples with intermediate $\alpha-\mathrm{CD}$ concentration after $3 \mathrm{~h}$ (Table VI.1). Nevertheless, the highest $\alpha-\mathrm{CD}$ concentration avoided $(p<0.05)$ glucoraphanin degradation after $24 \mathrm{~h}$ compared to samples with 10 and $30 \mathrm{mM} \alpha-\mathrm{CD}$ whose glucoraphanin levels were decreased $(p<0.05)$ by $95-96 \%$ after $24 \mathrm{~h}$. The used $40 \mathrm{mM} \alpha-\mathrm{CD}$ would still meet the European Food Safety Authority safety levels for this CD in a broccoli juice portion of $250 \mathrm{~mL}$ (EFSA, 2007).

\section{VI.4. CONCLUSIONS}

This research provides useful information regarding the effects of cyclodextrins (commonly used in the food industry to stabilize quality) on the glucoraphanin/sulforaphane system of broccoli juice. A high maltosyl- $\beta$-cyclodextrin concentration of $90 \mathrm{mM}$ (far from the low 
water solubility of $\beta$-cyclodextrin) would stabilize the glucoraphanin content of broccoli juice after $24 \mathrm{~h}$. Nevertheless, this concentration may be rejected by the food industry due to the high price of this cyclodextrin. Furthermore, such high concentration may compromise a safe consumption, unless further toxicological recommendations will be available regarding modified cyclodextrins. On the other side, addition of $40 \mathrm{mM} \alpha-$ cyclodextrin to broccoli juice will significantly retain glucoraphanin. Therefore, this study opens a new research line regarding to the use of different CDs to retain glucoraphanin in broccoli juice stabilizing its related chemopreventive potential upon subsequent industrial thermal or non-thermal treatments usually applied on such food beverages. Nevertheless, further research is also needed to study the possible encapsulation using CDs of other health-promoting compounds of broccoli such as phenolic compounds, vitamin $\mathrm{C}$ or lutein, even focussing in probable CDs selectivity towards those different compounds. Furthermore, another interesting line to continue this studies is how the application of cyclodextrins would affect the bioavailability of the phytochemicals. 
Table VI.1. Glucoraphanin and sulforaphane content $\left(\mu \mathrm{mol} \mathrm{L} \mathrm{L}^{-1} \mathrm{fw}\right)$ of broccoli juice treated with different concentrations of $\beta-$, maltosyl- $\beta-$ and $\alpha-$ cyclodextrin during $24 \mathrm{~h}$ at $22^{\circ} \mathrm{C}$ $(n=5 \pm S D)$. Different capital letters denote significant differences $(p<0.05)$ among different treatments for the same sampling time. Different lowercase letters denote significant differences $(\mathrm{p}<0.05)$ among different sampling times for the same treatment.

\begin{tabular}{|c|c|c|c|c|}
\hline Type & $\begin{array}{l}\text { Concentration } \\
(\mathrm{mM})\end{array}$ & $\begin{array}{l}\text { Time } \\
\text { (h) }\end{array}$ & $\begin{array}{l}\text { Glucoraphanin } \\
\left(\mu \mathrm{mol} \mathrm{L}{ }^{-1} \mathrm{fw}\right)\end{array}$ & $\begin{array}{l}\text { Sulforaphane } \\
\left(\mu \mathrm{mol} \mathrm{L}{ }^{-1} \mathrm{fw}\right)\end{array}$ \\
\hline \multirow[t]{5}{*}{$\overline{\mathrm{CTRL}}$} & & 0 & $211.0 \pm 7.0$ & $19.3 \pm 1.4$ \\
\hline & & 0.5 & $184.0 \pm 34.0$ & $48.9 \pm 4.9$ \\
\hline & & 1 & $158.1 \pm 15.2$ & $30.7 \pm 1.1$ \\
\hline & & 3 & $150.0 \pm 11.0$ & $84.6 \pm 4.7$ \\
\hline & & 24 & $19.1 \pm 2.9$ & nd \\
\hline \multirow[t]{15}{*}{$\alpha$-cyclodextrin } & 10 & 0 & $392.7 \pm 13.5$ & nd \\
\hline & & 0.5 & $411.5 \pm 20.3$ & $16.3 \pm 2.1$ \\
\hline & & 1 & $387.3 \pm 27.9$ & $12.0 \pm 7.2$ \\
\hline & & 3 & $343.4 \pm 2.9$ & nd \\
\hline & & 24 & $19.1 \pm 2.9$ & nd \\
\hline & 30 & 0 & $410.0 \pm 59.0$ & $12.2 \pm 3.3$ \\
\hline & & 0.5 & $404.9 \pm 48.5$ & $15.2 \pm 2.3$ \\
\hline & & 1 & $408.7 \pm 76.0$ & $22.7 \pm 2.1$ \\
\hline & & 3 & $294.5 \pm 6.5$ & $61.3 \pm 15.8$ \\
\hline & & 24 & $16.7 \pm 1.3$ & nd \\
\hline & 40 & 0 & $322.4 \pm 26.3$ & $0.6 \pm 0.01$ \\
\hline & & 0.5 & $316.2 \pm 81.5$ & nd \\
\hline & & 1 & $261.3 \pm 22.8$ & nd \\
\hline & & 3 & $280.8 \pm 26.3$ & $6.9 \pm 1.2$ \\
\hline & & 24 & $271.3 \pm 3.6$ & nd \\
\hline \multirow[t]{15}{*}{$\beta$-cyclodextrin } & 3 & 0 & $244.0 \pm 48.1$ & $108.1 \pm 17.1$ \\
\hline & & 0.5 & $231.7 \pm 56.2$ & $95.6 \pm 14.9$ \\
\hline & & 1 & $166.3 \pm 56.5$ & $284.3 \pm 36.9$ \\
\hline & & 3 & $92.8 \pm 8.6$ & $240.0 \pm 60.5$ \\
\hline & & 24 & $19.1 \pm 2.9$ & nd \\
\hline & 6 & 0 & $247.0 \pm 30.4$ & nd \\
\hline & & 0.5 & $207.7 \pm 33.5$ & $66.2 \pm 6.4$ \\
\hline & & 1 & $221.0 \pm 7.3$ & $15.7 \pm 0.5$ \\
\hline & & 3 & $137.3 \pm 51.9$ & $108.6 \pm 7.1$ \\
\hline & & 24 & $55.1 \pm 5.1$ & nd \\
\hline & 10 & 0 & $260.1 \pm 85.6$ & $16.6 \pm 5.5$ \\
\hline & & 0.5 & $262.2 \pm 31.3$ & $13.6 \pm 3.9$ \\
\hline & & 1 & $233.3 \pm 56.2$ & $43.9 \pm 1.4$ \\
\hline & & 3 & $229.0 \pm 12.5$ & $62.8 \pm 6.3$ \\
\hline & & 24 & $64.7 \pm 6.4$ & nd \\
\hline \multirow[t]{4}{*}{$\begin{array}{l}\text { Maltosyl- } \beta \text { - } \\
\text { cyclodextrin }\end{array}$} & 30 & 0 & $315.9 \pm 29.0$ & nd \\
\hline & & 0.5 & $287.0 \pm 12.9$ & $20.6 \pm 9.5$ \\
\hline & & 1 & $249.3 \pm 32.5$ & $35.2 \pm 1.7$ \\
\hline & & 3 & $144.7 \pm 70.3$ & $39.4 \pm 10.1$ \\
\hline
\end{tabular}




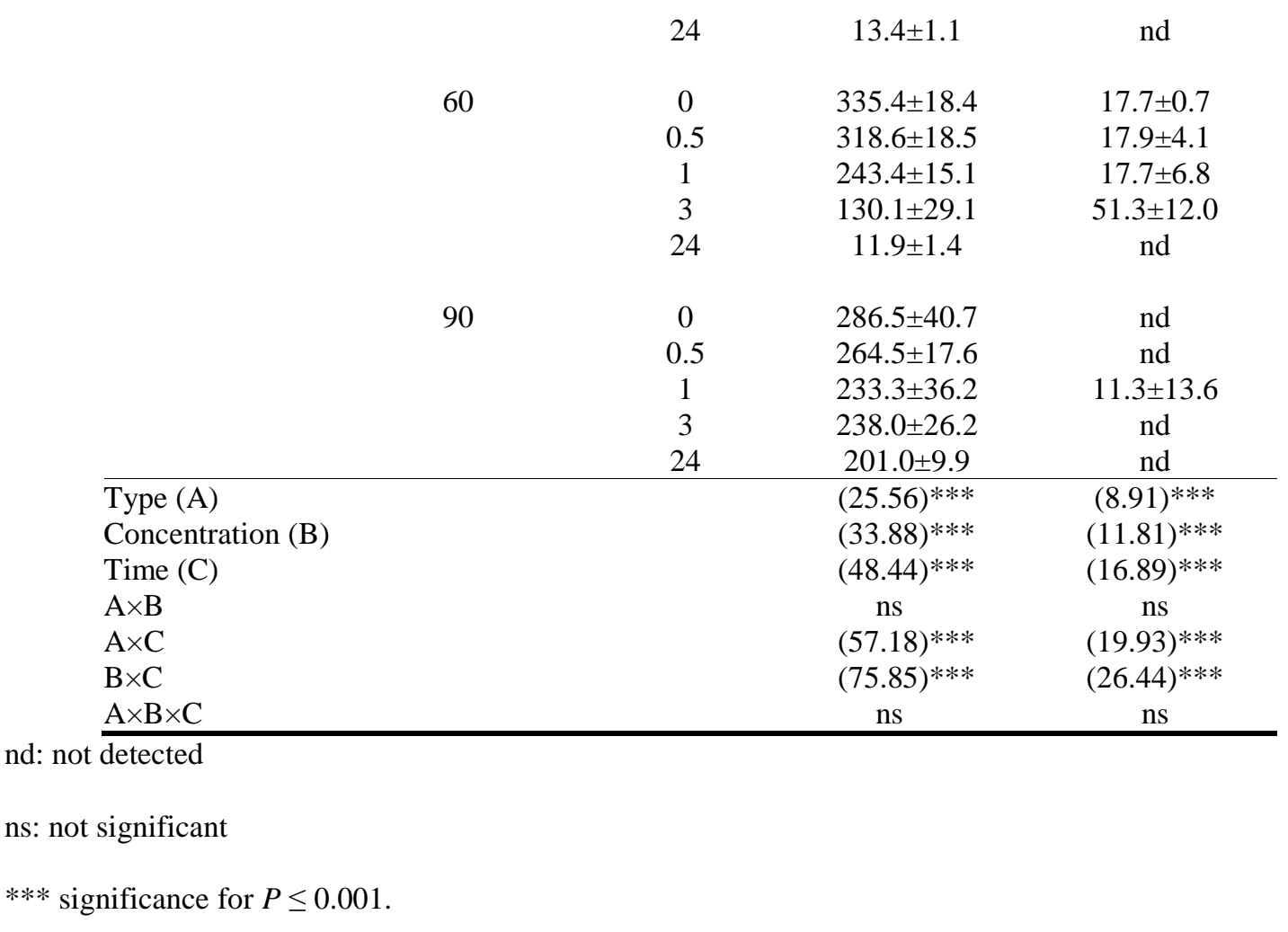




\section{CHAPTER VII}

\section{Effect of stevia supplementation of kale juice spheres on their quality changes during refrigerated shelf life}

Tâmmila Venzke Klug ${ }^{1}$, Elena Collado ${ }^{2}$, Ginés Benito Martínez-Hernández ${ }^{1,2}$, Francisco Artés ${ }^{1,2}$ and Francisco Artés-Hernández ${ }^{1,2}$

1 Postharvest and Refrigeration Group. Department of Food Engineering. Universidad Politécnica de Cartagena. Paseo Alfonso XIII, 48, 30203 Cartagena, Murcia, Spain.

${ }^{2}$ Institute of Plant Biotechnology. Universidad Politécnica de Cartagena. Campus Muralla del Mar, 30202 Cartagena, Murcia, Spain.

Submitted to a peer reviewed Journal included in the JCR of the ISI 


\section{VII .1. INTRODUCTION}

Kale (Brassica oleracea var. Sabellica L.) is a wintertime vegetable which has attracted special attention from consumers in the last years due to its high contents of health-promoting compounds. Among those compounds are glucosinolates>isothiocyanates, phenolics, carotenoids, minerals (i.e. calcium), vitamins, etc. (Korus, 2011; Šamec et al., 2018). Glucosinolates are sulphur-containing compounds that highly contribute to the characteristic bitter flavour of Brassica vegetables. Glucosinolates are largely stored in separate cell compartments from the enzyme myrosinase in intact cells from Brassica vegetables. Nevertheless, upon cell rupture (juicing, mastication, etc.) myrosinase comes rapidly into contact with glucosinolates leading to an almost instantaneous glucosinolate conversion to multiple compounds. Among those compounds are isothiocyanates, nitriles, thiocyanates, epithionitriles and oxazolidine-2-thiones being such conversion influenced by several factors like specifier proteins, temperature, $\mathrm{pH}$, ferrous ions $\left(\mathrm{Fe}^{2+}\right)$ presence, etc. (Hanschen et al., 2017). However, isothiocyanates are ideally preferred due to their high health-promoting properties contrary to nitriles and epithionitriles which have shown less health beneficial potential (Traka \& Mithen, 2008). Hence, glucosinolates content of Brassica vegetables has been recently recommended to be studied together with isothiocyanates content as a glucosinolates/isothiocyanates system (Wu et al., 2017). Glucoraphanin is one of the major broccoli glucosinolates that has been extensively studied due to the high health-promoting properties of its cognate isothiocyanate, namely sulforaphane (4-(methylsulphinyl) butyl isothiocyanate). Glucoraphanin content of kale has been reported to be very low (Korus et al., 2014; Velasco et al., 2007). Nevertheless, a recent screening of glucosinolates in kale varieties from different parts of the world has found large differences depending of variety, growing area, and even between individuals of the same variety and area (Hahn et al., 2016).

Bitterness of Brassica vegetables, due to the sulphur-containing compounds, can be masked by sweetening (Sindhu et al., 2012). Stevia (Stevia rebaudiana bertoni) is a plant widely known to its sweetener properties with very low caloric content (Megeji et al., 2005). Furthermore, stevia contains several compounds responsible of their antimicrobial and antioxidant properties, among other health-promoting properties (Ortiz-Viedma et al., 2017; Tadhani and Subhash, 2006). The effect of stevia on the glucoraphanin>sulforaphane system of kale juice has been not studied yet. Kale juice consumption may be even enhanced, 
together with sweetening, by innovative presentations such as spheres. In that sense, a double gelification technique for vegetable juices has been recently modelled and optimized with high mechanical resistance (Tsai et al., 2017b). Furthermore, the high Ca content of kale allows a perfect spherification without the need to add $\mathrm{Ca}$ salts during spherification as is normally done with food with low Ca content.

The aim of the present study was to assess the effect of stevia addition on the quality and glucoraphanin>sulforaphane system of kale juice spheres during chilling storage.

\section{2. MATERIALS AND METHODS}

\section{2.1. Preparation of ingredients}

Kale was obtained from a local producer (Sacoje S.L., Lorca, Spain) on October 2017. The latter plant material was grown under open air cultivation with integrated pest management cultural practices in fields from Lorca area (Murcia, Spain) according to the producer specifications. Kale was randomly hand-harvested at commercial ripening stage in the first morning hours $(\approx 8-9 \mathrm{~h})$. Immediately after harvesting, plant material was transported by car about $80 \mathrm{~km}$ to the Pilot Plant of our Research Group in the Universidad Politécnica de Cartagena. Then, it was stored at $5{ }^{\circ} \mathrm{C}$ and $90-95 \%$ relative humidity until next day when processing was conducted. Lemon juice was obtained with a hand-juicer from lemon fruit purchased in a local supermarket (Cartagena, Spain). Stevia (Stevia rebaudiana bertoni) leaves (origin from Granada, Spain) were purchased from a local store (Cartagena, Spain) being supplied as dried leaves contained in a bulk package (100 g) contained in a transparent plastic bag.

Stevia extract was obtained according to Ortiz-Viedma et al. (2017). Briefly, stevia leaves were previously grinded, with a domestic coffee grinder, to obtain a fine powder. Then, $5 \mathrm{~g}$ of grinded stevia powder were placed together with $1 \mathrm{~L}$ of 80:20 ethanol:water (v:v) in a glass bottle protected from light with aluminium foil. Subsequently, the mixture was mechanically stirred for $3 \mathrm{~h}$ at $25 \pm 1^{\circ} \mathrm{C}$ and then allowed to stand for $24 \mathrm{~h}$ at $25 \pm 1{ }^{\circ} \mathrm{C}$. The latter extract was filtered with 4-layers cheesecloth, dried at $40{ }^{\circ} \mathrm{C}$ in a rotary evaporator and then dissolved in $1 \mathrm{~L}$ of distilled water. The obtained concentrated stevia extract was stored at $4{ }^{\circ} \mathrm{C}$ in darkness until use next day. 


\section{2.2. Juice preparation}

After several assays, including sensorial ones, ingredients proportions selected were $200 \mathrm{~g}$ kale, $10 \mathrm{~mL}$ lemon juice and $30 \mathrm{~mL}$ of correspondent stevia extract (S10, S25 or S50; described below). All ingredients were then blended (MX2050 blender, Braun, Germany) and allowed to stand for 5 min to ensure maximum glucoraphanin>sulforaphane conversion according to previous findings (Dosz et al., 2014). Finally, juice was obtained from the latter blended mixture using a slow juicer (Silver Crest, Málaga, Spain) obtaining a clear kale juice maximizing the juice extraction from the previous blend mixture. The lemon juice proportion used was selected in order to obtain a final $\mathrm{pH}$ of 4.5. Maximum glucoraphanin $>$ sulforaphane conversion has been reported to occur at pH 4 (Hanschen et al., 2017). Nevertheless, pH 4.5 was selected in this study in order to ensure an excellent spherification since too acidic conditions may limit hydrogel formation during spherification (Martinsen et al., 1989). Accordingly, the previous concentrated stevia extract was diluted with distilled water under the proportions 10:90 (S10; concentrated extract:water, v:v), 25:75 (S25) and 50:50 (S50). A control juice (CTRL) was prepared with distilled water instead of stevia extract. The highest stevia concentration (S50) was selected based on the maximum stevia concentration in the prepared kale juice that still reached good sensory scores from an informal panel test conducted by 5 habitual consumers of Brassica vegetables. The minimum stevia concentration of the juice was selected in order to reach the minimum sweet flavour that still helped to smooth the strong bitter flavour from kale according to observations from the panel test.

\section{2.3 Kale juice spherification and storage conditions}

Spherification of kale juice was accomplished according to an optimized method with double gelation from Tsai et al. (2017b) with slight modifications. Briefly, the prepared kale juice was mixed with xanthan gum (Laguilhoat, Innovative Cooking S.L., Madrid, Spain), to a final concentration of $0.4 \%$. Xanthan gum was added in order to increase juice viscosity to allow a proper spherification process. In the first gelation step, $2.5 \mathrm{~mL}$ of juice were carefully dropped by mean of a $2.5 \mathrm{~mL}$ stainless spoon (Sole Graells, Barcelona, Spain), on to a $0.5 \%$ alginate (Laguilhoat, Innovative cooking S.L., Madrid, Spain) solution at a distance spoonsolution surface of $3 \mathrm{~cm}$. A special perforated stainless spoon for spherifications (Sole Graells, Barcelona, Spain) was used to carefully rotate the forming spheres during the first 
seconds of this first gelation that was allowed to occur for $24 \mathrm{~min}$. Subsequently, the first gelation-spheres were carefully collected with the perforated spoon and washed sequentially with water and then with $95 \%$ ethanol. Second gelation of latter washed spheres was then conducted for 6 min in a $1.27 \% \mathrm{CaCl}_{2}$ (Laguilhoat, Innovative cooking S.L., Madrid, Spain) solution. Final kale juice spheres were collected and washed as above described.

Kale juice spheres were stored in $50 \mathrm{~mL}$ plastic bottles (approximately 10 spheres per bottle) containing $40 \mathrm{~mL}$ of distilled water with $0.5 \% \mathrm{NaCl}$, namely government liquid. $\mathrm{NaCl}$ concentration was selected as having the same electrical conductivity (conductivitymeter GLP32, Crison, Barcelona, Spain) than the obtained kale juice. The similar electrical conductivities of government liquid and juice indicates similar electrolyte content avoiding spheres juice leakage due to osmosis processes. Bottles containing the kale juice spheres and government liquid were stored at $5{ }^{\circ} \mathrm{C}$ in darkness. Sampling was conducted after $0,3,5$ and 7 days. Five replicates ( 5 bottles) were prepared for each treatment (stevia concentration) and sampling time. On each sampling time, the juice from 5 spheres of the same replicate (bottle) was obtained and combined for juice quality determinations.

\section{2.4. Physical characterization of kale juice spheres}

Stereomicroscopic analysis of spheres surface was performed with a binocular stereo microscope (SZ61 TR Olympus, Center Valley, PA, USA) equipped with a high-resolution digital camera (Altra 20 Olympus, USA). Mean diameter (averaged from largest and shortest diameter) of spheres was measured using a digital calliper (Mitutoyo Absolute, Guipúzcoa, Spain).

The main physical characteristics of spheres were swelling capacity (SC), firmness and diameter, being all these parameters monitored during storage of spheres. SC of spheres was determined according to Tsai et al. (2017b). Briefly, excess water on the surface of spheres was gently removed with a paper towel being then the initial weight of the sphere (W1) registered. Then, the sphere was placed in $10 \mathrm{~mL}$ of distilled water and it was allowed to stand for $10 \mathrm{~min}$ at room temperature. Subsequently, water excess from sphere surface was newly removed and the final weight of this swollen sphere (W2) was registered. SC was calculated from Eq. VII.1 as follows: 


$$
\mathrm{SC}(\%)=[(\mathrm{W} 2-\mathrm{W} 1) / \mathrm{W} 1] \times 100
$$

Firmness of spheres was determined with a texture analyser (Brookfield, Toronto, Canada). A compression test was performed using a $3.5-\mathrm{cm} \varnothing$ plate at a test speed of $10.0 \mathrm{~mm} \mathrm{~s}^{-1}$ and a compression distance of $4 \mathrm{~mm}$. Firmness was expressed as the maximum force $(\mathrm{N})$ needed for compression. Five spheres were measured for each treatment.

Electrolyte migration from the juice to the government liquid was also estimated from measurement of electrical conductivity $\left(\mathrm{Ec} ; \mu \mathrm{S} \mathrm{cm}{ }^{-1}\right)$ of juice $(\mathrm{EcJ})$ contained in the spheres and $\mathrm{Ec}$ of the government liquid (EcL). Ec was measured using a conductivitymeter (Crison, Barcelona, Spain). Then, Ec ratio (Eq. VII.2) was calculated to better observe electrolyte migration on samples during storage:

$$
\text { Ec ratio }=\mathrm{EcJ} / \mathrm{EcL}
$$

\section{2.6. Physicochemical and colour quality of kale juice}

Throughout storage, the physicochemical quality of kale juice contained in the spheres was monitored according to soluble solids content (SSC), $\mathrm{pH}$ and titratable acidity (TA). SSC was determined by a digital hand-held refractometer (Atago N1; Tokyo, Kanto, Japan) at $20{ }^{\circ} \mathrm{C}$ and expressed as ${ }^{\circ}$ Brix. To obtain the $\mathrm{pH}$ of the juice a $\mathrm{pH}-$ meter (Basic20, Crison; Alella, Cataluña, Spain) was used. TA was determined by titration of $5 \mathrm{~mL}$ of the juice plus $45 \mathrm{~mL}$ of distilled water with $0.1 \mathrm{M} \mathrm{NaOH}$ to $\mathrm{pH} 8.1$ (T50, Metter Toledo; Milan, Italy) and expressed as $g$ citric acid $\mathrm{L}^{-1}$.

External colour of spheres and the contained juice were determined using a colourimeter (Chroma Meter CR-400, Konica Minolta, Japan). The colourimeter used the illuminant D65 that represents daylight more completely and accurately than B and C illuminants (Pathare et al., 2013). The colourimeter was calibrated with a white reference plate (illuminant D65), $2^{\circ}$ observer and 8-mm viewing aperture. External colour of spheres was obtained by three colour readings of each sphere which were then automatically averaged by the device. The external colour of five spheres per replicate (bottle) were measured. For juice colour, kale juice from spheres was introduced in a plastic cuvette $(50 \times 37 \times 13 \mathrm{~mm} ; 10 \mathrm{~mm}$ internal pass) $(\mathrm{CM}-\mathrm{A} 131$, 
Minolta, Japan) that was introduced in the correspondent special cuvette holder (CR-400 cuvette holder, Minolta, Japan) coupled to the colourimeter. Three colourimeter readings (averaged by the device) were taken from each cuvette with mixing (by inversion) of the cuvette between measurements.

${ }^{\circ}$ Hue has been reported as the most appropriate colour index for dark green Brassica vegetables (Rhim et al., 1989). ${ }^{\circ}$ Hue throughout storage was calculated as described in Eq. VII.3:

$$
{ }^{\circ} \mathrm{Hue}=\tan ^{-1}\left(\mathrm{~b} * / \mathrm{a}^{*}\right)
$$

\section{2.7. Microbial analyses}

Standard enumeration methods were used to determine the mesophilic, psychrophilic and yeast and moulds $(\mathrm{Y}+\mathrm{M})$ growth according to Martínez-Hernández et al. (2017). Briefly, 10-fold dilution series were prepared using sterile peptone saline solution $(\mathrm{pH} \mathrm{7})$ starting from 3 spheres (approximately $10 \mathrm{~g}$ ) for each replicate. All microbiological material was from Scharlau Chemie SA (Barcelona, Spain). Mesophiles and psychrophiles were pour plated while $\mathrm{Y}+\mathrm{M}$ were spread plated. Plate count agar for mesophiles and psychrophiles incubated at $30{ }^{\circ} \mathrm{C}$ for $48 \mathrm{~h}$ and at $5^{\circ} \mathrm{C}$ for 7 days, respectively. Rose Bengal agar for $\mathrm{Y}+\mathrm{M}$ incubated for 3-5 days at $25^{\circ} \mathrm{C}$. All microbial counts were reported as $\log \mathrm{CFU} \mathrm{g}^{-1}$.

\section{2.8. Glucoraphanin analysis}

Glucoraphanin content of kale juice was analysed as previously described (Magrath et al., 1993; Saha et al., 2012). Briefly, freeze-dried juice powder ( $0.2 \mathrm{~g})$ was weighed into glass screw-cap tubes $(10 \mathrm{~mL})$ and heated at $80{ }^{\circ} \mathrm{C}$ for $10 \mathrm{~min}$ using a shaking water bath. Then, 5 $\mathrm{mL}$ of methanol:water (80:20, v/v) was added to each sample and heating continued for 20 min at $80^{\circ} \mathrm{C}$. Subsequently, $1 \mathrm{~mL}$ of hot $\left(100^{\circ} \mathrm{C}\right)$ nanopure water was added to each sample being the heating bath continued for $30 \mathrm{~min}$. The extracts were centrifuged (4,000×g, $20 \mathrm{~min}$, $4{ }^{\circ} \mathrm{C}$ ) and supernatants were decanted and stored on ice. The pellets were re-extracted as previously described with $2.5 \mathrm{~mL}$ methanol-water $(90: 10, \mathrm{v} / \mathrm{v})$. Both supernatants were combined and made up to a final volume of $5 \mathrm{~mL}$ with methanol-water $(90: 10, \mathrm{v} / \mathrm{v})$. Desulphation of glucoraphanin was conducted using prepared DEAE Sephadex A25 (GE 
Healthcare, Uppsala, Sweden) mini-columns. For desulphation, each methanolic extract (1 $\mathrm{mL}$ ) was loaded onto the prepared mini-columns and the unbound material was removed using two washings with $0.5 \mathrm{~mL}$ of nanopure water and two washings with $0.02 \mathrm{M}$ sodium acetate ( $\mathrm{pH}$ 5.0) per column. Purified sulfatase from Helix pomatia (EC 10.000 units; Sigma-Aldrich, St Louis, MO, USA) $(75 \mu \mathrm{L})$ was loaded onto each prepared column and desulphation was performed overnight $(12 \mathrm{~h})$ at room temperature. The desulphoglucoraphanin was eluted with three nanopure water washings $(0.5+0.5+0.25)$, made up to a final volume of $1.5 \mathrm{~mL}$ with nanopure water and filtered with a polytetrafluoroethylene (PTFE) $0.22-\mu \mathrm{m}$ syringe filter.

The latter extracts were analysed using an UHPLC instrument (Shimadzu, Kyoto, Japan) equipped with a DGU-20A degasser, LC-30AD quaternary pump, SIL-30AC autosampler, CTO-10AS column heater and SPDM-20A photodiode array detector. Chromatographic analyses were carried out onto a Gemini C18 column $(250 \mathrm{~mm}$ x $4.6 \mathrm{~mm}, 2.6 \mathrm{~mm}$ particle size; Phenomenex, Macclesfield, UK) at $25^{\circ} \mathrm{C}$. The mobile phases were water (A) and acetonitrile (B). The flow rate was $1.5 \mathrm{~mL} \mathrm{~min}^{-1}$ with a linear gradient eluent starting with 2 $\%$ B to reach $20 \% \mathrm{~B}$ at $28 \mathrm{~min}$ and $2 \% \mathrm{~B}$ at $32 \mathrm{~min}$. The injection volume was $20 \mu \mathrm{L}$ and absorbance was registered at $229 \mathrm{~nm}$. Desulphoglucoraphanin was quantified using a desulphoglucoraphanin standard (Toronto Research Chemicals Inc., North York, Canada) and expressed as mmol kg-1 dry weight (dw).

\section{2.9. Endogenous sulforaphane and sulforaphane nitrile analyses}

The content of sulforaphane was analysed according to Ares et al. (2014) with slight modifications. Briefly, $0.2 \mathrm{~g}$ of freeze-dried powder was mixed with $5 \mathrm{~mL}$ of acidic water (pH 6.0 using $0.1 \mathrm{M} \mathrm{HCl}$ ) in a glass screw-capped tube. The mixture was incubated in a heating bath at $45^{\circ} \mathrm{C}$ for $2 \mathrm{~h}$ to allow glucoraphanin conversion to sulforaphane. Then, $25 \mathrm{~mL}$ of methyl-tert-butyl ether (MTBE) was added to the mixture and it was sonicated for $1 \mathrm{~min}$. Subsequently, the extract from the tube was dewatered using sodium sulphate $(5.5 \mathrm{~g})$ and the resulting extract was filtrated through a filter paper (Whatman 41). The collected filtrate was purified through an activated $(3 \mathrm{~mL}$ of MTBE $+3 \mathrm{~mL}$ ethyl acetate $+3 \mathrm{~mL}$ air) SI-1 silica cartridge (Phenomenex, Torrance CA, USA) and the eluent was discarded. Finally, the cartridge was washed with $2 \mathrm{~mL}$ methanol and the eluent was collected. The latter methanolic 
eluent was evaporated to dryness in a rotary evaporator at $45{ }^{\circ} \mathrm{C}$ being the dry residue resuspended in $1 \mathrm{~mL}$ acetonitrile followed by filtration with a PTFE $0.22-\mu \mathrm{m}$ syringe filter.

Chromatographic experiments were carried out on the UHPLC system. Separation was achieved on a Gemini C18 column $(250 \mathrm{~mm}$ x $4.6 \mathrm{~mm}, 2.6 \mathrm{~mm}$ particle size; Phenomenex, Macclesfield, UK). The column oven temperature was maintained at $25^{\circ} \mathrm{C}$ and the autosampler at $4{ }^{\circ} \mathrm{C}$. The mobile phase was a mixture of $20 \mathrm{mM}$ ammonium formate in water and acetonitrile $(55: 45, \mathrm{v} / \mathrm{v})$ and the injection volume of $5 \mu \mathrm{L}$ (draw speed of $50 \mu \mathrm{L} \mathrm{min}-1)$. The flow rate was $0.6 \mathrm{~mL} \mathrm{~min}{ }^{-1}$ in isocratic mode. The detection wavelength was $196 \mathrm{~nm}$. Sulforaphane was quantified using a commercial DL-sulforaphane standard (Sigma-Aldrich, St. Louis MO, USA) and expressed as $\mu \mathrm{mol} \mathrm{kg}^{-1} \mathrm{dw}$. Each of the five replicates was analysed in duplicate.

Furthermore, sulforaphane nitrile, the main product from glucoraphanin apart from sulforaphane, was also analysed in the previous extract. In that sense, the UHPLC system was coupled to a tandem quadrupole mass spectrometer (Waters Acquity TQD, Waters Corp., Milford, USA) operated in the ESI positive mode. Detection of the sulforaphane nitrile was conducted by the detection of their characteristic product ions $(55.0$ and $81.9 \mathrm{~m} / \mathrm{z})$. The detection of the latter product ions was conducted using the following UHPLC-MS/MS parameters as previously described (Álvarez-Jubete et al., 2014): 1) 55.0 m/z: $26 \mathrm{~V}$ cone, 20 eV collision energy; 2) $81.9 \mathrm{~m} / \mathrm{z}$ : $26 \mathrm{~V}$ cone, $14 \mathrm{eV}$ collision energy. Sulforaphane nitrile was quantified as sulforaphane equivalents due to unavailability of commercial standard.

\section{2.10. Myrosinase activity}

The myrosinase activity was analysed as early described (Oliviero et al., 2014; Sarvan et al., $2017)$ with slight modifications. Frozen juice samples $\left(-80^{\circ} \mathrm{C}\right)$ for myrosinase activity were previously ground using a mill (IKA, A 11 Basic, Berlin, Germany) with liquid $\mathrm{N}_{2}$. Then, 0.5 $\mathrm{g}$ of frozen ground sample was added to $10 \mathrm{~mL}$ of potassium phosphate buffer $(50 \mathrm{mM} ; \mathrm{pH} 7)$ and homogenised (Ultra Turrax ${ }^{\circledR}$ model 18T, IKA-Werke GmbH \& Co. KG, Staufen, Germany) for $5 \mathrm{~min}$ under ice bed. Subsequently, the samples were filtered through 4-layer cheesecloth and centrifuged at $14,000 \times \mathrm{g}$ for $15 \mathrm{~min}$ at $4{ }^{\circ} \mathrm{C}$. Subsequently, $3 \mathrm{~mL}$ of the latter supernatant was placed in a centrifugal filter tube (Amicon® Ultra-4 Ultracel ${ }^{\circledR} 30 \mathrm{kD}$, Millipore, Cork, Ireland) and centrifuged at $4,000 \times \mathrm{g}$ for $10 \mathrm{~min}$ at $4{ }^{\circ} \mathrm{C}$ to remove the 
compounds with molecular weight lower than myrosinase (sugars, glucosinolates, etc.). The concentrated enzyme, contained inside the filter, was dissolved in $470 \mu \mathrm{L}$ of phosphate buffer (50 mM, pH 7) being then used as myrosinase extract. Myrosinase activity was determined by the glucose formation released during hydrolysis of sinigrin by myrosinase using a coupled enzymatic procedure as described by Oliviero et al. (2014). A commercial glucose determination kit (D-glucose-HK enzyme kit, Megazyme, Bray, Ireland) was used being absorbance at $340 \mathrm{~nm}$ (NADPH formation which is stoichiometrically related to glucose) measured with a Multiscan plate reader (Tecan Infininte M200; Männedorf, Meilen, Switzerland). Briefly for the coupled myrosinase enzymatic procedure, $208 \mu \mathrm{L}$ of $0.525 \mathrm{mM}$ $\mathrm{MgCl}_{2}$ (containing $5.68 \mathrm{mM}$ ascorbic acid) were placed in flat-bottom polystyrene 96-well UV-Star plate (Greiner Bio-One; Frickenhausen, Baden-Württemberg, Germany). Then, 50 $\mu \mathrm{L}$ of myrosinase extract, $14 \mu \mathrm{L}$ of test kit solution $\mathrm{R} 1$ (buffer $\mathrm{pH}$ 7.6), $14 \mu \mathrm{L}$ of test solution R2 ( $\beta-\mathrm{NADP}$ plus ATP) and $5 \mu \mathrm{L}$ of test solution R3 were sequentially added. Subsequently, the latter reaction mixture was allowed to react for $5 \mathrm{~min}$ for permitting to react glucose contained originally in the kale juice observed when absorbance $(340 \mathrm{~nm})$ was then stabilized. Finally, $14 \mu \mathrm{L}$ of sinigrin solution $\left(30 \mathrm{mg} \mathrm{mL}^{-1}\right.$ ) was added and absorbance increment was registered for $8 \mathrm{~min}$. An external standard curve (0.2-1.2 enzymatic units $\mathrm{mL}^{-1}$ ) was made with commercial myrosinase (Thioglucosidase from Sinapis alba seed; Sigma Aldrich, Germany) being correlated myrosinase units with the registered absorbance $(340 \mathrm{~nm})$ increments for $8 \mathrm{~min}$. Myrosinase activity was expressed as $\mathrm{U} \mathrm{kg}^{-1} \mathrm{fw}$.

\section{2.11. Statistical analyses}

The experiment had a two-factor (treatment $\times$ storage time) design subjected to an ANOVA using SPSS software (v.19 IBM, New York, USA). Statistical significance was assessed at $\mathrm{p}=0.05$, and to separate the means the Tukey's multiple range test was used to separate the means.

\section{3. RESULTS AND DISCUSSION}

\section{3.1. Physical characteristics of spheres}

Kale juice spheres showed an initial diameter of $20.5 \pm 2 \mathrm{~mm}$ with a visual homogeneous surface as corroborated from stereo microscope captions (Figure VII.1A), although some 
protuberances were observed (Figures VII.1C, VII.1D) being probably owed to alginate or xanthan gum agglomerations resulted from undiluted particles. Nevertheless, the latter protuberances could not be easily detected by the consumer due to their small size $(0.2-0.3$ $\mathrm{mm})$. No influence $(\mathrm{p}<0.05)$ of stevia supplementation on sphere diameter neither on stereo microscope captions was found (Table VII.1).

Swelling of a hydrogel sphere indicates the decrease of ionic strength being associated low SC with higher stability of the hydrogel sphere and consequently higher sphere firmness (McKenna et al., 2010; Siepmann and Peppas, 2001). A previous study on formed beads (4.5$4.7 \mathrm{~mm}$ ) of radish leaves juice showed SC of 5.1-6.0 being correlated such SC levels with a high mechanical resistance of those beads (Tsai et al., 2017b). Swelling of our kale juice spheres was even lower, with $\mathrm{SC}<1.3$ for all samples, except $\mathrm{S} 25$ spheres ( $\mathrm{SC}=3.3)$, on processing day (Table VII.1). However, the latter SC value of S25 samples is still lower than values previously reported for other vegetables juices spheres (Tsai et al., 2017b). All spheres showed an initial firmness ranging from 60.4 to $88.7 \mathrm{~N}$, registering S25 samples the lowest firmness on processing day with $34.6 \mathrm{~N}$ (Table VII.1). The latter lower firmness of S25 spheres, also correlated with their higher SC, may be explained since the ionic concentration of S25 juice led to lower ionic strength during the second gelation step. Conclusively, low SC is beneficial since it is also related to low release of compounds from hydrogel capsules due to their high mechanical resistance as early reported (Tsai et al., 2017b).

Physical properties of spheres changed during storage as expected. Particularly, sphere firmness generally increased during the first 3 days of storage for all samples, except S50, with low variations $(<21 \mathrm{~N})$ from day 3 to the end of storage. Particularly, CTRL showed the highest firmness increase in the first 3 days while S10 and S25 showed increments of 30-45 N. Furthermore, CTRL registered the highest reduction of the electrolyte juice: government liquid ratio after 3 days. The latter behaviour may be explained since the lower ionic concentration of CTRL juice, without stevia, probably led to the observed electrolyte migration from the juice to the government liquid. Then, during these first 3 days of storage of CTRL the ionic concentration from the government liquid was increasing probably allowing a further gelification as observed in the firmness increase. On the other side, the high ionic concentration of T50 juice did not led to the observed electrolyte migration as observed in the low variations of the electrolyte juice: government liquid ratio of this treatment after 3 
days. Nevertheless, the diameter of all samples was not significantly changed during storage (data not shown).

Conclusively, the production of kale juice spheres with the used double gelation technique allowed to obtain hydrogel spheres with high uniform surface, high mechanical resistance (firmness), reduced swelling and unchanged size during storage. Among different kale juices spheres, T50 samples showed the lowest firmness changes during storage and low electrolyte migration.

\section{3.2. Physicochemical and colour quality of kale spheres}

The initial SSC of all samples ranged among $4.5-5{ }^{\circ}$ Brix, although S25 registered the lowest value with $4.2^{\circ}$ Brix (Table VII.2). The lower SSC of T25 may be explained by the previous high SC and low firmness which could led to a solids migration from the juice through the hydrogel structure. Nevertheless, the latter slight SSC differences among initial samples were diminished throughout storage. Accordingly, a high general SSC decrement was observed after 3 days remaining then SSC levels with low variations ( $<0.5$ SSC units) until the end of storage with SSC of 3.1-3.4, without significant differences among treatments. Furthermore, no high SSC variations were observed in other vegetable beverages containing brassica (Castillejo et al., 2017). CTRL samples showed initial pH and TA of 5.2 and $0.17 \mathrm{~g}$ citric acid $\mathrm{mL}^{-1}$ (Table VII.2). Addition of stevia extracts to kale juice did not induce $\mathrm{pH}$ changes while TA was slightly increased to $0.20-0.25 \mathrm{~g}$ citric acid $\mathrm{mL}^{-1}$. A general TA reduction was observed for all samples throughout storage reaching TA values of $0.08-0.12 \mathrm{~g}$ citric acid $\mathrm{mL}^{-1}$ without significant differences among treatments.

Colour changes of kale spheres may be expected due to colour changes of the juice itself or possible hydrogel structure colour changes. Accordingly, colour of spheres surface as well as the contained kale juice were monitored during storage. ${ }^{\circ}$ Hue was early recommended as a colour index for brassica vegetables with dark green colour (Shewfelt et al., 1984; Rhim et al., 1989; Pathare et al., 2013), such as that of kale, in order to express with an unique index the $a^{*}$ and $b^{*}$ differences among samples. Kale spheres showed an initial dark colour with $L^{*}, a^{*}$ and $b^{*}$ parameters of $24.4,-11.4$ and 15.3 respectively (data not shown), and ${ }^{\circ}$ Hue of 144.8 (Table VII.2). Stevia addition to kale juice did not induce colour changes neither on the juice (data not shown) or on the formed spheres (Table VII.2). A ${ }^{\circ}$ Hue ratio consisting of 
${ }^{\circ}$ Huespheres $/{ }^{\circ}$ Huejuice was calculated for all samples during storage in order to deduct possible hydrogel colour changes that may affect transparency of that film (data not shown). Nevertheless, the initial ${ }^{\circ}$ Huespheres $/{ }^{\circ}$ Huejuice ratio $(\approx 1)$ did not change during storage. Accordingly, ${ }^{\circ}$ Hue of spheres surface is presented in Table VII.2 since transparency of hydrogel film was not apparently changed. ${ }^{\circ}$ Hue of spheres increased throughout storage which means a decrease in green colour of kale spheres. The latter green colour degradation has been early reported in other beverages containing dark green brassica vegetables owed to chlorophylls degradation (Castillejo et al., 2018). The latter green colour degradation followed a zero order kinetic with R2 of 0.94-0.99 (data not shown). Among samples with stevia, S50 spheres showed the lowest ${ }^{\circ}$ Hue differences (6.9) after 7 days. The lower green colour degradation in the spheres with the highest stevia concentration may be owed to the high antioxidant properties of stevia which probably protected chlorophylls from enzymatic degradation.

In conclusion, addition of stevia extracts did not induce relevant changes on physicochemical quality of samples neither on processing day nor during storage when compared to CTRL samples. Particularly, spheres containing T50 juice showed the lowest colour changes after 7 days of storage.

\section{VII.3.3. Microbiological quality of kale spheres}

The initial mesophilic, psychrophilic and Y+M counts of CTRL spheres on processing day were 3.7, 5.0 and $3.6 \log \mathrm{CFU} \mathrm{g} \mathrm{g}^{-1}$, respectively (Table VII.3). Those microbial loads remained almost unchanged in stevia containing samples. Similarly, in other food products no immediate (on processing day) reductions on microbiological loads when using stevia extracts, obtained with the same extraction procedure, were observed (Ortiz- Viedma et al., 2017). As expected, mesophilic, psychrophilic and Y+M loads of samples increased throughout storage by $2.4-2.5,1.4-1.5$ and $2.8-3.0 \log$ units, respectively, after 7 days. No antimicrobial effects were observed from stevia incorporation in the kale spheres, even showing S50 samples similar increments after 7 days compared to CTRL. Stevia extracts have shown antimicrobial properties due to their phenolic profile (Ortiz- Viedma et al., 2017). Nevertheless, the hereby used stevia concentrations in this experiment were not probably enough to reach the beneficial antimicrobial properties. Furthermore, the antimicrobial effects 
achieved by the low $\mathrm{pH}$ of the juice and other antimicrobial compounds from kale, such as the formed isothiocyanates when juicing, could have masked the stevia antimicrobial effect. However, microbial loads of all samples were below 7 log units during storage.

\section{3.4. Glucoraphanin/sulforaphane system catalysed by endogenous myrosinase}

Initial glucoraphanin content of $2.33 \mathrm{mmol} \mathrm{kg}^{-1}$ was registered in CTRL kale spheres on processing day (Table VII.4). Sulforaphane content of CTRL kale spheres on processing day was $3.37 \mu \mathrm{mol} \mathrm{kg}{ }^{-1}$ with a myrosinase activity of $0.69 \mathrm{U} \mathrm{kg}^{-1}$ (Table VII.4). Sulforaphane nitrile, the reported predominant form from glucoraphanin apart from sulforaphane, of CTRL kale spheres was $0.26 \mu \mathrm{mol} \mathrm{kg}{ }^{-1}$. The low sulforaphane nitrile formation may be explained by the achieved low $\mathrm{pH}$ from kale juice (by addition of lemon juice) being similar acidic $\mathrm{pH}$ ranges optimized for a high glucoraphanin>sulforaphane formation (Hanschen et al., 2017). Myrosinase activity was maximum in CTRL samples on processing day being reduced by approximately $0.4 \mathrm{U}$ in stevia-containing samples, without significant differences among stevia concentrations. The latter reduction of myrosinase activity may be owed to the antioxidant properties of stevia as similarly found for other enzymes, such as peroxidase and polyphenoloxidase, in other fruit beverages (Barba et al., 2014). In agreement with latter finding, spheres containing high stevia concentrations showed lower sulforaphane formation while the spheres with the lowest stevia content (S10) showed higher sulforaphane content.

The myrosinase activity of CTRL samples was highly reduced (by about $0.6 \mathrm{U}$ ) after 3 days being enzymatic degradation in beverages higher than in solid food products with intact plant cells. In that sense, myrosinase activity of CTRL samples remained in the same range as for the rest of stevia-containing samples until the end of storage. Glucoraphanin content of samples remained with low variations from day 3 until the end of storage with levels ranging from 0.61 to $0.78 \mu \mathrm{mol} \mathrm{kg}{ }^{-1}$, regardless of stevia concentration. Sulforaphane contents of samples also decreased reaching minimum levels after 5 days with $0.48-0.86 \mu \mathrm{mol} \mathrm{kg}{ }^{-1}$ without remarkable changes until the end of storage. On the other side, the low sulforaphane nitrile contents from processing day were maintained during storage. The latter findings may be explained since sulforaphane, contrary to the relatively inert precursor glucoraphanin, is a highly reactive compound that is very unstable in aqueous solutions such as those of vegetables beverages (Castillejo et al., 2017; Franklin et al., 2014; Lamy et al., 2011). 


\section{4. CONCLUSIONS}

Kale juice sweeting with stevia is an excellent solution to reduce the strong bitter flavour of this vegetable that highly limits consumer's acceptance. Furthermore, the kale juice consumption may be even incremented if attractive presentations such as spherifications are used. The innovative double spherification technique currently used allowed to obtain kale juice spheres with excellent physical properties during chilling storage in government liquid containing $\mathrm{NaCl}$. The use of stevia extracts in kale juice spheres did not affect its physicochemical quality. Furthermore, throughout 7 days at $5{ }^{\circ} \mathrm{C}$, sulforaphane content of kale spheres, one of the most interesting bioactive compounds of this brassica, was not affected by this sweetening process. 
Table VII.1. Physical properties of spheres of kale juice with stevia during storage up to 7 days at 5 ${ }^{\circ} \mathrm{C}(\mathrm{n}=3 \pm \mathrm{SD})$. Different capital letters for each physical parameter show significant differences between treatments for the same sampling time. Different lowercase letters for each physical parameter show significant differences between sampling times for the same treatment. NS: not significant; $* * *(\mathrm{p}<0.001) ; * *(\mathrm{p}<0.01) ; *(\mathrm{p}<0.05)$.

\begin{tabular}{|c|c|c|c|c|}
\hline Day & Treatment & Diameter $(\mathbf{m m})$ & Swelling capacity (\%) & Firmness (N) \\
\hline \multirow[t]{4}{*}{0} & CTRL & 20.0 & $0.0 \pm 0.0 \mathrm{Bb}$ & $60.4 \pm 27.5 \mathrm{ABb}$ \\
\hline & $\mathrm{T} 10$ & 20.0 & $0.8 \pm 0.5 \mathrm{Bns}$ & $75.8 \pm 16.3 \mathrm{Ab}$ \\
\hline & $\mathrm{T} 25$ & 20.0 & $3.3 \pm 0.8 \mathrm{Aa}$ & $34.6 \pm 9.22 \mathrm{Bb}$ \\
\hline & T50 & 20.0 & $1.2 \pm 0.3 \mathrm{Bb}$ & $88.7 \pm 11.1$ Ans \\
\hline \multirow[t]{4}{*}{3} & CTRL & $19.76 \pm 1.79$ & $0.7 \pm 0.1 \mathrm{Aa}$ & $119.1 \pm 28.3 \mathrm{Aa}$ \\
\hline & $\mathrm{T} 10$ & $21.08 \pm 0.92$ & $0.1 \pm 0.1 \mathrm{Bns}$ & 105.3 $\pm 19.3 \mathrm{Aba}$ \\
\hline & $\mathrm{T} 25$ & $21.21 \pm 1.71$ & $0.0 \pm 0.0 \mathrm{Bc}$ & $81.4 \pm 9.25 \mathrm{Ba}$ \\
\hline & T50 & $19.92 \pm 1.29$ & $0.8 \pm 0.2 \mathrm{Ab}$ & $100.6 \pm 20.3 \mathrm{ABns}$ \\
\hline \multirow[t]{4}{*}{5} & CTRL & $21.03 \pm 1.26$ & $0.0 \pm 0.0 \mathrm{Bb}$ & $118.7 \pm 26.4 \mathrm{NSa}$ \\
\hline & $\mathrm{T} 10$ & $19.93 \pm 2.67$ & $0.9 \pm 0.5 \mathrm{Bns}$ & $104.7 \pm 11.5 \mathrm{NSa}$ \\
\hline & $\mathrm{T} 25$ & $19.74 \pm 0.66$ & $0.8 \pm 0.3 \mathrm{Bbc}$ & $91.8 \pm 16.6 \mathrm{NSa}$ \\
\hline & T50 & $17.58 \pm 0.90$ & $2.0 \pm 0.2 \mathrm{Aa}$ & $97.7 \pm 18.8 \mathrm{NSns}$ \\
\hline \multirow[t]{4}{*}{7} & CTRL & $19.18 \pm 1.30$ & $0.0 \pm 0.0 \mathrm{Bb}$ & $93.6 \pm 10.9 \mathrm{NSab}$ \\
\hline & $\mathrm{T} 10$ & $19.83 \pm 0.93$ & $0.1 \pm 0.1 \mathrm{Bns}$ & $102.1 \pm 9.7 \mathrm{NSab}$ \\
\hline & $\mathrm{T} 25$ & $20.60 \pm 1.39$ & $2.1 \pm 0.6 \mathrm{Aab}$ & $102.8 \pm 24.5 \mathrm{NSa}$ \\
\hline & T50 & $20.96 \pm 1.66$ & $0.9 \pm 0.1 \mathrm{Bb}$ & $107.4 \pm 23.2 \mathrm{NSns}$ \\
\hline \multicolumn{2}{|c|}{ Treatments } & NS & $* * *$ & $* *$ \\
\hline \multicolumn{2}{|c|}{ Days } & NS & $* * *$ & $* * *$ \\
\hline \multicolumn{2}{|c|}{ Days $\mathrm{x}$ Treatments } & NS & $* * *$ & $*$ \\
\hline
\end{tabular}


Table VII.2. Physicochemical properties (SSC, TA and Hue) of spheres of kale juice with stevia during storage up to 7 days at $5{ }^{\circ} \mathrm{C}(\mathrm{n}=3 \pm \mathrm{SD})$. Different capital letters for each physical parameter show significant differences between treatments for the same sampling time. Different lowercase letters for each physical parameter show significant differences between sampling times for the same treatment. NS: not significant; $* * *(p<0.001) ; * *(p<0.01) ; *(p<0.05)$.

\begin{tabular}{|c|c|c|c|c|}
\hline Day & Treatment & SST & TA & Hue spheres \\
\hline \multirow[t]{4}{*}{0} & CTRL & $4.97 \pm 0.15 \mathrm{Aa}$ & $0.173 \pm 0.025 \mathrm{a}$ & $144.82 \pm 0.80 \mathrm{Ad}$ \\
\hline & $\mathrm{T} 10$ & $4.46 \pm 0.35 \mathrm{ABa}$ & $0.197 \pm 0.014 \mathrm{a}$ & $142.33 \pm 0.38 \mathrm{BCd}$ \\
\hline & $\mathrm{T} 25$ & $4.20 \pm 0.10 \mathrm{Ba}$ & $0.249 \pm 0.001 \mathrm{a}$ & $141.49 \pm 0.29 \mathrm{Cd}$ \\
\hline & T50 & $4.53 \pm 0.23 \mathrm{ABa}$ & $0.209 \pm 0.056 \mathrm{a}$ & $143.92 \pm 0.92 \mathrm{ABd}$ \\
\hline \multirow[t]{4}{*}{3} & CTRL & $3.30 \pm 0.14 \mathrm{Bb}$ & $0.105 \pm 0.007 \mathrm{~b}$ & $147.93 \pm 0.52 \mathrm{Ac}$ \\
\hline & $\mathrm{T} 10$ & $3.05 \pm 0.21 \mathrm{Bb}$ & $0.115 \pm 0.001 \mathrm{~b}$ & $146.88 \pm 0.04 \mathrm{Bc}$ \\
\hline & $\mathrm{T} 25$ & $3.83 \pm 0.06 \mathrm{Ab}$ & $0.103 \pm 0.005 \mathrm{~b}$ & $146.58 \pm 0.14 \mathrm{Bc}$ \\
\hline & T50 & $3.80 \pm 0.05 \mathrm{Ab}$ & $0.102 \pm 0.014 \mathrm{~b}$ & $146.10 \pm 0.62 \mathrm{Bc}$ \\
\hline \multirow[t]{4}{*}{5} & CTRL & $3.40 \pm 0.26 \mathrm{ABb}$ & $0.173 \pm 0.076 \mathrm{~b}$ & $149.46 \pm 0.06 \mathrm{Ab}$ \\
\hline & $\mathrm{T} 10$ & $3.53 \pm 0.06 \mathrm{Ab}$ & $0.181 \pm 0.065 \mathrm{~b}$ & $147.73 \pm 0.50 \mathrm{Bb}$ \\
\hline & $\mathrm{T} 25$ & $3.40 \pm 0.01 \mathrm{ABc}$ & $0.107 \pm 0.011 \mathrm{~b}$ & $148.86 \pm 0.57 \mathrm{Ab}$ \\
\hline & T50 & $3.10 \pm 0.03 \mathrm{Bc}$ & $0.098 \pm 0.011 \mathrm{~b}$ & $149.03 \pm 0.11 \mathrm{Ab}$ \\
\hline \multirow[t]{4}{*}{7} & CTRL & $3.23 \pm 0.15 \mathrm{NSb}$ & $0.115 \pm 0.012 \mathrm{~b}$ & $151.35 \pm 0.15 \mathrm{Aa}$ \\
\hline & $\mathrm{T} 10$ & $3.13 \pm 0.06 \mathrm{NSb}$ & $0.095 \pm 0.053 \mathrm{~b}$ & $150.11 \pm 0.10 \mathrm{Ba}$ \\
\hline & $\mathrm{T} 25$ & $3.36 \pm 0.15 \mathrm{NSc}$ & $0.086 \pm 0.006 \mathrm{~b}$ & $150.65 \pm 0.23 \mathrm{ABa}$ \\
\hline & T50 & $3.26 \pm 0.15 \mathrm{NSc}$ & $0.102 \pm 0.002 \mathrm{~b}$ & $150.77 \pm 0.65 \mathrm{ABa}$ \\
\hline \multicolumn{2}{|c|}{ Treatments } & * & NS & $* * *$ \\
\hline \multicolumn{2}{|l|}{ Days } & $* *$ & $* * *$ & $* * *$ \\
\hline \multicolumn{2}{|c|}{ Days x Treatments } & $* * *$ & NS & $* * *$ \\
\hline
\end{tabular}


Table VII.3. Microbiological counts $\left(\log \mathrm{CFU} \mathrm{g}{ }^{-1}\right)$ of spheres of kale juice with stevia during storage up to 7 days at $5{ }^{\circ} \mathrm{C}(\mathrm{n}=3 \pm \mathrm{SD})$. Different capital letters for each physical parameter show significant differences between treatments for the same sampling time. Different lowercase letters for each physical parameter show significant differences between sampling times for the same treatment. NS: not significant; $* * *(\mathrm{p}<0.001)$; ** $(\mathrm{p}<0.01) ; *(\mathrm{p}<0.05)$.

\begin{tabular}{|c|c|c|c|c|}
\hline Day & Treatment & Mesophilic (CFU g $\left.{ }^{-1}\right)$ & Psychrophilic (CFU g ${ }^{-1}$ ) & $\overline{Y+M\left(C F U ~ g^{-1}\right)}$ \\
\hline \multirow[t]{4}{*}{0} & CTRL & $3.73 \pm 0.11 \mathrm{~d}$ & $5.00 \pm 0.15 \mathrm{c}$ & $3.60 \pm 0.07 \mathrm{~d}$ \\
\hline & $\mathrm{T} 10$ & $3.49 \pm 0.16 \mathrm{~d}$ & $4.76 \pm 0.11 \mathrm{c}$ & $3.27 \pm 0.12 \mathrm{~d}$ \\
\hline & $\mathrm{T} 25$ & $3.60 \pm 0.52 \mathrm{~d}$ & $4.83 \pm 0.05 \mathrm{c}$ & $3.57 \pm 0.12 \mathrm{~d}$ \\
\hline & T50 & $3.35 \pm 0.09 \mathrm{~d}$ & $5.00 \pm 0.07 \mathrm{c}$ & $3.50 \pm 0.12 \mathrm{~d}$ \\
\hline \multirow[t]{4}{*}{3} & CTRL & $4.98 \pm 0.06 \mathrm{c}$ & $4.91 \pm 0.14 \mathrm{c}$ & $4.06 \pm 0.19 \mathrm{c}$ \\
\hline & $\mathrm{T} 10$ & $4.98 \pm 0.17 \mathrm{c}$ & $4.96 \pm 0.01 \mathrm{c}$ & $4.16 \pm 0.04 \mathrm{c}$ \\
\hline & $\mathrm{T} 25$ & $4.84 \pm 0.03 \mathrm{c}$ & $5.02 \pm 0.08 \mathrm{c}$ & $3.98 \pm 0.35 \mathrm{c}$ \\
\hline & T50 & $4.60 \pm 0.09 \mathrm{c}$ & $5.01 \pm 0.12 \mathrm{c}$ & $3.52 \pm 0.34 \mathrm{c}$ \\
\hline \multirow[t]{4}{*}{5} & CTRL & $5.36 \pm 0.92 b$ & $5.85 \pm 0.26 \mathrm{~b}$ & $4.64 \pm 0.34 \mathrm{~b}$ \\
\hline & $\mathrm{T} 10$ & $5.47 \pm 0.07 \mathrm{~b}$ & $5.62 \pm 0.29 \mathrm{~b}$ & $4.35 \pm 0.30 \mathrm{~b}$ \\
\hline & $\mathrm{T} 25$ & $5.76 \pm 0.07 \mathrm{~b}$ & $5.92 \pm 0.04 \mathrm{~b}$ & $4.68 \pm 0.65 b$ \\
\hline & T50 & $5.60 \pm 0.14 b$ & $5.76 \pm 0,27 \mathrm{~b}$ & $5.16 \pm 0.58 \mathrm{~b}$ \\
\hline \multirow[t]{4}{*}{7} & CTRL & $6.28 \pm 0.15 \mathrm{a}$ & $6.50 \pm 0.57 \mathrm{a}$ & $6.50 \pm 0.56 \mathrm{a}$ \\
\hline & $\mathrm{T} 10$ & $5.88 \pm 0.49 \mathrm{a}$ & $6.20 \pm 0.74 \mathrm{a}$ & $6.24 \pm 0.66 \mathrm{a}$ \\
\hline & $\mathrm{T} 25$ & $7.00 \pm 0.36 \mathrm{a}$ & $6.32 \pm 0.31 \mathrm{a}$ & $6.33 \pm 0.29 \mathrm{a}$ \\
\hline & T50 & $5.89 \pm 0.50 \mathrm{a}$ & $6.46 \pm 0.13 \mathrm{a}$ & $6.47 \pm 0.13 \mathrm{a}$ \\
\hline \multicolumn{2}{|c|}{ Treatments } & * & NS & NS \\
\hline \multicolumn{2}{|c|}{ Days } & $* * *$ & $* * *$ & $* * *$ \\
\hline \multicolumn{2}{|c|}{ Days $x$ Treatments } & NS & NS & NS \\
\hline
\end{tabular}


Table VII.4. Glucoraphanin, sulforaphane, sulforaphane nitrile and myrosinase activity of spheres of kale juice with stevia during storage up to 7 days at $5{ }^{\circ} \mathrm{C}(\mathrm{n}=3 \pm \mathrm{SD})$. Different capital letters for each physical parameter show significant differences between treatments for the same sampling time. Different lowercase letters for each physical parameter show significant differences between sampling times for the same treatment. NS: not significant; *** $(\mathrm{p}<0.001) ; * *(\mathrm{p}<0.01) ; *(\mathrm{p}<$ $0.05)$.

\begin{tabular}{|c|c|c|c|c|}
\hline Day & Treatment & $\begin{array}{l}\text { Glucoraphanin } \\
\left(\mathrm{mmoles} \mathrm{kg}^{-1} \mathbf{d w}\right)\end{array}$ & $\begin{array}{l}\text { Sulforaphane } \\
\left(\mu \text { moles } \mathrm{kg}^{-1} \mathrm{dw}\right)\end{array}$ & $\begin{array}{l}\text { Myrosinase } \\
(\mathrm{U} / \mathrm{kg} \text { fw) }\end{array}$ \\
\hline \multirow[t]{4}{*}{0} & CTRL & $2.33 \pm 0.28 \mathrm{Aa}$ & $3.20 \pm 0.18 \mathrm{Ba}$ & $0.69 \pm 0.09 \mathrm{Aa}$ \\
\hline & S10 & $1.31 \pm 0.21 \mathrm{Ba}$ & $4.33 \pm 0.51 \mathrm{Aa}$ & $0.43 \pm 0.33 \mathrm{Ba}$ \\
\hline & S25 & $1.50 \pm 0.09 \mathrm{Ba}$ & $0.75 \pm 0.04 \mathrm{Db}$ & $0.26 \pm 0.03 \mathrm{Ba}$ \\
\hline & S50 & $1.56 \pm 0.08 \mathrm{Ba}$ & $2.19 \pm 0.35 \mathrm{Ca}$ & $0.34 \pm 0.01 \mathrm{Ba}$ \\
\hline \multirow[t]{4}{*}{3} & CTRL & $0.67 \pm 0.09 \mathrm{NSb}$ & $3.05 \pm 0.50 \mathrm{Aa}$ & $0.13 \pm 0.02 \mathrm{NSb}$ \\
\hline & S10 & $0.63 \pm 0.01 \mathrm{NSb}$ & $2.94 \pm 0.17 \mathrm{Ab}$ & $0.19 \pm 0.05 \mathrm{NSa}$ \\
\hline & S25 & $0.63 \pm 0.00 \mathrm{NSb}$ & $0.98 \pm 0.07 \mathrm{Ca}$ & $0.19 \pm 0.00 \mathrm{NSb}$ \\
\hline & S50 & $0.78 \pm 0.13 \mathrm{NSb}$ & $1.75 \pm 0.17 \mathrm{Ba}$ & $0.15 \pm 0.03 \mathrm{NSb}$ \\
\hline \multirow[t]{4}{*}{5} & CTRL & $0.62 \pm 0.05 \mathrm{Bb}$ & $0.86 \pm 0.22 \mathrm{Ab}$ & $0.11 \pm 0.01 \mathrm{Bb}$ \\
\hline & S10 & $0.61 \pm 0.04 \mathrm{Bb}$ & $0.68 \pm 0.08 \mathrm{ABc}$ & $0.06 \pm 0.01 \mathrm{Cb}$ \\
\hline & S25 & $0.74 \pm 0.04 \mathrm{Ab}$ & $0.61 \pm 0.09 \mathrm{ABb}$ & $0.18 \pm 0.01 \mathrm{Ab}$ \\
\hline & S50 & $0.75 \pm 0.01 \mathrm{Ab}$ & $0.48 \pm 0.05 \mathrm{Bb}$ & $0.11 \pm 0.04 \mathrm{Bb}$ \\
\hline \multirow[t]{4}{*}{7} & CTRL & $0.55 \pm 0.13 \mathrm{NSb}$ & $1.04 \pm 0.21 \mathrm{Ab}$ & $0.15 \pm 0.01 \mathrm{NSb}$ \\
\hline & S10 & $0.66 \pm 0.10 \mathrm{NSb}$ & $1.29 \pm 0.05 \mathrm{Ac}$ & $0.18 \pm 0.00 \mathrm{NSa}$ \\
\hline & S25 & $0.63 \pm 0.09 \mathrm{NSb}$ & $0.59 \pm 0.06 \mathrm{Bb}$ & $0.18 \pm 0.02 \mathrm{NSb}$ \\
\hline & S50 & $0.75 \pm 0.04 \mathrm{NSb}$ & $0.58 \pm 0.08 \mathrm{Bb}$ & $0.14 \pm 0.02 \mathrm{NSb}$ \\
\hline \multicolumn{2}{|c|}{ Treatments } & *** & $* * *$ & $* * *$ \\
\hline \multicolumn{2}{|c|}{ Days } & $* * *$ & $* * *$ & $* * *$ \\
\hline \multicolumn{2}{|c|}{ Days $\mathrm{x}$ Treatments } & $* * *$ & $* * *$ & $* * *$ \\
\hline
\end{tabular}


A

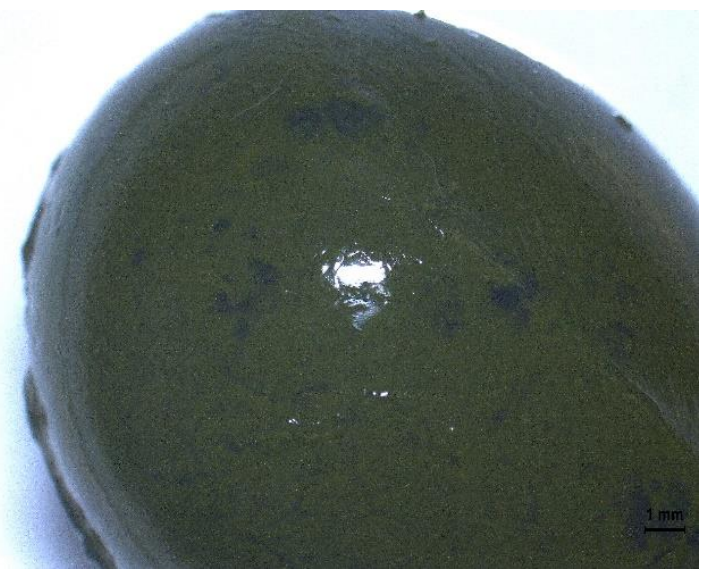

C

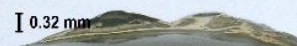

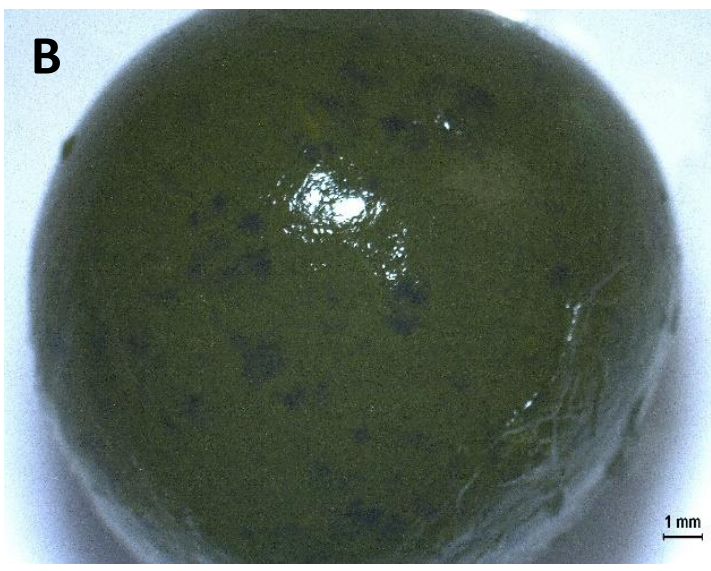

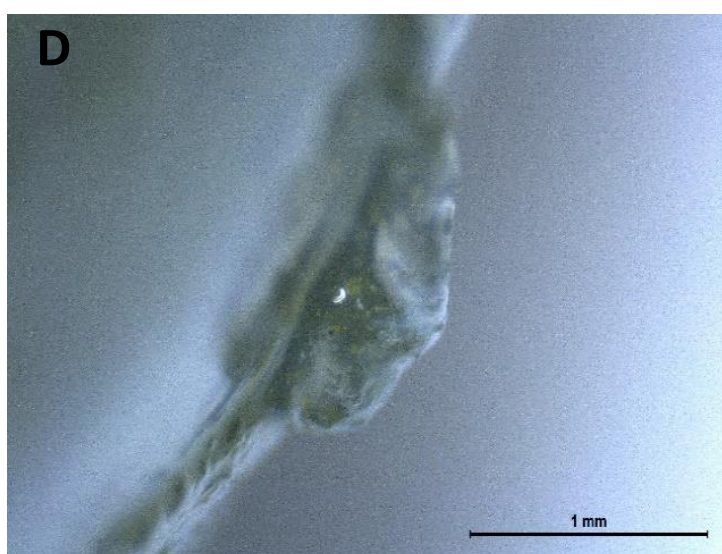

Figure VII.1. Details of kale spheres obtained with a stereo microscope at $\times 20$ magnification 


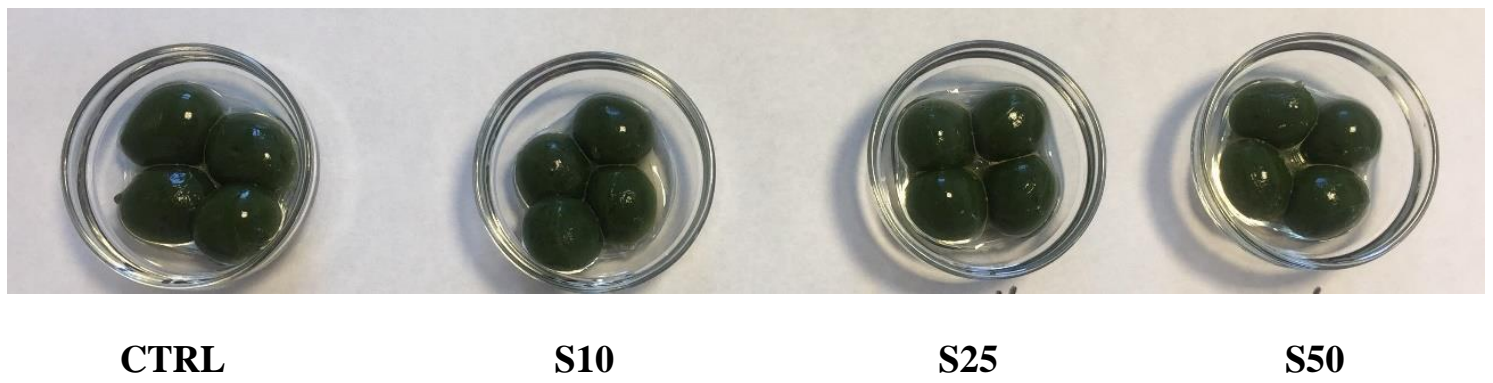

Figure VII.2. Kale juice spheres without (CTRL) and different stevia supplementation concentrations (S10, S25 and S50) 


\section{CONCLUSIONS}

In order to develop innovative vegetable-based formulations different emerging sustainable minimal processing techniques, such as high hydrostatic processing (HHP), high pressure assisted thermal processing (HPTP), semi-continuous micro wave (MW) and sous vide were studied. Such new elaborates included purees, juices, sauces and hummus prepared as 'fifth range' products with high quality and bioactive compounds content, and prolonged refrigerated shelf life. The main general conclusions of the current $\mathrm{PhD}$ Thesis are as follows:

1. Emerging processing techniques (HHP, HPTP and MW) were used to develop a new convenient pea puree, which reached a shelf life of 24 days of storage at $5^{\circ} \mathrm{C}$.

2. HHP treatment improved the rheological properties, viscosity and stability in pea-based puree and increased the particle size during storage.

3. For pea puree, PG was more thermo-resistant enzyme than PME and it could be used as an indicator of HHP efficiency.

4. HHP-treated pea puree showed the highest color and vitamin $\mathrm{C}$ retention during storage. However, MW-treated pea puree showed higher apparent viscosity.

5. HPTP treatment negatively affected thermolabile compounds and colour of pea puree.

6. MW and HHP treatments induced the highest sensory quality of pea puree after 24 days at $5^{\circ} \mathrm{C}$. Both processing treatments were quite interesting to develop pea purees and probably other legume-based products.

7. An innovative cowpea puree (78.8\% cowpea seeds) was developed under above cited techniques reaching a shelf life of 21 days at $5^{\circ} \mathrm{C}$.

8. The sous vide negatively affected the $\mathrm{G}^{\prime}$ and $\mathrm{G}^{\prime \prime}$ rheological modulus during storage of cowpea puree. This was mainly attributed to a loss of spreading characteristic of puree, what turned out the viscosity of the cowpea puree breakable. 
9. The semi-industrial continuous MW treatment improved the sensory quality and decreased the tannin content of a faba beans pesto sauce with a shelf life of 20 days at $5^{\circ} \mathrm{C}$.

10. MW heating using high power combined with short processing time, could be recommended as an emergent pasteurization technique for keeping quality of faba beans pesto sauce.

11. Two innovative broccoli (53\% either cv. Parthenon or Bimi) hummus were formulated under HHP and MW. Both treatments allowed obtaining a broccoli hummus with excellent sensory and bioactive quality up to 28 days at $5^{\circ} \mathrm{C}$.

12. In HHP-treated Parthenon hummus higher glucoraphanin content was found.

13. The three processing techniques (HHP, HPTP and MW) were able for controlling microbial loads at levels which did not reduce the shelf life of developed vegetable purees, together with other factors like good manufacturing practices and storage conditions. Vacuum packaging of samples also contribute to maintaining the initial low microbial counts during storage.

14. The effect of cyclodextrins (CDs) on the glucoraphanin/sulforaphane system of broccoli juice was studied.

15. A high maltosyl- $\beta-\mathrm{CD}$ concentration of $90 \mathrm{mM}$ would stabilize the glucoraphanin content of broccoli juice after $24 \mathrm{~h}$. However, such high level may compromise a safe consumption, unless further toxicological recommendations will be available regarding modified CDs. On the other hand the addition of $40 \mathrm{mM} \alpha-\mathrm{CD}$ to broccoli juice will significantly retain glucoraphanin content.

16. In order to obtain new kale juice spheres with stevia extracts, an innovative double spherification technique was used. The use of stevia extracts in kale juice spheres did not affect its physicochemical quality and bioactive contents during 7 days at $5^{\circ} \mathrm{C}$. 
17. Kale juice sweeting with stevia seems to be an excellent solution to reduce its strong bitter flavour. It is foreseeable that its consumption could be increased if attractive presentations such as spherifications are used. 


\section{SCIENTIFIC PUBLICATIONS DERIVED FROM THE PRESENT PhD THESIS}


Original papers published in peer-reviewed journals included in the Journal Citation Reports (JCR) of the Institute for Scientific Information (ISI)

- Klug, T.V., Collado, E., Martínez-Sánchez, A., Gómez, P.A., Aguayo, E., Otón, M., Artés, P. and Artés-Hernández, F. 2018. Innovative quality improvement by continuous microwave processing of a faba beans pesto sauce. Food Bioprocess Technol., 11:561-571, doi: 10.1007/s11947-017-2024-y.

- Klug, T.V., Martínez-Sánchez, A., Gómez, P.A., Collado, E., Aguayo, E., Artés, F. and Artés-Hernández, F. 2017. Improving quality of an innovative pea puree by high hydrostatic pressure. J. Sc. Food Agric., 97: 4362-4369, doi: 10.1002/jsfa.8454.

- Collado, E., Klug, T.V., Martínez-Sánchez, A., Artés-Hernández, F., Aguayo, E., Artés, F., Fernández, J.A. and Gómez, P.A. 2017. Immature pea seeds. Effect of storage under modified atmosphere packaging and sanitation with acidified sodium chlorite J. Sci. Food Agric., 97: 4370-4378, doi: 10.1002/jsfa.8513.

- Klug, T.V., Martínez-Hernández, G.B., Collado, E., Artés, F., Artés-Hernández, F. 2018. Effect of microwave and high pressure processing on quality of an innovative broccoli hummus. Food Bioprocess Technol., 11: 1464-1477, doi: 10.1007/s11947018-2111-8.

- Martínez-Hernández G.B., Klug T.V., Carrión-Monteagudo M.M., Artés F., LópezNicolás J.M., Artés-Hernández F. 2018. Effects of $\alpha-, \beta-$ and maltosyl- $\beta$ cyclodextrins use on the glucoraphanin/sulforaphane system of broccoli juice. J. Sci. Food Agric., In press, doi: 10.1002/jsfa.9269.

\section{Original papers published in peer-reviewed journal not included in the JCR-ISI}

- Gómez, P.A., Collado, E., Klug, T.V., Artés-Hernández, F., Aguayo, E., MartínezSánchez, A., Artés, F., Fernández, J.A. 2017. Nuevos alimentos de leguminosas autóctonas para promover su consumo seguro y de calidad en un entorno sostenible. Revista CTC Alimentación, 67: 18-23. 


\section{INTERNATIONAL CONGRESS}

- Klug, T.V., Collado, E., Martínez-Sánchez, A., Artés-Hernández, F., Gómez, P.A., Aguayo, E., Artés, F. 2016. Sensory and microbial quality of a pea puree processed under conventional or microwave treatment. VI Congreso Internacional de Ingeniería Química, Biotecnológica y Alimentaria (CIIQBA, 2016), La Habana, Cuba. 2125/11/2016.

- Collado, E., Klug, T.V., Artés-Hernández, F., Aguayo, E., Artés, F., Fernández, J.A. and Gómez, P.A. 2017. Quality changes of fresh and then microwaved minimally processed faba seeds. International Conference Legato-Eurolegume. Novi Sad, Serbia, $27-28 / 9 / 2017$.

- Klug, T.V., Collado, E., Martínez-Sánchez, A., Artés-Hernández, A., Gómez, P.A., Aguayo, E. and Artés, F. 2017. The effect of processing and different thermal treatment on the antioxidant capacity of peas puree. International Conference LegatoEurolegume. Novi Sad, Serbia, 27-28/9/2017.

- Collado, E., Klug, T.V., Artés-Hernández, F., Aguayo, E., Artés, F., Fernández, J.A. and Gómez, P.A. 2017. Avaliação da qualidade de grãos de feijão-fava minimamente processados e microondados durante armazenamento. $1^{\circ}$ Congresso Luso-Brasileiro de Horticultura. Lisboa, Portugal, 1-4/11/2017.

- Klug, T.V., Collado, E., Martínez-Sánchez, E., Artés-Hernández, F., Gómez, P.A., Aguayo, E. and Artés, F. 2017. Avaliação da qualidade de feijão caupi minimamente processado e microondado. $1^{\circ}$ Congresso Luso-Brasileiro de Horticultura. Lisboa, Portugal, 1-4/11/2017.

- Klug, T.V., Collado, E., Martínez-Sánchez, T., Artés-Hernández, T., Gómez, P.A., Aguayo, E., and Artés, F. 2017. Calidad sensorial y microbiológica de un puré de guisantes mínimamente procesado por microondas o por alta presión hidrostática. IX Congreso Iberoamericano de Tecnología Postcosecha y Agroexportaciones. Santiago, Chile, 29/11-01/12/2017. 
- Collado, E., Klug, T.V., Artés-Hernández, F., Aguayo, E., Artés, F., Fernández, J. and Gómez, P.A. 2017. Cambios en la calidad de guisantes mínimamente procesados en fresco y su respuesta al cocinado con microondas. IX Congreso Iberoamericano de Tecnología Postcosecha y Agroexportaciones. Santiago, Chile, 29/11-01/12/2017.

- Klug, T.V., Artés, F., Artés-Hernández, F. 2017. Puree-based vegetables beverages development under innovative minimal processing techniques. In: Proceedings of the 5th Workshop on Agri-Food Research WiA-16. Eds: F. Artés-Hernández, J.A. Fernández-Hernández, J. Calatrava, E. Aguayo, J.J. Alarcón, J.E. Cos. Editorial: CRAI Biblioteca, Universidad Politécnica de Cartagena, Murcia, España. ISBN: 97884-16325-29-0. 223 pp. Pp. 184-187. http://hdl.handle.net/10317/5558.

- Klug, T.V., Collado, E., Martínez-Sánchez, A., Gómez, P., Aguayo, E., Artés, F., Artés-Hernández, F. 2018. Effect of different thermal treatments on the antioxidant capacity of a pea puree. In: Proceedings of the 6th Workshop on Agri-Food Research WiA-17. Eds: F. Artés-Hernández, J.E. Cos, J.A. Fernández-Hernández, J. Calatrava, E. Aguayo, J.J. Alarcón, M. Egea. Editorial: CRAI Biblioteca, Universidad Politécnica de Cartagena, Murcia, España. ISBN: 978-84-16325-64-1. 208 pp Pp. 1518. Open access: http://hdl.handle.net/10317/6706.

- Collado, E., Klug, T.V., Artés-Hernández, F., Aguayo, E., Martínez-Sánchez, A., Artés, F., Gómez, P. 2018. Cambios en la calidad de semillas de haba mínimamente procesadas y microondadas. In: Proceedings of the 6th Workshop on Agri-Food Research WiA-17. Eds: F. Artés-Hernández, J.E. Cos, J.A. Fernández-Hernández, J. Calatrava, E. Aguayo, J.J. Alarcón, M. Egea. Editorial: CRAI Biblioteca, Universidad Politécnica de Cartagena, Murcia, España. ISBN: 978-84-16325-64-1. 208 pp Pp. 1922. Open access: http://hdl.handle.net/10317/6706.

- Klug, T.V., Collado, E., Martínez-Hernández, G.B., Artés, F., Artés-Hernández, F. 2018. Effect of stevia extracts on total phenolics and antioxidant capacity of kale juice spheres. In: Proceedings of the 7th Workshop on Agri-Food Research WiA-18. In press. 


\section{REFERENCES}

Acarturk, F., Imai, T., Saito, H., Ishikawa, M., Otagiri, M. 1993. Comparative study on inclusion complexation of maltosyl-beta-cyclodextrin, heptakis (2,6-di-O-methyl)-betacyclodextrin and beta-cyclodextrin with fucosterol in aqueous and solid state. Journal of Pharmacy and Pharmacology, 45: 1028-1032.

Acosta-Estrada, B.A., Gutiérrez-Uribe, J.A., Serna-Saldívar, S.O. 2014. Bound phenolics in foods, a review. Food Chemistry, 152: 46-55.

Adjei-Fremah, S., Jackai, L.E., Worku, M. 2015. Analysis of phenolic content and antioxidant properties of selected cowpea varieties tested in bovine peripheral blood. American Journal of Animal and Veterinary Sciences, 10(4): 235-245.

Aguilera, Y., Estrella, I., Benitez, V., Esteban, R.M., Martín-Cabrejas, M.A. 2011. Bioactive phenolic compounds and functional properties of dehydrated bean flours. Food Research International, 44: 774-780.

Ahmed, J., Shivhare, U.S., Raghavan, G.S.V. 2000. Rheological characteristics and kinetics of colour degradation of green chilli uree. Journal of Food Engineering, 44(4): 239-244.

Ahmed, J., Ramaswamy, H.S., Hiremath, N. 2005. The effect of high pressure treatment on rheological characteristics and colour of mango pulp. International Journal of Food Science and Technology, 40(8): 885-895.

Ahmed, J., Ramaswamy, H.S. 2007. Microwave pasteurization and sterilization of foods. Handbook of Food Preservation, 691-711.

Ahmed, J., Al-Salman, F., Almusallam, A.S. 2013. Effect of blanching on thermal color degradation kinetics and rheological behavior of rocket (Eruca sativa) puree. Journal of Food Engineering, 119(3): 660-667.

Aguiló-Aguayo I., Fortuny S.R., Martin-Belloso O. 2008. Comparative study on color, viscosity and related enzymes of tomato juice treated by high-intensity pulsed electric fields or heat. European Food Research Technology, 227: 559-606.

Alimarket, 2017. IV gama y otros refrigerados hortofrutícolas: Innovación e inversión. Informe Publicaciones Alimarket S.A. 154-166.

Almeida, D.T., Greiner, R., Furtunado, D.M.N., Trigueiro, I.N.S., Araújo, M.P.N. 2008. Content of some antinutritional factors in bean cultivars frequently consumed in Brazil. International Journal of Food Science and Technology, 43(2): 243-249.

Alshikh, N., de Camargo, A.C., Shahidi, F. 2015. Phenolics of selected lentil cultivars: Antioxidant activities and inhibition of low-density lipoprotein and DNA damage. Journal of Functional Foods, 18: 1022-1038.

Álvarez M.D., Fuentes R., Olivares M.D., Canet, W. 2014. Effects of high hydrostatic pressure on rheological and thermal properties of chickpea (Cicer arietinum L.) flour 
slurry and heat-induced paste. Innovative Food Science Emerging Technology, 21: 1223.

Álvarez, M.D., Fuentes, R., Guerrero, G., Canet, W. 2017a. Characterization of commercial Spanish hummus formulation: Nutritional composition, rheology, and structure. International Journal of Food Properties, 20(4): 845-863.

Álvarez, M.D., Herranz, B., Campos, G., Canet, W. 2017b. Ready-to-eat chickpea flour puree or cream processed by hydrostatic high pressure with final microwave heating. Innovative Food Science \& Emerging Technologies, 41: 90-99.

Álvarez-Jubete, L., Smyth, T.J., Valverde, J., Rai, D.K., Barry-Ryan, C. 2014. Simultaneous determination of sulphoraphane and sulphoraphane nitrile in Brassica vegetables using ultra-performance liquid chromatography with tandem mass spectrometry. Phytochemical Analysis, 25(2): 141-146.

Alves, M.J., Ferreira, I.C.F.R., Froufe, H.J.C., Abreu, R.M.V., Martins, A., Pintado, M. 2013. Antimicrobial activity of phenolic compounds identified in wild mushrooms, SAR analysis and docking studies. Journal of Applied Microbiology, 115(2): 346-357.

Andrés, V., Villanueva, M.J., Tenorio, M.D. 2016. The effect of high-pressure processing on colour, bioactive compounds, and antioxidant activity in smoothies during refrigerated storage. Food Chemistry, 192: 328-335.

Appelqvist, I.A.M., Cochet-Broch, M., Poelman, A.A.M., Day, L. 2015. Morphologies, volume fraction and viscosity of cell wall particle dispersions particle related to sensory perception. Food Hydrocolloids, 44: 198-207.

Ares A.M., Bernal J., Martín M.T., Bernal J.L., Nozal M.J. 2014. Optimized formation, extraction, and determination of sulforaphane in broccoli by liquid chromatography with diode array detection. Food Analytical Methods, 7: 730-740.

Arjmandi, M., Otón, M., Artés, F., Artés-Hernández, F., Gómez, P.A., Aguayo, E. 2017a. Microwave flow and conventional heating effects on the physicochemical properties, bioactive compounds and enzymatic activity of tomato puree. Journal of the Science of Food and Agriculture, 97(3): 984-990.

Arjmandi, M., Otón, M., Artés, F., Artés-Hernández, F., Gómez, P.A., Aguayo, E. 2017b. Continuous microwave pasteurization of a vegetable smoothie improves its physical quality and hinders detrimental enzyme activity. Food Science and Technology International, 23(1): 36-45.

Artés, F., Mínguez, M.I., Hornero, D. 2002. Analysing changes in fruit pigments. In: Colour in Food. Improving Quality. Editor D.B. Mac Dougall. Editorial. CRC Press and Woodhead Publishing Ltd. Cambridge, UK. Chapter 10. 248-282. ISBN 1855735903.

Artés, F., Artés-Hernández, F. 2003. Principios y diseño de industrias de procesado en fresco de hortalizas. In: Envasado y comercialización de frutas y hortalizas mínimamente procesadas. Edit. Gobierno de La Rioja, Logroño, Spain. 67-92. 
Artés, F., Gómez, P., Aguayo, E., Escalona, V., Artés-Hernández, F. 2009. Sustainable sanitation techniques for keeping quality and safety of fresh-cut plant commodities. Postharvest Biology and Technology, 51(3): 287-296.

Artés F., Artés-Hernández, F. 2012. Innovaciones en técnicas de procesado para facilitar el consumo de hortalizas y frutas. CTC Revista de Agroalimentación e Industrias Afines. 51: $9-15$.

Artés-Hernández, F., Formica-Oliveira, A.C., Artés, F., Martínez-Hernández, G.B. 2017. Improved quality of a vitamin B12-fortified "ready to blend" fresh-cut mix salad with chitosan. Food Science and Technology International, 23(6): 513-528.

ASTM 1986. Physical requirements guidelines for sensory evaluation laboratories. Philadelphia, USA: American Society for Testing Materials. (Special Technical Pub. 913)

Astray, G., Gonzalez-Barreiro, C., Mejuto, J.C., Rial-Otero, R., Simal-Gándara, J. 2009. A review on the use of cyclodextrins in foods. Food Hydrocolloids, 23(7): 1631-1640.

Ayaz, F.A., Hayirlioglu-Ayaz, S., Alpay-Karaoglu, S., Grúz, J., Valentová, K., Ulrichová, J., Strnad, M. 2008. Phenolic acid contents of kale (Brassica oleraceae L. var. acephala DC.) extracts and their antioxidant and antibacterial activities. Food Chemistry, 107(1): $19-25$.

Badiane, F.A., Diouf, M., Diouf, D. 2014. Cowpea, In: Broadening the genetic base of grain legumes. Eds. Singh, M., Bisht, I.S. and Dutta, M. Edit. Springer, India, 95-114.

Baginsky, C., Peña-Neira, A., Cáceres, A., Hernández, T., Estrella, I., Morales, H., Pertuzé, R. 2013. Phenolic compound composition in immature seeds of faba bean (Vicia faba L.) varieties cultivated in Chile. Journal of Food Composition and Analysis, 31(1): 1-6.

Balasundram, N., Sundram, K., Samman, S. 2006. Phenolic compounds in plants and agriindustrial by-products: Antioxidant activity, occurrence, and potential uses. Food Chemistry, 99(1): 191-203.

Baldwin, D.E. 2012. Sous vide cooking: A review. International Journal of Gastronomy and Food Science, 1(1): 15-30.

Barba, F.J., Criado, M.N., Belda-Galbis, C.M., Esteve, M.J., Rodrigo, D. 2014. Stevia rebaudiana Bertoni as a natural antioxidant/antimicrobial for high pressure processed fruit extract: processing parameter optimization. Food Chemistry, 148: 261-267.

Barba, F.J., Mariutti, L.R.B., Bragagnolo, N., Mercadante, A.Z., Barbosa-Cánovas, G.V., Orlien, V. 2017. Bioaccessibility of bioactive compounds from fruits and vegetables after thermal and nonthermal processing. Trends in Food Science and Technology, 67: 195206.

Basu, S., Shivhare, U.S., Singh, T.V., Beniwal, V.S. 2011. Rheological, textural and spectral characteristics of sorbitol substituted mango jam. Journal Food Engineering, 105: 503512. 
Becerra-Moreno, A., Alanís-Garza, P.A., Mora-Nieves, J.L., Mora-Mora, J.P., JacoboVelázquez, D.A. 2014. Kale: An excellent source of vitamin C, pro-vitamin A, lutein and glucosinolates. CYTA - Journal of Food, 12(3): 298-303.

Benlloch-Tinoco, M., Varela, P., Salvador, A., Martínez-Navarrete, N. 2012. Effects of microwave heating on sensory characteristics of kiwifruit puree. Food and Bioprocess Technology, 5(8): 3021-3031.

Benlloch-Tinoco, M., Igual, M., Rodrigo, D., Martínez-Navarrete, N. 2013. Comparison of microwaves and conventional thermal treatment on enzymes activity and antioxidant capacity of kiwifruit puree. Innovative Food Science \& Emerging Technologies, 19: 166172.

Benlloch-Tinoco, M., Igual, M., Salvador, A., Rodrigo, D., Martínez-Navarrete, N. 2014. Quality and acceptability of microwave and conventionally pasteurized kiwifruit puree. Food and Bioprocess Technology, 7(11): 3282-3292.

Benlloch-Tinoco, M., Igual, M., Rodrigo, D., Martínez-Navarrete, N. 2015. Superiority of microwaves over conventional heating to preserve shelf-life and quality of kiwifruit puree. Food Control, 50: 620-629.

Bennink, M.R., Barrett, K.G. 2004. Total phenolic content in canned beans. (Bean Improvement Cooperative (BIC), 47: 211-212.

Benzie, I.F., Strain, J.J. 1999. Ferric reducing/antioxidant power assay: Direct measure of total antioxidant activity of biological fluids and modified version for simultaneous measurement of total antioxidant power and ascorbic acid concentration. Methods in Enzymology, 299: 15-27.

Bhanja Dey, T., Chakraborty, S., Jain, K.K., Sharma, A., Kuhad, R.C. 2016. Antioxidant phenolics and their microbial production by submerged and solid state fermentation process: A review. Trends in Food Science and Technology, 53: 60-74.

Bi, X., Hemar, Y., Balaban, M.O., Liao, X. 2015. The effect of ultrasound on particle size, color, viscosity and polyphenol oxidase activity of diluted avocado puree. Ultrasonics Sonochemistry, 27: 567-575.

Bilbao-Sáinz, C., Butler, M., Weaver, T., Bent, J. 2007. Wheat starch gelatinization under microwave irradiation and conduction heating. Carbohydrate Polymers, 69: 224-232.

Black, E.P., Setlow, P., Hocking, A.D., Stewart, C.M., Kelly, A.L., Hoover, D.G. 2007. Response of spores to high-pressure processing. Comprehensive Reviews in Food Science and Food Safety, 6(4): 103-119.

Bornhorst, E.R., Liu, F., Tang, J., Sablani, S.S., Barbosa-Cánovas, G.V. 2017a. Food quality evaluation using model foods: a comparison study between microwave-assisted and conventional thermal pasteurization process. Food and Bioprocess Technology, 10(3): $1248-1256$. 
Bornhorst, E.R., Tang, J., Sablani, S.S., Barbosa-Cánovas, G.V., Liu, F. 2017b. Green pea and garlic puree model food development for thermal pasteurization process quality evaluation. Journal of Food Science, 82(7): 1631-1639.

Bourne, M. 2002. Food texture and viscosity: Concept and measurement. Academic Press, Cambridge, MA, 48. 1-32. ISBN: 978-0-12-119062-0.

Boye, J., Zare, F., Pletch, A. 2010. Pulse proteins: processing, characterization, functional properties and applications in food and feed. Food Research International, 43(2): 414431.

Brand-Williams, W., Cuvelier, M E., Berset, C. 1995. Use of a free radical method to evaluate antioxidant activity. LWT - Food Science and Technology, 28(1): 25-30.

Bricker, G.V., Riedl, K.M., Ralston, R.A., Tober, K.L., Oberyszyn, T.M. Schwartz S.J. 2014. Isothiocyanate metabolism, distribution, and interconversion in mice following consumption of thermally processed broccoli sprouts or purified sulforaphane. Molecular Nutrition \& Food Research, 58: 1991-2000.

Brooks, J.D., Paton, V.G., Vidanes, G., 2001. Potent induction of phase 2 enzymes in human prostate cells by sulforaphane. Cancer Epidemiology, Biomarkers \& Prevention, 10: 949954.

Buck, P.A. 1956. Origin and taxonomy of broccoli. Economic Botanic, 10: 250-253.

Bunaciu, A.A., Aboul-Enein, H.Y., Fleschin, S. 2012. FTIR spectrophotometric methods used for antioxidant activity assay in medicinal plants. Applied Spectroscopy Reviews, 47(4):245-255.

Busambwa, K., Sunkara, R., Diby, N., Offei-Okyne, R., Boateng, J. Verghese, M. 2016. Cytotoxic and apoptotic effects of sprouted and non-sprouted lentil, green and yellow split-peas. International Journal of Cancer Research, 12: 51-60

Cai, R., Hettiarachchy, N.S., Jalaluddin, M. 2003. High-performance liquid chromatography determination of phenolic constituents in 17 varieties of cowpeas. Journal of Agricultural and Food Chemistry, 51(6): 1623-1627.

Camiro-Cabrera, M., Escobedo-Avellaneda, Z., Salinas-Roca, B., Martín-Belloso, O., WeltiChanes, J. 2017. High hydrostatic pressure and temperature applied to preserve the antioxidant compounds of mango pulp (Mangifera indica L.). Food and Bioprocess Technology, 10(4): 639-649.

Cano, A., Hernández-Ruíz, J., García-Cánovas, F., Acosta, M., Arnao, M.B. 1998. An endpoint method for estimation of the total antioxidant activity in plant material. Phytochemical Analysis, 9(4): 196-202.

Cano, M.P. 1991. HPLC separation of chlorophyll and carotenoid pigments of four kiwi fruit cultivars. Journal of Agricultural and Food Chemistry, 39(10): 1786-1791.

Cao, X., Zhang, Y., Zhang, F., Wang, Y., Yi, J., Liao, X. 2011. Effects of high hydrostatic pressure on enzymes, phenolic compounds, anthocyanins, polymeric color and color of strawberry pulps. Journal of the Science of Food and Agriculture, 91(5): 877-885. 
Carbonaro, M., Nardini, M., Maselli, P., Nucara, A. 2015. Chemico-physical and nutritional properties of traditional legumes (lentil, lens culinaris 1., and grass pea, lathyrus sativus 1.) from organic agriculture: an explorative study. Organic Agriculture, 5(3): 179-187.

Carreau, P. J., Cotton, F., Citerne, G. P., Moan M. 2002. Rheological properties of concentrated suspensions: application to foodstuffs. In Engineering and Food for the 21st Century, ed. by Welti-Chanes J, Barbosa-Canovas GV and Aguilera JM. CRC Press, Boca Raton, FL, 327-346.

Cartea, M.E., Velasco P. 2008. Glucosinolates in brassica foods: bioavailability in food and significance for human health. Phytochemistry Reviews, 7: 213-229.

Cartea, M.E., Francisco, M., Soengas, P., Velasco, P. 2011. Phenolic compounds in brassica vegetables. Molecules, 16(1): 251-280.

Carvalho, A.F.U., de Sousa, N.M., Farias, D.F., da Rocha-Bezerra, L.C.B., da Silva, R.M.P., Viana, M.P., Filho, F.R.F. 2012. Nutritional ranking of 30 brazilian genotypes of cowpeas including determination of antioxidant capacity and vitamins. Journal of Food Composition and Analysis, 26(1-2): 81-88.

Carvalho, M., Lino-Neto, T., Rosa, E., Carnide, V. 2017. Cowpea: a legume crop for a challenging environment. Journal of the Science of Food and Agriculture, 97(13): 42734284.

Cassidy, A., Hanley, B., Lamuela-Raventos, R.M. 2000. Isoflavones, lignans and stilbenesorigins, metabolism and potential importance to human health. Journal of the Science of Food and Agriculture, 80: 1044-1062.

Castillejo, N., Martínez-Hernández, G.B., Gómez, P.A., Artés F., Artés-Hernández, F. 2016. Red fresh vegetables smoothies with extended shelf life as an innovative source of healthpromoting compounds. Journal of Food Science and Technology, 53: 1475-1486.

Castillejo, N., Martínez-Hernández, G.B., Monaco, K., Gómez, P.A., Aguayo, E., Artés, F., Artés-Hernández, F. 2017. Preservation of bioactive compounds of a green vegetable smoothie using short time-high temperature mild thermal treatment. Food Science and Technology International, 23(1): 46-60.

Castillejo, N., Martínez-Hernández, G.B., Lozano-Guerrero, A.J., Pedreño-Molina, J.L., Gómez, P., Aguayo, E., Artés, F., Artés-Hernández F. 2018. Microwave heating modelling of a green smoothie. Effects on glucoraphanin, sulforaphane and $\mathrm{s}-$-methyl cysteine sulphoxide changes during storage. Journal of the Science of Food and Agriculture, 98(5): 1863-1872.

Chakraborty, S., Kaushik, N., Rao, P.S., Mishra, H.N. 2014. High-pressure inactivation of enzymes: a review on its recent applications on fruit purees and juices. Comprehensive Reviews in Food Science and Food Safety, 13(4): 578-596.

Chakraborty, S., Rao, P.S., Mishra, H.N. 2015. Effect of combined high pressure-temperature treatments on color and nutritional quality attributes of pineapple (Ananas comosus L.) puree. Innovative Food Science and Emerging Technologies, 28: 10-21. 
Chandrasekaran, S., Ramanathan, S., Basak, T. 2013. Microwave food processing-a review. Food Research International, 52(1): 243-261.

Chatjigakis, A.K., Donze, C., Coleman, A.W., Cardot, P. 1992. Solubility behavior of betacyclodextrin in water/cosolvent mixtures. Analytical Chemistry, 64: 1632-1634.

Chong, J., Poutaraud, A., Hugueney, P. 2009. Metabolism and roles of stilbenes in plants. Plant Science, 177(3): 143-155.

Cifuentes-Gómez, T., Rodríguez-Mateos, A., González-Salvador, I., Alañón, M.E., Spencer, J.P.E. 2015. Factors affecting the absorption, metabolism, and excretion of cocoa flavanols in humans. Journal of Agricultural and Food Chemistry, 63(35): 7615-7623.

Clarke, J.D., Hsu, A., Riedl, K., Bella, D., Schwartz, S.J., Stevens, J.F., Ho, E. 2011. Bioavailability and inter-conversion of sulforaphane and erucin in human subjects consuming broccoli sprouts or broccoli supplement in a cross-over study design. Pharmacology Research, 64: 456-463

Collado, E., Klug, T.V., Martínez-Sánchez, A., Artés-Hernández, F., Aguayo, E., Artés, F., Fernández, J.F., Gómez P. 2017. Immature pea seeds: effect of storage under modified atmosphere packaging and sanitation with acidified sodium chlorite. Journal of the Science of Food and Agriculture, 97: 4370-4378.

Cömert, E.D., Gökmen, V. 2017. Antioxidants bound to an insoluble food matrix: their analysis, regeneration behavior, and physiological importance. Comprehensive Reviews in Food Science and Food Safety, 16(3): 382-399

Comunian, T.A., Favaro-Trindade C.S. 2016. Microencapsulation using biopolymers as an alternative to produce food enhanced with phytosterols and omega-3 fatty acids: A review. Food Hydrocolloids, 61: 442-457.

Considine, K.M., Kelly, A.L., Fitzgerald, G.F., Hill, C., Sleator, R.D. 2008. High-pressure processing - Effects on microbial food safety and food quality. FEMS Microbiology Letters, 281(1): 1-9.

Contador, R., Gonzalez-Cebrino, F., Garcia-Parra, J., Lozano, M., Ramırez R. 2012. Effect of hydrostatic high pressure and thermal treatment on two types of pumpkin puree and changes during refrigerated storage. Journal of Food Processing and Preservation, 38: 704-712.

Cramer, J.M., Teran-Garcia, M., Jeffery, E.H. 2012. Enhancing sulforaphane absorption and excretion in healthy men through the combined consumption of fresh broccoli sprouts and a glucoraphanin-rich powder. British Journal of Nutrition, 107: 1333-1338.

Crelier, S., Robert, M.C., Claude, J. Juillerat, M.A. 2001. Tomato (lycopersicon esculentum) pectinmethylesterase and polygalacturonase behaviors regarding heat and pressure induced inactivation. Journal of Agricultural and Food Chemistry, 49: 5566-5575.

Cubero, J. I. (1974) On the evolution of Vicia faba L. Theoretical and Applied Genetics, 45: $47-51$. 
Cui, E.J., Song, N.Y., Shrestha, S., Chung, I.S., Kim, J.Y., Jeong, T.S., Baek, N.I. 2012. Flavonoid glycosides from cowpea seeds (Vigna sinensis K.) inhibit LDL oxidation. Food Science and Biotechnology, 21(2): 619-624.

Dahl, W.J., Foster, L.M., Tyler, R.T. 2012. Review of the health benefits of peas (Pisum Sativum L.). British Journal of Nutrition, 108: S3-S10.

Dávalos, A., Gómez-Cordovés, C., Bartolomé, B. 2004. Extending applicability of the oxygen radical absorbance capacity (orac-luorescein) assay. Journal Agricultural Food Chemistry, 52: 48-54.

Davey, M.W., Montagu, M.V., Inzé, D., Sanmartin, M., Kanellis A., Smirnoff, N., Benzie, I. J.J., Strain, J.J., Favell, D., Fletcher, J. 2000. Plant L-ascorbic acid: chemistry, function, metabolism, bioavailability and effects of processing. Journal of the Science of Food Agriculture, 80: 825-860.

De Ancos, B., Cano, M.P., Hernandez, A., Monreal, M. 1999. Effects of microwave heating on pigment composition and colour of fruit purées. Journal of the Science of Food and Agriculture, 79(5): 663-670.

De Ancos, B., Fernández-Jalao, I., Sánchez-Moreno, C. 2016. Compuestos funcionales en productos de IV y V Gama. Revista Iberoamericana de Tecnología Postcosecha, 17(2): $130-148$.

Deka, D., Sit, N. 2016. Dual modification of taro starch by microwave and other heat moisture treatments. International Journal of Biological Macromolecules, 92:416-422.

Deng, Q., Zinoviadou, K.G., Galanakis, C.M., Orlien, V., Grimi, N., Vorobiev, E., Lebovka, N., Barba, F.J. 2015. The effects of conventional and non-conventional processing on glucosinolates and its derived forms, isothiocyanates: extraction, degradation, and applications. Food Engineering Reviews, 7(3): 357-381.

Deng, Y., Padilla-Zakour, O., Zhao, Y., Tao, S. 2015. Influences of high hydrostatic pressure, microwave heating, and boiling on chemical compositions, antinutritional factors, fatty acids, in vitro protein digestibility, and microstructure of buckwheat. Food and Bioprocess Technology, 8(11): 2235-2245.

Devasagayam, T.P.A., Tilak, J., Boloor, K.K., Sane, K.S., Ghaskadbi, S.S., Lele, R.D. 2004. Free radicals and antioxidants in human health: current status and future prospects. Journal of the Association of Physicians of India, 52: 794-804.

Díaz-Batalla, L., Widholm, J.M., Fahey, G.C., Castano-Tostado, E., Paredes-Lopez, O. 2006. Chemical components with health implications in wild and cultivated Mexican common bean seeds (Phaseolus vulgaris L.). Journal of Agricultural and Food Chemistry, 54(6): 2045-2052.

Díaz-Molins, P. 2009. Calidad y deterioro de platos sous vide preparados a base de carne y pescado y almacenados en refrigeración. Ph. D. Thesis. Universidad de Murcia, Murcia, Spain. 23-120. 
Dini, I., Tenore, G.C., Dini, A. 2013. Effect of industrial and domestic processing on antioxidant properties of pumpkin pulp. LWT - Food Science and Technology, 53(1): $382-385$.

Dixon, R. A., Paiva, N.L. 1995. Stress-induced phenylpropanoid metabolism. The Plant Cell, 7(7): 1085-1097.

Dosz, E.B., Jeffery, E.H. 2013a. Commercially produced frozen broccoli lacks the ability to form sulforaphane. Journal of Functional Foods, 5: 987-990.

Dosz, E.B., Jeffery, E.H. 2013b. Modifying the processing and handling of frozen broccoli for increased sulforaphane formation. Journal of Food Science, 78(9): 1459-1463.

Dosz, E.B., Ku, K.M., Juvik, J.A., Jeffery, E.H. 2014. Total myrosinase activity estimates in brassica vegetable produce. Journal of Agricultural and Food Chemistry, 62(32): 80948100.

Duc, G., Marget, P., Esnault, R., Guen, L. 1999. Genetic variability for feeding value of faba bean seeds (Vicia faba): Comparative chemical composition of isogenics involving zerotannin and zero-vicine genes. The Journal of Agricultural Science, 133: 185-196.

Dueñas, M., Estrella, I., Hernández, T. 2004. Occurrence of phenolic compounds in the seed coat and the cotyledon of peas (Pisum sativum L.). European Food Research and Technology, 219(2): 116-123.

Dueñas, M., Fernández, D., Hernández, T., Estrella, I., Muñoz, R. 2005. Bioactive phenolic compounds of cowpeas (Vigna sinensis L). Modifications by fermentation with natural microflora and with Lactobacillus plantarum ATCC 14917. Journal of the Science of Food and Agriculture, 85(2): 297-304.

EFSA. 2007. Opinion of the scientific panel on dietetic products, nutrition and allergies related to the safety of alpha-cyclodextrin. EFSA Journal 5:537-n/a.

Ehlers, J.D., Hall, A.E. 1996. Genotypic classification of cowpea based on responses to heat and photoperiod. Crop Science, 36(3): 673-679.

Eldridge, C.F., Bunge, M.B., Bunge, R. P. 1989. Differentiation of axon-related Schwann cells in vitro: II. Control of myelin formation by basal lamina. The Journal of Neuroscience : The Official Journal of the Society for Neuroscience, 9(2): 625-638.

Escobedo-Avellaneda, Z., Pateiro-Moure, M., Chotyakul, N., Torres, J.A., Welti-Chanes, J., Pérez-Lamela, C. 2011. Benefits and limitations of food processing by high-pressure technologies: Effects on functional compounds and abiotic contaminants. CYTA Journal of Food, 9(4): 351-364.

Espinosa-Muñoz, L., Symoneaux, R., Renard, C. M. C. G., Biau, N., Cuvelier, G. (2012). The significance of structural properties for the development of innovative apple puree textures. LWT - Food Science and Technology, 49: 221-228.

Fahey, J.W., Zalcmann, A.T., Talalay, P. 2001. The chemical diversity and distribution of glucosinolates and isothiocyanates among plants. Phytochemistry, 56(1): 5-51. 
Fahey, J.W., Wehage, S.L., Holtzclaw, W.D., Kensler, T.W., Egner, P.A., Shapiro, T.A., Talalay, P. 2012. Protection of humans by plant glucosinolates: Efficiency of conversion of glucosinolates to isothiocyanates by the gastrointestinal microflora. Cancer Prevention Research, 5: 603-611.

Fahey, J.W., Wade, K.L., Wehage, S.L., Holtzclaw, WD., Liu, H., Talalay, P., Fuchs, E., Stephenson, K.K. 2017. Stabilized sulforaphane for clinical use: Phytochemical delivery efficiency. Molecular Nutrition \& Food Research, 61: 1-10.

Faller, A.L.K., Fialho, E. 2010. Polyphenol content and antioxidant capacity in organic and conventional plant foods. Journal of Food Composition and Analysis, 23(6): 561-568.

FAOSTAT 2018. Production - Crops, pulses. https://goo.gl/ccjQUY. Acessed: February 2018.

Flores, P., Hellín, P., Fenoll, J. 2012. Determination of organic acids in fruits and vegetables by liquid chromatography with tandem-mass spectrometry. Food Chemistry, 132(2), 1049-1054.

Formica-Oliveira, A.C., Martínez-Hernández, G.B., Díaz-López, V., Artés, F., ArtésHernández, F. 2017. Use of postharvest UV-B and UV-C radiation treatments to revalorize broccoli byproducts and edible florets. Innovative Food Science \& Emerging Technologies, 43: 77-83.

Franklin, S.J., Dickinson, S.E., Karlage, K.L., Bowden, G.T., Myrdal, P.B. 2014. Stability of sulforaphane for topical formulation. Drug Development and Industrial Pharmacy, 40(4): 494-502.

Fratianni, F., Cardinale, F., Cozzolino, A., Granese, T., Albanese, D., Di Matteo, M., Zaccardelli, M., Coppola, R., Nazzaro, F. 2014. Polyphenol composition and antioxidant activity of different grass pea (Lathyrus sativus), lentils (Lens culinaris), and chickpea (Cicer arietinum) ecotypes of the Campania region (Southern Italy). Journal of Functional Foods, 7(1): 551-557.

Frota, K.M.G., Mendonça, S., Saldiva, P.H.N., Cruz, R.J., Arêas, J.A.G. 2008. Cholesterollowering properties of whole cowpea seed and its protein isolate in hamsters. Journal of Food Science, 73(9): 235-240.

Galazka, V.B., Sumner, I. G., Ledward, D.A. 1996. Changes in protein-protein and proteinpolysaccharide interactions induced by high pressure. Food Chemistry, 57(3): 393-398.

García-Parra, J., Contador, R., Delgado-Adámez, J., González-Cebrino, F., Ramírez, R. 2014. The applied pretreatment (blanching, ascorbic acid) at the manufacture process affects the quality of nectarine puree processed by hydrostatic high pressure. International Journal of Food Science Technology, 49: 1203-1214.

García-Parra, J., González-Cebrino, F., Delgado, J., Cava, R., Ramírez, R. 2016. High Pressure Assisted Thermal Processing of Pumpkin Purée: Effect on Microbial Counts, Color, Bioactive Compounds and Polyphenoloxidase Enzyme. Food and Bioproducts Processing, 98: 124-132. 
Gärtner, A., Wese, U. 1986. Molecular and functional aspects of superoxide dismutases. In: Vögtle, F., Weber, E. (Eds.). Biomimetic and Bioorganic Chemistry II. Vol. 132. Springer-Verlag, Berlin, Germany. 1-61.

Geveke, D.J., Aubuchon, I., Zhang, H.Q., Boyd, G., Sites, J.E., Bigley, A.B.W. 2015. Validation of a pulsed electric field process to pasteurize strawberry purée. Journal of Food Engineering, 166: 384-389.

Ghawi, S.K., Methven, L., Niranjan, K. 2013. The potential to intensify sulforaphane formation in cooked broccoli (Brassica oleracea var. italica) using mustard seeds (Sinapis alba). Food Chemistry, 138: 1734-1741.

Giusti, F., Caprioli, G., Ricciutelli, M., Vittori, S., Sagratini, G. 2017. Determination of fourteen polyphenols in pulses by high performance liquid chromatography-diode array detection (hplc-dad) and correlation study with antioxidant activity and colour. Food Chemistry, 221: 689-697.

Gonçalves, A., Goufo, P., Barros, A., Domínguez-Perles, R., Trindade, H., Rosa, E.A.S., Ferreira, L., Rodrigues, M. 2016. Cowpea (Vigna unguiculata L. Walp), a renewed multipurpose crop for a more sustainable agri-food system: Nutritional advantages and constraints. Journal of the Science of Food and Agriculture, 96(9): 2941-2951.

González-Cebrino, F., García-Parra, J., Contador, R., Tabla, R. Ramírez, R. 2012. Effect of high-pressure processing and thermal treatment on quality attributes and nutritional compounds of 'Songold' plum puree. Journal of Food Science, 77: C866-C873.

González-Fandos, E., García-Linares, M.C., Villarino-Rodríguez, A., García-Arias, M.T., García-Fernández, M.C. 2004. Evaluation of the microbiological safety and sensory quality of rainbow trout (Oncorhynchus mykiss) processed by the sous vide method. Food Microbiology, 21(2): 193-201.

González-Tejedor, G.A., Martínez-Hernández, G.B., Garre, A., Egea, J.A., Fernández, P.S., Artés-Hernández, F. 2017. Quality changes and shelf-life prediction of a fresh fruit and vegetable purple smoothie. Food and Bioprocess Technology, 10(10): 1905-1906.

Goyoaga, C., Burbano, C., Cuadrado, C., Romero, C., Guillamón, E., Varela, A., Pedrosa, M., Muzquiz, M. 2011. Content and distribution of protein, sugars and inositol phosphates during the germination and seedling growth of two cultivars of Vicia faba. Journal of Food Composition and Analysis, 24(3): 391-397.

Gross, G.G. 1985. Biosynthesis and metabolism of phenolic acids and monolignols. In Takayoshi Higuchi (Ed.), Biosynthesis and biodegradation of wood components, 229271.

Gross, K.C. 1892. A rapid and sensitive spectrophotometric method for assaying polygalacturonase using 2-cyanoacetamide. Journal of Horticultural Science, 17: 933934.

Gründemann, C., Huber, R. 2018. Chemoprevention with isothiocyanates - From bench to bedside. Cancer Letters, 414: 26-33. 
Guan, D., Chen, H., Ting, E. Y., Hoover, D. G. 2006. Inactivation of Staphylococcus aureus and Escherichia coli O157:H7 under isothermal-endpoint pressure conditions. Journal of Food Engineering, 77(3): 620-627.

Guo, Y., Bruno, R.S. 2015. Endogenous and exogenous mediators of quercetin bioavailability. Journal of Nutritional Biochemistry, 26(3): 201-210.

Gupta, P., Singh, R., Malhotra, S., Boora, K.S., Singal, H.R. 2010. Characterization of seed storage proteins in high protein genotypes of cowpea [Vigna unguiculata (L.) Walp]. Physiology and Molecular Biology of Plants: An International Journal of Functional Plant Biology, 16(1): 53-8.

Gupta, P., Kim, B., Kim, S.H., Srivastava, S.K. 2014. Molecular targets of isothiocyanates in cancer: Recent advances. Molecular Nutrition and Food Research, 58(8): 1685-1707.

Guzmán, G.R., Dorantes, A.L., Hernández, U.H., Hernández, S.H., Ortíz, A., Mora, E.R. 2002. Effect of zinc and copper chloride on the color of avocado puree heated with microwaves. Innovative Food Science \& Emerging Technologies, 3(1): 47-53.

Ha, T.J., Lee, B.W., Park, K.H., Jeong, S.H., Kim, H.T., Ko, J.M., Baek, I.Y., Lee, J.H. 2014. Rapid characterisation and comparison of saponin profiles in the seeds of Korean Leguminous species using ultra performance liquid chromatography with photodiode array detector and electrospray ionisation/mass spectrometry (UPLC-PDA-ESI/MS) analysis. Food Chemistry, 146: 270-277.

Hahn, C., Müller, A., Kuhnert, N., Albach, D. 2016. Diversity of kale (brassica oleracea var. sabellica): glucosinolate content and phylogenetic relationships. Journal of Agricultural and Food Chemistry, 64(16):3215-3225.

Hanschen, F.S., Lamy, E., Schreiner, M., Rohn, S. 2014. Reactivity and stability of glucosinolates and their breakdown products in foods. Angewandte Chemie International Edition, 53(43): 11430-11450.

Hanschen, F.S., Klopsch, R., Oliviero, T., Schreiner, M., Verkerk, R., Dekker, M. 2017. Optimizing isothiocyanate formation during enzymatic glucosinolate breakdown by adjusting $\mathrm{pH}$ value, temperature \& dilution in Brassica vegetables \& Arabidopsis thaliana. Scientific Reports, 7: 1-15.

Hayes, J.D., Kelleher, M.O., Eggleston, I.M. 2008. The cancer chemopreventive actions of phytochemicals derived from glucosinolates. European Journal of Nutrition, 47(SUPPL. 2): $73-88$.

Hayman, M.M., Anantheswaran, R.C., Knabel, S.J. 2007. The effects of growth temperature and growth phase on the inactivation of Listeria monocytogenes in whole milk subject to high pressure processing. International Journal of Food Microbiology, 115(2): 220-226.

Hedley, C. 2001. Carbohydrates in grain legume seeds. improving nutritional quality and agronomic characteristics. CABI Publishing, Wallingford, UK. 
Hefni, M.E., Shalaby, M.T., Witthöft, C.M. 2015. Folate content in faba beans (Vicia faba L.) -effects of cultivar, maturity stage, industrial processing, and bioprocessing. Food Science \& Nutrition, 3(1): 65-73.

Hefni, M., Witthöft, C.M. 2014. Folate content in processed legume foods commonly consumed in Egypt. LWT - Food Science and Technology, 57(1): 337-343.

Heinz, V., Buckow, R. 2010. Food preservation by high pressure. Journal Für Verbraucherschutz Und Lebensmittelsicherheit, 5(1): 73-81.

Heleno, S.A., Ferreira, I.C.F.R., Calhelha, R.C., Esteves, A.P., Martins, A., Queiroz, M.J.R. P. 2014. Cytotoxicity of Coprinopsis atramentaria extract, organic acids and their synthesized methylated and glucuronate derivatives. Food Research International, 55: $170-175$.

Heleno, S.A., Martins, A., Queiroz, M.J.R.P., Ferreira, I.C.F.R. 2015. Bioactivity of phenolic acids: Metabolites versus parent compounds: A review. Food Chemistry, 173: 501-513.

Hendrickx, M., Ludikhuyze, L., Van den Broeck, I., Weemaes, C. 1998. Effects of high pressure on enzymes related to food quality. Trends in Food Science and Technology, 9(5): 197-203.

Hill, A. 1998. Microwave ovens. ILSI Europe Microwave Oven Task Force. Brussels, Belgium.

Hirayama, F., Uekama, K. 1999. Cyclodextrin-based controlled drug release system. Advanced Drug Delivery Reviews, 36: 125-141.

Hirsch, D., Tene, O. 2013. Hummus: the making of an Israeli culinary cult. Journal of Consumer Culture, 13(1): 25-45.

Ho, Y.S., Magnenat, J.L., Gargano, M., Cao, J. 1998. The nature of antioxidant defense mechanisms: A lesson from transgenic studies. Environmental Health Perspectives, 106(SUPPL. 5): 1219-1228.

Holst, B., Williamson, G. 2004. A critical review of the bioavailability of glucosinolates and related compounds. Natural Product Reports, 21(3): 425-447

Hoogenboom, R., Wilms, T.F.A., Erdmenger, T., Schubert, U.S. 2009. Microwave-assisted chemistry: A closer look at heating efficiency. Australian Journal of Chemistry, 62(3): 236-243.

Hooper, L., Cassidy, A. 2006. A review of the health care potential of bioactive compounds. Journal of the Science of Food and Agriculture, 86: 1805-1813.

Hu, X., Wei, B., Li, H., Wu, C., Bai, Y., Xu, X., Jin, Z., Tian, Y. 2012. Preparation of the $\beta-$ cyclodextrin-vitamin $\mathrm{C}(\beta-\mathrm{CD}-\mathrm{Vc})$ inclusion complex under high hydrostatic pressure (HHP). Carbohydrate Polymers, 90: 1193-1196.

Hurtado, A., Guàrdia, M.D., Picouet, P., Jofré, A., Ros, J.M., Bañón, S. 2017. Stabilization of red fruit-based smoothies by high-pressure processing. Part A. Effects on microbial 
growth, enzyme activity, antioxidant capacity and physical stability. Journal of the Science of Food and Agriculture, 97(3): 770-776.

Ibarra, I.A.M. 2017. Caracterización de la esferificación funcional de alginato, goma xantana y pulpa de guanábana. Tesis. Universidad Autónoma Agraria Antonio Narro, Coahuila, México, p.53.

Iborra-Bernad, C., Philippon, D., García-Segovia, P., Martínez-Monzó, J. 2013. Optimizing the texture and color of sous-vide and cook-vide green bean pods. LWT - Food Science and Technology, 51(2): 507-513.

Iborra-Bernad, C., García-Segovia, P., Martínez-Monzó, J. 2015. Physico-chemical and structural characteristics of vegetables cooked under sous-vide, cook-vide, and conventional boiling. Journal of Food Science, 80(8): E1725-E1734.

Icier, F., Yildiz, H., Baysal, T. 2006. Peroxidase inactivation and colour changes during ohmic blanching of pea puree. Journal of Food Engineering, 74:424-429.

ICNIRP. 1998. Guidelines on limits of exposure to time-varying electric, magnetic and electromagnetic fields (up to $300 \mathrm{GHz}$ ). Health Physics, 74:494-522

Ihl, M., Monslaves, M., Bifani, V. 1998. Chlorophyllase inactivation as a measure of blanching eficacy and colour retention of artichokes (Cynara scolymus L.). LebensmittelWissenschaft-und-Technologie, 31: 50-56.

Ikegwu, O.J., Okechukwu, P.E., Ekumankama, E.O., Okorie, P.A., Odo, M.O. 2013. Modelling the effect of toasting time on the functional properties of Brachystegia eurycoma flour. Nigerian Food Journal, 31: 108-114

Iqbal, A., Khalil, I.A., Ateeq, N., Sayyar-Khan, M. 2006. Nutritional quality of important food legumes. Food Chemistry, 97(2): 331-335.

IRPA. 1988. Guidelines on limits of exposure to radiofrequency electromagnetic fields in the frequency range from $100 \mathrm{kHz}$ to $300 \mathrm{GHz}$. Health Physics, 54 (1): 115-123.

ISO 2007. Sensory analysis-general guidance for the design of test rooms. In ISO (Ed.), (Vol. 8589:2007). ISO

ISO 2012. Sensory analysis -- General guidelines for the selection, training and monitoring of selected assessors and expert sensory assessors. In I. O. f. S. (ISO) (Ed.), 8586:2012. Geneva.

Itoh, A., Isoda, K., Kondoh, M., Kawase, M., Watari, A., Kobayashi, M., Tamesada, M., Yage, K. 2010. Hepatoprotective effect of syringic acid and vanillic acid on ccl 4 induced liver injury. Biological \& Pharmaceutical Bulletin, 33(6): 983-987.

Jacobo-Velázquez, D. A., Hernández-Brenes, C. 2010. Biochemical changes during the storage of high hydrostatic pressure processed avocado paste. Journal of Food Science, 6: 264-270.

Javier, G.S., de los Reyes, R., Jara, A., de los Reyes, E. 2015. Microwave energy transduction using planar technology. Electronics Letters, 51(6): 499-501. 
JECFA. beta-cyclodextrin. Evaluations of the Joint FAO/WHO Expert Committee on Food Additives (JECFA). Available online at: http://apps.who.int/food-additives-contaminants jecfa database/chemical.aspx?chemID=2066 [05 March 2018].

Jeffery, E.H., Brown, A.F., Kurilich, A.C., Keck, A.S., Matusheski, N., Klein, B.P., Juvik, J. A. 2003. Variation in content of bioactive components in broccoli. Journal of Food Composition and Analysis, 16(3): 323-330.

Jin, Y., Wang, M., Rosen, R.T., Ho, C.T. 1999. Thermal degradation of sulforaphane in aqueous solution. Journal of Agricultural and Food Chemistry, 47: 3121-3123.

Juge, N., Mithen, R.F., Traka, M. 2007. Molecular basis for chemoprevention by sulforaphane: a comprehensive review. Cellular and Molecular Life Sciences, 64: 1105.

Jukanti, A.K., Gaur, P.M., Gowda, C.L., Chibbar, R.N. 2012. Nutritional quality and health benefits of chickpea (Cicer arietinum L.): A review. British Journal of Nutrition, 108: S11-26.

Kaur, M., Velmurugan, B., Rajamanickam, S., Agarwal, R., Agarwal, C. 2009. Gallic acid, an active constituent of grape seed extract, exhibits anti-proliferative, pro-apoptotic and antitumorigenic effects against prostate carcinoma xenograft growth in nude mice. Pharmaceutical Research, 26(9): 2133-2140.

Khayat, S., Fanaei, H., Ghanbarzehi, A. 2017. Minerals in pregnancy and lactation: A review article. Journal of Clinical and Diagnostic Research, 11(9): QE01-QE05.

Kiddle, G., Bennett, R.N., Botting, N.P., Davidson, N.E., Robertson, A.A.B., Wallsgrove, R. M. 2001. High-performance liquid chromatographic separation of natural and synthetic desulphoglucosinolates and their chemical validation by UV, NMR and chemical ionisation-MS methods. Phytochemical Analysis, 12(4): 226-242.

Kim, S.H., Yu, B.R., Chung, I. M. 2015. Changes in the contents and profiles of selected phenolics, soyasapogenols, tocopherols, and amino acids during soybean-rice mixture cooking: Electric rice cooker vs electric pressure rice cooker. Food Chemistry, 176(0): $45-53$.

Kirse, A., Karklina, D., Muizniece-brasava, S., Galoburda, R. 2016. Physicochemical stability of pulse spreads during storage after sous vide treatment and high pressure processing, 10: 809-813.

Kirse, A., Galoburda, R., Muizniece-Brasava, S., Karklina, D., Skudra, L. 2017. Improvement of microbiological safety and shelf-life of pulse spreads through sous vide and high pressure processing. Agronomy Research, 15: 1304-1315.

Klug, T.V., Martínez-Sánchez, A., Gómez P., Collado, E., Aguayo E., Artés F., ArtésHernández F. 2017. Improving quality of an innovative pea puree by high hydrostatic pressure. Journal of the Science of Food and Agriculture, 97(13): 4362-4369.

Klug, T.V., Collado, E., Martínez-Sánchez, A., Gómez, P. A., Aguayo, E., Otón, M., Artés, F., Artés-Hernandez, F. 2018. Innovative quality improvement by continuous microwave processing of a Faba beans pesto sauce. Food and Bioprocess Technology, 11: 561-571. 
Klug, T. V., Martínez-Hernández, G. B., Collado, E., Artés, F., \& Artés-Hernández, F. (2018b). Effect of microwave and high pressure processing on quality of an innovative broccoli hummus. Food and Bioprocess Technology, In Press, doi:10.1007/s11947-0182111-8.

Koç, M., Baysan, U., Devseren, E., Okut, D., Atak, Z., Karataş, H., Kaymak-Ertekin, F. 2017. Effects of different cooking methods on the chemical and physical properties of carrots and green peas. Innovative Food Science and Emerging Technologies, 42: 109-119.

Kocot, J., Luchowska-Kocot, D., Kiełczykowska, M., Musik, I., Kurzepa, J. 2017. Does vitamin $\mathrm{C}$ influence neurodegenerative diseases and psychiatric disorders? Nutrients, 9(7): 1-29.

Koh, E., Wimalasiri, K.M.S., Chassy, A.W., Mitchell, A.E. 2009. Content of ascorbic acid, quercetin, kaempferol and total phenolics in commercial broccoli. Journal of Food Composition and Analysis, 22(7-8): 637-643.

Korus, A. 2011. Effect of preliminary processing, method of drying and storage temperature on the level of antioxidants in kale (Brassica oleracea L. var. acephala) leaves. LWT Food Science and Technology, 44(8): 1711-1716.

Korus, A., Słupski, J., Gębczyński, P., Banaś, A. 2014. Effect of preliminary processing and method of preservation on the content of glucosinolates in kale (Brassica oleracea L. var. acephala) leaves. LWT - Food Science and Technology, 59: 1003-1008.

Kratz, J.M., Andrighetti-Frohner, C.R., Leal, P.C., Nunes, R.J., Yunes, R.A., Trybala, E. 2008. Evaluation of anti-HSV-2 activity of gallic acid and pentyl gallate. Biological and Pharmaceutical Bulletin, 31: 903-907.

Krebbers, B., Matser, A.M., Hoogerwerf, S.W., Moezelaar, R., Tomassen, M.M.M., Van der Berg, R.W. 2003. Combined high-pressure and thermal treatments for processing of puree: evaluation of microbial inactivation and quality parameters. Innovative Food Science and Emerging Technology, 4: 377-385.

Krishnaswamy, K., Orsat, V., Gariépy, Y., Thangavel, K. 2013. Optimization of microwaveassisted extraction of phenolic antioxidants from grape seeds (Vitis vinifera). Food and Bioprocess Technology, 6(2): 441-455.

Lamy, E., Scholtes, C., Herz, C., Mersch-Sundermann, V. 2011. Pharmacokinetics and pharmacodynamics of isothiocyanates. Drug Metabolism Reviews, 43(3): 387-407.

Landl, A., Abadias, M., Sárraga, C., Viñas, I., Picouet, P.A. 2010. Effect of high pressure processing on the quality of acidified Granny Smith apple purée product. Innovative Food Science and Emerging Technologies, 11(4): 557-564.

Lee, P., Rogers, M. A. 2012. Effect of calcium source and exposure-time on basic caviar spherification using sodium alginate. International Journal of Gastronomy and Food Science, 1(2): 96-100. 
Leite, T.S., de Jesus, A.L.T., Schmiele, M., Tribst, A.A.L., Cristianini, M. 2017. High pressure processing (HPP) of pea starch: Effect on the gelatinization properties. LWT Food Science and Technology, 76: 361-369.

Lima, A.I.G., Mota, J., Monteiro, S.A.V.S., Ferreira, R.M.S.B. 2016. Legume seeds and colorectal cancer revisited: Protease inhibitors reduce MMP-9 activity and colon cancer cell migration. Food Chemistry, 197: 30-38.

Linert, W., Margl, P., Renz, F. 1992. Solute-solvent interactions between cyclodextrin and water: a molecular mechanical study. Chemical Physics, 161: 327-338.

Linsberger-Martin, G., Weiglhofer, K., Phuong, T.P.T., Berghofer, E. 2013. High hydrostatic pressure influences antinutritional factors and in vitro protein digestibility of split peas and whole white beans. LWT - Food Science and Technology, 51(1): 331-336.

Lisiewska, Z., Kmiecik, W., Gebczynski, P. 1999. Effect of cultivar and seed maturity on amino acid content in fresh and canned broad bean (Vicia faba v. major). Molecular Nutrition \& Food Research, 43: 95-99.

Lisiewska, Z., Kmiecik, W., Słupski, J. 2004. Contents of chlorophylls and carotenoids in frozen dill: effect of usable part and pre-treatment on the content of chlorophylls and carotenoids in frozen dill (Anethum graveolens L.), depending on the time and temperature of storage. Food Chemistry, 84(4): 511-518.

Liu, F., Wang, Y., Bi, X., Guo, X., Fu, S., Liao, X. 2013. Comparison of microbial inactivation and rheological characteristics of mango pulp after high hydrostatic pressure treatment and high temperature short time treatment. Food and Bioprocess Technology, 6(10):2675-2684.

Liu-Smith, F., Meyskens, F. L. 2016. Molecular mechanisms of flavonoids in melanin synthesis and the potential for the prevention and treatment of melanoma. Molecular Nutrition and Food Research, 60(6): 1264-1274.

Llorach, R., Gil-Izquierdo, A., Ferreres, F., Tomás-Barberán, F.A. 2003. HPLC-DADMS/MS ESI Characterization of unusual highly glycosylated acylated flavonoids from cauliflower (brassica oleracea 1. var. botrytis) agroindustrial byproducts. Journal of Agricultural and Food Chemistry, 51(13): 3895-3899.

Llorach, R., Martínez-Sánchez, A., Tomás-Barberán, F.A., Gil, M.I., Ferreres, F. 2008. Characterisation of polyphenols and antioxidant properties of five lettuce varieties and escarole. Food Chemistry, 108(3): 1028-1038.

López-Nicolás, J.M., Bru, R., Sánchez-Ferrer, A., García-Carmona, F. 1995. Use of 'soluble lipids' for biochemical processes: linoleic acid-cyclodextrin inclusion complexes in aqueous solutions. Biochemical Journal, 308: 151-154.

López-Nicolás, J.M., Núñez-Delicado, E., Sánchez-Ferrer, A., García-Carmona, F. 2007a. Kinetic model of apple juice enzymatic browning in the presence of cyclodextrins: the use of maltosyl- $\beta$-cyclodextrin as secondary antioxidant. Food Chemistry, 101: 11641171. 
López-Nicolás, J.M., Pérez-López, A.J., Carbonell-Barrachina, A., García-Carmona, F. 2007b. Kinetic study of the activation of banana juice enzymatic browning by the addition of maltosyl-beta-cyclodextrin. Journal of Agricultural and Food Chemistry, 55: 9655-9662.

López-Nicolás, J.M., Pérez-López, A.J., Carbonell-Barrachina, Á., García-Carmona, F. 2007c. Use of natural and modified cyclodextrins as inhibiting agents of peach juice enzymatic browning. Journal of Agricultural and Food Chemistry, 55(13): 5312-5319.

López-Sánchez, P., Nijsse, J., Blonk, H.C.G., Bialek, L., Schumm, S., Langton, M. 2011. Effect of mechanical and thermal treatments on the microstructure and rheological properties of carrot, broccoli and tomato dispersions. Journal of the Science of Food and Agriculture, 91: 207-217.

López-Sánchez. P. 2011. Microstructure and rheological properties of plant particle suspensions prepared using different physical treatments. PhD thesis, Department of Chemical and Biological Engineering, Chalmers University of Technology, Göteborg, Sweden.

López-Sánchez, P., Chapara, V., Schumm, S. Farr, R. 2012. Shear elastic deformation and particle packing in plant cell dispersions. Food Biophysics, 7: 1-14

Lorenzo, J.M., Munekata, P.E., Dominguez, R., Pateiro, M., Saraiva, J.A., Franco, D. 2018. Main groups of microorganisms of relevance for food safety and stability. Innovative Technologies for Food Preservation, 3: 53-107.

MAGRAMA. 2017. Informe del consumo de alimentación en España. Ministerio de Agricultura y Pesca, Alimentación y Medio Ambiente. Madrid, Spain. http://www.mapama.gob.es/es/ Accessed on May 2018.

Magrath, R., Herron, C., Giamoustaris, A., Mithen, R. 1993. The inheritance of aliphatic glucosinolates in brassica napus. Plant Breeding, 111(1): 55-72.

Marszalek, K., Mitek, M., Skapska. S. 2015. Effect of continuous flow microwave and conventional heating on the bioactive compounds, color, enzyme activity, microbial and sensory quality of strawberry puree. Food and Bioprocess Technology, 8(9): 1864-1876.

Marszalek, K., Woźniak, L., Skąpska, S., Mitek, M. 2016. A comparative study of the quality of strawberry purée preserved by continuous microwave heating and conventional thermal pasteurization during long-term cold storage. Food and Bioprocess Technology, 9(7): 1100-1112.

Martínez-Hernández, G.B., Gómez, P.A., Pradas, I., Artés, F., Artés-Hernández, F. 2011. Moderate UV-C pretreatment as a quality enhancement tool in fresh-cut Bimi broccoli. Postharvest Biology and Technology, 62(3): 327-337.

Martínez-Hernández, G.B., Artés-Hernández, F., Colares-Souza, F., Gómez, P.A., GarcíaGómez, P., Artés, F. 2013a. Innovative Cooking Techniques for Improving the Overall Quality of a Kailan-Hybrid Broccoli. Food and Bioprocess Technology, 6(8): 2135-2149. 
Martínez-Hernández, G.B., Artés-Hernández, F., Gómez, P.A., Artés, F. 2013b. Comparative behaviour between kailan-hybrid and conventional fresh-cut broccoli throughout shelflife. LWT- Food Science and Technology, 50(1): 298-305.

Martínez-Hernández, G.B., Artés-Hernández, F., Gómez, P.A., Artés, F. 2013c. Induced changes in bioactive compounds of kailan-hybrid broccoli after innovative processing and storage. Journal of Functional Foods, 5(1): 133-143.

Martínez-Hernández, G.B., Artés-Hernández, F., Gómez, P.A., Formica, A.C., Artés, F. 2013d. Combination of electrolysed water, UV-C and superatmospheric $\mathrm{O}_{2}$ packaging for improving fresh-cut broccoli quality. Postharvest Biology and Technology, 76: 125-134.

Martínez-Hernández, G.B., Gómez, P.A., Artés, F., Artés-Hernández, F. 2015. Nutritional quality changes throughout shelf-life of fresh-cut kailan-hybrid and 'Parthenon' broccoli as affected by temperature and atmosphere composition. Food Science and Technology International, 21(1): 14-23.

Martínez-Hernández, G.B., Perla A.G., Artés-Hernández, F., Artés, F. 2016. Innovative industrial cooking of broccoli for improving health-promoting compounds. Broccoli: Cultivation, Nutritional Properties and Effects on Health. In: Nova Science Publishers, editor. pp. 299-334.

Martínez-Hernández, G.B., Amodio, M.L., Colelli, G. 2017. Carvacrol-loaded chitosan nanoparticles maintain quality of fresh-cut carrots. Innovative Food and Science Emerging Technologies, 41: 56-63.

Martinsen, A., Skjåk-Bræk, G., Smidsrød, O. 1989. Alginate as immobilization material: I. Correlation between chemical and physical properties of alginate gel beads. Biotechnology and Bioengineering, 33(1): 79-89.

Martos-Fuentes, M.M. 2017. Genotyping, phenotyping and transcriptomic analysis of accessions of Vicia faba, Pisum sativum and Vigna unguiculata. $\mathrm{PhD}$ thesis, Institute of Plant Biotechnology. Universidad Politécnica de Cartagena, Cartagena, Spain.

Martos-Fuentes, M, Sánchea-Navarro V, Ruiz-Hérnandez M.V, Weiss J., Egea-Gilabert, C., Zornoza, R., Faz, A., Fernández, J.A., Egea-Cortines, M. 2015. Genetic and growth conditions determine the protein content in cowpea (Vigna unguiculata). In Eucarpia International Symposium on Protein Plants, 143-144.

Matusheski, N.V., Juvik, J.A., Jeffery, E.H. 2004. Heating decreases epithiospecifier protein activity and increases sulforaphane formation in broccoli. Phytochemistry 65:1273-1281.

Matusheski, N.V., Jeffery, E.H. 2001. Comparison of the bioactivity of two glucoraphanin hydrolysis products found in broccoli, sulforaphane and sulforaphane nitrile. Journal of Agricultural and Food Chemistry, 49: 5743-5749.

McCord, J. M. 2000. The evolution of free radicals and oxidative stress. American Journal of Medicine, 108(8): 652-659.

McCrory, M.A., Hamaker, B.R., Lovejoy, J.C., Eichelsdoerfer, P.E. 2010. Pulse consumption, satiety, and weight management. Advances in Nutrition, 1: 17-30. 
McKenna, B.A., Nicholson, T.M., Wehr, J.B., Menzies, N.W. 2010. Effects of $\mathrm{Ca}, \mathrm{Cu}, \mathrm{Al}$ and La on pectin gel strength: implications for plant cell walls. Carbohydrate Research, 345(9): 1174-1179.

Meda, V., Orsat, V., Raghavan, V. 2016. Microwave heating and the dielectric properties of foods. The Microwave Processing of Foods: Second Edition (Second Edi). Elsevier.

Medina-Meza, I.G., Barnaba, C., Villani, F., Barbosa-Cánovas, G.V. 2015. Effects of thermal and high pressure treatments in color and chemical attributes of an oil-based spinach sauce. LWT - Food Science and Technology, 60: 86-94.

Megeji, N.W., Kumar, J.K., Singh, V., Kaul, V.K., Ahuja, P.S. 2005. Introducing Stevia rebaudiana, a natural zero-calorie sweetener. Current Science, 88(5): 801-804.

Mercali, G.D., Gurak, P.D., Schmitz, F., Marczak, L.D.F. 2015. Evaluation of non-thermal effects of electricity on anthocyanin degradation during ohmic heating of jaboticaba (Myrciaria cauliflora) juice. Food Chemistry, 171: 200-205.

Mintel. 2010. Prepared meals. London, UK: Mintel Reports.

Mitchell, D.C., Lawrence, F.R., Hartman, T.J. 2009. Consumption of dry beans, peas, and lentils could improve diet quality in the U.S. population. Journal of the American Dietetic Association, 109: 909-1013.

Moelants, K.R.N., Cardinaels, R., Jolie, R.P., Verrijssen, T.A.J., Buggenhout, S.V., Zumalacarregui, L.M., Loey, A.M.V., Moldenaers, P., Hendrickx, M.E. 2013. Relation between particle properties and rheological characteristics of carrot-derived suspensions. Food and Bioprocess Technology, 6: 1127-1143.

Morales-de la Peña, M., Elez-Martínez, P., Martín-Belloso, O. 2011. Food preservation by pulsed electric fields: an engineering perspective. Food Engineering Reviews, 3(2): 94107.

Moreira-Araújo, R.S. Sampaio, G.R., Soares, R.A.M., Silva, C.P., Arêas, J.A.G. 2017. Identification and quantification of antioxidant compounds in cowpea. Revista Ciência Agronômica, 48(5): 799-805.

Mukhopadhyay, S., Sokorai, K., Ukuku, D., Fan, X., Juneja, V. 2017. Effect of high hydrostatic pressure processing on the background microbial loads and quality of cantaloupe puree. Food Research International, 91:55-62.

Munday, R., Munday, C. M. 2004. Induction of phase ii detoxification enzymes in rats by plant-derived isothiocyanates: comparison of allyl isothiocyanate with sulforaphane and related compounds. Journal of Agricultural and Food Chemistry, 52(7): 1867-1871.

Munyaka, A.W., Makule, E.E., Oey, I., Loey, A.V., Hendrickx, M. 2010. Thermal stability of l-ascorbic acid and ascorbic acid oxidase in broccoli (brassica oleracea var. italica). Journal of Food Science, 75(4): 336-340.

Murcia, M.A., López, A.B., Martínez, T.M., García, C.F. 2000. Effect of industrial processing on chlorophyll content of broccoli. Journal of the Science of Food and Agriculture, 80(10): 1447-1451. 
Muzquiz, M., Varela, A., Burbano, C., Cuadrado, C., Guillamón, E., Pedrosa, M.M. 2012. Bioactive compounds in legumes: Pronutritive and antinutritive actions. implications for nutrition and health. Phytochemistry Reviews, 11(2-3): 227-244.

Neeto, H., Chen, H. 2014. Alternative food processing technologies, in Food Processing: Principles and Applications, ed. by Clark S, Jung S and Lamsal B. Wiley, Hoboken, NJ,. 137-169.

Norton, T., Sun, D.W. 2008. Recent advances in the use of high pressure as an effective processing technique in the food industry. Food and Bioprocess Technology, 1(1): 2-34.

Ntatsi, G., Gutiérrez-Cortines, M.E., Karapanosa, I., Barros, A., Weiss , J., Balliu , A., Rosa, E. A. S., Savvas, D. 2018. The quality of leguminous vegetables as influenced by preharvest factors. Scientia Horticulturae, 232: 191-205.

O’Neil, C.E., Nicklas, T.A., \& Fulgoni III, V.L. 2014. Chickpeas and hummus are associated with better nutrient intake, diet quality, and levels of some cardiovascular risk factors: national health and nutrition examination survey 2003-2010. Nutrition \& Food Sciences, 4(1): $1-8$.

Oey, I., Lille, M., Van Loey, A., Hendrickx, M. 2008. Effect of high-pressure processing on colour, texture and flavour of fruit- and vegetable-based food products: a review. Trends in Food Science and Technology, 19(6): 320-328.

Ojwang, L. O., Yang, L., Dykes, L., Awika, J. 2013. Proanthocyanidin profile of cowpea (Vigna unguiculata) reveals catechin-O-glucoside as the dominant compound. Food Chemistry, 139(1-4): 35-43.

Oliviero, T., Verkerk, R., Van Boekel, M.A., Dekker M. 2014. Effect of water content and temperature on inactivation kinetics of myrosinase in broccoli (Brassica oleracea var. italica). Food Chemistry, 163:197-201.

Ölmez, H., Kretzschmar, U. 2009. Potential alternative disinfection methods for organic fresh-cut industry for minimizing water consumption and environmental impact. LWT Food Science and Technology, 42(3): 686-693.

Olsen, H., Aaby, K., Borge, G .I.A. 2009. Characterization and quantification of flavonoids and hydroxycinnamic acids in curly kale (brassica oleracea 1. convar. acephala var. sabellica) by hplc-dad-esi-msn. Journal of Agricultural and Food Chemistry, 57: 28162825.

Opazo-Navarrete, M., Tabilo-Munizaga, G., Vega-Gálvez, A., Miranda, M., Pérez-Won, M. 2012. Effects of high hydrostatic pressure (HHP) on the rheological properties of Aloe vera suspensions (Aloe barbadensis Miller). Innovative Food Science and Emerging Technologies, 16: 243-250.

Oroian, M., Escriche, I. 2015. Antioxidants: characterization, natural sources, extraction and analysis. Food Research International, 74: 10-36. 
Orsat, V., Raghavan, G.S.V., Krishnaswamy, K. 2016. Microwave technology for food processing: An overview of current and future applications. The Microwave Processing of Foods. Second Edition . Elsevier Ltd.

Ortega-Anta, R., López-Sobaler, A., Andrés-Carvajales, P., Requejo-Marcos, A., AparicioVizuete, A., Molinero- Casares, L. 2008. Programa para evaluación de dietas y gestión de datos de alimentación DIAL $1.0^{\circledR}$. Madrid, Spain. ALCE Ingeniería.

Ortíz-Viedma, J., Romero, N., Puente, L., Burgos, K., Toro, M., Ramírez, L., Rodriguez, A., Barros-Velazquez, J., Aubourg, S.P. 2017. Antioxidant and antimicrobial effects of stevia (Stevia rebaudiana Bert.) extracts during preservation of refrigerated salmon paste. European Journal of Lipid Science and Technology, 119(10): 1600467.

Oszmianski, J., Wolniak, M., Wojdyło, A., Wawer, I. 2008. Influence of apple puree preparation and storage on polyphenol contents and antioxidant activity. Food Chemistry, 107(4): 1473-1484.

Paciulli, M., Medina-Meza, I. G., Chiavaro, E., Barbosa-Cánovas, G.V. 2016. Impact of thermal and high pressure processing on quality parameters of beetroot (Beta Vulgaris L.). LWT - Food Science and Technology, 68: 98-104.

Palafox-Carlos, H., Ayala-Zavala, J.F., González-Aguilar. G.A. 2011. The role of dietary fiber in the bioaccessibility and bioavailability of fruit and vegetable antioxidants. Journal of Food Science, 76(1): 6-15.

Parmar, N., Singh, N., Kaur, A., Virdi, A.S., Thakur, S. 2016. Effect of canning on color, protein and phenolic profile of grains from kidney bean, field pea and chickpea. Food Research International, 89: 504-513.

Parolini, C., Manzini, S., Busnelli, M., Rigamonti, E., Marchesi, M., Diani, E., Sirtori, C.R., Chiesa, G. 2013. Effect of the combinations between pea proteins and soluble fibres on cholesterolaemia and cholesterol metabolism in rats. British Journal of Nutrition, 110: 1394-1401.

Pathare, P.B., Opara, U L., Al-Said, F.A.J. 2013. Colour measurement and analysis in fresh and processed foods: A review. Food and Bioprocess Technology, 6(1): 36-60.

Patras, A., Brunton, N.P., Da Pieve, S., Butler, F. 2009. Impact of high pressure processing on total antioxidant activity, phenolic, ascorbic acid, anthocyanin content and colour of strawberry and blackberry purées. Innovative Food Science and Emerging Technologies, 10(3): 308-313.

Patras, A., Brunton, N., Da Pieve, S., Butler, F., Downey, G. 2009. Effect of thermal and high pressure processing on antioxidant activity and instrumental colour of tomato and carrot purées. Innovative Food Science and Emerging Technologies, 10(1): 16-22.

Patrick, J.W., Stoddard, F.L. 2010. Physiology of flowering and grain filling in faba bean. Field Crops Research, 115(3): 234-242. 
Petzold, G., Caro, M., Moreno, J. 2014. Influence of blanching, freezing and frozen storage on physicochemical properties of broad beans (Vicia faba L). International Journal of Refrigeration, 40: 429-434.

Pham-Huy, L.A., He, H., Pham-Huy, C. 2008. Free radicals, antioxidants in disease and health. International Journal of Biomedical Science , 4(2): 89-96.

Piazzon, A., Vrhovsek, U., Masuero, D., Mattivi, F., Mandoj, F., Nardini, M. 2012. Antioxidant activity of phenolic acids and their metabolites: Synthesis and antioxidant properties of the sulfate derivatives of ferulic and caffeic acids and of the acyl glucuronide of ferulic acid. Journal of Agricultural and Food Chemistry, 60(50): 1231212323.

Picouet, P.A., Landl, A., Abadías, M., Castellari, M., Viñas, I. 2009. Minimal processing of a Granny Smith apple purée by microwave heating. Innovative Food Science \& Emerging Technologies, 10(4): 545-550..

Piteira, M.F., Maia, J.M., Raymundo, A., Sousa, I. 2006. Extensional flow behaviour of natural fibre-filled dough and its relationship with structure and properties. Journal of Non-Newtonian Fluid Mechanics, 137: 72-80.

Plaza-González, P., Monzó-Cabrera, J., Catalá-Civera, J. M., Sánchez-Hernández, D. 2005. Effect of mode-stirrer configurations on dielectric heating performance in multimode microwave applicators. IEEE Transactions on Microwave Theory and Techniques, 53(5): 1699-1705.

Polydera, A.C., Stoforos, N.G., Taoukis, P.S. 2005. Quality degradation kinetics of pasteurised and high pressure processed fresh Navel orange juice: Nutritional parameters and shelf life. Innovative Food Science and Emerging Technologies, 6: 1-9.

Price, M.L., Scoyoc, S.V., Butler, L. 1978. A critical evaluation of the vanillin reaction as an assay for tannin on sorghum grain. Journal of Agricultural and Food Chemistry, 26(5): 1214-1218.

Prior, R.L., Cao, G., Martin, A., Sofic, E., McEwen, J., O’Brien, C., Lischner, N., Ehlenfeldt, M., Kalt, W., Krewer, G., Mainland, C.M. 1998. Antioxidant capacity as influenced by total phenolic and anthocyanin content, maturity, and variety of vaccinium species. Journal of Agricultural and Food Chemistry, 46(7): 2686-2693.

Przywitowski, M., Mikulski, D., Zdunczyk, Z., Rogiewicz, A., Jankowski, J. 2016. The effect of dietary high-tannin and low-tannin faba bean (Vicia faba L.) on the growth performance, carcass traits and breast meat characteristics of finisher turkeys. Animal Feed Science and Technology, 221: 124-136.

Puligundla, P., Abdullah, S.A., Choi, W., Jun, S., Oh, S. Ko, S. 2013. Potentials of microwave heating technology for select food processing applications - a brief overview and update. Journal of Food Processing \& Technology, 4(11):1-9.

MaCrae, R., Robinson, R.K., Sadler, M.J. (Eds.). 1993. Encyclopaedia of Food Science, Food Technology and Nutrition, Academic Press, London, U.K. 
Rakic, S., Petrovic, S., Kukic, J., Jadranin, M., Tesevic, V., Povrenovic, D. 2007. Influence of thermal treatment on phenolic compounds and antioxidant properties of oak acorns from Serbia. Food Chemistry, 104(2): 830-834.

Randhir, R., Shetty, K. 2004. Microwave-induced stimulation of IL-DOPA, phenolics and antioxidant activity in faba bean (Vicia faba) for Parkinson's diet. Process Biochemistry, 39(11): 1775-1784.

Rao, P.U., Belavady, B. 1978. Oligosaccharides in pulses: varietal differences and effects of cooking and germination. Journal of Agricultural and Food Chemistry, 26: 316-319.

Rascon Escajeda, L.F., Cruz Hernandez, M., Rodriguez Jasso, R.M., Charles Rodriguez, A. V., Robledo Olivo, A., Contreras Esquivel, J.C., Belmares-Cerda, R. 2018. Discussion between alternative processing and preservation technologies and their application in beverages: A review. Journal of Food Processing and Preservation, 42(1): 1-15.

Rastogi, N.K., Raghavarao, K.S.M.S., Balasubramaniam, V.M., Niranjan, K., Knorr, D. 2007. Opportunities and challenges in high pressure processing of foods. Critical Reviews in Food Science and Nutrition, 47(1): 69-112,

Ratner, A., Goren, R., Monseline, S.P. 1969. Activity of pectin esterase and cellulase in the abscission zone of citrus leaf explants. Journal of Plant Physiology, 44:1717-1723.

Redovniković, I. R., Repajić, M., Fabek, S., Delonga, K., Toth, N., Furač, J. V. 2012. Comparison of selected bioactive compounds and antioxidative capacity in different broccoli cultivars. Acta Alimentaria, 41(2): 221-232.

Regier, M., Knoerzer, K., Schubert, H. 2016. Introducing microwave-assisted processing of food: Fundamentals of the technology. The Microwave Processing of Foods: Second Edition (Second Edi).

Regulation EC 1441/2007. 2007. Commission regulation on microbiological criteria for foodstuffs. Official Journal of the European Union, 322, 12-29.

Renna, M., Gonnella, M., Giannino, D., Santamaria, P. 2014. Quality evaluation of cookchilled chicory stems (Cichorium intybus L., Catalogna group) by conventional and sous vide cooking methods. Journal of the Science of Food and Agriculture, 94(4): 656-665.

Resurrección, F.P., Tang, J., Pedrow, P., Cavalieri, R., Liu, F., Tang, Z. 2013. Development of a computer simulation model for processing food in a microwave assisted thermal sterilization (MATS) system. Journal of Food Engineering, 118(4): 406-416.

Rhim, J.W., Nunes, R.V., Jones, V.A., Swartzel, K.R. 1989. Kinetics of color change of grape juice generated using linearly increasing temperature. Journal of Food Science, 54(3): 776-777.

Rice-Evans, C.A., Miller, N.J., Paganga, G. 1996. Structure-antioxidant activity relationships of flavonoids and phenolic acids. Free Radical Biology and Medicine, 20(7):933-956.

Rice-Evans, C., Miller, N., Paganga, G. 1997. Antioxidant properties of phenolic compounds. Trends in Plant Science, 2(4): 152-159. 
Richardson, P. 2001. Thermal technologies in food processing. Editorial: Woodhead. Reino Unido.

Ritz, M., Freulet, M., Orange, N., Federighi, M. 2000. Effects of high hydrostatic pressure on membrane proteins of Salmonella typhimurium. International Journal of Food Microbiology, 55(1-3): 115-119.

Rodgers, S. 2007. Innovation in food service technology and its strategic role. International Journal of Hospitality Management, 26:899-912.

Rodríguez, J.A., Nespereira, B., Pérez-Ilzarbe, M., Eguinoa, E., Páramo, J.A. 2005. Vitamins $\mathrm{C}$ and $\mathrm{E}$ prevent endothelial VEGF and VEGFR-2 overexpression induced by porcine hypercholesterolemic LDL. Cardiovascular Research, 65(3):665-673.

Rodríguez-Hidalgo, S., Artés-Hernández, F., Gómez, P.A., Fernández, J.A., Artés, F. 2010. Quality of fresh-cut baby spinach grown under a floating trays system as affected by nitrogen fertilisation and innovative packaging treatments. Journal of the Science of Food and Agriculture, 90(6): 1089-1097.

Rodríguez-Roque, M.J., De Ancos, B., Sánchez-Vega, R., Sánchez-Moreno, C., Cano, M.P., Elez-Martínez, P., Martín-Belloso, O. 2016. Food matrix and processing influence on carotenoid bioaccessibility and lipophilic antioxidant activity of fruit juice-based beverages. Food \& Function, 7(1): 380-389.

Rodríguez-Verástegui, L.L., Martínez-Hernández, G.B., Castillejo, N., Gómez, P.A., Artés, F., Artés-Hernández, F. 2015. Bioactive compounds and enzymatic activity of red vegetable smoothies during storage. Food and Bioprocess Techonoly, 9(1): 137-146.

Rogers, G. 2009. Agronomic programme to improve the uniformity of broccoli for once-over mechanical harvesting. Project VG06053. Edit. Applied Horticultural Research, Eveleigh, Australia. 23-25

Rovere, P., Sandei, L., Colombi, A., Munari, M., Ghiretti, G., Carpi, G. 1997. Effects of highpressure treatment on chopped tomatoes. India Conserve, 72:3-12.

Saha, S., Roy, M.N. 2017. Encapsulation of vitamin C into $\beta$-cyclodextrin for advanced and regulatory release, in Vitamin C, ed. by Hamza AH. InTech, Rijeka, Chapter 07, 129145 .

Saha, S., Hollands, W., Teucher, B., Needs, P.W., Narbad, A., Ortori, C.A., Barreti, D.A., Rossiter, J. T., Mithen, R. F., Kroon, P.A. 2012. Isothiocyanate concentrations and interconversion of sulforaphane to erucin in human subjects after consumption of commercial frozen broccoli compared to fresh broccoli. Molecular Nutrition \& Food Research, 56(12): 1906-1916.

Saikaew, K., Lertrat, K., Meenune, M., Tangwongchai, R. 2018. Effect of high-pressure processing on colour, phytochemical contents and antioxidant activities of purple waxy corn (Zea mays L. var. ceratina) kernels. Food Chemistry, 243: 328-337. 
Salazar-González, C., Martín-González, M.F.S., López-Malo, A., Sosa-Morales, M.E. 2012. Recent studies related to microwave processing of fluid foods. Food and Bioprocess Technology, 5(1): 31-46.

Saltveit, M.E. 2000. Wound induced changes in phenolic metabolism and tissue browning are altered by heat shock. Postharvest Biology and Technology, 21(1): 61-69,

Šamec, D., Urlić, B., Salopek-Sondi, B. 2018. Kale (Brassica oleracea var. acephala) as a superfood: review of the scientific evidence behind the statement. Critical Reviews in Food Science and Nutrition: 1-37.

Sánchez-Moreno C., Plaza L., De Ancos B. Cano M.P. 2003. Vitamin C, provitamin A carotenoids, and other carotenoids in high-pressurized orange juice during refrigerated storage. Journal of Agricultural and Food Chemistry, 51:647-653.

Sánchez-Moreno, C., Plaza, L., Elez-Martínez, P., De Ancos, B., Martín-Belloso, O., Cano, M.P. 2005. Impact of high pressure ad pulsed electric fields on bioactive compounds and antioxidant activity in orange juice in comparison with traditional thermal processing. Journal of Agricultural and Food Chemistry, 53: 4403-4409.

Sánchez-Moreno, C., Plaza, L., De Ancos, B., Cano, M. P. 2006. Impact of high-pressure and traditional thermal processing of tomato purée on carotenoids, vitamin $\mathrm{C}$ and antioxidant activity. Journal of the Science of Food and Agriculture, 86(2): 171-179.

Sarvan, I., Kramer, E., Bouwmeester, H., Dekker, M., Verkerk, R. 2017. Sulforaphane formation and bioaccessibility are more affected by steaming time than meal composition during in vitro digestion of broccoli. Food Chemistry, 214: 580-586.

Sato, A.C.K., Rosiane, L.C. 2009. Effect of particle size on rheological properties of jaboticaba pulp. Journal of Food Engineering, 91: 566-570.

Savage, G.P., Deo, S. 1989. The nutritional value of peas (Pisum sativum). A literature review. Nutrition Abstracts and Reviews, 59 (2): 66-89.

Schellekens, M. 1996. New research issues in sous-vide cooking. Trends in Food Science and Technology, 7(8): 256-262.

Shao, P., Zhang, J., Fang, Z., Sun, P. 2014. Complexing of chlorogenic acid with $\beta$ cyclodextrins: Inclusion effects, antioxidative properties and potential application in grape juice. Food Hydrocolloids 41: 132-139.

Shewfelt, R.L., Heaton, E.K., Batal, K.M. 1984. Nondestructive color measurement of fresh broccoli. Journal of Food Science, 49(6): 1612-1613.

Shi, H., Noguchi, N., Niki, E. 1999. Comparative study on dynamics of antioxidative action of $\alpha$-tocopheryl hydroquinone, ubiquinol, and $\alpha$-tocopherol against lipid peroxidation. Free Radical Biology and Medicine, 27(3-4): 334-346.

Shimelis, E., Rakshit, S. 2005. Effect of microwave heating on solubility and digestibility of proteins and reduction of antinutrients of selected common bean (Phaseolus Vulgaris L.) varieties grown in Ethiopia. Italian Journal of Food Science, 17(4): 407-418. 
Siddhuraju, P., Becker, K. 2006. The antioxidant and free radical scavenging activities of processed cowpea (Vigna unguiculata (L.) Walp.) seed extracts. Food Chemistry: 101(1), $10-19$.

Siepmann, J., Peppas, N.A. 2001. Modeling of drug release from delivery systems based on hydroxypropyl methylcellulose (HPMC). Advanced Drug Delivery Reviews, 48(2-3): 139-157.

Silva, F.V.M., Gibbs, P.A. 2010. Non-proteolytic Clostridium botulinum spores in low-acid cold-distributed foods and design of pasteurization processes. Trends in Food Science and Technology, 21(2): 95-105.

Sindhu, S., Maya, P., Indira, T.N. 2012. A method for preparation of mustard (Brassica juncea) powder with retained pungency and reduced bitterness. LWT - Food Science and Technology, 49(1): 42-47.

Singh, B., Singh, J.P., Kaur, A., Singh, N. 2017a. Phenolic composition and antioxidant potential of grain legume seeds: A review. Food Research International, 101: 1-16.

Singh, B., Singh, J.P., Shevkani, K., Singh, N., Kaur, A. 2017b. Bioactive constituents in pulses and their health benefits. Journal of Food Science and Technology, 54(4): 858870.

Singleton, V.L., Rossi, J.A. 1965. Colourimetry of total phenolics with phospomolobdicphosphotungstic acid reagents. American Journal of Enology and Viticulture, 16: 144158.

Singleton, V.L., Orthofer, R., Lamuela-Raventós, R.M. 1999. Analysis of total phenols and other oxidation substrates and antioxidants by means of folin-ciocalteu reagent. Methods in Enzymology, 299: 152-178.

Sinha, S.K., Kumar, M., Kumar, A., Bharti, S., Shahi, V.K. 2013. Antioxidant activities of different tissue extract of faba bean (Vicia faba L.) containing phenolic compounds. Legume Research, 36(6): 496-504.

Sønderby, I.E., Geu-Flores, F., Halkier, B.A. 2010. Biosynthesis of glucosinolates - gene discovery and beyond. Trends in Plant Science, 15(5):283-290.

Soobrattee, M.A., Neergheen, V. S., Luximon-Ramma, A., Aruoma, O.I., Bahorun, T. 2005. Phenolics as Potential Antioxidant Therapeutic Agents: Mechanism and actions. Mutation Research - Fundamental and Molecular Mechanisms of Mutagenesis, 579(1-2): 200-213.

Strack, D. 1997. Phenolic metabolism. In: P.M. Dey and J.B. Harborne (eds), Plant Biochemistry. Academic Press, London, 387-416. ISBN: 9780080525723.

Sulaiman, A., Silva, F.V.M. 2013. High pressure processing, thermal processing and freezing of "Camarosa" strawberry for the inactivation of polyphenoloxidase and control of browning. Food Control, 33(2): 424-428.

Tadhani, M.B., Subhash, R. 2006. In vitro antimicrobial activity of Stevia rebaudiana Bertoni leaves. Tropical Journal of Pharmaceutical Research, 5: 557-560. 
Talalay, P., Fahey, J.W., Holtzclaw, W.D., Prestera, T., Zhang, Y. 1995. Chemoprotection against cancer by Phase 2 enzyme induction. Toxicology Letters, 82: 173-179.

Téllez-Luis, S.J., Ramírez, J.A., Pérez-Lamela, C., Vázquez, M., Simal-Gándara, J. 2001. Application of high hydrostatic pressure in the food preservation. Ciencia y Tecnologia Alimentaria, 3(2): 66-80.

Terefe, N.S., Yang, Y.H., Knoerzer, K., Buckow, R., Versteed, C. 2010. High pressure and thermal inactivation kinetics of polyphenol oxidase and peroxidase in strawberry puree. Innovative Food and Science Emerging Technologies, 11: 52-60.

Timmermans, R.A.H., Nierop-Groot, M.N., Nederhoff, A.L., van Boekel, M.A.J.S., Matser, A.M., Mastwijk, H.C. 2014. Pulsed electric field processing of different fruit juices: Impact of $\mathrm{pH}$ and temperature on inactivation of spoilage and pathogenic microorganisms. International Journal of Food Microbiology, 173: 105-111.

Tiwari, B.K., Singh, N. 2012. Pulse Chemistry and Technology. Cambridge: Royal Society of Chemistry, 310p.

Tomás-Barberán, F.A., Espín, J.C. 2001. Phenolic compounds and related enzymes as determinants of quality in fruits and vegetables. Journal of the Science of Food and Agriculture, 81(9): 853-876.

Traka, M., Mithen, R. 2008. Glucosinolates, isothiocyanates and human health. Phytochemistry Reviews, 8: 269-282.

Troszyńska, A., Amarowicz, R., Lamparski, G., Wołejszo, A., Baryłko-Pikielna, N. 2006. Investigation of astringency of extracts obtained from selected tannins-rich legume seeds. Food Quality and Preference, 17(1-2): 31-35.

Tsai, F.H., Chiang, P.Y., Kitamura, Y., Kokawa, M., Islam, M. Z. 2017a. Producing liquidcore hydrogel beads by reverse spherification: Effect of secondary gelation on physical properties and release characteristics. Food Hydrocolloids, 62: 140-148.

Tsai, F.H., Kitamura, Y., Kokawa, M. 2017b. Liquid-core alginate hydrogel beads loaded with functional compounds of radish by-products by reverse spherification: Optimization by response surface methodology. International Journal of Biological Macromolecules, 96: 600-610.

Tumpanuvatr, T., Jittanit, W. 2012. The temperature prediction of some botanical beverages, concentrated juices and purees of orange and pineapple during ohmic heating. Journal of Food Engineering, 113(2): 226-233.

Turkmen, N., Sari, F., Velioglu, Y.S. 2005. The effect of cooking methods on total phenolics and antioxidant activity of selected green vegetables. Food Chemistry, 93(4): 713-18.

USDA Nutrient Database for Standard Reference, Release 28. (2017). USDA-ARS, Beltsville, MD. Nutrient Data Laboratory Home Page. Available at: https:// ndb.nal.usda.gov/ndb/search [03 March 2018]. 
Vallejo, F., Tomás-Barberán, F., García-Viguera, C. 2002. Glucosinolates and vitamin C content in edible parts of broccoli florets after domestic cooking. European Food Research and Technology, 215(4): 310-316.

Vallejo, F., Tomás-Barberán, F.A., Ferreres, F. 2004. Characterisation of flavonols in broccoli (Brassica oleracea L. var. italica) by liquid chromatography-UV diode-array detectionelectrospray ionisation mass spectrometry. Journal of Chromatography A, 1054(1-2): 181-193.

Van het Hof, K.H., de Boer, B.C., Tijburg, L.B., Lucius, B.R., Zijp, I., West, C.E., Hautvast, J.G., Weststrate, J.A. 2000. Carotenoid bioavailability in humans from tomatoes processed in different ways determined from the carotenoid response in the triglyceriderich lipoprotein fraction of plasma after a single consumption and in plasma after four days of consumption. Journal of Nutrition, 130(5): 1189-1196.

Van Ommen Kloeke, A.E.E., Van-Gestel, C.A.M., Styrishave, B., Hansen, M., Ellers, J., Roelofs, D. 2012. Molecular and life-history effects of a natural toxin on herbivorous and non-target soil arthropods. Ecotoxicology, 21(4): 1084-1093.

Vázquez-Gutiérrez, J.L., Plaza, L., Hernando, I, Sánchez-Moreno, C., Quiles, A., De Ancos, B., Cano, M.P. 2013. Changes in the structure and antioxidant properties of onions by high pressure treatment. Food \& Function, 4: 586-591.

Veiga, M.D., Merino, M., Fernández, D., Lozano, R. 2002. Characterization of some cyclodextrin derivatives by thermal analysis. Journal of Thermal Analysis and Calorimetry 68:511-516.

Vega M.P., Torres, A.M., Cubero, J.I., Kole, C. 2012. Faba Bean. Genetics, genomics and breeding of cool season grain legumes. Editor Vega M.P., Torres, A.M., Cubero, J.I., Kole, C. Editorial. CRC Press Taylor \& Francis Group. Chapter 5: 50-97. ISBN 9781578087655 .

Vega, P., Castells, P. 2012. Spherification. C. Vega, J. Ubbink, E. van der Linden (Eds.). The kitchen as the laboratory. Columbia University Press, New York, USA, pp. 25-32

Velasco, P., Cartea, M.E., González, C., Vilar, M., Ordás, A. 2007. Factors affecting the glucosinolate content of kale (brassica oleracea acephala group). Journal of Agricultural and Food Chemistry, 55(3): 955-962.

Velasco, P., Francisco, M., Moreno, D.A., Ferreres, F., García-Viguera, C., Cartea, M.E. 2011. Phytochemical fingerprinting of vegetable Brassica oleracea and Brassica napus by simultaneous identification of glucosinolates and phenolics. Phytochemical Analysis, 22(2): $144-152$.

Verkerk, R., Schreiner, M., Krumbein, A., Ciska, E., Holst, B., Rowland, I., De Schrijver, R., Hansen, M., Gerhäuser, C., Mithen, R., Dekker, M. 2009. Glucosinolates in Brassica vegetables: The influence of the food supply chain on intake, bioavailability and human health. Molecular Nutrition and Food Research, 53: 219-265. 
Vidal-Valverde, C., Frias, J., Sotomayor, C., Díaz-Pollan, C., Fernández, M., Urbano, G. 1998. Nutrients and antinutritional factors in faba beans as affected by processing. European Food Research and Technology, 207(2): 140-145.

Vig, A.P., Rampal, G., Thind, T.S., Arora, S. 2009. Bio-protective effects of glucosinolates A review. LWT - Food Science and Technology, 42(10): 1561-1572.

Vilar, M., Cartea, M. E., Padilla, G., Soengas, P., Velasco, P. 2008. The potential of kales as a promising vegetable crop. Euphytica, 159(1-2): 153-165.

Villarino-Rodríguez, A. 2009. Efecto del almacenamiento sobre el valor nutritivo, la calidad higiénico-sanitaria y sensorial de la trucha arco-iris (Oncorhynchus mykiss) procesada mediante la tecnología sous vide. Ph. D. Thesis. Universidad de León,León, Spain. 56-60

Volf, I., Ignat, I., Neamtu, M., Popa, V. I. 2014. Thermal stability, antioxidant activity, and photo-oxidation of natural polyphenols. Chemical Papers, 68(1): 121-129.

Walkling-Ribeiro, M., Noci, F., Cronin, D.A., Lyng, J.G., Morgan, D.J. 2010. Shelf life and sensory attributes of a fruit smoothie-type beverage processed with moderate heat and pulsed electric fields. LWT - Food Science and Technology, 43(7): 1067-1073.

Wallace, T.C., Murray, R., Zelman, K.M. 2016. The nutritional value and health benefits of chickpeas and hummus. Nutrients, 8(12): 1-10.

Wallsgrove, R.M., Bennett, R.N. 1995. The biosynthesis of glucosinolatos in Brassicas. In: Wallsgrove RM, editor. Amino Acids and their derivatives in higher plants. Cambridge, UK: Cambridge University Press, 243-259.

Waly, M.I., Al-Attabi, Z., Guizani, N. 2015. Low nourishment of vitamin c induces glutathione depletion and oxidative stress in healthy young adults. Preventive Nutrition and Food Science, 20(3): 198-203.

Wang, L., Sun, D.W. 2012. Heat and mass transfer in thermal food processing. En: Thermal food processing: new technologies and quality issues. Sun, D-W. (Ed.). Editorial: CRC Press. Estados Unidos.

Wang, R., Xu, Q., Yao, J., Zhang, Y., Liao, X., Hu, X., Wu, J., Zhang, Y. 2013. Post-Effects of High Hydrostatic Pressure on Green Color Retention and Related Properties of Spinach Puree during Storage. Innovative Food Science and Emerging Technologies, 17: 63-71.

Wang, S., Melnyk, J. P., Tsao, R., Marcone, M. F. 2011. How natural dietary antioxidants in fruits, vegetables and legumes promote vascular health. Food Research International, 44(1): 14-22. .

Wäppling Raaholt, B., Isaksson, S. 2016. Improving the heating uniformity in microwave processing. The Microwave Processing of Foods, Second Edition: 381-406.

Watanabe, S., Karakawa, M., Hashimoto, O. 2010. Computer simulation of temperature distribution of frozen material heated in a microwave oven. IEEE Transactions on Microwave Theory and Techniques, 58: 1196-1204. 
Watts, P. 2011. Global pulse industry: state of production, consumption and trade; marketing challenges and opportunities. In: Pulse Foods: Processing, quality and nutraceutical applications. pp. 437-464. Tiwari, B. K., Gowen, A., and McKenna, B., Eds. Elsevier.

Wellburn, A.R. 1994. The spectral determination of chlorophylls a and b, as well as total carotenoids, using various solvents with spectrophotometers of different resolution. Journal of Plant Physiology, 144(3): 307-313.

Wilkowska, A., Ambroziak, W., Czyzowska, A., Adamiec, J. 2016. Effect of microencapsulation by spray-drying and freeze-drying technique on the antioxidant properties of blueberry (vaccinium myrtillus) juice polyphenolic compounds. Polish Journal of Food and Nutrition Sciences, 66(1): 11-16.

Williams, D.J., Critchley, C., Pun, S., Chaliha, M., O’Hare, T.J. 2010. Key role of $\mathrm{Fe}^{2+}$ in epithiospecifier protein activity. Journal of Agricultural and Food Chemistry, 58: 85128521.

Wu, H., Liang, H., Yuan, Q., Wang, T., Yan, X. 2010. Preparation and stability investigation of the inclusion complex of sulforaphane with hydroxypropyl- $\beta$-cyclodextrin. Carbohydrate Polymers, 82: 613-617.

Wu, L., Noyan Ashraf, M.H., Facci, M., Wang, R., Paterson, P.G., Ferrie, A., Juurlink, B.H.J. 2004. Dietary approach to attenuate oxidative stress, hypertension, and inflammation in the cardiovascular system. Proceedings of the National Academy of Sciences, 101(18): 7094-7099.

Wu, T. 2008. Environmental perspectives of microwave applications as remedial alternatives: review. Practice Periodical of Hazardous, Toxic, and Radioactive Waste Management, 12(2): 102-115.

Wu, X., Sun, J., Haytowitz, D.B., Harnly, J.M., Chen, P., Pehrsson, P.R. 2017. Challenges of developing a valid dietary glucosinolate database. Journal of Food Composition and Analysis, 64:78-84.

Wu, Y., Mao, J., Mei, L., Liu, S. 2013. Kinetic studies of the thermal degradation of sulforaphane and its hydroxypropyl- $\beta$-cyclodextrin inclusion complex. Food Research International, 53: 529-533.

Xie, F., Li, M., Lan, X., Zhang, W., Gong, S., Wu, J., Wang, Z. 2017. Modification of dietary fibers from purple-fleshed potatoes (heimeiren) with high hydrostatic pressure and high pressure homogenization processing: a comparative study. Innovative Food Science and Emerging Technologies, 42:157-164.

Xu, B., Chang, S.K.C. 2008. Effect of soaking, boiling, and steaming on total phenolic contentand antioxidant activities of cool season food legumes. Food Chemistry, 110(1): $1-13$.

Xu, B., Chang, S.K.C. 2012. Comparative study on antiproliferation properties and cellular antioxidant activities of commonly consumed food legumes against nine human cancer cell lines. Food Chemistry, 134(3): 1287-1296. 
Xu, Z., Wang, Y., Ren, P., Ni, Y., Liao, X. 2016. Quality of banana puree during storage: a comparison of high pressure processing and thermal pasteurization methods. Food and Bioprocess Technology, 9(3): 407-420.

Yamagishi, S.I., Matsui, T. 2016. Protective role of sulphoraphane against vascular complications in diabetes. Pharmaceutical Biology, 54(10): 2329-2339.

Yao, Y., Cheng, X., Wang, L., Wang, S., Ren, G. 2011. Biological potential of sixteen legumes in china. International Journal of Molecular Sciences, 12(10): 7048-7058.

Yi, J., Kebede, B.T., Grauwet, T., Loey, A.V., Hu, X., Hendrickx, M. 2016. Comparing the impact of high-pressure processing and thermal processing on quality of 'hayward' and 'jintao' kiwifruit purée: untargeted headspace fingerprinting and targeted approaches. Food and Bioprocess Technology, 9(12): 2059-2069.

Yordanov, D.G., Angelova, G.V. 2010. High pressure processing for foods preserving. Biotechnology \& Biotechnological Equipment, 24(3): 1940-1945.

Yoshigae, Y., Sridar, C., Kent, U.M., Hollenberg, P.F. 2013. The inactivation of human CYP2E1 by phenethyl isothiocyanate, a naturally occurring chemopreventive agent, and its oxidative bioactivation. Drug Metabolism and Disposition, 41(4): 858-869.

Zapata S., Dufour J.P. 1992. Ascorbic, dehydroascorbic and isoascorbic and simultaneous determinations by reverse phase ion interaction HPLC. Journal of Food Science, 57: 506511.

Zhang, Y., Talalay, P., Cho, C.G., Posner, G.H. 1992. A major inducer of anticarcinogenic protective enzymes from broccoli: isolation and elucidation of structure. Proceedings of the National Academy of Sciences 89:2399-2403.

Zhang, Z., Sun, D.W. 2006. Effects of cooling methods on the cooling efficiency and quality of cooked rice. Journal of Food Engineering, 77: 269-274.

Zhao, L., Wang, S.Y., Liu, F.X., Dong, P., Huang, W.S., Xiong, L., Liao, X.J. 2013. Comparing the effects of high hydrostatic pressure and thermal pasteurization combined with nisin on the quality of cucumber juice drinks. Innovative Food Science \& Emerging Technologies, 17: 27-36.

Zhou, C. L., Liu, W., Zhao, J., Yuan, C., Song, Y., Chen, D., Ni, Y.Y., Li, Q. 2014. The effect of high hydrostatic pressure on the microbiological quality and physical-chemical characteristics of pumpkin (Cucurbita maxima Duch.) during refrigerated storage. Innovative Food Science and Emerging Technologies, 21: 24-34.

Zhou, L., Tey, C.Y., Bingol, G., Bi, J. 2016. Effect of microwave treatment on enzyme inactivation and quality change of defatted avocado puree during storage. Innovative Food Science \& Emerging Technologies, 37: 61-67.

Zhu, J., Kuznetsov, A.V., Sandeep, K.P. 2007. Mathematical modeling of continuous flow microwave heating of liquids (effects of dielectric properties and design parameters). International Journal of Thermal Sciences, 46(4): 328-341. 
Zia-Ul-Haq, M., Ahmad, S., Amarowicz, R., De Feo, V. 2013. Antioxidant activity of the extracts of some cowpea (Vigna unguiculata (L) Walp.) cultivars commonly consumed in Pakistan. Molecules, 18(2): 2005-2017. 